\author{
UNIVERSIDADE DE SÃO PAULO \\ ESCOLA DE ENGENHARIA DE SÃO CARLOS \\ DEPARTAMENTO DE ENGENHARIA MECÂNICA
}

\title{
DESENVOLVIMENTO E IMPLEMENTAÇÃO DE UM SISTEMA INTEGRADO PARA O PROJETO, OTIMIZAÇÃO E FABRICAÇÃO DE PEÇAS ATRAVÉS DO PROCESSO DE FILAMENTO WINDING
}

Márcio Marques da Silva

Tese apresentada à Escola de Engenharia de São Carlos, da Universidade de São Paulo, como parte dos requisitos para obtenção do título de Doutor em Engenharia Mecânica.

Área de concentração: Projeto Mecânico

São Carlos

2015

ESTE EXEMPLAR TRATA-SE DA VERSÃO CORRIGIDA.

A VERSÃO ORIGINAL ENCONTRA-SE JUNTO AO DEPARTAMENTO DE ENGENHARIA MECÂNICA DA EESC-USP. 
AUTORIZO A REPRODUCÃO TOTAL OU PARCIAL RESTE TRABALHO, POR QUALQUER MEIO ĆONVENCIONAL OU ELETRONIICO, PARA FINS DE ESTUDO E PESQUISA, DESDE QUE CITADA A FONTE.

Ficha catalográfica elaborada pela Biblioteca Prof. Dr. Sérgio Rodrigues Fontes da EESC/USP com os dados inseridos pelo(a) autor(a).

SILVA, MARCIO MRRQUES DA

Desenvolvimento e implementaço de un sistema

s3586d integrado para o projeto, otimiraço e fabricaço de

d peças atraves do processo de filamento winding / MdiRCIO MRRQUES DA SILVR; orientador Jonas de Carvalho. SIo

Carlos, 2015.

Tese (Doutorado) - Programa de P6s-Graduaçalo em Engenharia Mecanica e Área de Concentracto em Projeto Kecanico -- Escola de Engenharia de SIo Carlos da Universidade de SIo Paulo, 2015.

1. Enrolamento filamentar. 2. CNC. 3. Compositos. 4. Polimeros reforçados. 5. Título. I. Título.

Eduardo Graziosi Silva - CRB - 8/8907 
Candidato: Bacharel MARCIO MARQUES DA SILVA.

Título da tese: "Desenvolvimento e implementação de um sistema integrado para o projeto, otimização e fabricação de peças através do processo de filament winding ".

Data da defesa: 29/05/2015

Comissão Julgadora:

Resultado:

Prof. Associado Jonas de Carvalho

Arrovaro.

(Orientador)

(Escola de Engenharia de São Carlos/EESC)

Prof. Dr. Alessandro Roger Rodrigues

Aprovado

(Escola de Engenharia de São Carlos/EESC)

Prof. Dr. Marcelo Aparecido Chinelatto

(Escola de Engenharia de São Carlos/EESC)

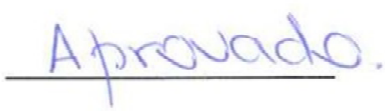

Prof. Dr. Flávio Yukio Watanabe

(Universidade Federal de São Carlos/UFSCar)

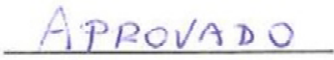

Dr. Pedro Yoshito Noritomi

APROVADO

(Centro de Tecnologia da Informação Renato Archer/CTI)

Coordenador do Programa de Pós-Graduação em Engenheira Mecânica: Prof. Associado Gherhardt Ribatski

Presidente da Comissão de Pós-Graduação:

Prof. Associado Paulo César Lima Segantine 


\section{DEDICATÓRIA}

Dedico este trabalho aos meus pais Neuza e Marino, minha noiva Alessandra Zeffa, a meu professor e orientador Prof. Dr. Jonas de Carvalho quem contribuíram direta e indiretamente para que a realização deste trabalho fosse possível. 


\section{AGRADECIMENTOS}

Agradeço a Deus pelo dom da vida, ao meu orientador Prof. Dr. Jonas de Carvalho que proporcionou esta grata e maravilhosa experiência, aos meus pais Neuza e Marino e minha noiva Alessandra Zeffa pela força e apoio para que este trabalho acontecesse, aos técnicos da Romi, Sr Petrini e Sr M. Dória que contribuíram com apoio técnico. Também agradeço àqueles que contribuíram de alguma forma para que este trabalho pudesse ser realizado. 


\section{EPÍGRAFE}

"Seja você quem for, seja qual for a posição social que você tenha na vida, a mais alta ou a mais baixa, tenha sempre como meta muita força, muita determinação e sempre faça tudo com muito amor e com muita fé em Deus, que um dia você chega lá. De alguma maneira você chega lá."

Ayrton Senna.

"Jamais considere seus estudos como uma obrigação, mas como uma oportunidade invejável para aprender a conhecer a influência libertadora da beleza do reino do espírito, para seu próprio prazer pessoal e para proveito da comunidade à qual seu futuro trabalho pertencer."

Albert Einstein. 


\section{RESUMO}

SILVA. M.M. Desenvolvimento e implementação de um sistema integrado para o projeto, otimização e fabricação de peças através do processo de filamento winding. Tese de Doutorado - Engenharia Mecânica, Escola de Engenharia de São Carlos, Universidade de São Paulo, São Carlos Maio de 2015.

$\mathrm{Na}$ busca de materiais de baixa densidade, alta resistência e baixo custo, o processo de Filament Winding, ou Enrolamento Filamentar, surge como uma das opções de processo automatizado para a fabricação de componentes em materiais compósitos reforçados por fibras (FRP - Fiber Reinforced Polymers). Tendo uma ampla aplicação estrutural, o tipo de fibra, o tipo de matriz, a orientação das fibras, as camadas de reforço, o mandril a ser utilizado e a otimização da trajetória de deposição das fibras são características essenciais para obtenção de uma peça com as características desejadas no processo. Dentre as necessidades para a utilização deste processo, exerce um papel de destacada influência a geração dos dados da trajetória de deposição da fibra, bem como a geração dos dados operacionais do processo. Este trabalho tem por objetivos desenvolver um programa para a geração destes dados, bem como os dispositivos necessários para a execução do processo de Filament Winding em torno CNC comercial. Os dados das trajetórias são gerados de modo integrado ao sistema CAD, representados por meio dos ângulos das trajetórias, e são alimentados em um programa computacional desenvolvido para este fim, que gera 0 código CN para a fabricação da peça no equipamento. Para a execução deste código na máquina CNC, foram desenvolvidos sistema de fixação do mandril e alimentador da fibra (incluindo tensionador) que possibilitam a execução do processo neste tipo de equipamento. Todo o sistema desenvolvido foi implementado e utilizado para a confecção de tubos com diferentes trajetórias de preenchimento, validando o sistema computacional e o processo desenvolvido.

Palavras-chave: Enrolamento Filamentar, CNC, Compósitos, Polímeros reforçados. 


\begin{abstract}
SILVA. M.M. Development and implementation of an integrated system for the design, optimization and manufacturing parts using the filament winding process. PhD Thesis - Mechanical Engineering, School of Engineering of São Carlos, University of São Paulo, São Carlos, May, 2015.
\end{abstract}

In the search of low density, high strength and low cost materials, Filament Winding seems to be an option of automated process to manufacture components in Composite Materials Reinforced by Fibers (FRP - Fiber Reinforced Polymers). Due to its large application in structural engineering, aspects such as fibers, matrices, fiber paths and laminate sequence are essential characteristics to obtain the desired final part. Among the requirements to use the Filament Winding Process, the definition of the fiber paths as well as the laminate sequence play fundamental roles in order to achieve the optimum structural performance of the composite part. This work aims to develop the necessary program to generate this data and devices required for the implementation of Filament Winding process in a commercial CNC machine tool. The data of the trajectories are generated in the CAD system, represented by the angles of the trajectories, and are fed in a computer program developed for this purpose, which generates the NC code for the manufacture of the part in the machine. In order to carried out this code in the CNC machine there were developed mandrel fixation system and fiber feeder (including tensioner were deverloped) that enable to wind the part in this type of equipment. The system developed has been implemented and used for the manufacture of tube parts with different fiber paths, validating the integrated system and the process developed.

Key-words: Filament Winding, CNC, Composites, Fiber Reinforced Polymers (FRP). 


\section{LISTA DE FIGURAS}

Figura 1 - Evolução da produção de alguns materiais nos EUA. …..........................7

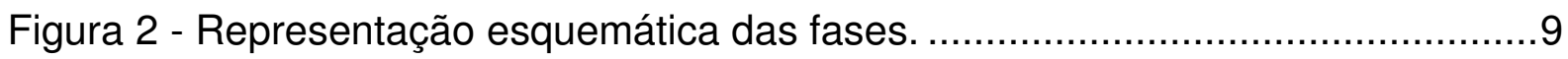

Figura 3 - Esquema de classificação dos vários tipos de compósitos.....................10

Figura 4 - Vista explodida da aeronave EMB-145, mostrando as partes fabricadas em compósitos. Cortesia da EMBRAER. .............................................................12

Figura 5 - Fotomicrografia de um WC-Co metal duro..........................................13

Figura 6 - Padrão de deformação na matriz em volta da fibra quando sujeita à tensão.

Figura 7 - Efeito da deformação ao redor da fibra na matriz sob tensão: (a) fibra contínua. (b) fibra descontínua.

Figura 8 - Gráfico de tensão vs posição quando o comprimento da fibra (a) é igual ao comprimento crítico, (b) é maior que o comprimento crítico.

Figura 9 - Gráfico tensão vs posição quando o comprimento da fibra é menor que o comprimeto crítico para um compósito reforçado por fibras que está submetido a uma tensão à tração igual a resistência à tração da fibra.

Figura 10 - Exemplo de MCRF: (a) partículas aleatórias, (b) fibras descontínuas unidirecinais, (c) fibras descontínuas aleatórias e (d) fibras contínuas direcionais. ..20 Figura 11 - Distribuição da carga na fibra: (a) Fibra envolvida pela matriz. (b) Seção da fibra. (c) Característica da distribuição da tensão na fibra. ................................29

Figura 12 - Compressão e restrição lateral fornecida pela matriz.............................29

Figura 13 - Carretel com fibra de vidro 408/3 Tex 90 T/M....................................31

Figura 14 - Processo de produção de fibras de vidro.............................................33

Figura 15 - Produção de fibras grafitadas contínuas com precursores PAN, ilustrando

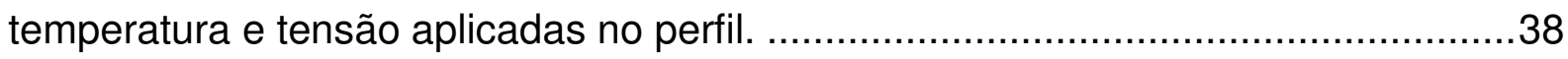

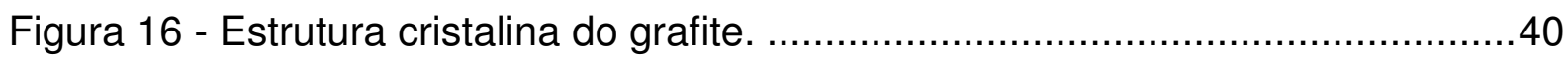

Figura 17 - Fases no processo de fabricação das fibras.........................................41

Figura 18 - Microestrutura de uma fibra de carbono de alto módulo.........................42

Figura 19 - Tipos de microestrutura da fibra derivada do grafite............................42

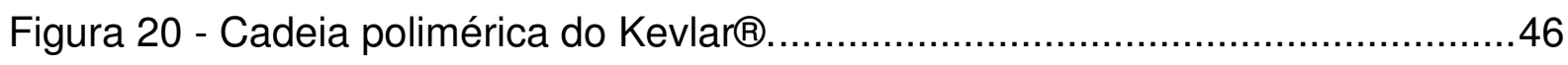

Figura 21 - Estrutura da fibra polimérica. ....................................................... 47

Figura 22 - Efeito do tratamento superficial na fibra...........................................51

Figura 23 - Sistema de coordenada do material....................................................56 
Figura 24 - Ação da tensão em um pequeno elemento de um material reforçado por fibra.

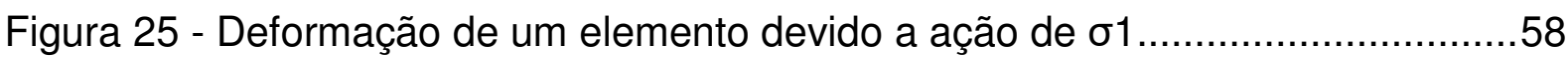

Figura 26 - Deformação de um elemento devido a ação de o2................................59

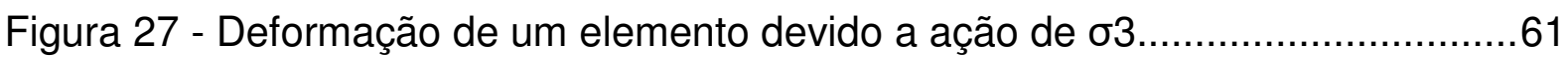

Figura 28 - À esquerda falha por tração na direção 1. À direita falha por compressão. Ambos pelo critério de Tsai wu.

Figura 29 - À esquerda falha à tração na direção 2 pelo critério de Tsai Whu. À direita falha à compressão pelo critério de Tsai Whu.

Figura 30 - À esquerda falha devido ao cisalhamento positivo, à direita falha devido ao cisalhamento reverso. Critério de Tsai Whu. .67

Figura 31- Processo de centrifugação. 68

Figura 32 - Produção de Sheet Molding Compound. 70

Figura 33 - Processo de compressão com sheet molding compound. 70

Figura 34 - (a) Processo de fabricação de compósitos por laminação contínua. (b) Placa de fibra de vidro ondulada. .71

Figura 35 - Processo de Hand Lay Up............................................................

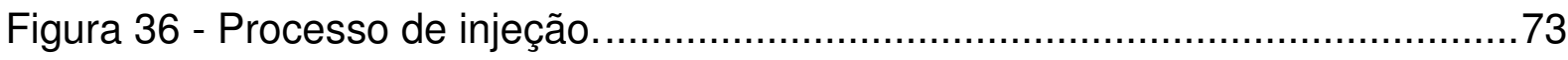

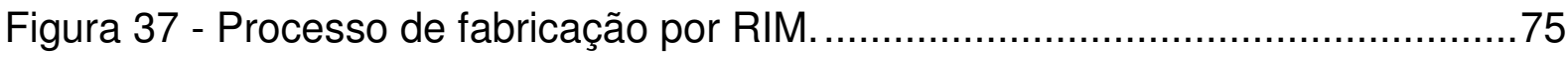

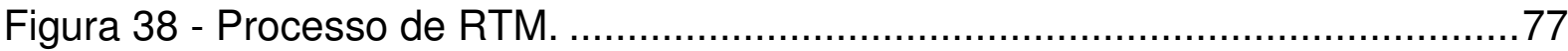

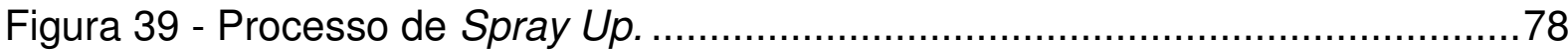

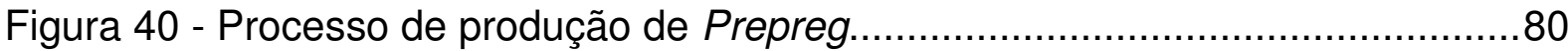

Figura 41 - (a) Processo de manufatura de BMC. (b) Produto BMC.........................81

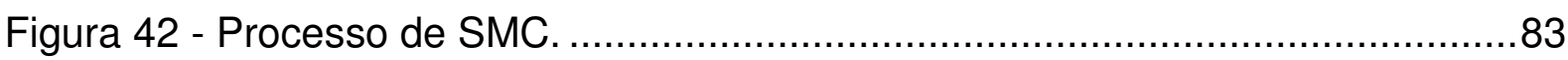

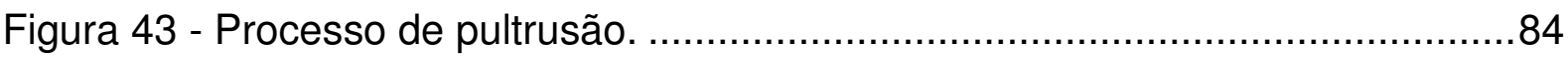

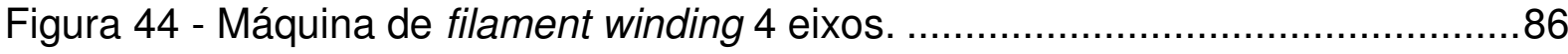

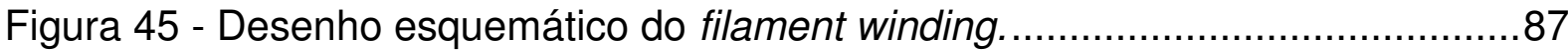

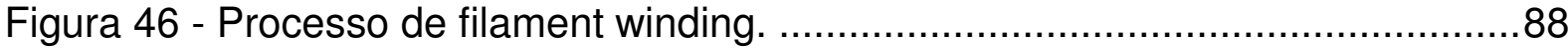

Figura 47 - Dispositivos do processo de filament winding ....................................8

Figura 48 - Dispositivo de impregnação de resina (matriz) nas fibras durante 0 processo de filament winding.............................................................................90

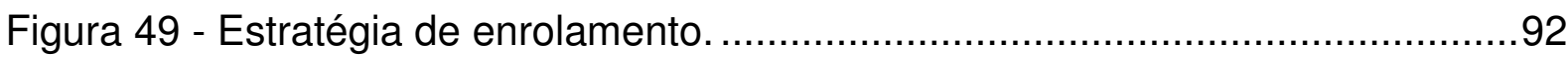

Figura 50 - Sequencia de enrolamento. ............................................................... 
Figura 51- Estratégias de enrolamento. .95

Figura 52 - Estratégia de enrolamento e resultado superficial. ................................95

Figura 53 - Forças que atuam na fibra durante o enrolamento. .............................97

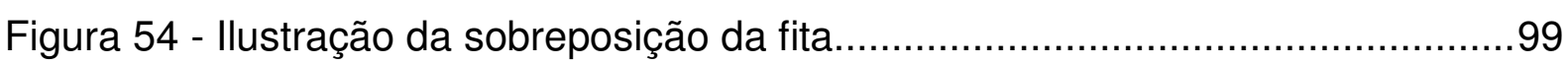

Figura 55 - Ângulo de enrolamento na superfície de revolução. .............................100

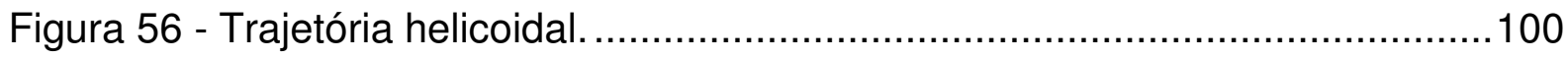

Figura 57 - Trajetória da fibra em uma superfície cilíndrica e os dados construtivos da

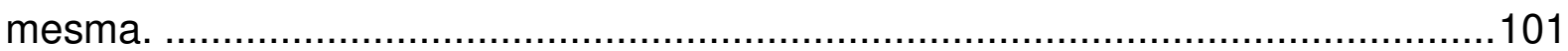

Figura 58 - Máquina de filament winding com CNC. ..........................................103

Figura 59 - Máquinas para filament winding fabricadas pela empresa Entec. ........105

Figura 60 - Máquinas para filament winding fabricadas pela EHA. ........................106

Figura 61 - Célula de produção para o processo de filament winding desenvolvido pela

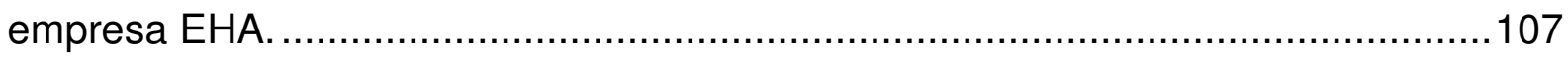

Figura 62 - Máquina para filament winding comercial. .....................................108

Figura 63 - Célula robótica e peça produzida pela célula......................................109

Figura 64 - Máquina de filament winding usada por ABDALLA para fins acadêmicos.

Figura 65 - Peças produzidas por ABDALLA (2005) ..........................................111

Figura 66 - Componentes de uma máquina para filament winding com CNC........112

Figura 67 - Design de uma proposta para máquina de filament winding.................112

Figura 68 - (a) Robô com dispositivo para filament winding. (b) Dispositivo com tensionador, olhal, mandril e sistema de tensionamento das fibras. ......................113

Figura 69 - Máquina de filament winding con controle de tensão nas fibras. ..........115

Figura 70 - Sistema de controle de tensão do processo de filament winding...........115

Figura 71 - Sistema de tensinamento utilizado por SCHOLLIERS.........................117

Figura 72 - Sistema de impregnação tipo Funil. ..................................................118

Figura 73 - Sistema de impregnação tipo Banheira com rolos.............................119

Figura 74 - Sistema de impregnação tipo tambor................................................119

Figura 75 - Máquina de fiar controlada por cartão perfurado. ..............................123

Figura 76 - (a) Dispositivo copiador, (b) acionamento por came e (c) torno CNC...125 Figura 77 - Coordenadas cartesianas. Plano X e Y. Divisão em mm, cada divisão

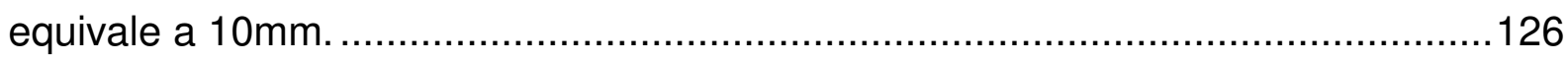

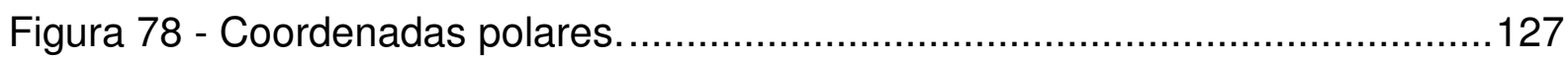


Figura 79 - Máquinas CNC. Torno e Centro de usinagem. ..................................129

Figura 80 - Parâmetros requeridos pelo software Cadfil. ......................................134

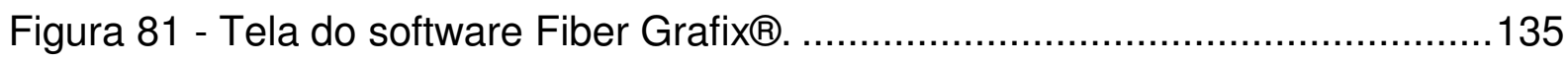

Figura 82 - Fiber Grafix®, módulo de simulação de máquina. .............................135

Figura 83 - Tela do módulo de análise.........................................................136

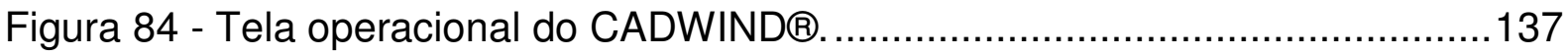

Figura 85 - Metodologia para desenvolvimento de produto. .................................140

Figura 86 - Fluxograma da proposta do programa..........................................142

Figura 87 - Fluxograma do programa para Filament Winding .............................143

Figura 88 - Ilustração do mandril com os acessórios nas extremidades.................146

Figura 89 - Ponto para arraste do mandril....................................................147

Figura 90 - Mandril montado no torno com acessórios. ......................................147

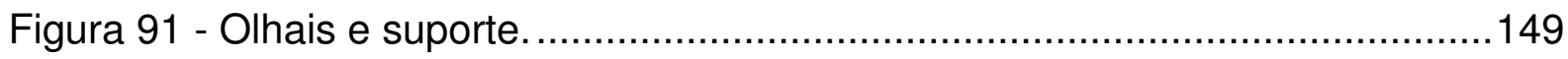

Figura 92 - Olhais e suporte fixados no magazine de ferramentas do torno...........149

Figura 93 - Montagem do rolo e acessórios na base. .........................................151

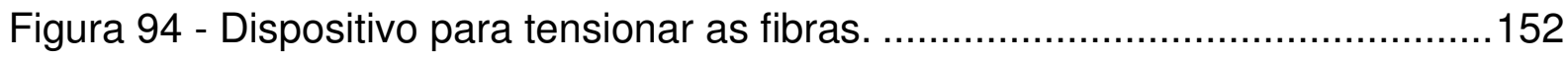

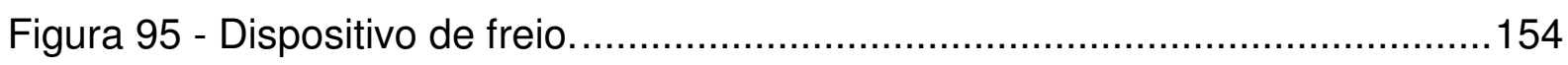

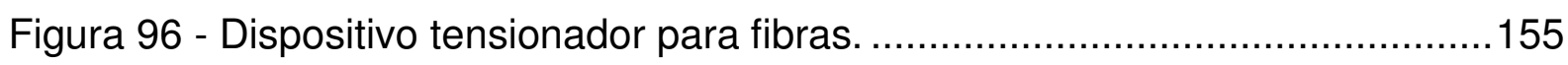

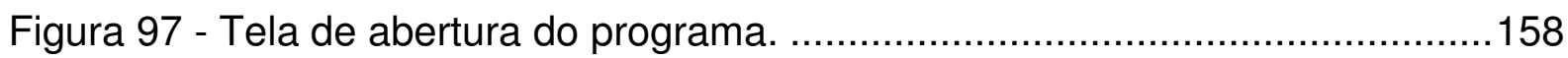

Figura 98 - Tela com dados do usuário e resultados do programa.......................159

Figura 99 - Trajetória helicoidal gerada pelas planilhas resultantes do programa...161

Figura 100 - Teste com marcador realizando as trajetórias das fibras na superfície do

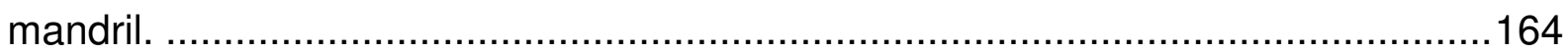

Figura 101 - Ponto fixado na placa por meio de castanhas torneáveis...................165

Figura 102 - Mandril e acessórios montados no torno CNC.................................166

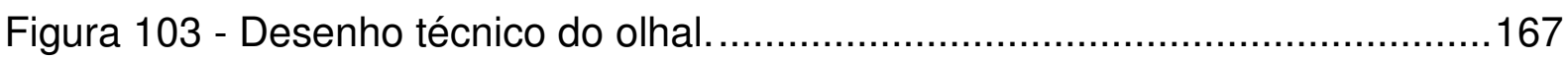

Figura 104 - Fixação do dispositivo tensionador, posição do carretel e fibras

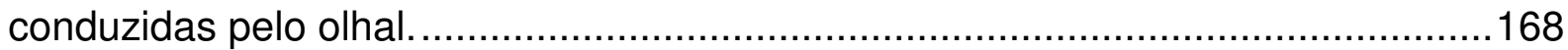

Figura 105 - Primeiro projeto do dispositivo tensionador. .....................................169

Figura 106 - Revestimentos com vários ângulos..............................................173

Figura 107 - Enrolamento tipo aro, mecha largura 10mm.................................174

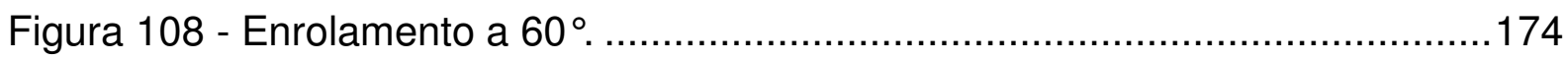

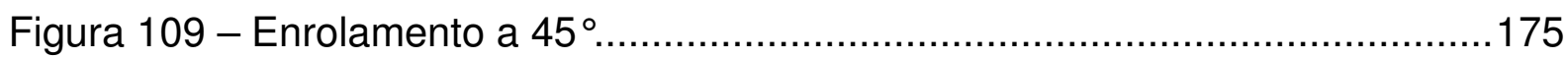


Figura 110 - Enrolamento a $30^{\circ}$.

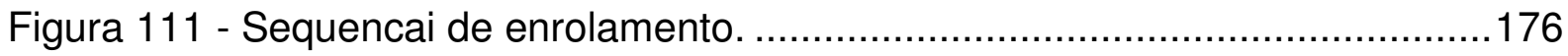

Figura 112 - Enrolamento tipo aro controlando eixo C....................................179

Figura 113 - Trepidações ocorridas durante o enrolamento com o controle do eixo

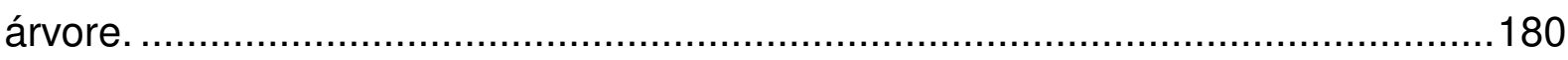

Figura 114 - Enrolamento a $60^{\circ}$ com novo código CN. ......................................181

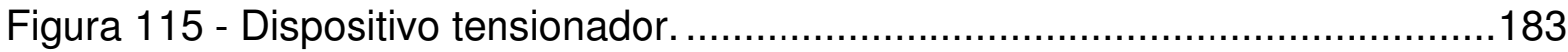

Figura 116 - Dispositivo com tubo ao invés de eixo. ........................................185

Figura 117 - Tendência à sobreposição das fibras..............................................185

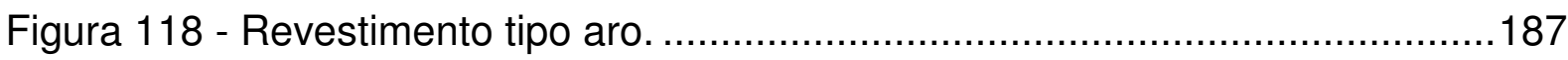

Figura 119 - Transição entre o revestimento tipo aro e o revestimento a $30^{\circ}$.........188

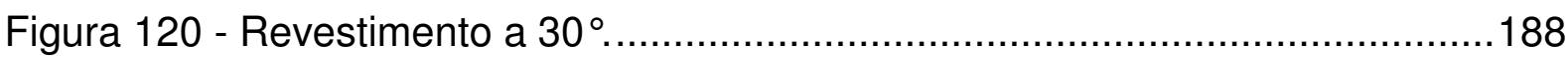

Figura 121 - Transição entre os revestimentos $30^{\circ}$ e $45^{\circ}$....................................189

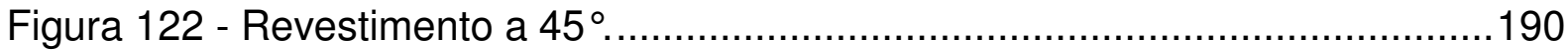

Figura 123 - Transição entre os revestimentos $45^{\circ}$ e $60^{\circ}$....................................191

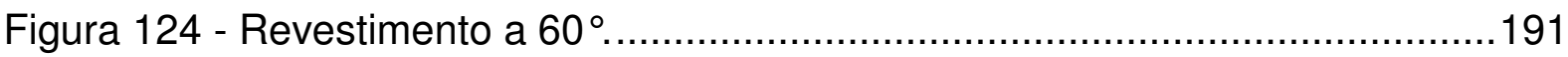

Figura 125 - Tubos enrolados com aplicação de resina.......................................193

Figura 126 - Proposta para evitar sobreposição das fibras no tensionador. ............196

Figura 127 - Filamentos com má impregnação de resina. ....................................198

Figura 128 - Remoção do papel do tubo manufaturado.......................................198

Figura 129 - Regiões de medição dos tubos.........................................................201

Figura 130 - Mandril, tubo e contra ponto. .....................................................202

Figura 131 - Proposta de uma máquina dedicada para Filament Winding..............204

Figura 132 - Proposta de uma máquina dedicada para Filament Winding..............207 


\section{LISTA DE TABELAS}

Tabela 1 - Propriedade das matrizes termorrígidas à temperatura ambiente. 25

Tabela 2 - Propriedades das matrizes Poliamidas Aromáticas à temperatura ambiente. 26

Tabela 3 - Característica dos diversos materiais para reforços por fibras. 28

Tabela 4 - Tipos e propriedades das fibras de vidro. .33

Tabela 5 - Atmosfera oxidante para carbonização das fibras PAN. ...........................37

Tabela 6 - Propriedades das fibras baseadas em carbono....................................44

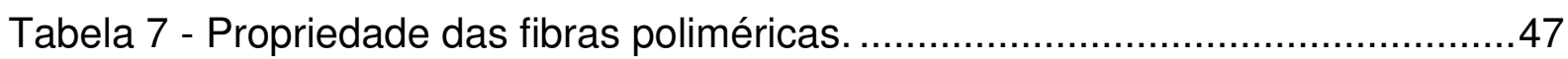

Tabela 8 - Comparativo de materiais compósitos e materiais tradicionais................49

Tabela 9 - Efeito dos vários agentes de acoplamento na fibra de vidro ....................53

Tabela 10 - Formulação típica para revestimento da fibra de vidro..........................54

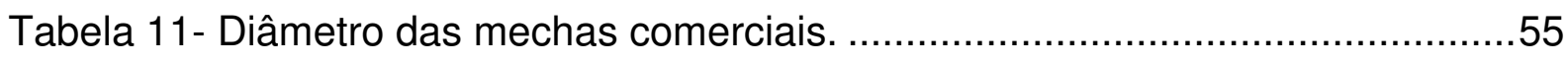

Tabela 12 - Sistema de mandris utilizados em filament winding ............................121

Tabela 13 - Coordenadas absolutas e incrementais. .........................................127

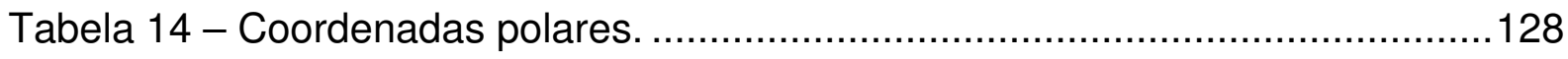

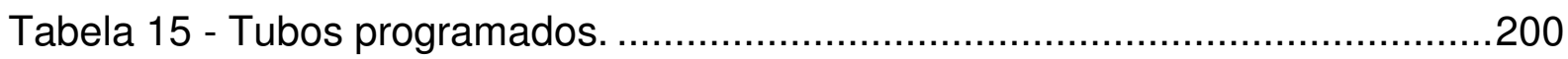

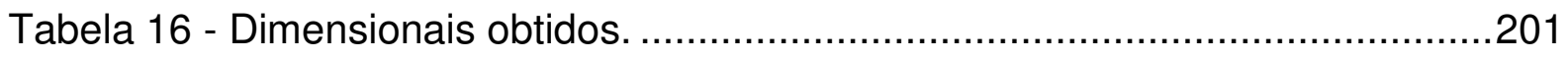




\section{LISTA DE ABREVIATURAS E SIGLAS}

CAD - Computer Aided Design

CAE - Computer Aided Engineering

CAM - Computer Aided Manufacturing

CNC - Comando Numérico Computadorizado

MCRF - Materiais Compósitos Reforçados por Fibras

PAN - Poliacrilanitrila (Polyacrylonitrile)

$\mathrm{BMI}$ - Matriz Bismaleimide

RTM - Resin Transfer Molding

RRIM - Reinforced Reaction Injection Molding

BMC - Bulk Molding Compound

SMC - Sheet Molding Compound

USB - Universal Serial Bus 


\section{SUMÁRIO}

AGRADECIMENTOS

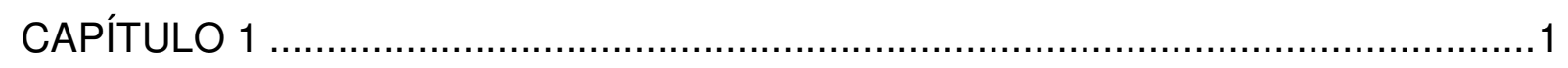

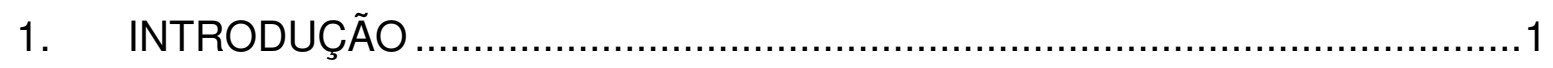

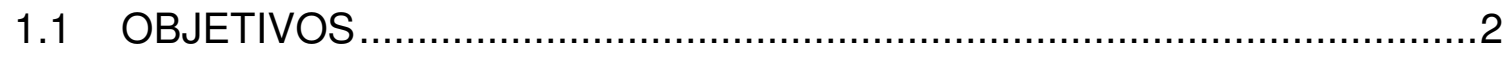

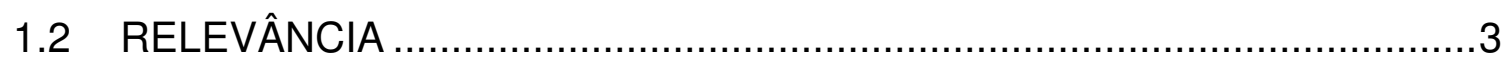

1.3 SINOPSES DAS CONTRIBUIÇÕES DO TRABALHO ...............................

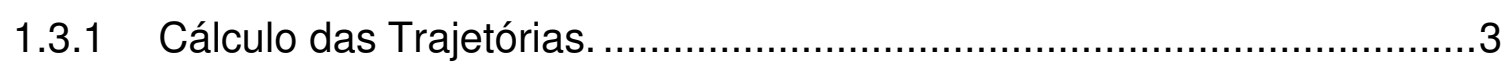

1.3.2 Projeto preliminar de uma máquina de Filament Winding ......................4

1.3.3 Fabricação de peça tubular para validação do sistema...........................4

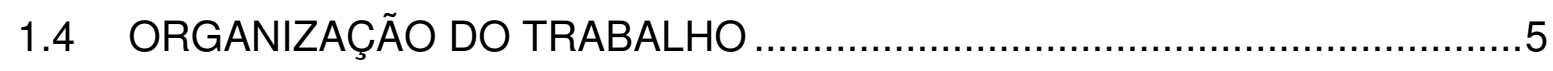

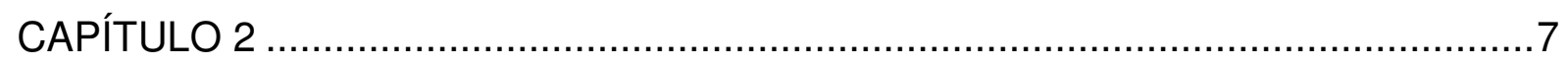

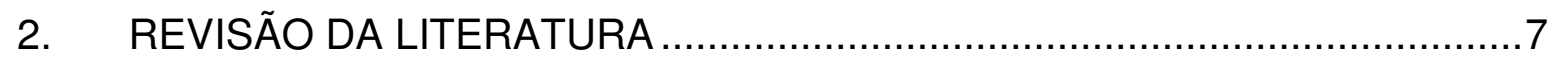

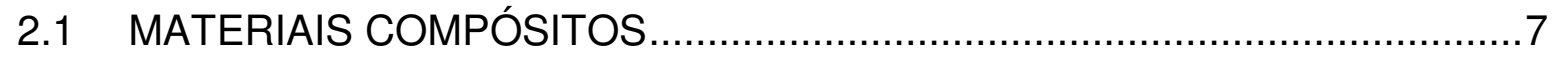

2.1.2 COMPÓSITOS REFORÇADOS POR PARTÍCULAS ............................12

2.1.3 COMPÓSITOS REFORÇADOS POR FIBRAS...................................14

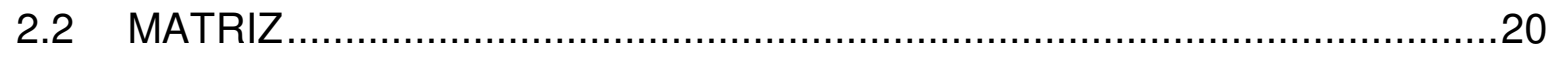




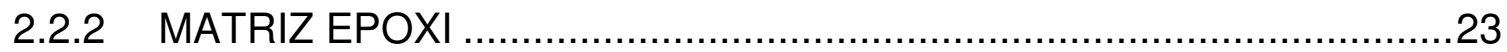

2.2.3 MATRIZ BISMALEIDE (BMI) E POLYIMIDE (POLIIMIDA) ..................23

2.2.4 MATRIZ ÉSTER VINÍLICA ............................................................23

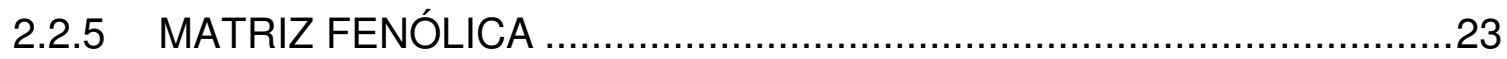

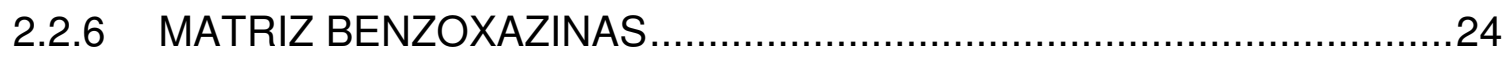

2.2.7 MATRIZ PHTHALONITRILE (FTALONITRILA) …..............................24

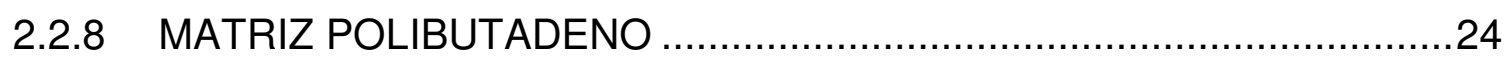

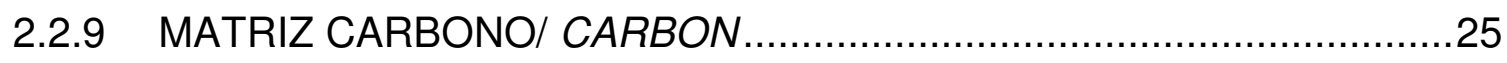

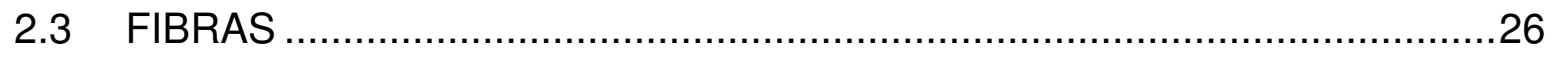

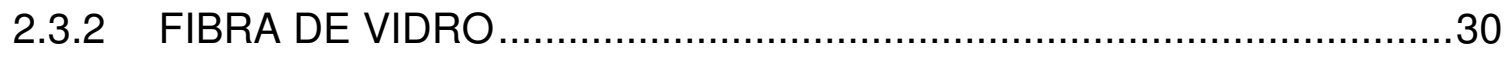

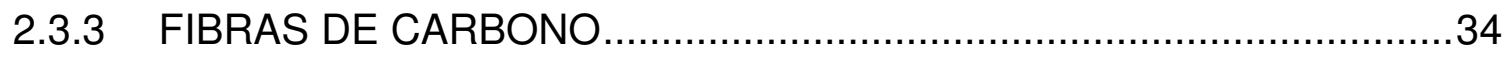

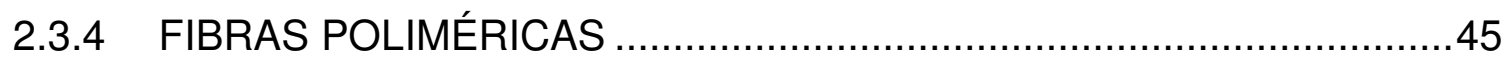

2.4 TRATAMENTOS NA SUPERFÍCIE DAS FIBRAS...................................50

2.4.2 TRATAMENTO DAS FIBRAS DE CARBONO..................................50

2.4.3 TRATAMENTO DAS FIBRAS DE VIDRO …..................................52

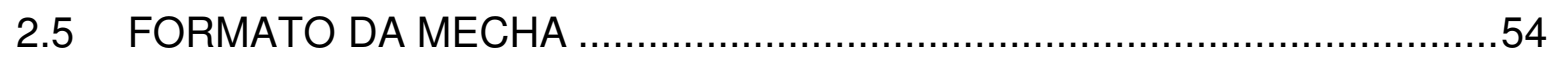

2.6 CARACTERÍSITCAS DA TENSÃO-DEFORMAÇÃO ELÁSTICA LINEAR DOS MATERIAIS REFORÇADOS POR FIBRAS......................................................55

2.6.2 TEORIA DE FALHA EM MATERIAIS REFORÇADOS POR FIBRAS:

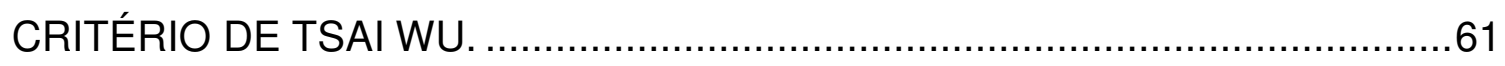

2.7 PROCESSOS DE FABRICAÇÃO EM COMPÓSITOS .................................67

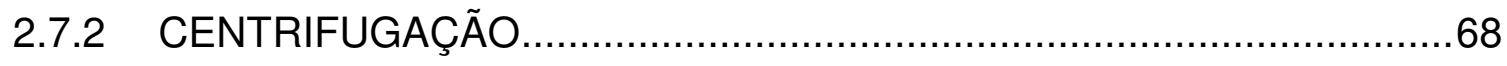

2.7.3 PROCESSO POR COMPRESSÃO OU MOLDAGEM POR

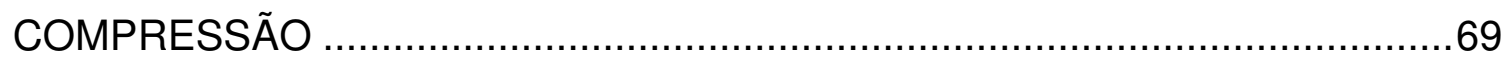

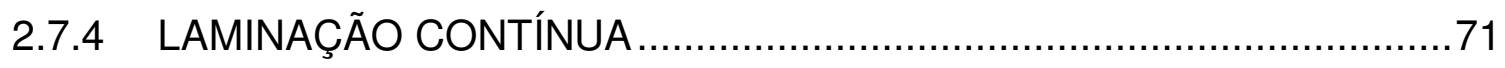

2.7.5 HAND LAY UP (MOLDAGEM MANUAL) .........................................

2.7.6 PROCESSO POR INJEÇÃO ……………..................................... 
2.7.7 REIFORCED REACTION INJECTION MOLDING - RRIM (MOLDAGEM POR MISTURA E INJEÇÃO) .74

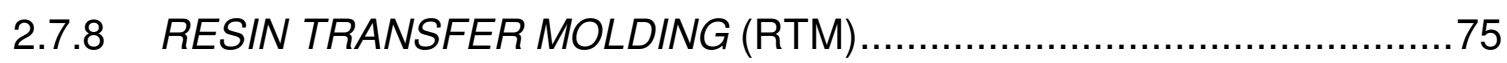

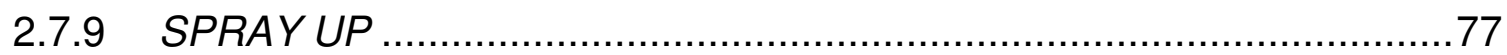

2.7.10 PREPREG (PRÉ-IMPREGNADOS) .................................................

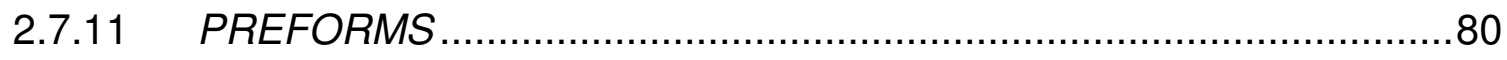

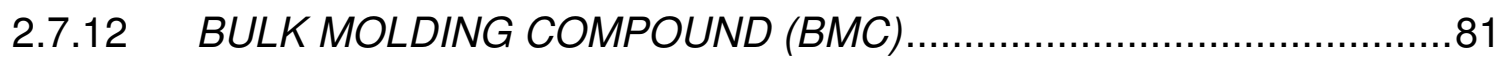

2.7.13 SHEET MOLDING COMPOUND (SMC) …….............................

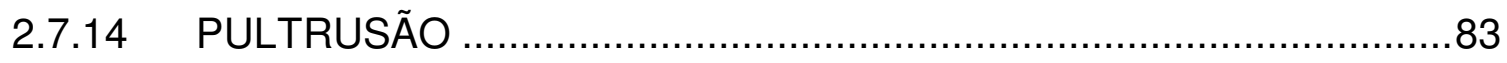

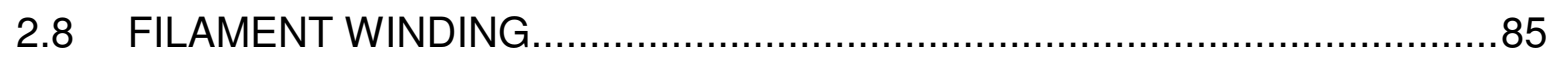

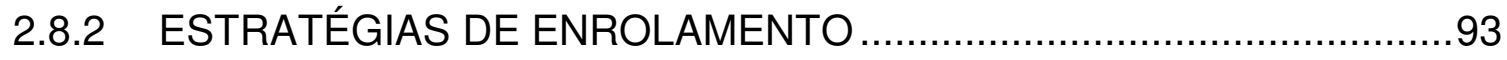

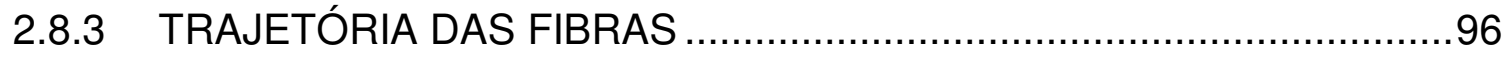

2.8.4 TRAJETÓRIA HELICOIDAL …….................................................100

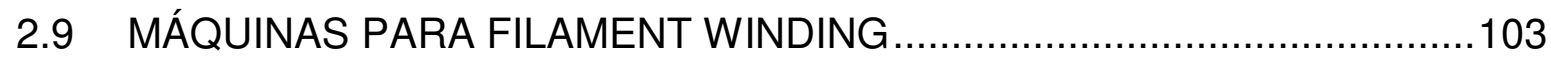

2.9.1 MAQUINAS COMERCIAIS PARA FILAMENT WINDING ..................104

2.9.2 MAQUINAS ACADÊMICAS PARA FILAMENT WINDING.................110

2.9.3 SISTEMA DE TENSIONAMENTO DAS FIBRAS..............................114

2.9.4 SISTEMA IMPREGNAÇÃO DAS FIBRAS .......................................117

2.9.5 SISTEMA DE ORIENTAÇÃO DAS FIBRAS ……….........................120

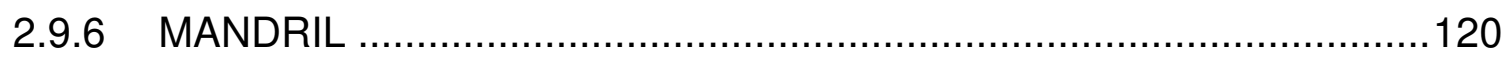

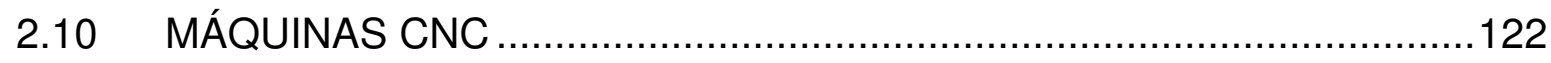

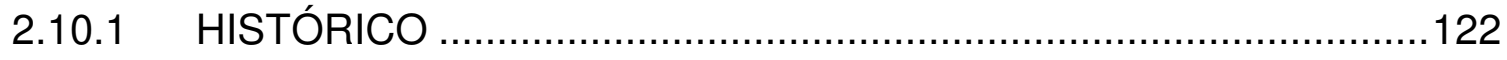

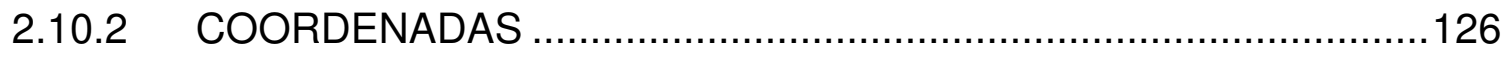

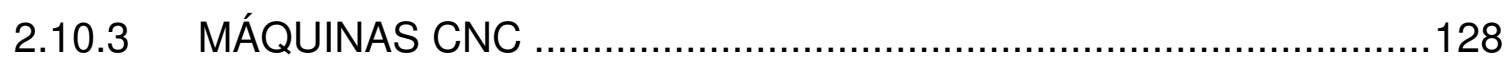

2.10.11 LINGUAGEM ISSO DE PROGRAMAÇÃO EM CNC.......................130

2.10.12 LINGUAGEM DE PROGRAMAÇÃO C.......................................131

2.11 SOFTWARE PARA FILAMENT WINDING …..................................132 


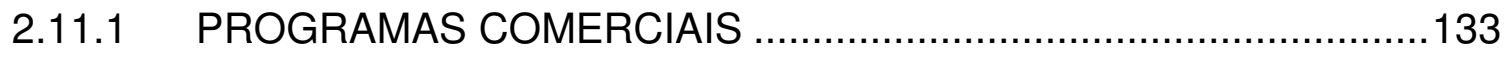

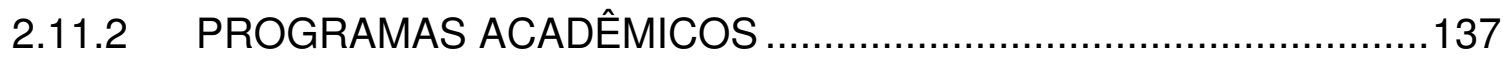

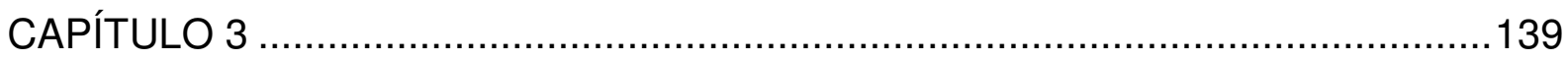

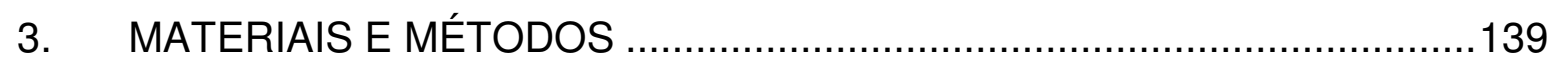

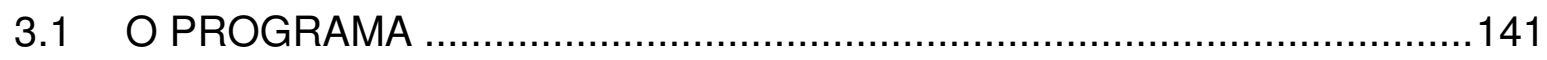

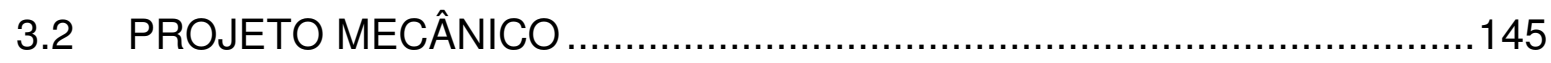

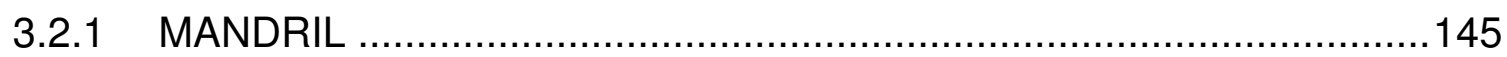

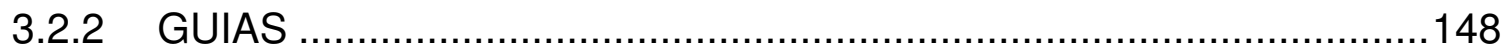

3.2.3 DISPOSITIVO TENSIONADOR ...................................................150

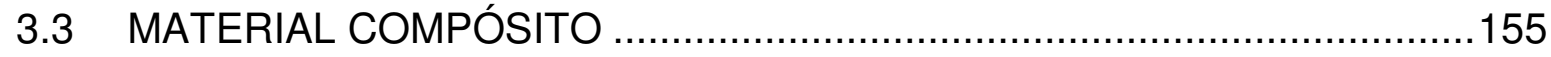

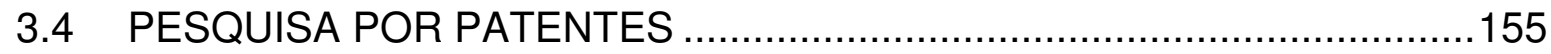

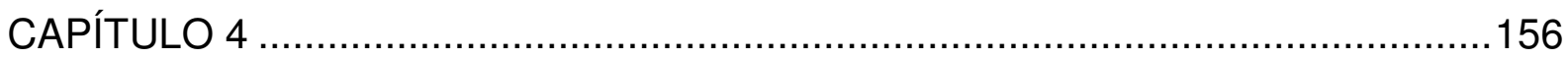

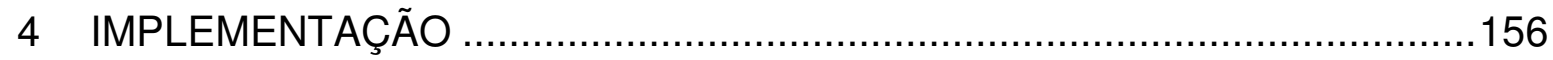

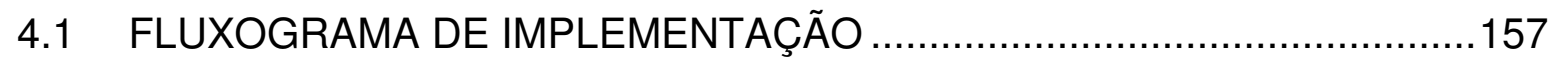

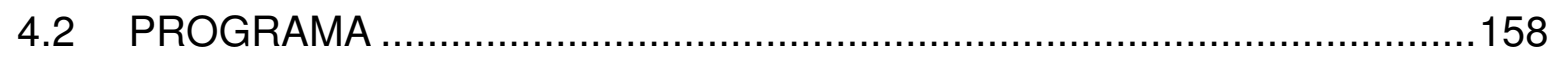

4.2.1 TESTE FÍSICO DO PROGRAMA …………..................................163

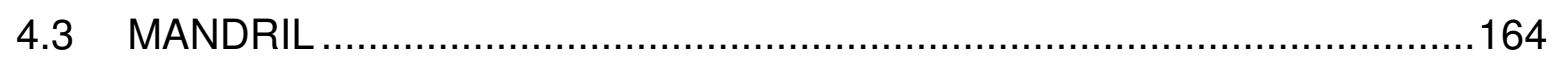

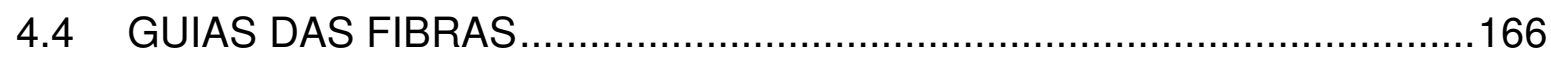

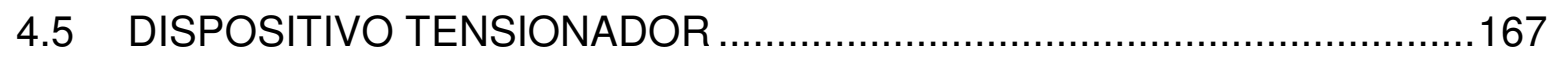

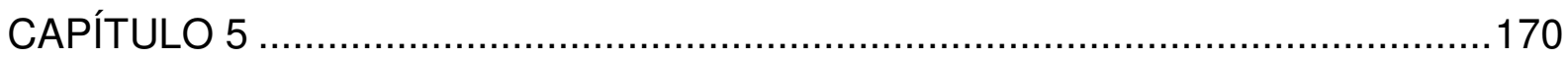

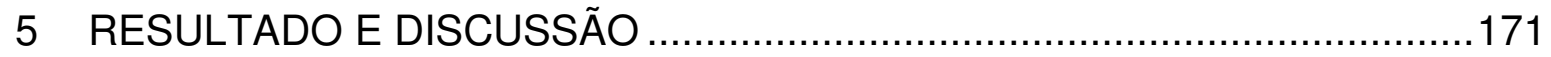

5.1 AVALIAÇÃO DAS TRAJETÓRIAS NO CAD ......................................171

5.2 TESTE DE PROGRAMA NO TORNO CNC …......................................177

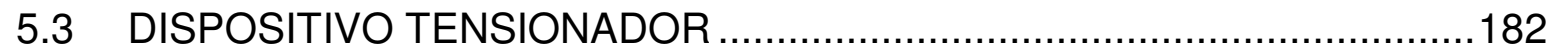

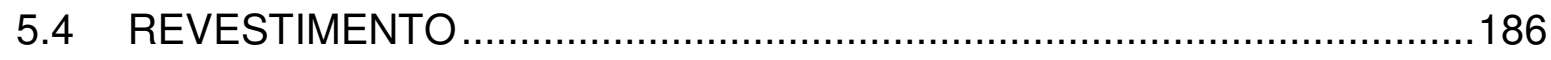

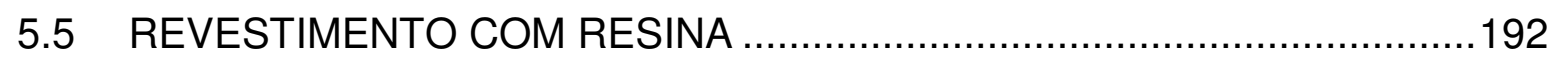

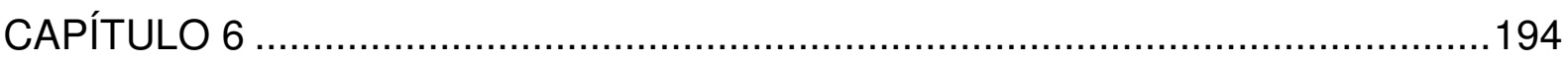




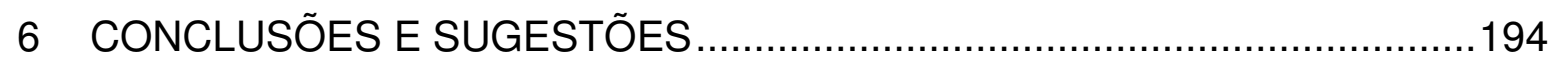

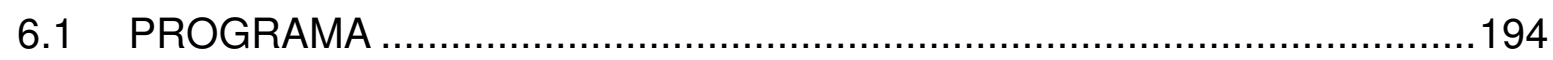

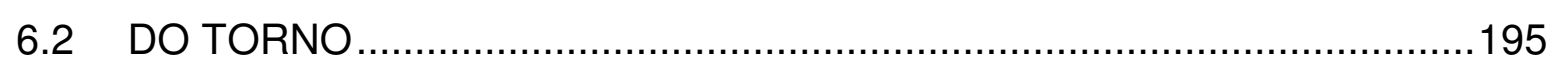

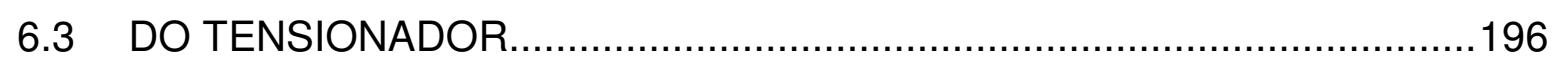

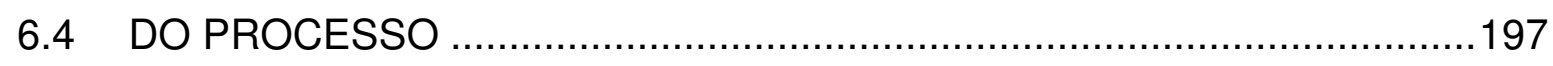

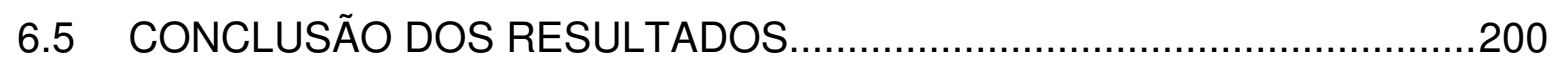

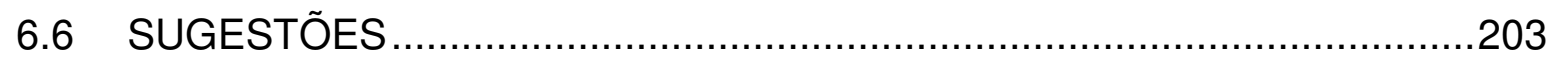

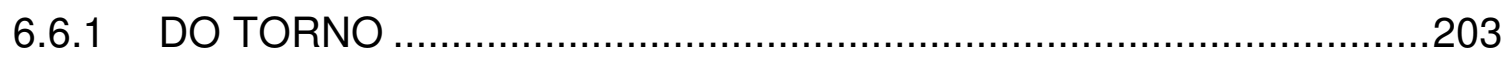

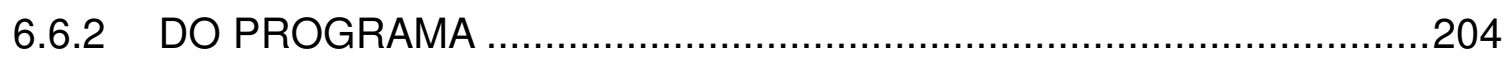

6.6.3 DOS DISPOSITIVOS E ACESSÓRIOS ..........................................204

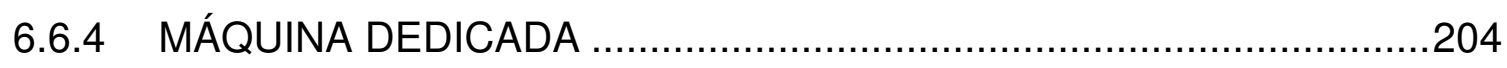

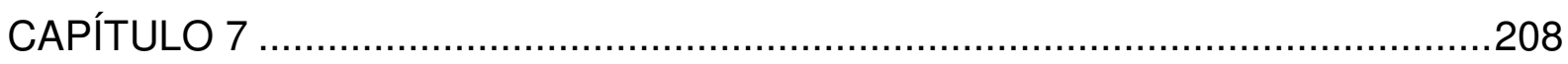

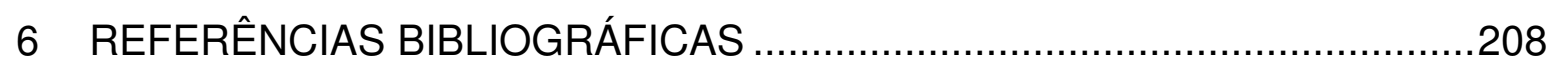


$X X X$ 


\section{CAPÍTULO 1}

\section{INTRODUÇÃO}

A humanidade sempre busca materiais que possam ser utilizados nas suas mais variadas necessidades (indústria, agricultura, bens de consumo, etc.). Segundo BEAUMONT (1989), observa-se na história da humanidade, que dentre as diversas maneiras de avaliação do padrão de vida de um país ou sociedade, o consumo de materiais de engenharia por indivíduo, disponível em forma de bens e serviços, pode ser uma das mais explícitas. Os bens manufaturados, sejam de consumo ou produção, são obtidos por meio da conversão dos materiais de engenharia, adicionando-Ihes valor. A história tem demonstrado que quanto mais eficientes forem os sistemas de produção, melhor será o padrão de vida da sociedade.

Sendo assim um dos índices de qualidade de vida de uma determinada comunidade está vinculado ao consumo de materiais de engenharia por indivíduo em forma de bens e serviços. Segundo BEAUMONT (1989), no ano 2000 a.C., esta hipótese pode ser comprovada por fatos históricos como o consumo de pederneira, utilizada como ferramenta de corte. Em torno de 1500 a.C., a tonelagem de bronze, provavelmente, revelou quem eram as grandes potências mundiais; e mais recentemente, por volta de 1850 d.C., teria sido o aço, seguido pelas ligas leves (no projeto de aviões) e as superligas (para motores a jato). Então, no final de 1963, uma série de experiências na Royal Aircraft Establishment em Farnborough, na Inglaterra, levou à descoberta, em meados de 1964, das fibras de carbono de alta resistência e alta rigidez e de seus compósitos. Nas duas décadas seguintes, a produção de Materiais Compósitos Reforçados por Fibras (MCRF) havia crescido a uma taxa desfrutada apenas pelo aço até seu apogeu. Sem dúvida, presencia-se uma revolução dos materiais de engenharia. No início, o grande estímulo à produção de MCRF estava relacionado à característica de combinar alta resistência mecânica e rigidez com baixo peso específico, o que confere uma grande eficiência estrutural. 
Nesta perspectiva de obter materiais de baixo peso e alta resistência mecânica, as mais variadas geometrias são planejadas e desenvolvidas. Embora geometrias de maior complexidade apareçam no ambiente industrial, geometrias cilíndricas e tubulares continuam a serem produzidas em grande escala. Neste ponto, um dos processos de fabricação chamado Filament Winding, tem grande aplicação na engenharia e na indústria.

Diâmetro, comprimento, estratégia de enrolamento, variação do diâmetro (geometria) ao longo do comprimento (cone, domo, etc.), largura da fita, tipo de fibra, tipo de resina, etc. São dados que definem e interferem na manufatura e desempenho do produto final.

\subsection{OBJETIVOS}

Os objetivos deste trabalho estão divididos em:

Programa: Elaborar um programa computacional que calcule as trajetórias das fibras para um tubo de diâmetro e comprimentos determinados, respeitando a estratégia de enrolamento definida pelo usuário. Este trabalho visa valores de diâmetro constante ao longo do comprimento e estratégia de enrolamento constante em cada camada de enrolamento. Este programa gera dados em planilhas de Excel para verificação das trajetórias, representadas em curvas, em CAD (adotado o software Solid Edge da Siemens) e gera arquivo texto com o código NC para o programa de manufatura em torno $\mathrm{CNC}$.

Projeto Mecânico: Projetar um sistema para fixação do mandril da peça a ser manufaturada, este sistema deverá ser flexível à construção de outras geometrias (limitada a valores de diâmetro e comprimento). Projetar um sistema de condução das fibras ao longo do diâmetro e comprimento da peça a ser manufaturada. Projetar um sistema de tensionamento das fibras para o enrolamento.

Validação: Projetar a peça no sistema CAD, definir e avaliar as trajetórias das fibras e gerar o código CNC. Manufaturar a peça no sistema desenvolvido e avaliar os resultados obtidos. 
Proposta preliminar de Equipamento para Filament Winding: A partir dos resultados obtidos, propor o projeto mecânico para a construção de uma máquina dedicada para a manufatura de peças (baixo volume) por meio do processo de Enrolamento Filamentar (Filament Winding).

\subsection{RELEVÂNCIA}

$\mathrm{Na}$ literatura são relatados trabalhos que tratam do uso de sistemas integrados para Projeto e Fabricação de peças pelo processo de Enrolamento Filamentar. Muitos dos exemplos citados tratam de sistemas fechados, com geração de dados de processo específicos para um determinado equipamento. Alguns sistemas comerciais disponíveis são limitados a aplicações usuais, como tubos e vasos de pressão, não possibilitando alterações nos códigos fonte. A possibilidade de desenvolver um sistema integrado "in-house" permite maior flexibilidade para geração de trajetórias para peças com geometrias mais diversificadas, uma vez que, tendo-se o domínio dos algoritmos de cálculo, poder-se-á altera-los em função de cada nova aplicação desejada. Adicionalmente, a possibilidade da utilização de máquinas comerciais, como no caso um torno CNC, para utilização em processo de Enrolamento Filamentar, viabiliza a utilização deste processo sem necessidade de aquisição de máquinas específicas, dedicadas e geralmente de alto custo, o que representa uma diversificação na fabricação de peças através deste processo.

\subsection{SINOPSES DAS CONTRIBUIÇÕES DO TRABALHO}

\subsubsection{Cálculo das Trajetórias.}

Elaboração de um programa para calcular a trajetória das fibras em um tubo de diâmetro e comprimento conhecidos, cujas dimensões serão fornecidas pelo usuário. O programa será escrito em C\# com a ideia de informações provenientes do usuário tais como diâmetro e comprimento do tubo, estratégia de enrolamento (ângulos $0^{\circ}$, $30^{\circ}, 45^{\circ}$ e $60^{\circ}$ ), etc., seja possível gerar planilhas em Excel para verificação das 
trajetórias em formato de curvas em software CAD (neste trabalho será adotado o Solid Edge) e uma vez verificada as trajetórias, seja possível gerar um programa de máquina CNC para construção da peça num torno CNC (neste trabalho o torno Romi Centur 30D será utilizado). O programa a princípio visa um torno CNC, mas com o objetivo de uma proposta futura de uma máquina para Filament Winding dedicada, cujo projeto é contemplado neste trabalho, no qual o programa forneça os dados necessários para a máquina coordenar os movimentos dos eixos da mesma e produzir o produto elaborado.

\subsubsection{Projeto preliminar de uma máquina de Filament Winding.}

Projeto mecânico e proposta de uma máquina de Filament Winding com finalidade de pesquisas acadêmicas utilizando o programa que será elaborado neste trabalho.

\subsubsection{Fabricação de peça tubular para validação do sistema.}

Elaborar um projeto mecânico para a manufatura de uma peça tubular em material compósito reforçado por fibra a ser produzido em um torno CNC. Inicialmente é proposto um tubo de diâmetro e comprimento invariáveis e ângulo (estratégia de enrolamento) definidos constantes para cada revestimento. As fibras utilizadas para a manufatura desta peça não serão impregnadas com resina.

As peças produzidas por este sistema poderiam ser impregnadas com resina desde que proteções contra respingos de resina fossem construídos e instalados. Dependendo do compósito a ser manufaturado poderia ser feito o processo de enrolamento a seco (Dry Wind) e posteriormente ser feito infiltração de resina com auxílio de uma bomba de vácuo. 


\subsection{ORGANIZAÇÃO DO TRABALHO}

Este texto está organizado da seguinte forma:

- Capítulo 1: Introdução: o tema e objetivos desta pesquisa são abordados e detalhados neste capítulo.

- Capítulo 2: Revisão Bibliográfica: São apresentados de maneira sintética os principais conceitos relacionados às tecnologias utilizadas na pesquisa, tais como cálculo de trajetórias e resistência mecânica, juntamente com uma revisão bibliográfica específica do tema de pesquisa.

- Capítulo 3: Materiais e Métodos: São apresentados os materiais, métodos e programas computacionais que serão utilizados no desenvolvimento do projeto proposto.

- Capítulo 4: Projeto Mecânico e Procedimentos: São apresentados os dispositivos e peças construídos, disposição das peças e procedimentos adotados.

- Capítulo 5: Resultados Experimentais e Discussão: São apresentados os resultados obtidos e considerações sobre a parte experimental.

- Capítulo 6: Comentários Finais e Sugestões: São apresentados os comentários relativos ao resultado do experimento e apresentadas sugestões em função dos resultados. 


\section{REVISÃO DA LITERATURA}

\subsection{MATERIAIS COMPÓSITOS}

Segundo PADILHA (1997) materiais compósitos são materiais projetados de modo a conjugar características (principalmente mecânicas) desejáveis de dois ou mais materiais. Um exemplo típico é o compósito de fibra de vidro em matriz polimérica. A fibra de vidro confere resistência mecânica, enquanto a matriz polimérica, na maioria dos casos, constituídas de resina epoxídica é responsável pela transferência esforço solicitado ao compósito para as fibras. A matriz pode ser polimérica, metálica ou cerâmica. $O$ reforço pode estar na forma de dispersão de partículas, fibras, bastonetes, lâminas ou plaquetas. A grande expansão do uso de materiais compósitos ocorreu nos anos de 1970 conforme figura 1.

Figura 1 - Evolução da produção de alguns materiais nos EUA.

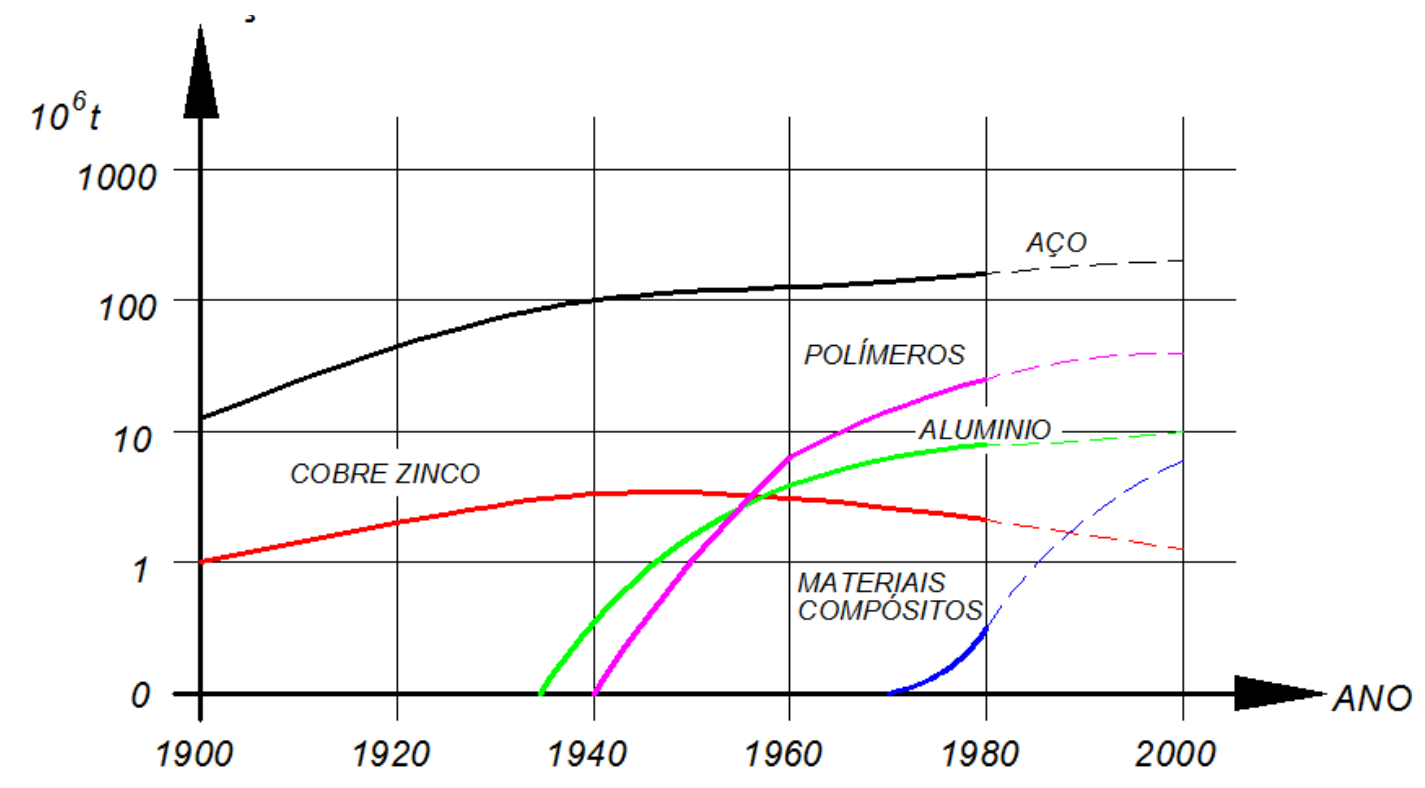


Fonte: Adaptado de PADILHA (1997).

FILHO (2001) diz que existem patenteados mais de 50.000 tipos de materiais de engenharia dos quais os projetistas podem utilizar. Estes materiais podem ser classificados em: metais, polímeros, cerâmicos e compósitos.

CALLISTER (1993) afirma que muito da nossa tecnologia moderna requer materiais das mais incomuns combinações de propriedades que exigem mais dos materiais convencionais existentes como metais, cerâmicas e polímeros. Isto é caracterizado em materiais que são empregados nas áreas aeronáutica, naval e aplicações de transporte. Por exemplo, engenheiros aeronáuticos estão aumentando a pesquisa por materiais que tenham estrutura de baixa densidade, sejam resistentes, rígidos, resistentes à abrasão e impactos e de difícil corrosão. Frequentemente materiais resistentes são relativamente densos; também, aumentando a resistência ou dureza geralmente resulta em uma diminuição na resistência ao impacto. A combinação das propriedades dos materiais tem sido é motivo de estudo e desenvolvimento de materiais compósitos. Geralmente um compósito é considerado como qualquer material multifase que exibi uma significante proporção de propriedades de ambas as fases constituintes tais como a melhor combinação das propriedades que realiza. De acordo com o princípio de ação combinada, as melhores combinações de propriedades são formadas também pela combinação de dois ou mais distintos materiais onde a permutação ou troca de propriedades também ocorrem.

Segundo CALLISTER (1993) muitos materiais compósitos são compostos justamente por duas fases: uma chamada de matriz, a qual é contínua e envolve a outra fase, esta frequentemente chamada de fase dispersa. As propriedades dos compósitos são uma função de propriedades das fases constituintes, sua quantidade relativa e a geometria da fase dispersa. Geometria da fase dispersa neste contexto 
significa o formato e tamanho das partículas, distribuição e orientação. Características estas representadas na figura 2.

Figura 2 - Representação esquemática das fases.

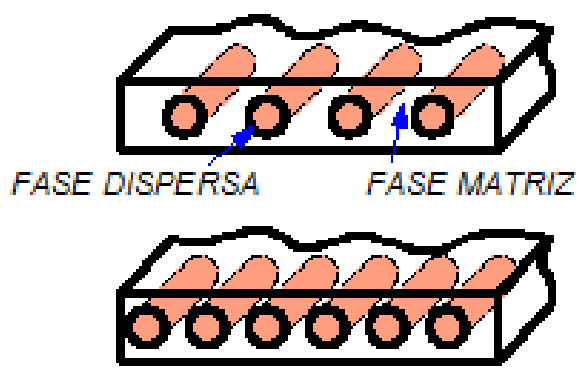

(a)
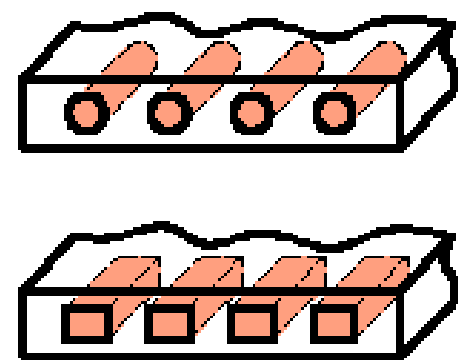

(c)
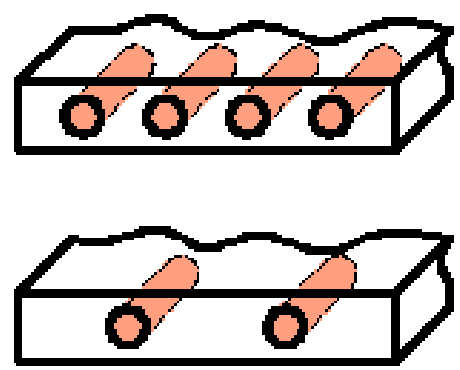

(b)
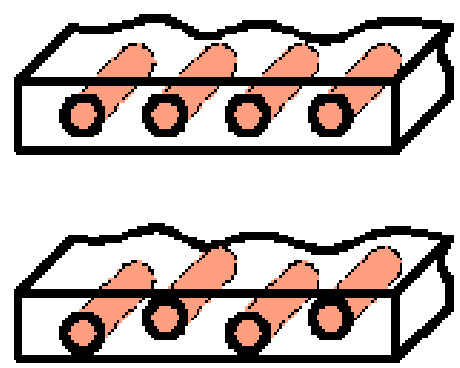

(d)

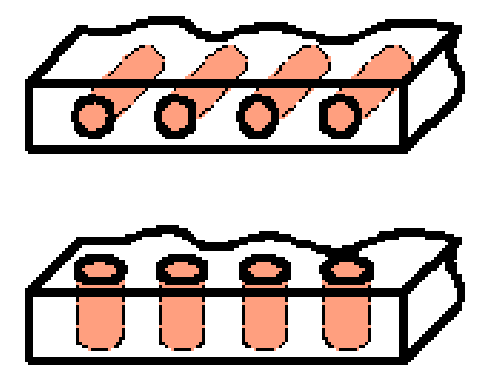

(e)

Fonte: Adaptado de CALLISTER (1993).

A figura 2 ilustra uma representação esquemática dos posicionamentos das fibras (ou reforços) na fase dispersa que podem influenciar as propriedades dos compósitos: (a) concentradas, (b) afastadas, (c) formato das fibras, (d) distribuição e (c) orientação. 
CALLISTER (1993) subdivide compósitos reforçados em três grandes grupos e subdividem estes grandes grupos em outras subdivisões. O compósito pode ser subdividido em: Reforçado com partículas, Reforçado por fibras e Estrutural. Esta representação pode ser visto na figura 3.

Figura 3 - Esquema de classificação dos vários tipos de compósitos.

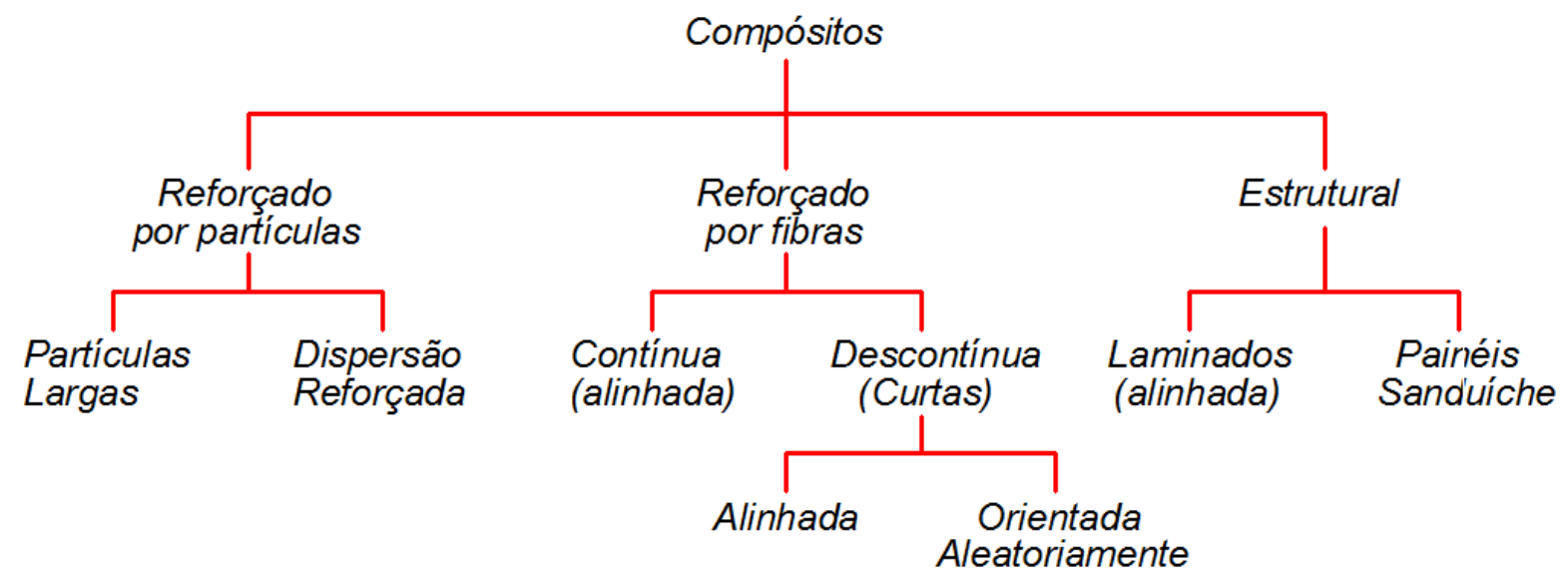

Fonte: Adaptado de CALLISTER (1993).

MILTON (2002) diz que o que dá aos compósitos sua utilidade é que eles frequentemente combinam os atributos dos materiais constituintes. Por exemplo, suponha que um dos materiais seja isotrópico e condutor: um metal de alta condutividade e o outro seja um plástico isolante elétrico. Coloca-se, um destes dois materiais, em camadas alternadas em um laminado, obtém-se um compósito altamente anisotrópico que tem propriedades de condução do metal nas direções paralelas às camadas e propriedades isolantes do plástico normal às camadas. Concreto é considerado barato e menos denso que o aço, mas rompe facilmente sobtensão. Em contraste o aço é considerado resistente, mas caro e mais denso que o concreto. Colocando o concreto em volta das barras de metal obtém-se um compósito, nominalmente chamado, concreto reforçado, que é barato, relativamente leve e forte. Madeira é um exemplo de material que é resistente na direção da fibra, mas as fibras se separam facilmente. Alternando as camadas da madeira que são resistentes em uma direção com camadas de madeira que são resistentes em outra direção, obtém-se um compensado que é resistente em ambas as direções. 
Segundo a Associação Latino-Americana de Materiais (2015) define materiais compósitos como materiais de moldagem estrutural, formados por uma fase contínua polimérica (matriz) e reforçada por uma fase descontínua (fibras) que se agregam de maneira física e química após um processo de crosslinking polimérico (cura). $\mathrm{Na}$ moldagem destas duas fases ocorre um crosslinking polimérico através de um processo de cura, que acopla as duas fases proporcionando aos materiais propriedades específicas que definem sua moderna e ampla aplicabilidade. Leveza, flexibilidade, durabilidade, resistência, adaptabilidade são algumas das propriedades que garantem aos compósitos o título de "produto do futuro". Devido a massa específica das resinas e das fibras de reforço, os produtos fabricados a partir dos compósitos apresentam leveza. Devido a esta e a outras propriedades características dos materiais compósitos é que eles são amplamente utilizados nos setores de aeronáutica, naval, automobilístico e outros. Os compósitos apresentam excepcional inércia química, o que permite sua utilização em uma ampla gama de ambientes agressivos quimicamente.

A combinação de baixa massa específica com valores elevados de resistência e rigidez, que os compósitos poliméricos proporcionam, permite que esses materiais sejam empregados nas indústrias aeronáuticas e espacial, substituindo materiais metálicos tradicionais. Componentes estruturais de aeronaves para fins comerciais e militares tais como flaps, lemes, carenagens, tanques de combustíveis, entre outras peças, tem sido manufaturadas a partir de materiais compósitos, antes produzidos com alumínio, titânio e ligas de aço. Além da resistência mecânica, rigidez e baixa densidade, estes materiais também possuem resistência à fadiga, corrosão, baixa condutividade térmica e a possibilidade de obtenção de superfícies complexas. CÂNDIDO (2000). A figura 4 ilustra componentes aeronáuticos manufaturados a partir de materiais compósitos reforçados por fibras. 
Figura 4 - Vista explodida da aeronave EMB-145, mostrando as partes fabricadas em compósitos. Cortesia da EMBRAER.

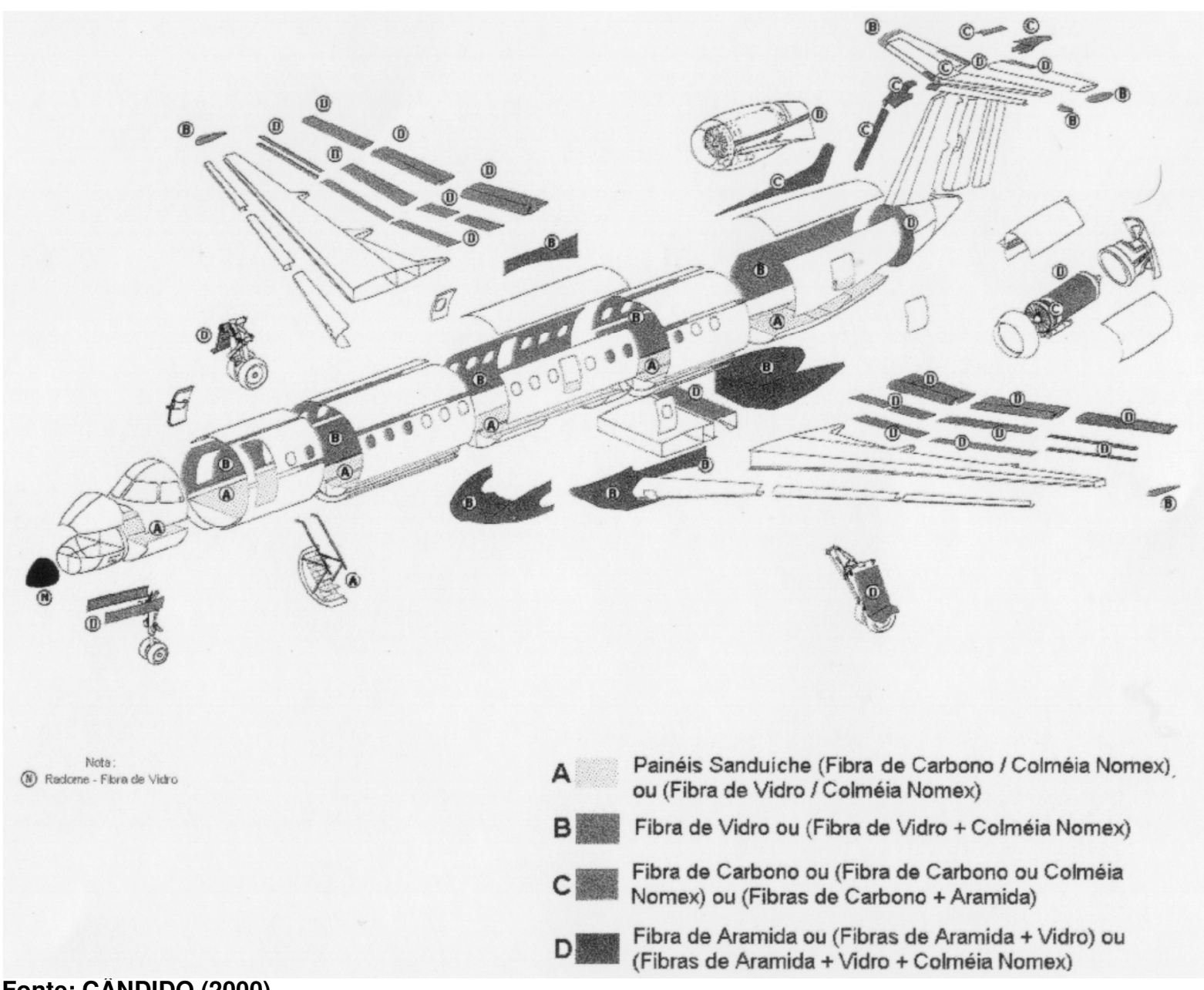

Fonte: CANDIDO (2000).

\subsubsection{COMPÓSITOS REFORÇADOS POR PARTÍCULAS}

De acordo com CALLISTER (1993) este tipo de compósito é classificado em: Partículas largas e Dispersão reforçada. Estes tipos são baseados em reforço ou fortalecimento do mecanismo. Partículas Largas é um termo usado para indicar que 
a interação entre partícula e matriz não pode ser tratada no nível atômico ou molecular, ao invés disto, mecanismo contínuo. Este reforço por partículas tende a restringir o movimento da fase matriz ao redor de cada partícula. Na sua essência, a matriz transfere uma parte da tensão aplicada às partículas, as quais apresentam uma fração da carga. O grau de reforço ou desempenho mecânico depende da força de ligação na interface partícula e matriz. As partículas podem ter uma boa variedade de geometrias, mas elas devem ter aproximadamente a mesma dimensão em todas as direções (equiaxial). Para um efetivo reforço, as partículas devem ser uniformemente distribuídas em toda a matriz. A figura 5 ilustra a micrografia de um metal duro WCCo.

Figura 5 - Fotomicrografia de um WC-Co metal duro.

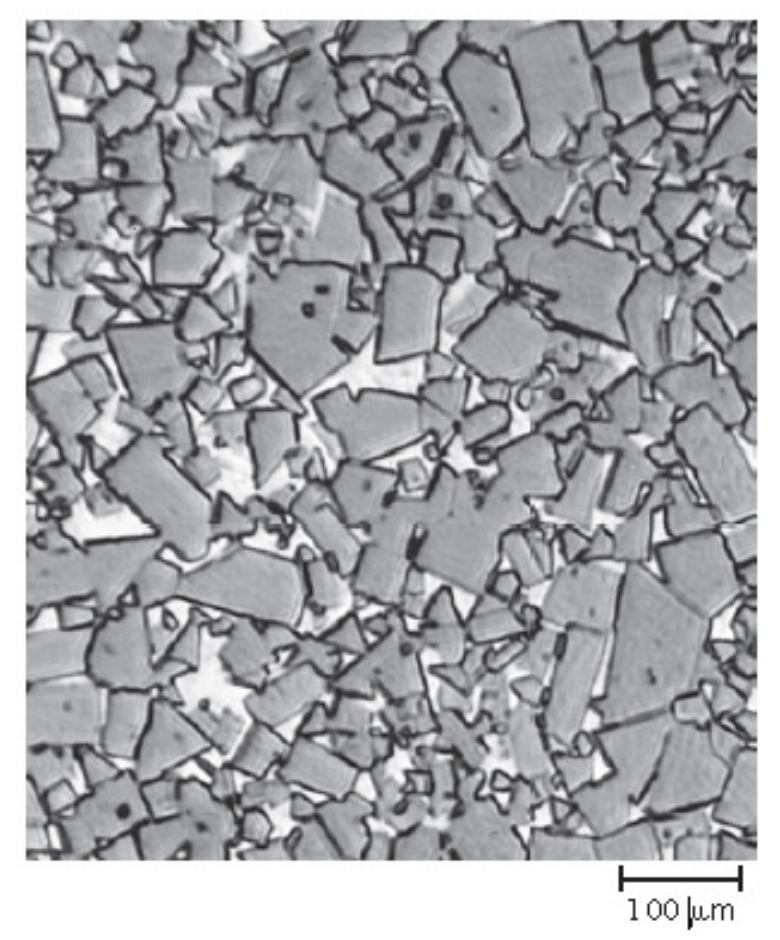

Fonte: CALLISTER (1993).

Compósito por Dispersão Reforçada: neste tipo de compósito as partículas são normalmente menores, tendo diâmetros entre 0,01 e 0,1 $\mu \mathrm{m}$. A interação partícula-matriz que leva ao reforço ocorre no nível atômico ou molecular. $O$ mecanismo de reforço é similar à precipitação de endurecimento, onde a matriz carrega a maior parte da carga aplicada, as pequenas partículas dispersas impedem 
o movimento de deslocamento. Assim a deformação plástica é restrita de tal modo que a resistência à tração e a dureza, melhoram.

Metais e ligas metálicas podem ser reforçados e endurecidos pela dispersão uniforme de diversos volumes percentuais de partículas finas de um material duro ou inerte. A fase dispersa pode ser metálica ou não. Materiais óxidos frequentemente são usados.

\subsubsection{COMPÓSITOS REFORÇADOS POR FIBRAS}

Segundo CALLISTER (1993) os compósitos mais importantes são aqueles nos quais a fase dispersa está no formato de fibra. O objetivo do projeto de compósitos reforçado por fibras frequentemente incluem resistência alta e/ ou rigidez e baixa densidade. Estas características são expressas em termos de parâmetros de resistência e módulo específicos, os quais correspondem, respectivamente, aos módulos de resistência à tração e módulo de elasticidade.

CARVALHO (1996) define material compósito como toda espécie de material formado por dois ou mais constituintes colados juntos numa direção apropriada. A ideia básica é que os pontos fracos de um material possam ser reforçados ou melhorados usando outro material. Entre todas as possíveis aplicações de compósitos reforçados por fibras, a maior área de aplicação é a estrutural. A distinção é feita entre compósitos reforçados por fibras picadas (ou curtas) e por fibras contínuas (enrolamento). Para aplicações de alto desempenho, fibras contínuas e alinhadas na forma de pré-impregnados unidirecionais são muito utilizados. Dificuldade de manusear estes materiais em superfícies complexas tem sido superada com o uso de compósitos têxteis, como exemplo o uso de tecidos ou malhas trançados em duas ou três direções. A função primária da fibra é resistir ao carregamento e dar a maior parte da rigidez requerida pelo componente para atingir os objetivos da concepção do projeto. Por outro lado, a função primária da matriz é manter as fibras juntas, distribuir a carga e proteger as fibras da corrosão externa.

Segundo CALLISTER (1993) a característica mecânica de um compósito reforçado por fibra depende não somente das propriedades da fibra, mas também do grau no qual um carregamento aplicado é transmitido para as fibras na fase matriz. 0 
importante para a extensão desta transmissão de carregamento é a magnitude da ligação da interface entre as fases fibra e matriz. Sob uma tensão aplicada, a ligação entre fibra e matriz cessa onde a fibra termina, obtendo-se um padrão de deformação da matriz como mostrado na figura 6 . Em outras palavras, não há transmissão de carga da matriz para cada extremidade da fibra.

Figura 6 - Padrão de deformação na matriz em volta da fibra quando sujeita à tensão.

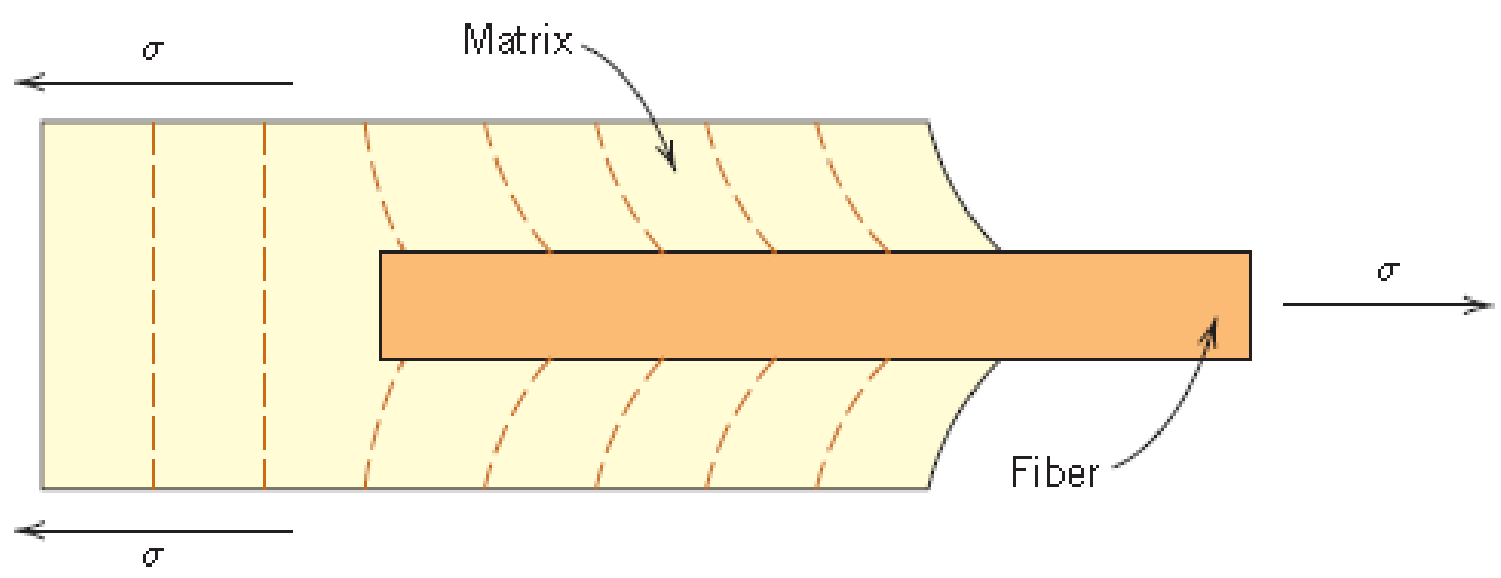

Fonte: Adaptado de CALLISTER (1993).

MATHEWS \& RAWLINGS (1994) definem o comprimento da fibra (Ic) como o comprimento mínimo da fibra para um dado diâmetro (d), que admita a tensão de ruptura à tração da fibra em lugar de tensão de cisalhamento da interface, isto é, o comprimento mínimo da fibra necessário para a tensão transmitida alcançar a tensão de ruptura da fibra. 
Então:

$$
l_{c}=\frac{\sigma_{f} \cdot d}{2 \cdot \tau_{f}}
$$

Onde:

$l_{c}=$ comprimento crítico da fibra;

$\sigma_{f}=$ resistência à tração de ruptura da fibra;

$\tau_{f}=$ menor resistência ao cisalhamento da matriz ou da interface;

$d$ = diâmetro da seção da fibra.

As características mecânicas dos MCRF não dependem somente das propriedades das fibras, mas da magnitude com que o carregamento é transmitido às fibras por meio da matriz. Essa transferência de carregamento é ilustrada na figura $7^{\mathfrak{a}}$ e $7 b$ em função do comprimento da fibra e da adesão interfacial entre a fibra e matriz.

Figura 7 - Efeito da deformação ao redor da fibra na matriz sob tensão: (a) fibra contínua. (b) fibra descontínua. 


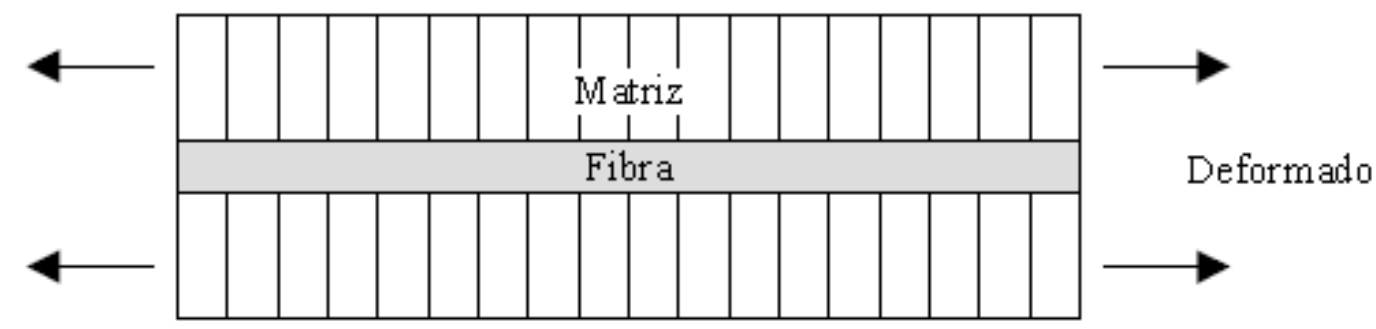

(a)

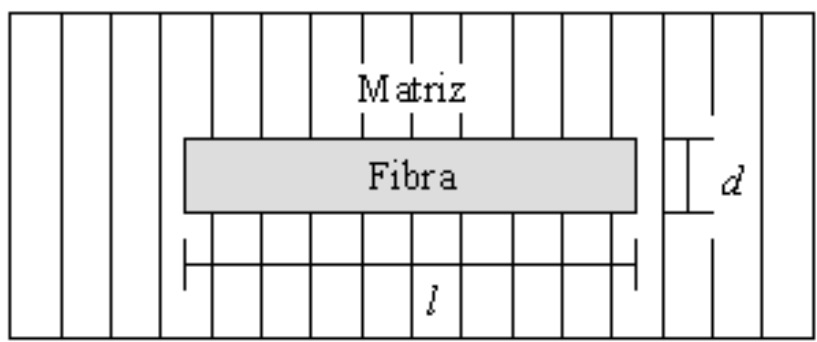

Não Deformado
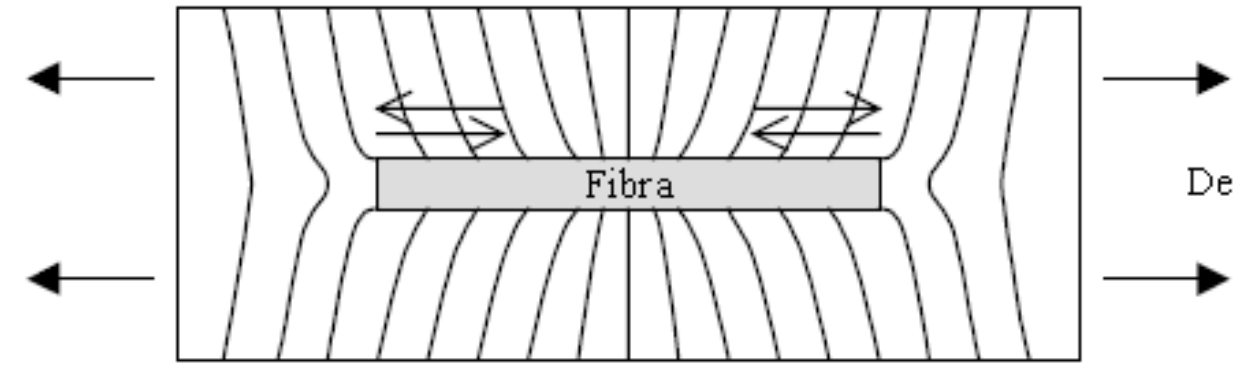

\section{Deformado}

(b)

Fonte: Adaptado de MATTEWS \& RAWLINGS (1994).

Segundo CALLISTER (1993) para fibras de vidro e carbono, o comprimento crítico situa-se entre 20 a 150 vezes o diâmetro da fibra. O arranjo e a orientação das fibras relativas entre elas, a concentração das fibras e toda a distribuição das fibras têm uma significante influência na resistência e em outras propriedades dos compósitos reforçados por fibras. Com respeito à orientação, duas possibilidades são possíveis: (1) um alinhamento paralelo do eixo longitudinal das fibras em uma única direção e (2) posicionado ao acaso (acomodado sem orientação pré-definida). Fibras contínuas são normalmente alinhadas ao passo que fibras não contínuas podem ou não ter orientação definida. Quando a distribuição das fibras é uniforme, o compósito exibe melhores propriedades mecânicas. 
De acordo com FILHO (2001), quando uma tensão $\sigma_{f}$ é aplicada à fibra, cujo comprimento é igual ao comprimento crítico $(I=l c)$, o perfil de posição da tensão aplicada, mostrado na figura 8a, alcança o carregamento máximo apenas no centro axial da fibra. Com o aumento do comprimento da fibra, a eficiência do reforço aumenta, pois o máximo carregamento se distribui ao longo de boa parte da fibra, como mostra a figura $8 \mathrm{~b}$ pelo perfil de posição da tensão axial para $l>l_{c}$ quando a tensão aplicada é igual a resistência da fibra $\sigma_{f}$.

Figura 8 - Gráfico de tensão vs posição quando o comprimento da fibra (a) é igual ao comprimento crítico, (b) é maior que o comprimento crítico.
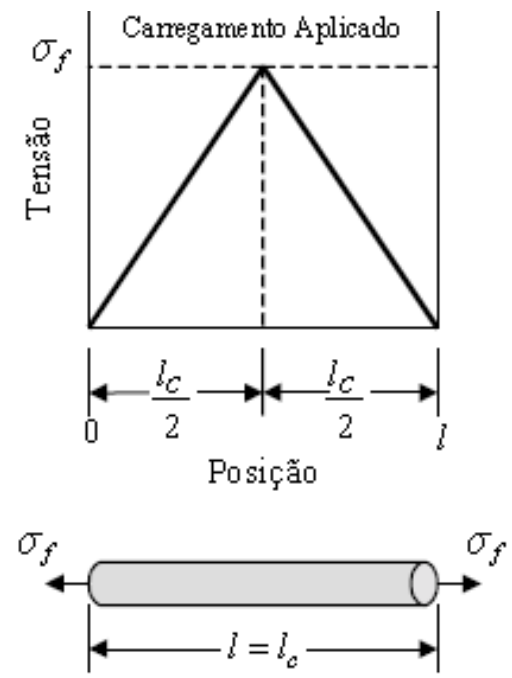

(a)
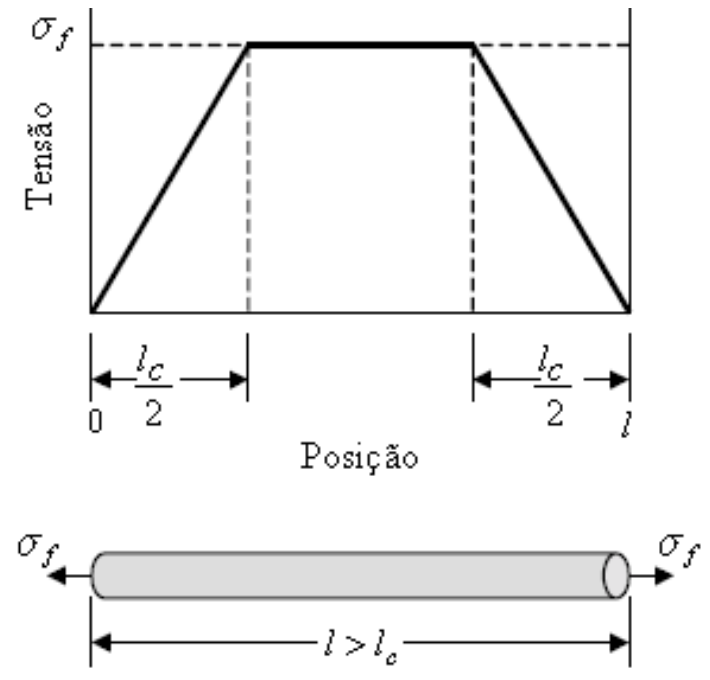

(b)

Fonte: FILHO (2001) e CALLISTER (1993).

A figura 9 mostra o perfil de posição da tensão aplicada para $l>l_{c}$. Neste caso a matriz se deforma ao redor da fibra (figura 9b) de modo que não há transferência efetiva da tensão, e consequentemente, uma baixa eficiência do reforço por parte da fibra. Estes se comportam como compósitos particulados (FILHO 2001). 
Figura 9 - Gráfico tensão vs posição quando o comprimento da fibra é menor que o comprimeto crítico para um compósito reforçado por fibras que está submetido a uma tensão à tração igual a resistência à tração da fibra.
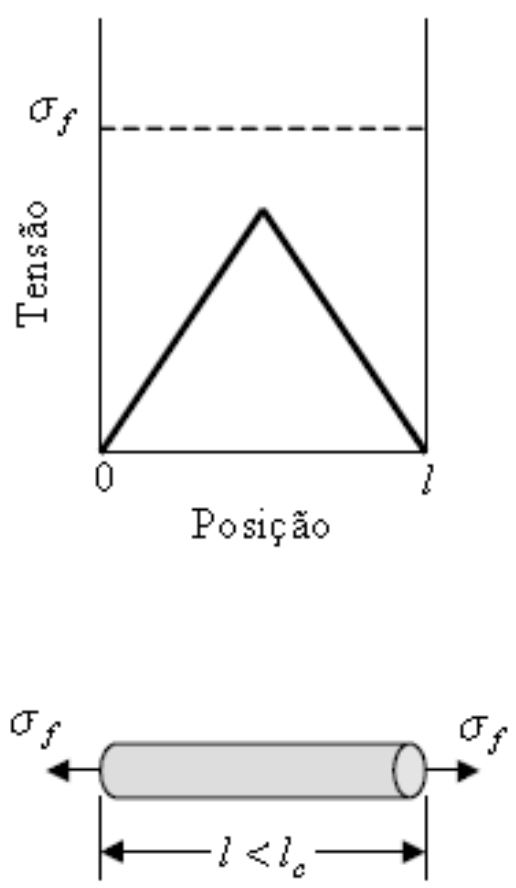

Fonte: CALLISTER (1993).

Segundo FILHO (2001) o reforço fibroso caracteriza-se pelo seu comprimento ser muito maior que a dimensão da seção transversal (diâmetro), conhecida como razão de aspecto (aspecto ratio) pode variar consideravelmente. A figura 10 mostra esquematicamente alguns exemplos de compósitos reforçados por fibras e partículas. 
Figura 10 - Exemplo de MCRF: (a) partículas aleatórias, (b) fibras descontínuas unidirecinais, (c) fibras descontínuas aleatórias e (d) fibras contínuas direcionais.

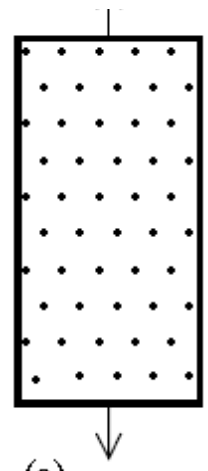

(a)

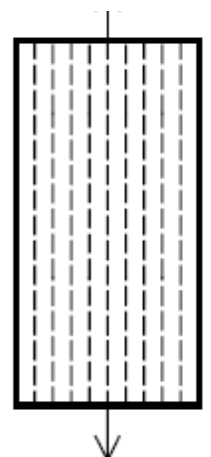

(b)

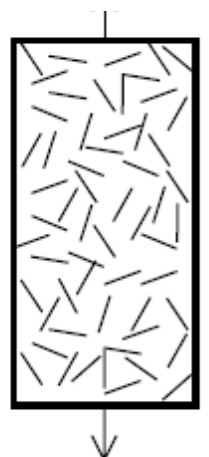

(c)

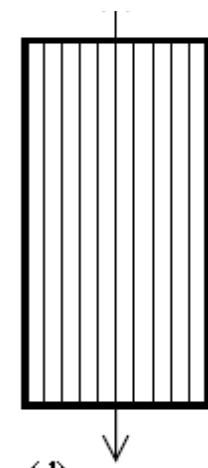

(d)

Fonte: MATEWS \& RAWLINGS (1994) e FILHO (2001).

\subsection{MATRIZ}

De acordo com CALLISTER (1993), a fase matriz de um compósito reforçado por fibras possui várias funções.

- A primeira função da matriz é unir as fibras e agir como o meio na qual as tensões externas aplicadas são transmitidas e distribuídas às fibras. Apenas uma pequena proporção da tensão aplicada é sustentada pela matriz.

- A segunda função da matriz é proteger as fibras de ações externas como abrasão mecânica e reações químicas do ambiente externo. Tais interações podem introduzir falhas na superfície capazes de produzir trincas que podem levar a falha em níveis baixos de tensão.

- A terceira função, a matriz separa as fibras, em virtude da suavidade e plasticidade relativa, prevenindo a propagação de pequenas trincas de fibra para fibra, as quais podem resultar em uma falha catastrófica, servindo como uma barreira à propagação da trinca.

Segundo HYER (1998), a matriz, também chamada de resina, geralmente compõe de $30 \%$ a $40 \%$ de um material compósito. Ela mantém o formato da estrutura do compósito, alinhando os reforços (fibras), transfere o carregamento às fibras $\mathrm{e}$ protege as mesmas contra abrasão e corrosão. A limitação de um compósito pode 
bem ser a função das propriedades da matriz, como exemplo a estabilidade térmica e a temperatura máxima de trabalho.

De acordo com SCHOLLIERS (1992), os materiais das matrizes poliméricas podem ser divididos em duas classes: termorrígidas e termoplásticas. Elas se diferem na estrutura intermolecular, a cadeia molecular da termorrígida é interconectada com ligações químicas (cross-link) e as termoplásticas não. Termorrígidas requerem cura para alcançar a estrutura cross-link e não podem ser refundidas devido a este tipo de ligação. Termoplásticas são aquecidas, moldadas de acordo com o formato desejado e solidificadas para chegar à forma desejada. Termorrígidas requerem um tempo maior de processamento que as termoplásticas, devido ao longo tempo do ciclo de cura, embora a maioria das termoplásticas exijam temperatura e pressão mais elevadas devido a sua viscosidade. Termoplásticas em geral têm resistência e dureza inferiores às termorrígidas, mas são mais resistentes ao meio ambiente.

HYER (1998) também define duas classes de matrizes, Termorrígidas ou Termofixas e Termoplásticas, a diferença entre elas está no comportamento quando aquecidas. Termorrígidas sofre uma mudança química irreversível quando aquecida, chamado de cura. Depois de curada ela não pode mais ser fundida, se aquecida acima de seu limite ela se degrada. Termoplásticas são reversíveis, podem ser fundidas, resfriadas e curadas. Uma vez curadas num formato, podem ser aquecidas e remodeladas. A matriz também é responsável pela geometria do compósito. As fibras embora tenham a resistência à tração muito superior à matriz, não possuem geometria definida, elas se adaptam às superfícies as quais são posicionadas. Uma vez removidas e postas em outra superfície, elas se adaptam novamente, não tendo assim geometria definida. A matriz, uma vez curada, leva as fibras e a matriz, o compósito em si, a uma geometria definida.

As matrizes podem ser de materiais poliméricos, metálicos ou sintéticos. A escolha do material da matriz dependerá das propriedades físicas, mecânicas e térmicas exigidas, bem como do processo de fabricação escolhido e do custo associado. Neste caso, as matrizes poliméricas são as mais utilizadas, devido ao baixo custo, fácil moldagem, boa resistência química e baixo peso específico. Por outro lado, comparadas às matrizes de material metálico e cerâmico, fatores como baixa resistência mecânica, baixo módulo de elasticidade e baixa temperatura de 
serviço, limitam seu uso. Estas matrizes também tendem a se degradar à exposição prolongada da luz e solventes (FILHO 2001).

As matrizes poliméricas mais utilizadas para compósitos aeroespaciais são as termofixas ou termorrígidas, consistindo de uma cadeia de polímeros que são permanentemente curadas dentro de uma rede de reticulados (network crosslinked) quando misturada a um catalisador ou exposta ao calor. Resinas termoplásticas representam uma pequena, mas crescente categoria de matrizes nas aplicações que requerem resistência ao impacto (AEROSPACE COMPOSITES).

Ambas as matrizes, termorrígida e termoplástica, podem são curadas com aplicação de calor, podendo ser em autoclaves ou fornos. A temperatura de cura é determinada pelo fabricante, é importante não exceder essa temperatura para não prejudicar as propriedades dessas resinas. Cessando o calor a matriz endurece e toma formato (geometria desejada). A matriz termoplástica por sua vez, tem a capacidade de ser fundida e remodelada novamente, oferecendo o potencial para corrigir eventuais anomalias ou tornando mais fácil algum reparo na geometria.

Em menor escala, metais (tais como alumínio, titânio e magnésio) e cerâmicas (tais como carbeto de silício) são usados como matrizes, para aplicações específicas, tais como componentes aeroespaciais, onde o coeficiente de expansão térmica e a ausência de saída de gases são necessários. AEROSPACE COMPOSITES (2008).

Segundo HYER (1998) as matrizes termorrígidas são as mais utilizadas devido as suas excelentes propriedades mecânicas, elas mantêm suas propriedades mecânicas quando solicitadas em altas temperaturas, ambientes úmidos e resistência química. Também possui boa estabilidade dimensional, facilmente processada, baixo custo e exibe boa adesão a maioria das fibras. O processo de cura das termorrígidas é acompanhado da adição de um agente que reage com o epóxi que é incorporado à sua cadeia molecular, assim as propriedades desta matriz são afetadas pelo reagente utilizado. Alguns dos reagentes mais utilizados são ácidos anídricos e aminas multifuncionais. Aminas alifáticas são de cura rápida enquanto aminas aromáticas são menos reativas, mas resultam em uma alta temperatura de transição vítrea. Uma vez misturados, epóxi e agentes, a resina líquida se converte num sólido pela aplicação 
de calor. A cura do epóxi é lenta, chegando a levar horas para a cura total. Como resultado, uma estrutura frágil é obtida.

AEROSPACE COMPOSITES (2008) caracteriza os tipos de matrizes em:

\subsubsection{MATRIZ EPOXI}

Contribui com resistência, durabilidade e resistência química ao compósito. Elas oferecem alto desempenho às elevadas temperaturas, na presença de calor e umidade, onde a temperatura de trabalho são superiores a $121^{\circ} \mathrm{C}$. Estas matrizes podem ser encontradas no estado líquido, sólido e semissólido e são tipicamente curadas pela reação com aminas ou anidridos. Muitas aplicações aeroespaciais são curadas por amina, epóxis multifuncionais que requerem cura em temperaturas elevadas.

\subsubsection{MATRIZ BISMALEIDE (BMI) E POL YIMIDE (POLIIMIDA)}

São matrizes com propriedades químicas muito próximas, são utilizadas onde aplicações com temperaturas elevadas são necessárias tais como aeronaves e mísseis. BMI é utilizada para trabalho com calor e umidade em temperaturas em torno de $232^{\circ} \mathrm{C}$ enquanto algumas polyimides podem ser usadas em torno de $371^{\circ} \mathrm{C}$ por poucos períodos de tempo. BMI e polyimides exibem alta absorção de umidade e baixos valores de dureza comparados a éster vinílica e epóxi.

\subsubsection{MATRIZ ÉSTER VINÍLICA}

São matrizes que fornecem excelente resistência e dureza, permitem uma absorção de umidade muito baixa e possuem boas propriedades elétricas comparadas às outras matrizes, embora tenha um custo elevado. A temperatura de trabalho desta matriz em ambiente úmido é em torno dos $149^{\circ} \mathrm{C}$ e são endurecidas com termoplásticas ou partículas esféricas de borracha. São processadas da mesma forma que as matrizes epóxi, graças a sua viscosidade e os voláteis nominais.

\subsubsection{MATRIZ FENÓLICA}

São baseadas em uma combinação de um álcool aromático e um aldeído, tais como fenol combinado com formaldeído. Elas são utilizadas em aplicações onde a resistência à chama, tais como painéis dos interiores de aeronaves e baixa emissão de fumaça são importantes. Devido sua boa absorção de calor e durabilidade, é muito 
utilizada para aplicações de bocal de foguete. Estas matrizes liberam vapor de água e formaldeído durante os processos de cura, que podem produzir vazios (ou bolhas) no compósito. Diante desta situação, esta matriz quando utilizada em moldes, a estratégia para de saída de gases no molde é crucial para permitir a liberação dos vapores.

\subsubsection{MATRIZ BENZOXAZINAS}

É uma matriz subclasse da fenólica, formada pela reação de um fenol com um aldeído e uma amina aromática, tem aplicações em compósitos avançados para eletrônica. Este material exibe baixa retração, baixa absorção de umidade, alta propriedade de retenção de calor e umidade e alta resistência. Em adição tem excelente desempenho frente à chama, fumaça e produtos tóxicos.

\subsubsection{MATRIZ PHTHALONITRILE (FTALONITRILA)}

São uma classe de matriz menos conhecidas, desenvolvidas pela U.S. Naval Research Laboratory para trabalho em temperaturas elevadas em torno de $371^{\circ} \mathrm{C}$, tais como componentes de motores.

\subsubsection{MATRIZ POLIBUTADENO}

Apresentam boas propriedades elétricas e resistência química, são utilizadas como alternativa frente a epóxi em aplicações de compósitos com reforço de E-glass (fibra de vidro específica para aplicações elétricas) usado em redomas de paredes finas (normalmente essa resina é uma borracha).

Embora as matrizes (ou resinas) termorrígidas sejam predominantes nas aplicações aeroespaciais, um grupo pequeno de matrizes (ou resinas) termoplásticas tem desempenhado um papel particular em aplicações onde a propensão ao impacto ocorre, como as pontas das asas. Trabalhos que envolvem Poliestersulfona (PES) e Poliesterimida (PEI) tem mostrado um caminho para o uso de polímeros cristalinos, tais como Polisulfeto de fenileno (PPS), os quais oferecem grande resistência aos solventes e outros produtos químicos. Devido a sua capacidade de ser refundida, termoplásticas podem ser soldadas, isto é, fundidas no local da aplicação com calor, sem a necessidade de catalisadores. 


\subsubsection{MATRIZ CARBONO/ CARBON}

Nem termorrígida nem termoplástica, pirolizada e densificada por formas descontínuas de carbono, esta matriz suporta temperaturas altíssimas em torno de $1650^{\circ} \mathrm{C}$, utilizadas em componentes de naves espaciais, componentes de bloqueio das aeronaves, propulsores de mísseis e tubagem de exaustão de foguetes.

Tabela 1 - Propriedade das matrizes termorrígidas à temperatura ambiente.

\begin{tabular}{|c|c|c|c|c|c|}
\hline Propriedades & Poliéster & Vinil Ester & Epóxi & BMI & Poliamida \\
\hline Densidade $\left(\mathrm{kg} / \mathrm{m}^{3}\right)$ & $\begin{array}{l}1100- \\
1500\end{array}$ & 1150 & $1100-1400$ & 1320 & $1430-1890$ \\
\hline Mód. Elasticidade (GPa) & $1,2-4,5$ & $3-4$ & $2-6$ & 3.6 & $3,1-4,9$ \\
\hline Mód. Cisalhamento (GPa) & $0,7-2$ & - & $1,1-2,2$ & 1,8 & - \\
\hline Res. à Tração (MPa) & $40-90$ & $65-90$ & $35-130$ & $48-78$ & $70-120$ \\
\hline Res. à Compressão (MPa) & $90-250$ & 127 & $100-200$ & 200 & - \\
\hline Alongamento (\%) & $2-5$ & $1-5$ & $1-8,5$ & $1-6,6$ & $1,5-3$ \\
\hline $\begin{array}{l}\text { Coef. Expansão Térmica } \\
\left(\times 10^{-6} /{ }^{\circ} \mathrm{C}\right)\end{array}$ & $60-200$ & 53 & $45-70$ & 49 & 90 \\
\hline $\begin{array}{ll}\text { Condut. } & \text { Térmica } \\
\left(\mathrm{W} / \mathrm{m} /{ }^{\circ} \mathrm{C}\right) & \end{array}$ & 0,2 & - & $0,1-0,2$ & - & - \\
\hline Calor Específico $\left(\mathrm{J} / \mathrm{kg} /{ }^{\circ} \mathrm{k}\right)$ & - & - & $1250-1800$ & - & - \\
\hline Tem. Trans. Vítrea $\left({ }^{\circ} \mathrm{C}\right)$ & $50-110$ & $100-150$ & $50-250$ & $\begin{array}{c}250- \\
300\end{array}$ & $280-320$ \\
\hline Absorção de Água (\%) & $0,1-0,3$ & - & $0,1-0,4$ & - & 0,3 \\
\hline Retração na cura (\%) & $4-12$ & $1-6$ & $1-5$ & - & - \\
\hline
\end{tabular}

Fonte: HYER (1998). 
Tabela 2 - Propriedades das matrizes Poliamidas Aromáticas à temperatura ambiente.

\begin{tabular}{|c|c|c|c|c|c|c|c|c|c|c|}
\hline \multirow{9}{*}{ 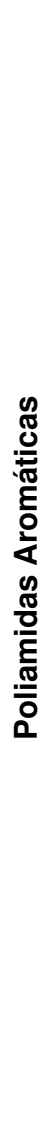 } & $\begin{array}{c}\text { PC: } \\
\text { Policarbonato }\end{array}$ & $\begin{array}{l}1060- \\
1200\end{array}$ & $2,2-2,4$ & $\begin{array}{l}45- \\
70\end{array}$ & 86 & $\begin{array}{l}50- \\
100\end{array}$ & 70 & 0,2 & 133 & 0,1 \\
\hline & $\begin{array}{c}\text { Nylon: Nylon } \\
6,6\end{array}$ & 1140 & $1,4-2,8$ & $\begin{array}{l}60- \\
75\end{array}$ & 34 & $\begin{array}{l}40- \\
80\end{array}$ & 90 & 0,2 & $50-60$ & 1,3 \\
\hline & $\begin{array}{c}\text { PP: } \\
\text { Polipropileno }\end{array}$ & 900 & $1-1,4$ & $\begin{array}{l}25- \\
38\end{array}$ & - & 300 & 110 & 0,2 & -20 a -5 & 0,03 \\
\hline & $\begin{array}{c}\text { OS: } \\
\text { Polisulfano }\end{array}$ & 1240 & 2,5 & $\begin{array}{l}70- \\
75\end{array}$ & - & $\begin{array}{l}50- \\
100\end{array}$ & $56-100$ & - & 190 & 0,2 \\
\hline & $\begin{array}{c}\text { PEEK: } \\
\text { Poliéster }\end{array}$ & 1320 & - & $\begin{array}{l}92- \\
100\end{array}$ & - & 150 & - & - & 143 & 0,1 \\
\hline & $\begin{array}{c}\text { PPS: } \\
\text { Polifeilene } \\
\text { Sulfido }\end{array}$ & 1340 & 3,3 & $\begin{array}{l}70- \\
75\end{array}$ & 110 & 3 & $54-110$ & - & 85 & 0,2 \\
\hline & $\begin{array}{c}\text { Poliamida } \\
\text { imide (Torlon) }\end{array}$ & 1400 & 5 & $\begin{array}{l}95- \\
185\end{array}$ & 276 & $\begin{array}{l}12- \\
18\end{array}$ & 36 & - & $\begin{array}{l}243- \\
274\end{array}$ & 0,3 \\
\hline & $\begin{array}{l}\text { Poliéster } \\
\text { imide }\end{array}$ & 1270 & 3 & 105 & 140 & 60 & 62 & - & 217 & 0,25 \\
\hline & Propriedades & $\begin{array}{c}\text { Densida } \\
\text { de } \\
\left(\mathrm{kg} / \mathrm{m}^{3}\right)\end{array}$ & $\begin{array}{c}\text { Mód. } \\
\text { Elasticida } \\
\text { de }\end{array}$ & $\begin{array}{c}\text { Res. } \\
\text { à } \\
\text { Traç } \\
\text { ão }\end{array}$ & $\begin{array}{c}\text { Res. à } \\
\text { Compress } \\
\text { ão }\end{array}$ & $\begin{array}{l}\text { Alon } \\
\text { g. } \\
(\%)\end{array}$ & $\begin{array}{c}\text { Coef. } \\
\text { Expans } \\
\text { ão } \\
\text { Térmica }\end{array}$ & $\begin{array}{l}\text { Cond. } \\
\text { Térmi } \\
\text { ca }\end{array}$ & $\begin{array}{c}\text { Temp. } \\
\text { Transiç } \\
\text { ão } \\
\text { Vítrea }\end{array}$ & $\begin{array}{l}\text { Absorç } \\
\text { ão de } \\
\text { água }\end{array}$ \\
\hline
\end{tabular}

Fonte: HYER (1998).

\subsection{FIBRAS}

Fase reforço ou também conhecido como reforço, as fibras são a parte do compósito que fornecem a resistência mecânica. De acordo com CALLISTER (1993) uma característica importante na maioria destes materiais, especialmente frágeis, é que uma fibra de diâmetro pequeno é mais forte que o material a granel. A probabilidade da presença de um defeito superficial crítico que pode levar à fratura diminui com a diminuição do volume da amostra e esta característica é usada como vantagem em compósitos reforçados por fibras.

CALLISTER (1993) classifica as fibras, com base no diâmetro e características, em três grupos: whiskers, fibers e wires.

Whiskers são cristais muito finos e únicos que possuem grandes proporções comprimento para diâmetro. Como consequência deste pequeno tamanho eles têm 
alto grau de perfeição cristalina e são virtualmente livres de falhas, os quais contam com excepcional resistência. São conhecidos como materiais resistentes. Embora sejam altamente resistentes, whiskers não são utilizados extensivamente devido ao seu custo. Whiskers incluem materiais como grafite, carbeto de silício, nitreto de silício e óxido de alumínio.

HYER (1998) define whiskers como o alinhamento e ajuntamento das unidades básicas de um material na mesma direção.

Fibras são classificadas em policristalinas e amorfas e possuem diâmetros pequenos. Materiais fibrosos são geralmente polímeros ou cerâmicos (por exemplo: polímero de aramida, vidro, carbono, boro, óxido de alumínio e carbeto de silício).

Fios finos (fine wires) têm relativamente diâmetros grandes, estes materiais incluem aço, molibdênio e tungstênio. São utilizados como reforços radiais em pneus automotivos, filamento enrolados em carcaça de foguetes e enrolados em mangueiras de pressão.

Muitos autores como HYER(1998) e CALLISTER(1993) falam de fibras utilizadas como reforço, porém a revista AEROSPACE COMPOSITES (2008) traz um resumo bem explicado sobre alguns tipos de fibras, aplicações e propriedades. Esta matéria encontrada na página 15 abrange desde fibras bem conhecidas como carbono, vidro, até fibras menos usuais como quartzo e basalto.

De acordo com AEROSPACE COMPOSITES (2008) as fibras de vidro são os reforços mais comuns encontrados em materiais compósitos reforçados por fibras na indústria, porém fibras de carbono apresentam resistência e rigidez superior, são mais usadas no setor aeroespacial. 
Tabela 3 - Característica dos diversos materiais para reforços por fibras.

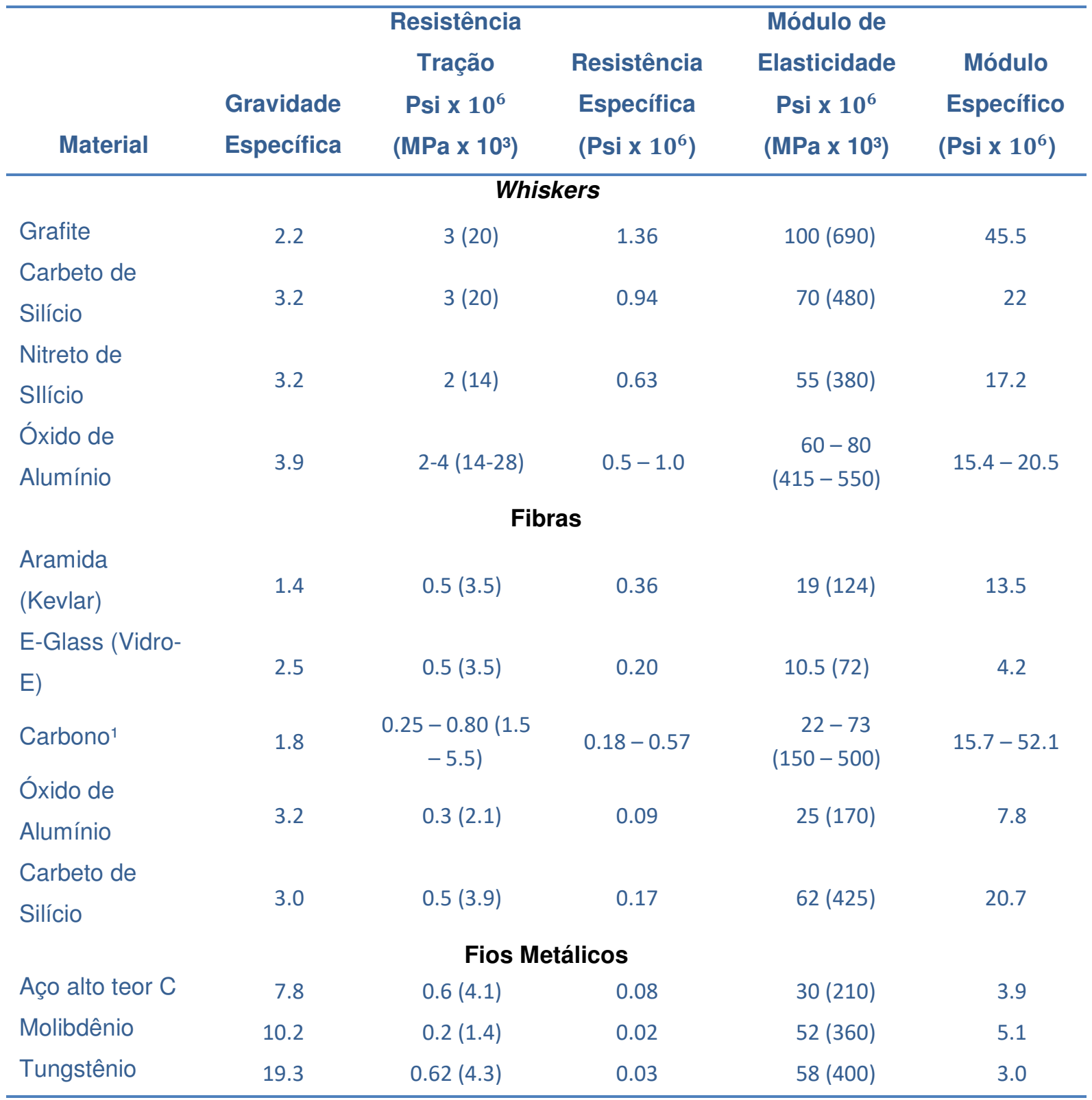

10 termo Carbono foi utilizado ao invés de grafite para denotar estas fibras, elas são compostas de regiões de grafite cristalino e também de materiais não cristalinos e áreas de cristais desalinhados.

Fonte: CALLISTER (1993).

De acordo com HYER (1998) uma vez obtido um material resistente e rígido em formato de fibras, uma mudança no uso deste material se faz necessária. Existe a necessidade das fibras estarem orientadas na direção do carregamento e as forças do carregamento serem transferidas para as fibras e igualmente importante, as fibras precisam ser de um formato que as deixem prontamente dispostas para o uso. A figura 11 ilustra um exemplo de carregamento aplicado nas fibras. 
Figura 11 - Distribuição da carga na fibra: (a) Fibra envolvida pela matriz. (b) Seção da fibra. (c) Característica da distribuição da tensão na fibra.

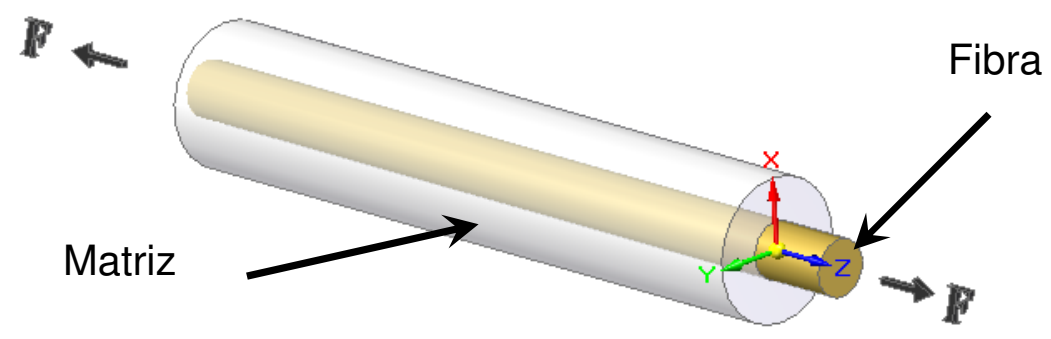

(a)
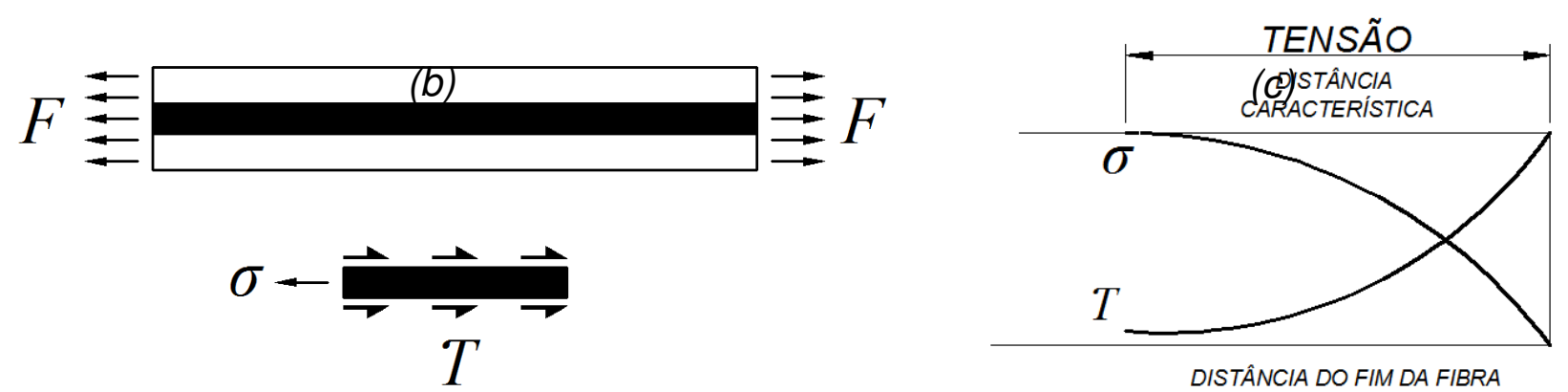

Fonte: HYER (1998).

A figura 11 ilustra o comportamento da fibra e matriz quando sujeitas à tração. A figura 12 ilustra o comportamento da fibra e matriz quando sujeitas à compressão.

Figura 12 - Compressão e restrição lateral fornecida pela matriz.

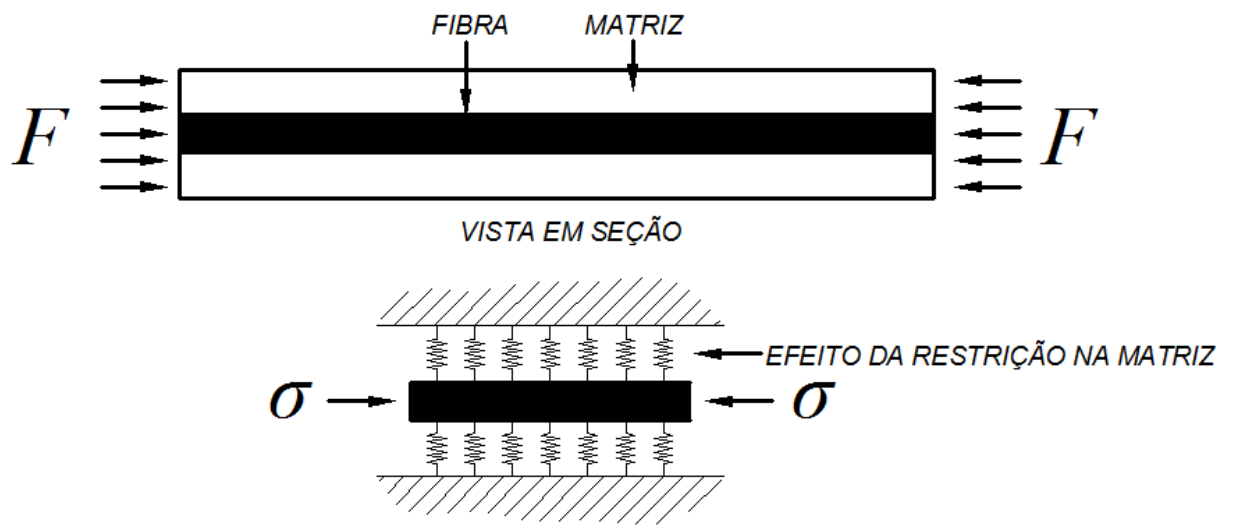

Fonte: HYER (1998). 


\subsubsection{FIBRA DE VIDRO}

Incluindo as fibras de vidro-E, chamado assim devido sua constituição química faz dela um excelente isolante elétrico e bom condutor de rádio transmissor. As primeiras fibras de vidro de alta resistência foram desenvolvidas para fins militares nos anos de 1960 e foram conhecidas como S-Glass nos Estados Unidos, R-Glass na Europa e T-Glass no Japão. As resistentes à corrosão ou E-CR Glass, tem grande resistência à corrosão em ambientes ácidos, são tidas como superiores às E-Glass nestes ambientes. A figura 13 ilustra um tecido de fibra de vidro, muito utilizada em processos de pré-impregnados e conformação de compósitos.

As fibras de vidro tem um desempenho baixo comparado às fibras de carbono, porém sua utilização é muito ampla devido às boas propriedades mecânicas e seu custo.

Sílica, SiO2, forma a base de quase todos os vidros comerciais e existe na forma de um polímero ( $\left.\mathrm{SiO}_{2}\right)$ n. Este polímero não é fundido, mas com o aumento da temperatura à $2.000^{\circ} \mathrm{C}$ ele se torna maleável. Acima desta temperatura ele inicia o processo de decomposição. Neste processo, prolongando o aquecimento à $1.200^{\circ} \mathrm{C}$ a estrutura será induzida a uma cristalização, uma estrutura vítrea de quartzo. Este polímero é útil para muitas aplicações industriais. HYER (1993).

Segundo CALLISTER (1993) as fibras de vidro podem ser utilizadas de forma contínua como num enrolamento (Filament Winding) e de forma descontínua, ou seja, picotada. O reforço com fibras de vidro são os mais comuns e utilizados em materiais compósitos devido aos fatores:

1. É facilmente extraído para as fibras de alta resistência a partir do estado fundido.

2. É uma fibra prontamente disponível no mercado utilizada em uma larga variedade de técnicas de manufatura de compósitos.

3. Como fibra é relativamente forte e quando envolvida numa matriz ela produz um compósito que possui uma resistência muito elevada.

4. Quando acoplada a diversos materiais plásticos, que possuem uma inércia química que rende ao compósito uma utilidade em uma variedade de ambientes corrosivos. 
As aplicações da fibra de vidro são muito variadas: automobilística, aeronáutica, náutica, construção de piscinas, cadeiras, orelhões, na área civil, pias, cubas, banheiras, tem crescido sua aplicação. A figura 14 ilustra a aplicação da fibra de vidro na indústria náutica

Figura 13 - Carretel com fibra de vidro 408/3 Tex 90 T/M.

Fonte: Fibertex ${ }^{1}$.

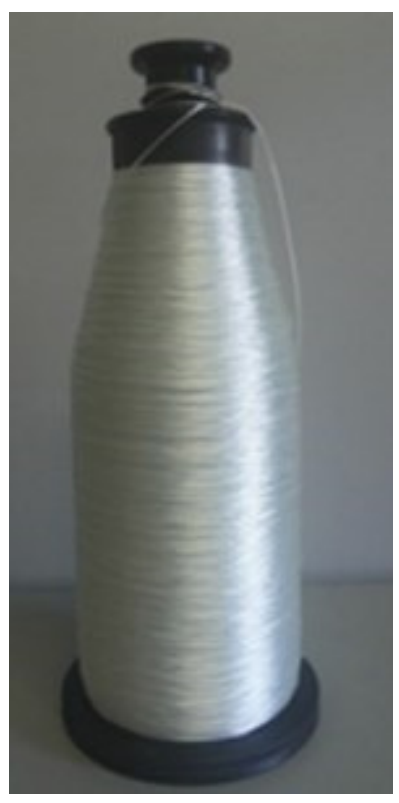

Segundo CALLISTER (1993) as características da superfície do compósito reforçado por fibras de vidro são importantes, pois uma falha na superfície pode afetar as propriedades mecânicas do compósito. As falhas na superfície podem ser geradas por atrito ou abrasão com outro material. A maioria das fibras de vidro tem a limitação da temperatura de serviço a $200^{\circ} \mathrm{C}$. Com o uso de sílica fundida pura nos compósitos reforçados por fibra, tais como resinas poliamidas, a temperatura de trabalho pode ser aumentada para até $300^{\circ} \mathrm{C}$. Os polímeros em geral tem temperatura de trabalho inferior a esta.

HYER (1993) descreve quatro tipos de formas vítreas utilizadas na manufatura de fibras de vidro: A, C, E e S. Tipo A, um vidro tipo refrigerante de limão, foi o primeiro a ser utilizado e ainda permanece sendo utilizado em poucas aplicações. Tipo E, um vidro boro-sílica, foi desenvolvido para uma melhor resistência ao ataque de água e concentrações químicas. Relativo ao tipo E, o Tipo $C$ foi desenvolvido para melhorar

${ }_{1}^{1}$ Disponível em: http://www.nei.com.br/fornecedor/fibra-de-vidro-da-fibertex. Acesso em Jan. 2015. 
a durabilidade quando exposta ao ácido e alcalino. Tipo S possui um aumento de resistência e rigidez, e faz deste uma escolha natural para o uso em aplicações que exijam alto desempenho, onde alta resistência e rigidez são necessárias. Uma vez encontrada a correta composição do vidro, as fibras podem ser fabricadas utilizando um número de técnicas. Cada método é uma variação da forma generalizada de produção, às vezes chamada de atenuação. HYER (1993) define em cinco componentes principais, ilustrados na figura 14:

1. A matéria prima é posta num recipiente, este recipiente alimenta um forno. As fibras são estiradas através de minúsculos bocais, um processo chamado bushing contendo liga de platina acontece enquanto a fibra é estirada. Por convenção o número de bocais costuma ser 200 ou múltiplo deste. Um resfriamento é aplicado após este para estabilizar o processo. Este estiramento pode produzir um material com as unidades básicas alinhadas.

2. Aplicação de um spray de água para refrigerar as fibras.

3. Uma calibração é efetuada.

4. Uma junção das fibras individuais para combiná-las em um reboque.

5. Uma pinça ou mandril de enrolamento recebe as fibras. 
Figura 14 - Processo de produção de fibras de vidro.
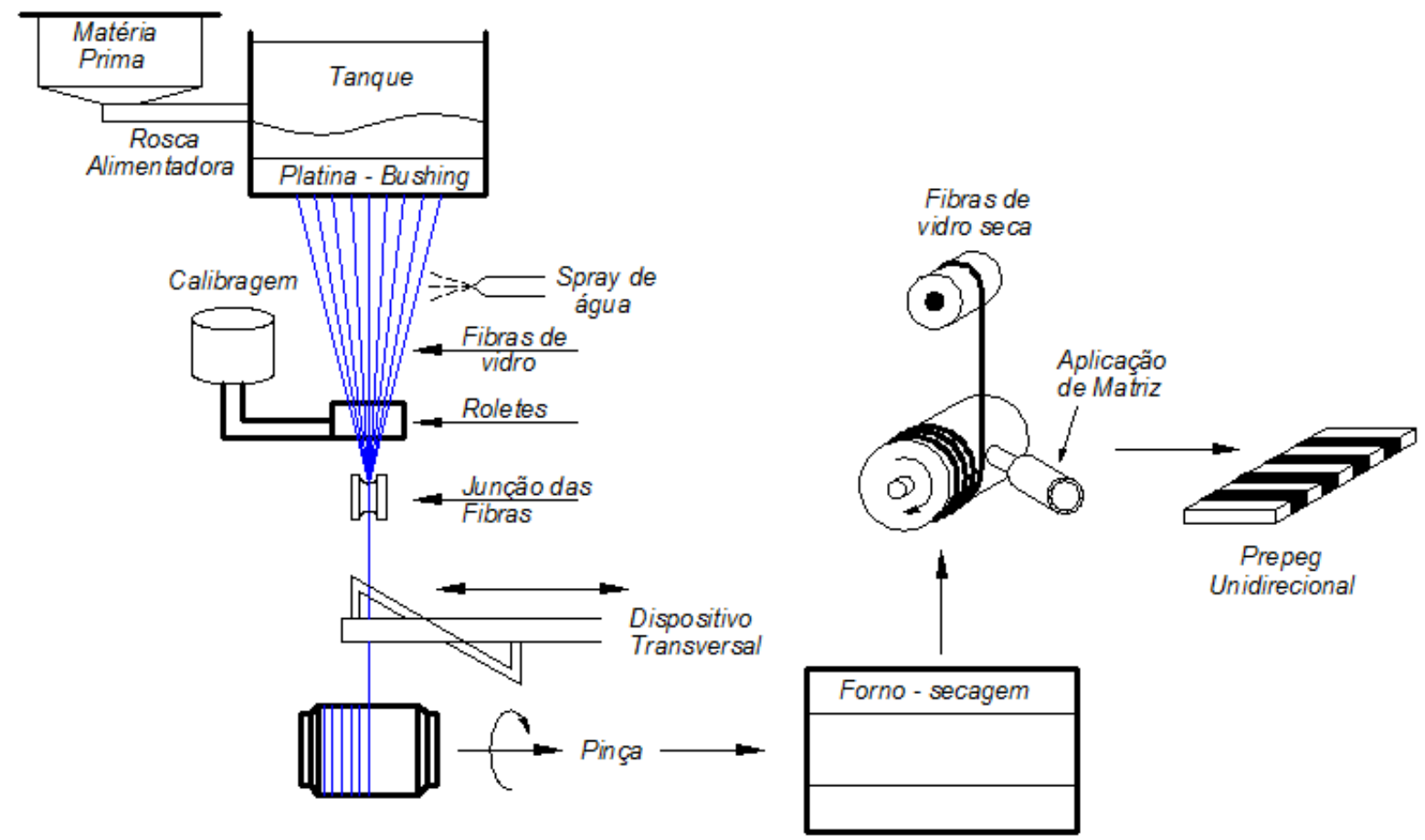

Fonte: Adaptado de HYER (1993).

Tabela 4 - Tipos e propriedades das fibras de vidro.

Propriedades

Tipo E Tipo Tipo S

C

\begin{tabular}{l|lll|} 
Diâmetro $(\mu \mathrm{m})$ & $8-14$ & - & 10 \\
Densidade $\left(\mathrm{Kg} / \mathrm{m}^{3}\right)$ & 2540 & 2490 & 2490 \\
Módulo de Tensão $(\mathrm{GPa})$ & 72.4 & 68.9 & 85.5 \\
Resistência à Tração $(\mathrm{MPa})$ & 3450 & 3160 & 4590 \\
Alongamento $(\%)$ & $1.8-3.2$ & 4.8 & 5.7 \\
Coeficiente térmico de expansão $\left(\mathrm{x} 10-6 /{ }^{\circ} \mathrm{C}\right)$ & 5.0 & 7.2 & 5.6 \\
Condutividade térmica $\left(\mathrm{W} / \mathrm{m}^{\circ} \mathrm{C}\right)$ & 1.3 & - & - \\
Calor específico $\left(\mathrm{J} / \mathrm{Kg} /{ }^{\circ} \mathrm{K}\right)$ & 840 & 780 & 940 \\
\cline { 2 - 4 }
\end{tabular}

Fonte: Adaptado de HYER (1993). 


\subsubsection{FIBRAS DE CARBONO}

AKATO (2012) diz que fibras de carbono são materiais altamente resistentes que tem atraído à atenção do mundo como grande promessa de material de engenharia. O termo fibra de carbono é definido a um material que é tratado com calor à alta temperatura $\left(1.000^{\circ} \mathrm{C}\right.$ a $\left.3.000^{\circ} \mathrm{C}\right)$ e notavelmente propriedades diferenciadas. $\mathrm{A}$ fibra de carbono possui 92 a 99,99\% de carbono.

No século passado, as fibras de carbono eram obtidas pela decomposição de fibras naturais tais como bambu e algodão. Thomas Edison (1880) utilizou filamentos de carbono para as primeiras lâmpadas incandescentes. Estas fibras não eram resistentes, ao contrário eram frágeis. Isto ocorria devido à presença de poros, resultantes do processo de pirólise de Rayon. Elas foram deixadas de ser utilizadas devido a estes problemas. As fibras de carbono eram usadas como isolação e não conseguiam competir com as fibras de vidro. Mais tarde, as fibras de carbono foram produzidas pelo processo de Rayon, pelo qual obtiveram fibras de alto módulo de resistência. Iniciou-se a produção de fibras contínuas com resistência entre $690 \mathrm{e}$ $1.030 \mathrm{MPa}$ e módulo de elasticidade da ordem de $40 \mathrm{MPa}$. Mais adiante o processo de grafitização foi utilizado em fibras obtidas pelo processo Rayon, estas fibras tinham resistência térmica da ordem de $330^{\circ} \mathrm{C}$ a $900^{\circ} \mathrm{C}$. O processo de grafitização por tensão é um processo de transformação de um estado sólido de um carbono não grafitado dentro de uma estrutura grafitada pelo tratamento térmico combinado com a aplicação de tensão mecânica, resultando em um definido grau de grafitização sendo obtido com a diminuição da temperatura após curtos períodos de tratamento térmico e ausência de tensão. AKATO (2012).

O processo de Poliacrilanitrila (PAN) foi desenvolvido após o surgimento deste novo processo Rayon, e em 1966 Courtelle desenvolveu uma especialmente preparada fibra PAN, oxidada a $200^{\circ} \mathrm{C}$ sobtensão. Subsequente carbonização a $1000^{\circ} \mathrm{C}$ resultaram em fibras de carbono com módulo de tensão da ordem de $155 \mathrm{a}$ $190 \mathrm{GPa}$, estes valores foram aumentados para 350 a $420 \mathrm{GPa}$ depois de um tratamento à $2.500^{\circ} \mathrm{C}$. Neste ano de 1966 várias patentes do processo PAN foram concedidas. A busca pelo baixo custo do processo de fabricação das fibras de carbono levou a utilização do piche como precursor de fibras de carbono. Em 1965 fibras com 
precursores de policloreto de vinila (PVC) foram utilizados como matéria prima na produção de fibras de carbono. Entre os anos de 1970 e 1971, melhoramentos nos processos de fabricação das fibras de carbono a base de piche tencionando as fibras durante o estágio inicial da carbonização com temperaturas de $2.500^{\circ} \mathrm{C}$, um grau elevado de orientação preferencial no plano base pode ser induzido obtendo-se fibras de resistência à tração da ordem de $2.585 \mathrm{MPa}$ e módulo de elasticidade da ordem de 480 GPa. Em 1973, mesofase em estado líquido foi desenvolvida a partir do piche e transformada em precursores de fibras. Estas fibras foram transformadas em fibras de carbono pela oxidação e carbonização subsequente a $1000-3000^{\circ} \mathrm{C}$ que conduzindo as fibras com elevado grau de orientação preferencial devido ao estado líquido cristalino ser formado antes da fiação. AKATO (2012).

Atualmente a maioria das fibras é obtida por precursores PAN, devido à sua alta resistência à tração, módulo de elasticidade e falha em tensão com alto rendimento comparado às fibras com precursores de piche e Rayon. As fibras de precursores baseados em piche possuem boas propriedades térmicas e elétricas. Companhias asiáticas, europeias e norte-americanas têm produzido e comercializado com sucesso fibras de carbono com precursores PAN e piche ao passo que fibras baseadas em precursores Rayon não tem tido tão boa aceitação no mercado. A indústria de fibras de carbono tem experimentado um ressurgimento significativo devido à crescente demanda para a tecnologia em uma ampla gama de aplicações, após anos de prosperidade seguidos de queda rápida dos juros. AKATO (2012).

Outros precursores tais como para resinas fenólicas, poliamida e álcool-polivinil também foram usados, mas em baixa escala.

\subsubsection{PRECURSORES PAN}

Há um número de precursores PAN, todos produzem fibras baseadas em acrílico que contém pelo menos $85 \%$ de acrilonitrila, este pode incluir polímeros secundários ou um banho químico residual durante o processo. Estes polímeros secundários são segredos industriais, cuja adição resulta à fibra, uma pequena melhora das suas propriedades mecânicas. HYER (1993).

No processo de precursores PAN, se for aquecido às altas temperaturas promoverá a carbonização, mas não vai render a fibra resistência e rigidez, a menos 
que uma pré-oxidação ou estabilização seja realizada. Durante este processo uma estrutura termicamente estável é obtida e mais adiante, mediante aquecimento, a arquitetura original da fibra é retida. A estabilização geralmente é um tratamento térmico entre $200^{\circ} \mathrm{C}$ a $300^{\circ} \mathrm{C}$ em uma atmosfera oxigenada, como resultado um esqueleto de polímero do precursor é submetido a uma série de reações químicas até resultar numa formação de polynaphthyridine, uma substancia com a estrutura da formação de grafite. Cadeias do tipo cross-link ocorrem neste processo devido a ação de agentes oxidantes ou catalisadores. Mais adiante com a ação de calor, esta estrutura do precursor dá um aumento nos núcleos de grafite cujos planos base dos átomos de carbono é orientada paralelamente à cadeia do polímero. Uma retração significante, da ordem de até $40 \%$ ocorre na estabilização, isto pode ser reduzido durante o processo pelo tensionamento durante o tratamento térmico ou por infiltração de finos agregados de sílica nas fibras. As partículas da sílica se alojam entre os interstícios e em volta da fibra essencialmente bloqueando os vazios da fibra. Com estes métodos é possível reduzir a retração em $20 \%$. A carbonização da fibra é um processo que envolve aquecimento da ordem de $1.000^{\circ} \mathrm{C}$ em uma atmosfera inerte ou moderadamente oxidada. HYER (1993).

Um dos tipos de processo para fabricação de fibras PAN de alta resistência e alto módulo de elasticidade ocorre primeiramente aquecendo as fibras PAN em uma atmosfera oxidante até elas se tornarem permeadas com oxigênio. Mais adiante as fibras são aquecidas para iniciar a carbonização, enquanto estão sujeitas à tensão em uma atmosfera não oxidante. Finalmente para aumentar a resistência à tração, as fibras são tratadas termicamente em uma atmosfera inerte entre $1.300^{\circ} \mathrm{C}$ e $1.800^{\circ} \mathrm{C}$. Pesquisas mostraram que se a carbonização é feita em uma atmosfera oxidante, então os níveis de oxigênio devem estar entre 50 a 170 ppm.

HYER (1993) realizou um estudo utilizando o gás argônio para levar o oxigênio (entre 2.8 e 1500 ppm. As fibras foram testadas par determinar a resistência à tração e módulo de elasticidade. O resultado obtido é apresentado na tabela 5.

No processo PAN a grafitização, ilustrado na figura 15, da fibra ocorre pelo aquecimento da fibra carbonizada a uma temperatura superior a $3.000^{\circ} \mathrm{C}$ numa atmosfera inerte. Esta etapa pode durar entre 1 a 20 minutos. Quando aplicada uma tensão nesta etapa, há uma melhora nas propriedades mecânicas e redução da 
retração da fibra. O precursor inicia o processo com uma tensão aplicada enquanto a temperatura é elevada. A tensão é reduzida ou aliviada antes da fase de pré-oxidação e vai aumentando durante a fase de pré-oxidação. A fibra é continuamente aquecida e grafitada sob alta tensão. A fibra grafitada é bobinada (enrolada) num carretel e seca. A velocidade deste processo é tipicamente entre 6 a $12 \mathrm{~m} /$ hora, mas pode alcançar 45m/ hora. HYER (1993).

Após a grafitização da fibra, a mesma recebe revestimento de materiais especiais em sua superfície, esta operação recebe o nome de Calibragem. Calibragem ou revestimento superficial da fibra é usado para melhorar a lubrificação e proteger as fibras durante o processo subsequente e manuseio. Outros materiais químicos também são aplicados na operação de Calibragem para auxiliar a interação entre fibra e matriz.

Tabela 5 - Atmosfera oxidante para carbonização das fibras PAN.

\begin{tabular}{ccc}
\hline $\begin{array}{c}\text { Atmosfera Oxidante } \\
\text { (PPM) }\end{array}$ & $\begin{array}{r}\text { Resistência à } \\
\text { Tração } \\
(\text { GPa })\end{array}$ & $\begin{array}{c}\text { Módulo de Elasticidade } \\
(\text { GPa })\end{array}$ \\
\hline 2.8 & 1.45 & 152 \\
18 & 2.00 & 152 \\
35 & 2.07 & 162 \\
50 & 2.14 & 172 \\
110 & 2.19 & 214 \\
170 & 2.17 & 186 \\
330 & 1.46 & 152 \\
430 & 1.24 & 165 \\
650 & 0.82 & 155 \\
800 & 0.75 & 155 \\
1500 & 0.79 & 155
\end{tabular}

Fonte: Adaptado de P. G. ROSE; Patente 3,600,018: 02 de Maio de 1972; Rolls Royce Ltda, Inglaterra. 
Figura 15 - Produção de fibras grafitadas contínuas com precursores PAN, ilustrando temperatura e tensão aplicadas no perfil.

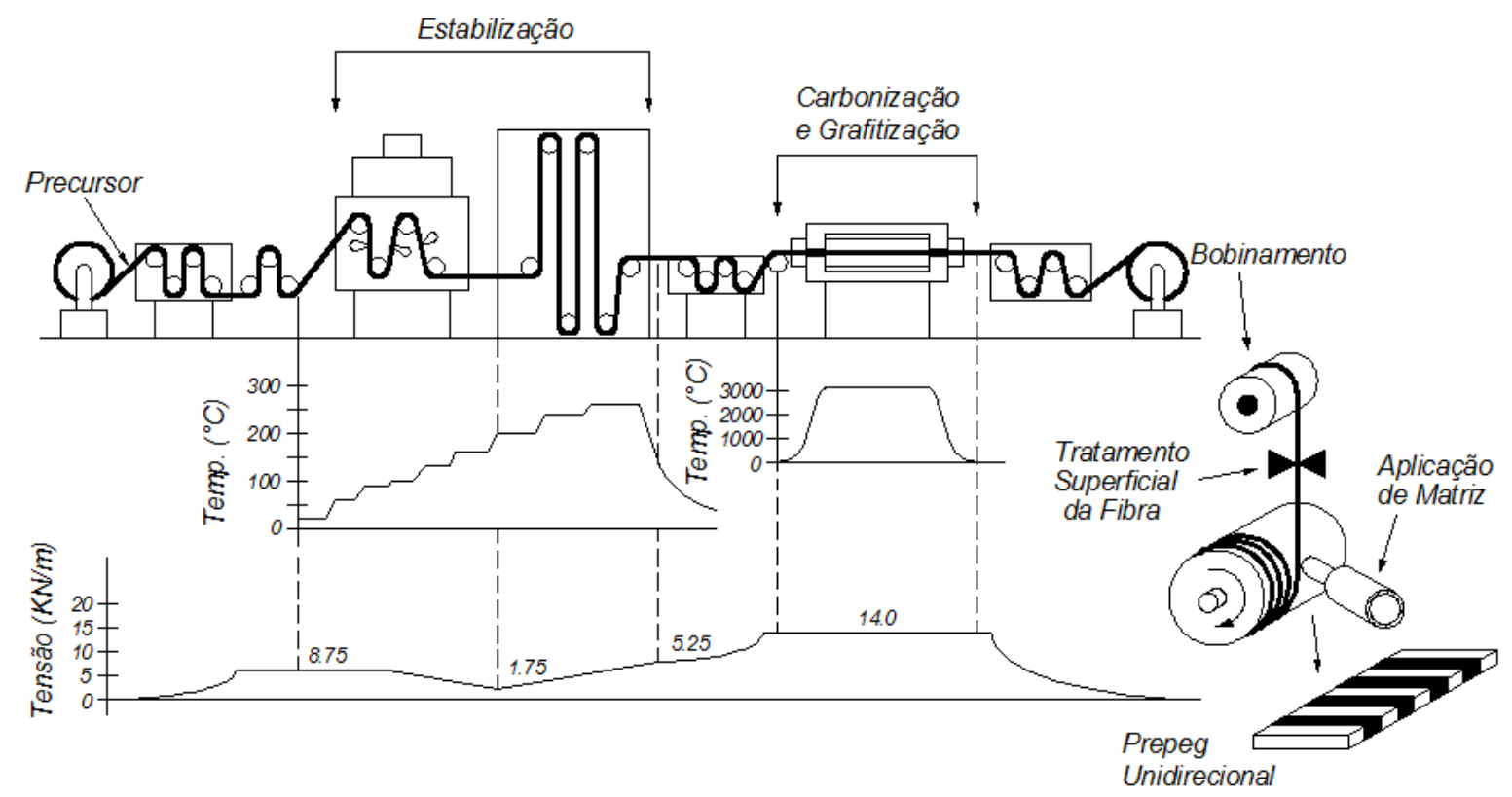

Fonte: Adaptado de HYER (1993).

\subsubsection{FIBRAS DERIVADAS DE PICHE}

Segundo HYER (1993) dois fatores se devem ao uso de fibras derivadas de precursores piche: primeiro elas tem alto rendimento e segundo alta taxa de produção. Embora estas fibras sejam mais frágeis e densas, o processo de produção de tipos específicos a partir de derivados de petróleo é criticamente importante para o sucesso da produção de fibras de altos módulos e alta resistência. O processo básico da produção desta fibra é uma destilação de óleos residuais deixados pela térmica e craqueamento $^{2}$ catalítico do óleo cru. Resíduos da produção de asfalto, asfalto natural, óleo de xisto e alcatrão de carvão também podem ser utilizados. Estes produtos derivados de óleo pesado são introduzidos em um reator ou uma série de reatores onde são aquecidos à temperaturas entre $350^{\circ} \mathrm{C}$ e $500^{\circ} \mathrm{C}$. Nestes reatores ocorrem craqueamento térmico, polimerização e condensação, estas reações liberam gases e óleos leves que são conduzidos a outro reator e são condensados. O material resultante deste processo é uma substância pesada enriquecida com carbono que será a base para o precursor da fibra baseada em piche. A matéria prima preferencial

\footnotetext{
2 Craqueamento: processo químico da indústria petrolífera usados para quebrar moléculas orgânicas complexas como querogênios ou hidrocarbonetos são quebradas em moléculas mais simples por quebras de ligações carbono-carbono nos precursores pela ação de calor e/ou catalisador.
} 
para a produção destas fibras é o líquido cristal, ou mesofase e o piche. A mesofase é uma substância altamente anisotrópica em forma de cristais, chamadas de esferulitas, misturada com um piche isotrópico médio. Sob a ação de calor, as esferulitas crescem e expandem à custa de um campo isotrópicos em volta delas. Quando a temperatura atinge $350^{\circ} \mathrm{C}$ as esferulitas amolecem e podem ser mecanicamente deformadas neste estado. Quando a mesofase atinge $75 \%$ de carbono, esta substância pode ser submetida à formação de fibras através de técnicas como Melt Spinning (fiação a partir do fundido). O tratamento dos derivados de petróleo nos reatores pode durar várias horas para assegurar que as condições necessárias à fabricação das fibras sejam satisfeitas. Aditivos também podem ser usados para aumentar o peso molecular ou promover uma melhor fiação da fibra. Há vários tipos de fiação das fibras, extrusão, centrífuga, extrusão por pressão, pulverização ou por jato. Quando a viscosidade de fusão é alta e o objetivo é a produção de fibras contínuas, o processo de extrusão é usado.

Depois de fiadas, as fibras são submetidas a um gás oxidante a uma temperatura inferior a temperatura de fiação ou elas são submetidas a um tratamento químico que as torna infusível. Um dos métodos, por exemplo, consiste em tratar as fibras por sete horas sob uma temperatura de $100^{\circ} \mathrm{C}$ numa atmosfera contendo ozônio, em seguida a temperatura é aumentada em $1^{\circ} \mathrm{C}$ por minuto até atingir $300^{\circ} \mathrm{C}$. Este último estágio é crítico e importante, pois garante à fibra reter o formato, durante a grafitização e carbonização. Todavia se durante o processo a oxidação for muito longa, a fibra se tornará frágil.

\subsubsection{MICROESTRUTURA DO GRAFITE NAS FIBRAS}

Segundo HYER (1993), entender a microestrutura básica do grafite nas fibras após o processamento é importante para entender as propriedades mecânicas finais da fibra. Grafite é uma forma primitiva de estrutura cristalina com planos de átomos de carbono arranjados numa célula unitária hexagonal ilustrado na figura 16. Estas células possuem ligação covalente de átomos de carbono adjacentes, chamados de planos basais. Estes planos são empilhados uns sobre os outros para formar uma microestrutura em camadas. Nesta estrutura há uma considerável falta de isotropia. 
Figura 16 - Estrutura cristalina do grafite.

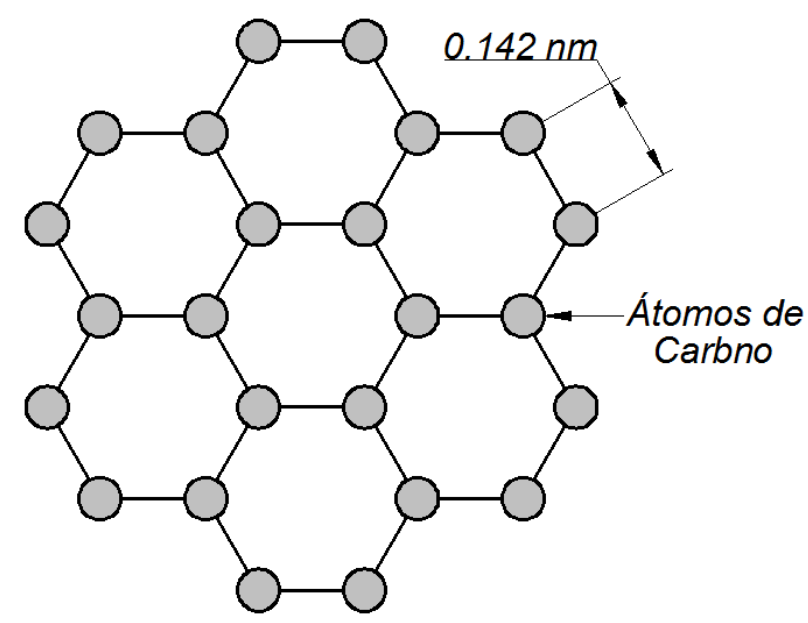

Fonte: HYER (1993).

Pelo processo de tensionamento das fibras durante a grafitização e com o tratamento térmico em altas temperaturas, o grau de orientação ao longo da fibra é aumentado. Isto leva a um aumento de rigidez na direção axial. Em temperaturas abaixo de $800^{\circ} \mathrm{C}$ a unidade de estrutura básica, que consiste de pequenos comprimentos de duas ou três camadas paralelas de carbono, começa a empilhar e formar uma estrutura de colunas desordenadas com liberação de impurezas e voláteis. Entre $800^{\circ} \mathrm{C}$ e $1.500^{\circ} \mathrm{C}$ a estrutura em forma de colunas aumenta o comprimento com um alto grau de orientação da unidade básica da estrutura. Entre $1.500^{\circ} \mathrm{C}$ e $1.900^{\circ} \mathrm{C}$ a estrutura em forma de coluna desaparece formando fitas onduladas ou camadas enrugadas pela junção das colunas. Próximo de $2.100^{\circ} \mathrm{C}$ a maioria da ondulação desaparece e o defeito nos planos é bem reduzido. Acima de $2.100^{\circ} \mathrm{C}$ rigidez, camadas planas de carbono e um crescimento tridimensional de cristal se iniciam. A figura 17 ilustra este processo de fabricação. Deste modo, grafitização corresponde à remoção de defeitos estruturais, primeiro entre as camadas, que são achatadas, seguidas da remoção da desorientação transversal, que é aumento da orientação axial paralela para as fibras. A figura 18 ilustra a microestrutura da fibra de carbono de alto módulo (HYER 1993). 
Figura 17 - Fases no processo de fabricação das fibras.

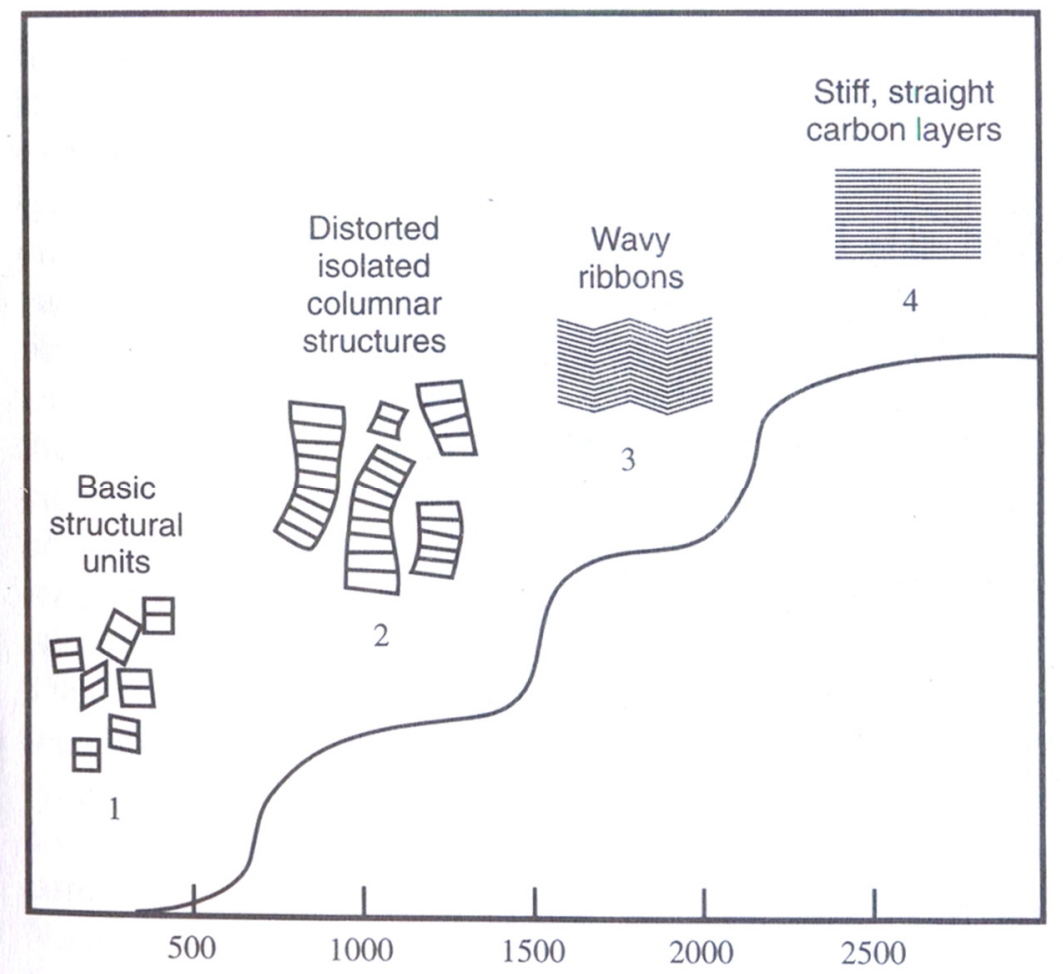

HYER (1993).

Fonte: 
Figura 18 - Microestrutura de uma fibra de carbono de alto módulo.

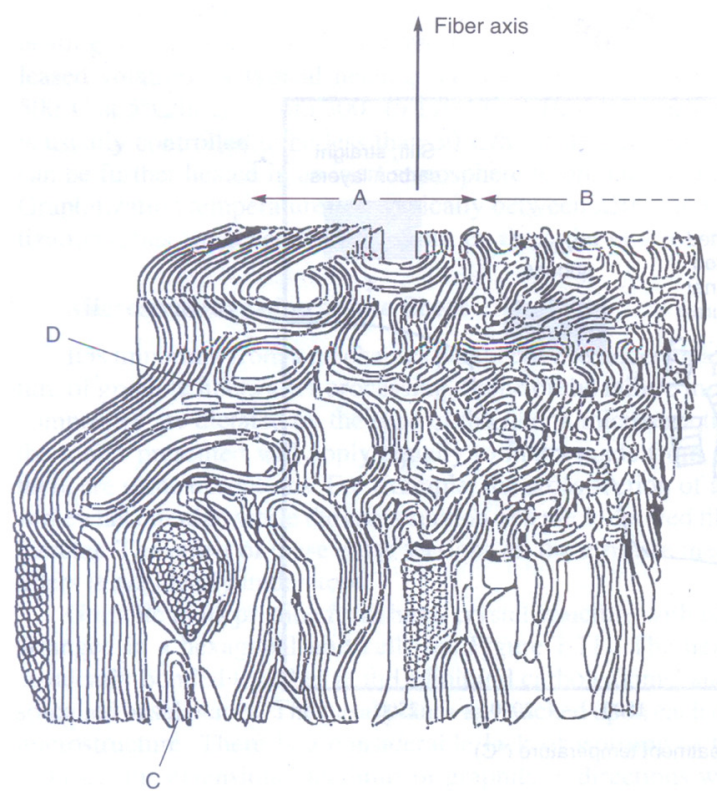

Fonte:

HYER (1993).

Quatro modelos básicos de estruturas são bem utilizadas, sendo a mais comum a skin-core todas ilustradas na figura 19. As fibras exibem uma pele que é um pouco mais grafitada que o núcleo. A espessura da pele é comumente em torno de $1 \times 10^{-6} \mathrm{e}$ formado por planos basais embrulhados em volta da circunferência. Os planos basais do núcleo são alinhados radialmente ou em alguns casos randomicamente. A larga formação de cristalitos desorientados na região da pele acredita-se, ser a falha da fibra sobtensão aplicada. Fibras com estrutura do tipo Skin-core (a) é típica de fibras PAN derivadas de grafite. Estrutura tipo Onion skin (b) é observado em fibras baseadas em carbono derivadas de benzeno produzido em baixas temperaturas no tratamento térmico. Radial (c) é um arranjo onde os planos basais são orientados randomicamente numa seção transversal. Transversely isotropic (d) como o nome diz, é um tipo de arranjo isotrópico transversalmente. HYER (1993).

Figura 19 - Tipos de microestrutura da fibra derivada do grafite. 


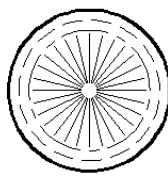

(a) Skin-core

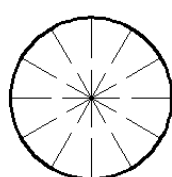

(c) Radial

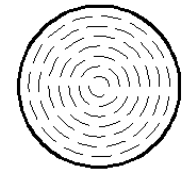

(b) Onion skin

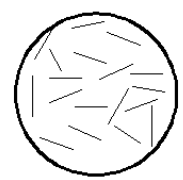

(d) Transversely isotropic

Fonte: HYER (1993). 
Tabela 6 - Propriedades das fibras baseadas em carbono.

\begin{tabular}{|c|c|c|c|c|c|}
\hline \multirow{2}{*}{ Propriedades } & \multicolumn{3}{|c|}{ PAN } & \multirow{2}{*}{$\begin{array}{c}\text { Pitch } \\
\text { Type-P4 }\end{array}$} & \multirow{2}{*}{ Rayon } \\
\hline & $\mathbf{I M}^{1}$ & $I M^{2}$ & $\mathrm{UHM}^{3}$ & & \\
\hline $\begin{array}{l}\text { Diâmetro } \\
(\mu \mathrm{m})\end{array}$ & $8-9$ & $7-10$ & $7-10$ & $10-11$ & 6.5 \\
\hline $\begin{array}{c}\text { Densidade } \\
\left(\mathrm{kg} / \mathrm{m}^{3}\right)\end{array}$ & $\begin{array}{c}1780- \\
1820\end{array}$ & $\begin{array}{c}1670- \\
1900\end{array}$ & 1860 & 2020 & $\begin{array}{c}1530- \\
1660\end{array}$ \\
\hline $\begin{array}{c}\text { Módulo de } \\
\text { Tensão (GPa) }\end{array}$ & $228-276$ & $331-400$ & 517 & 345 & $41-393$ \\
\hline $\begin{array}{l}\text { Resistência à } \\
\text { tração (MPa) }\end{array}$ & $\begin{array}{l}2410- \\
2930\end{array}$ & $\begin{array}{l}2070- \\
2900\end{array}$ & 1720 & 1720 & $620-2200$ \\
\hline $\begin{array}{c}\text { Alongamento } \\
(\%)\end{array}$ & 1.0 & 0.5 & $0.3-0.4$ & $0.4-0.9$ & $1.5-2.5$ \\
\hline $\begin{array}{c}\text { Coeficiente de } \\
\text { expansão } \\
\text { térmica } \\
\left(\times 10-6 /{ }^{\circ} \mathrm{C}\right)\end{array}$ & -0.1 a -0.5 & $-0.5 a-1.2$ & -1.0 & $-0.9 a-1.6$ & - \\
\hline $\begin{array}{c}\text { Direção da } \\
\text { fibra } \\
\text { perpendicular } \\
\text { à direção da } \\
\text { fibra }\end{array}$ & $7-12$ & $7-12$ & - & 7.8 & - \\
\hline $\begin{array}{l}\text { Condutividade } \\
\text { térmica }(\mathrm{W} / \\
\left.\mathrm{m} /{ }^{\circ} \mathrm{C}\right)\end{array}$ & 20 & $70-105$ & 140 & - & 38 \\
\hline $\begin{array}{c}\text { Calor } \\
\text { específico (J/ } \\
\left.\mathrm{Kg} /{ }^{\circ} \mathrm{K}\right)\end{array}$ & 950 & 925 & - & - & - \\
\hline
\end{tabular}

Fonte: HYER (1993). 


\subsubsection{FIBRAS POLIMÉRICAS}

Uma relativamente nova classe de fibras tem surgido e aumentado seu uso em materiais compósitos reforçados por fibras. Fibras poliméricas, usando um método adequado de fabricação, têm mostrado alta resistência e rigidez. Como resultado deste processo de fabricação, o resultado é um alinhamento de da cadeia polimérica ao longo do eixo da fibra ilustrado na figura 20. Uma destas é a fibra de aramida, conhecida como Kevlar®, que foi desenvolvida pela Dupont Company em 1968, é uma poliamida aromática chamada Poly (paraphenylene terephthalamide) ou Poliaramida. Os anéis aromáticos tornam esta fibra bem rígida. HYER (1993).

Fibra aramida apresenta excepcional resistência ao impacto e resistência à tração. As propriedades desta fibra fazem dela uma excelente escolha para as pás do rotor de helicópteros, motores sólidos de foguetes, tanques de gás pressurizados e outras peças que devem suportar alta tensão, vibração e impacto potencial. AEROSPACE COMPOSITES (2008).

A fabricação de fibras sintéticas poliméricas difere da fabricação de fibras inorgânicas devido a unidirecional cadeia natural da polimérica. Este processo de fabricação de fibras resistentes e rígidas se divide em duas categorias básicas: (1) fusão ou fiação por jato a seco de um líquido na fase cristalino e (2) fusão ou fiação por gel e extensão convencional dos polímeros aleatórios helicoidais. Kevlar® é produzido por extrusão e fiação. Uma solução de polímero e solvente é mantida em baixa temperatura, entre $50^{\circ} \mathrm{C}$ e $80^{\circ} \mathrm{C}$, antes de ser extrudada em um cilindro aquecido a $200^{\circ} \mathrm{C}$, o solvente evapora e a fibra é enrolada em um tambor. As fibras, neste estágio, têm baixa resistência e rigidez, em seguida elas são submetidas a uma tensão com aquecimento para alinhar as cadeias poliméricas ao longo do eixo da fibra. Após, o alinhamento das fibras mostram significante aumento da resistência e rigidez. HYER (1993). 
Figura 20 - Cadeia polimérica do Kevlar®.

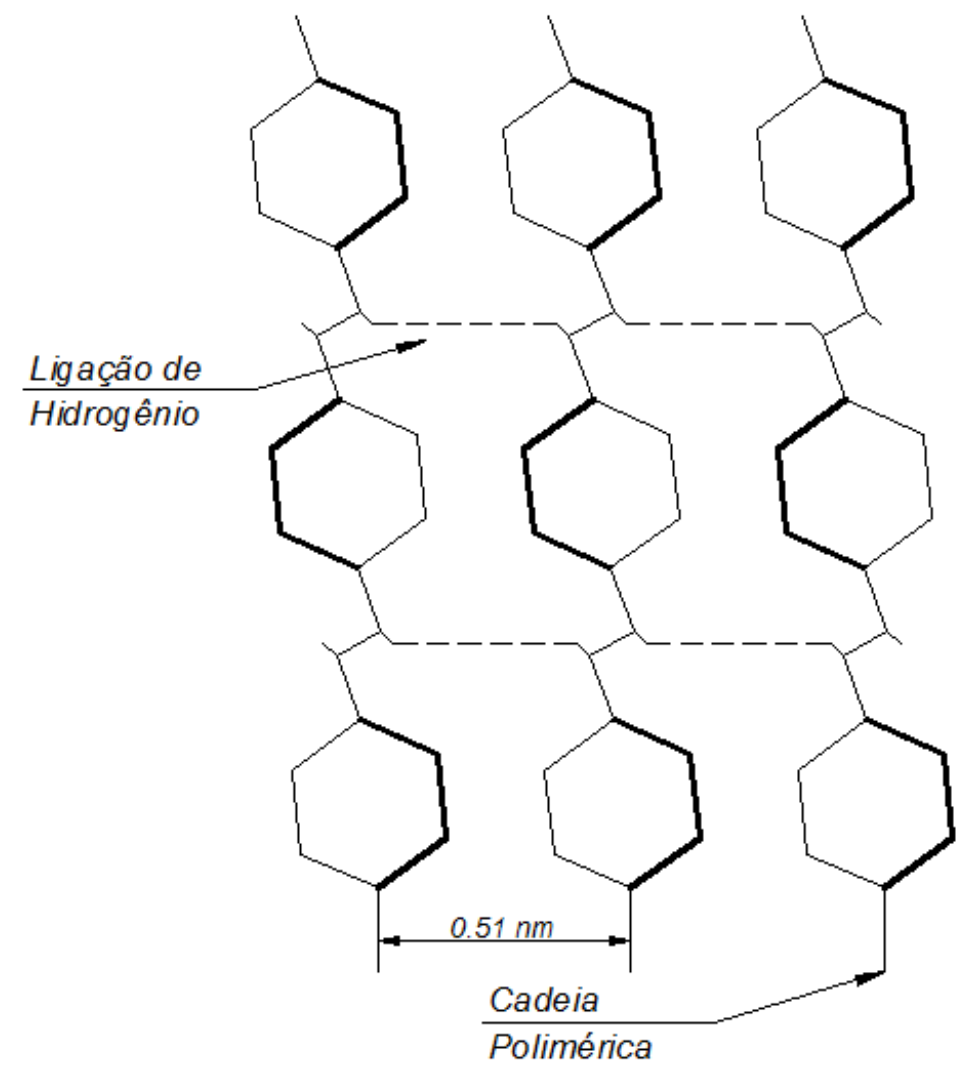

Fonte: HYER (1993).

\subsubsection{MICROESTRUTURA DAS FIBRAS POLIMÉRICAS}

As moléculas poliméricas formam uma rígida folha plana, as folhas são empilhadas uma sobre as outras com uma fraca ligação de hidrogênio entre elas. Estas folhas são dobradas na direção axial e orientadas radialmente, com as dobras geralmente ocorrendo nas ligações de hidrogênio. Fibras poliméricas geralmente são caracterizadas pela baixa densidade, boa resistência química e alta resistência à tração. A figura 21 ilustra esta estrutura. 
Figura 21 - Estrutura da fibra polimérica.

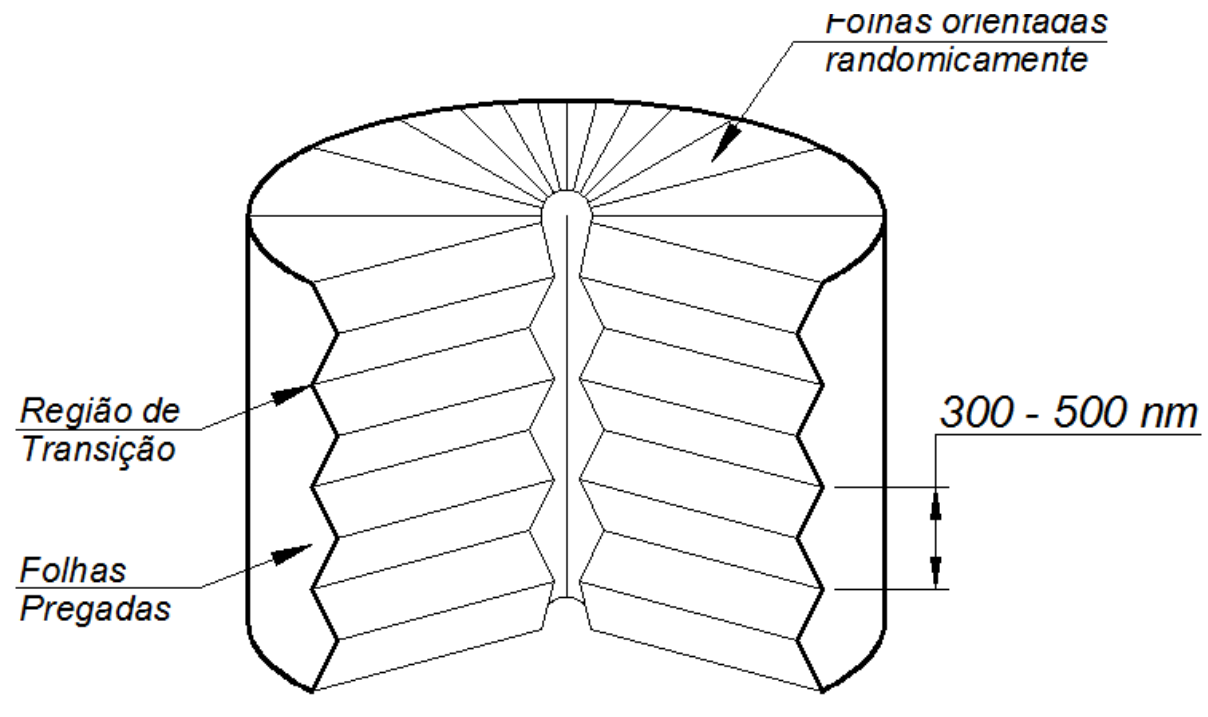

HYER

Tabela 7 - Propriedade das fibras poliméricas.

Propriedades

Diâmetro $(\mu \mathrm{m})$

Densidade $\left(\mathrm{Kg} / \mathrm{m}^{3}\right)$

Módulo de Tensão (GPa)

Resistência à Tração (MPa)

Alongamento (\%)

Coeficiente térmico de expansão $\left(x 10-6 /{ }^{\circ} \mathrm{C}\right)$

Direção da fibra

Perpendicular à direção da fibra

Condutividade térmica $\left(\mathrm{W} / \mathrm{m}^{\circ} \mathrm{C}\right)$

Calor específico $\left(\mathrm{J} / \mathrm{Kg} /{ }^{\circ} \mathrm{K}\right)$

Fonte: HYER (1993).

Kevlar $29 \quad$ Kevlar $49 \quad$ Spectra 900

\begin{tabular}{|ccc|}
\hline 12 & 12 & 38 \\
1440 & 1479 & 970 \\
62 & 131 & 117 \\
2760 & $2800-$ & 2580 \\
& 3792 & \\
$3-4$ & $2.2-2.8$ & $4-5$ \\
-2 & -2 & - \\
59 & 59 & - \\
- & $0.04-0.5$ & - \\
- & 1420 & - \\
\hline
\end{tabular}


A revista AEROSPACE COMPOSITES (2008) abrange outras fibras que também são produzidas, mas não são tão popularmente conhecidas como as fibras de carbono, vidro e Kevlar®. Algumas destas são:

Fibras de alto módulo de polietilene possui baixa resistência elástica sobtensão com temperatura limitada a $98^{\circ} \mathrm{C}$. Elas são valorizadas pela leveza, alta resistência, excelente resistência química e à umidade, baixa constante dielétrica e excelente resistência ao impacto. É uma fibra apropriada para aplicações antibalísticas.

Fibras de quartzo um pouco mais cara que as fibras de vidro, baixa densidade, alta resistência e alta rigidez comparada às fibras de vidro tipo $E$, e duas vezes a resistência ao alongamento, faz dela uma boa escolha quando a aplicação necessita de durabilidade. O coeficiente de expansão térmica é praticamente zero. É capaz de manter suas propriedades quando sujeitas às altas temperaturas, sob $1.050^{\circ} \mathrm{C}$ a $1.250^{\circ} \mathrm{C}$, por pequenos períodos de tempo. Apresentam melhores propriedades eletromagnéticas que as fibras de vidro e tem aplicação em Radomes (nariz de avião) aeronáuticos.

Fibras de cerâmica apresentam alta e altíssima resistência às temperaturas, mas baixa resistência e relativamente pobre em temperatura ambiente. Embora sejam tipicamente as mais caras das fibras, seu custo é compensado pela resistência à chama em interiores de aeronaves, as quais suportam temperaturas a $1.093^{\circ} \mathrm{C}$ por quinze minutos sem penetração de chama.

Fibras de boro produzidas por um processo de vapor deposição no qual o boro é depositado num filamento fino de tungstênio ou carbono são cinco vezes mais fortes e duas vezes mais rígidas que o aço. Devido ao seu relativamente grande diâmetro, a fibra de boro possui excelentes propriedades compressivas e resistência a flambarem. Tem aplicações em peças que necessitam de resistência ao empenamento, componentes das barras do ônibus espacial e reparos em remendos de aeronaves.

Fibras Poly p-phenylene-2, 6-benzobisoxale (PBO) exibe módulo de tensão e resistência à tração quase que o dobro das fibras de aramida (Kevlar®). Estas fibras tem aplicação em fabricação de coletes antibalísticos. 
Fibras de basalto um produto barato de coloração marron-dourado com propriedades próximas às de vidro, foi inicialmente produzida na Rússia, exibe melhor resistência química e alcalina que as fibras de vidro e tem sua aplicação no campo aeroespacial, substituindo as fibras de vidro tipo $\mathrm{E}$.

As fibras também podem ser combinadas em num reforço híbrido, obtendo as melhores propriedades da cada componente e reduzindo o custo. Arranjo híbrido de fibras de carbono/ aramida e carbono/ vidro que tem sido utilizada na fabricação de nervuras de inversores de propulsão de aeronaves e espelhos de telescópio.

Tabela 8 - Comparativo de materiais compósitos e materiais tradicionais.

$\begin{array}{cccccc} & & \text { Módulo } & & \text { Coeficiente } & \\ \text { Material } & \text { Específica } & \text { de } & \text { Resistência } & \text { Térmico de } & \text { Alongam. } \\ & \left(\mathrm{g} / \mathrm{cm}^{3}\right) & \text { Rigidez } & \text { à Tração } & \text { Expansão } & (\%) \\ & & (\mathrm{GPa}) & (\mathrm{MPa}) & \left(10-6^{\circ} \mathrm{C}\right) & \end{array}$

\begin{tabular}{l|ccccc}
\hline Fibra PAN T300 & 1,76 & 230 & 3600 & $-0,50$ & 1,50 \\
Fibra PAN IM-7 & 1,76 & 276 & 5080 & - & 1,80 \\
Fibra PAN M55J & 1,91 & 538 & 4033 & - & 0,80 \\
Fibra K1100 (piche) & 2,20 & 931 & 3172 & $-1,45$ & 0,25 \\
Fibra Kevlar ${ }^{\circledR} 49$ & 1,44 & 131 & 3600 & $-4,90$ & 2,80 \\
Fibra Vidro Tipo S & 2,49 & 85.6 & 4585 & 1,60 & 5,70 \\
Fibra Vidro Tipo E & 2,54 & 72.5 & 3445 & 5,40 & 4,88 \\
Fibra de Boro & 2,60 & 400 & 3600 & 4,50 & 0,80 \\
Aço AISI 1010 (a frio) & 7,87 & 200 & 365 & 12,20 & 20 \\
Aço AISI 4340 (temp-rev) & 7,85 & 212 & 1595 & 12,30 & 12 \\
Alumínio 6061-T6 & 2,70 & 68.2 & 290 & 22,90 & 10 \\
Titânio Ti-6Al-4V, STA & 4,43 & 110 & 1103 & 8,60 & 8 \\
\hline
\end{tabular}

Fonte: AEROSPACE COMPOSITES (2008). 


\subsection{TRATAMENTOS NA SUPERFÍCIE DAS FIBRAS}

Um material compósito pode ser feito a partir de uma fibra altamente resistente e uma matriz devidamente apropriada e não exibir a resistência esperada. A razão disto está na resistência na interface fibra-matriz que é igualmente importante no desempenho do compósito. A área superficial da interface fibra-matriz para uma única camada de um típico compósito com fibras de carbono, é cerca de 50 vezes a área da superfície da camada. Para melhorar a interface entre fibra-matriz, a superfície da fibra deve ser tratada por agentes ou processos de tratamento interfacial e dimensionamento, que produzem mudanças químicas na superfície. Diferentes tratamentos são utilizados pelas indústrias que produzem materiais compósitos. Lubrificantes e protetores são utilizados imediatamente após a formação da fibra para proteger as fibras quando as mesmas forem sujeitadas nos roletes e molinetes. Revestimento com agentes são utilizados para aumentar a adesão entre fibra e matriz e às vezes, alguns revestimentos especiais podem ser aplicados para proteger às fibras de ataque ambiental, tais como água salgada. O mesmo revestimento utilizado para proteger a fibra durante o processo de fabricação pode também servir para melhorar a adesão fibra-matriz. Alguns tratamentos interfaciais com plasma, condicionamento ácido, irradiação e oxidação também podem ser utilizados.

\subsubsection{TRATAMENTO DAS FIBRAS DE CARBONO}

Fibras à base de grafite normalmente são frágeis e sujeitas à abrasão quando manuseadas. Para protegê-las uma aplicação de cola epóxi é aplicada na superfície das fibras. Em alguns casos, a adição de polímero vinílico na cola epóxi é incorporada para melhorar as características de manuseio. Coberturas Pyrolitic mostram uma melhora na resistência à tração e aumento da resistência à oxidação das fibras. Outro componente que mostrou uma melhora na resistência à tração da fibra é o tratamento com bromo em fibras sem revestimento. Nesta técnica a fibra de carbono é imersa em bromo líquido ou em bromo dissolvido em solvente. Após a remoção do bromo, resquícios de bromo ficam depositados na superfície da fibra. Este tipo de revestimento melhora a resistência à oxidação das fibras. HYER (1993).

Carboneto de metal também é utilizado, no lugar de nitreto de boro, para melhorar a resistência à oxidação da fibra. Quando o carboneto é exposto a uma 
temperatura de $400^{\circ} \mathrm{C}$ ele se converte num óxido refratário que melhorar a resistência da fibra à oxidação, ele age não somente como uma barreira química, mas como um escudo térmico, que melhora a durabilidade da fibra. $\mathrm{Na}$ busca pelo melhor desempenho da adesão fibra-matriz, muitas modificações foram feitas na resina e o critério para definir qual a resina mais apropriada foi sua propriedade de fusão, mas algumas resinas não tinham esta característica tão boa quanto desejada, como o caso das poli (p-fenileno). Assim muitas técnicas foram desenvolvidas para melhorar a adesão fibra-matriz. Como resultado, diversos métodos foram desenvolvidos, tais como: tratamento com ácidos, tratamento com oxidação, tratamento com plasma, revestimento com carbono, revestimento com resinas, tratamento com amônia e tratamento eletrolítico.

Tratamento com ácidos melhoram a adesão entre fibras de carbono e resinas de baixa propriedade de fusão. Ácido hipocloroso tem mostrado significante aumento no módulo de cisalhamento do material compósito, assim como o tratamento com amônia a $1000^{\circ} \mathrm{C}$. Tratamento eletrolítico melhora a adesão fibra-matriz e é utilizado para melhorar a reatividade da superfície da fibra e depositar grupos químicos na superfície da fibra que auxiliam na adesão entre fibra-matriz. Oxidação das fibras pelo aquecimento a $1000^{\circ} \mathrm{C}$ em uma atmosfera oxidante promove uma corrosão na fibra que leva a uma grande adesão da fibra na matriz. Melhora significativa na adesão da fibra-matriz foram encontradas em fibras tratadas pelo plasma. As fibras são fiadas numa câmara com tratamento térmico de plasma de argônio ou oxigênio, ou misturas de hidrogênio e nitrogênio ou fluoreto de carbono. A temperatura de tratamento com plasma pode alcançar $8000^{\circ} \mathrm{C}$. Um revestimento com polímero na superfície das fibras às vezes é incorporado nos revestimentos para melhorar a adesão fibra-matriz. Polímeros termoplásticos tais como, polisulfone ou policarbonato são usados como revestimento para mais tarde, serem impregnadas com resinas termorrígidas. $O$ resultado é uma região de interfase entre fibra e matriz que apresentam uma significante melhora no módulo de cisalhamento. O desenvolvimento de uma região de interfase melhora a eficiência na distribuição do carregamento e reduz a tendência a trincas na região da interface. HYER (1993).

A figura 22 mostra uma vista microscópica dos vários efeitos da aplicação ou Figura 22 - Efeito do tratamento superficial na fibra. não, dos tratamentos na superfície 
da fibra: (a) mostra uma falha num compósito reforçado com fibra de carbono não tratada, (b) Também mostra uma falha na interface do compósito de uma fibra com superfície não tratada, porém neste exemplo observa-se uma melhor adesão comparada a malha em (a), (c) ilustra o efeito de tratamento superficial pobre, ou não adequado, a matriz termoplástica, devido à formação de esferas como consequência do tratamento, faz o mínimo contato com a fibra e (d) mostra a área de contato entre fibra e matriz é maximizada resultante de um bom tratamento superficial.

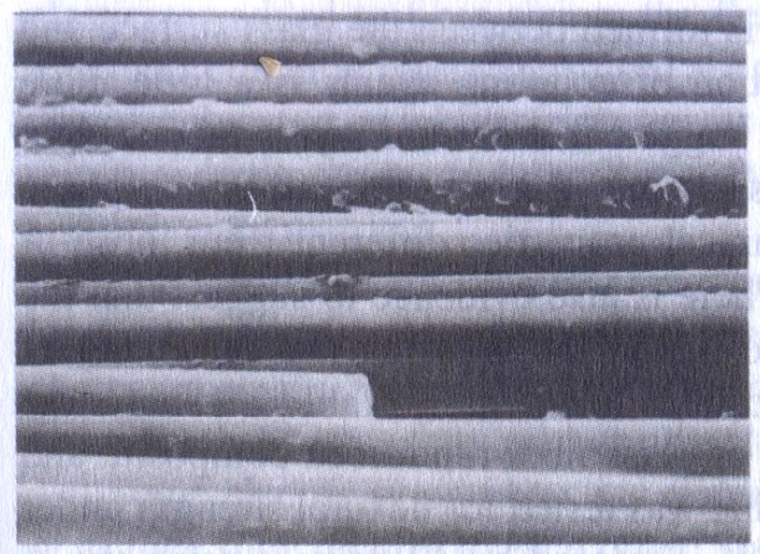

(a)

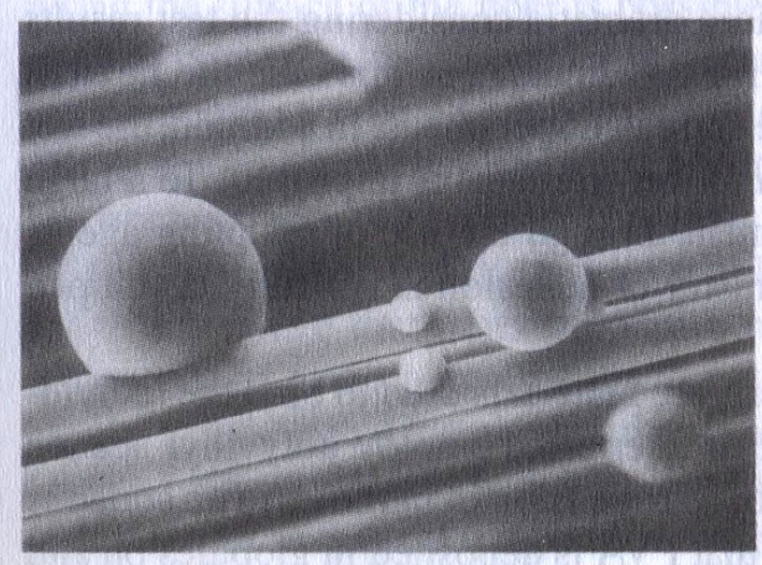

(c)

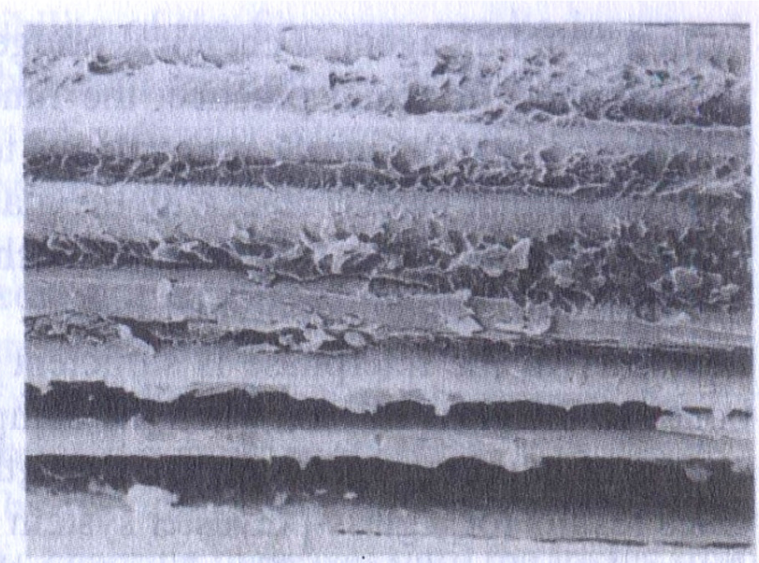

Fonte: HYER (1993). (b)

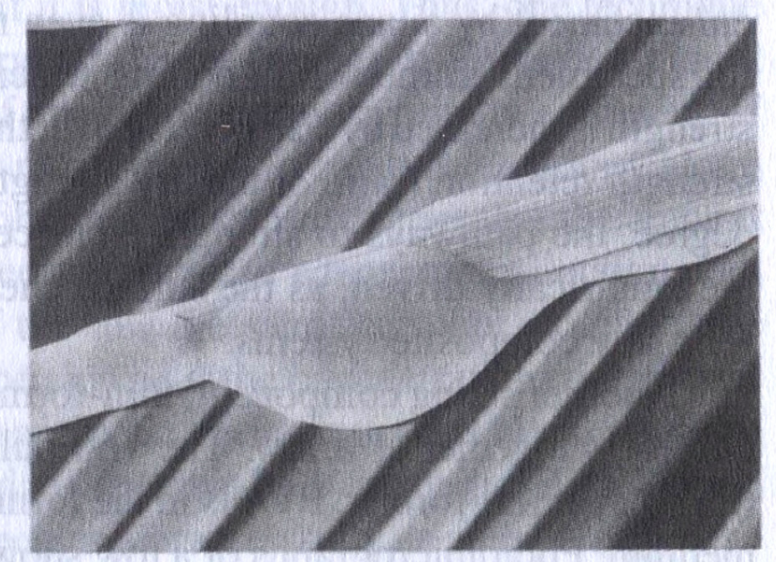

(d)

\subsubsection{TRATAMENTO DAS FIBRAS DE VIDRO}

O revestimento das fibras de vidro é utilizado em matriz polimérica e deve realizar diversos objetivos simultaneamente. Promover boa adesão fibra-matriz, promover boa coesão entre as fibras de vidro que formam o carretel, conferir certas características manuais tais como dureza ou propriedade de serem picadas, fornecer a adequada proteção da fibra durante o processo e conferir propriedade antiestática 
para que cargas estáticas não se acumulem na superfície da fibra. Para que as fibras sejam mais eficientes como reforços, alguns métodos de acoplamento de fibras hidrofílicas com matriz polimérica hidrófoba devem ser utilizados. Um material hidrofóbrio não absorve água e hidrofílico absorve. Estes agentes são uma classe de químicos que são: orgânico metálico e silicone orgânico, processando funcionalidade dual. Um ensaio em fibras de vidro revestidas, sendo submetida à tensão em ambiente seco e úmido, este último em água fervente por duas horas. HYER (1993).

Tabela 9 - Efeito dos vários agentes de acoplamento na fibra de vidro.

\begin{tabular}{|c|c|c|c|}
\hline $\begin{array}{l}\text { Nome tradicional } \\
\text { do agente de } \\
\text { acoplamento }\end{array}$ & $\begin{array}{r}\text { Resistênc } \\
\text { Seca }\end{array}$ & $\begin{array}{l}\text { exão a } 25^{\circ} \mathrm{C}(\mathrm{MPa}) \\
\text { Depois de } 2 \text { horas } \\
\text { em água fervente }\end{array}$ & $\begin{array}{l}\text { Resistência à } \\
\text { retenção de } \\
\text { umidade (\%) }\end{array}$ \\
\hline Nenhum & 42,3 & 24,7 & 58 \\
\hline Volan A (DuPont) & 50,8 & 43,7 & 86 \\
\hline $\begin{array}{ll}\text { A172 } & \text { (Union } \\
\text { Carbide) }\end{array}$ & 50,8 & 48,0 & 94 \\
\hline $\begin{array}{l}\text { A174 } \\
\text { Carbide) }\end{array}$ & 60,0 & 56,4 & 94 \\
\hline
\end{tabular}

Fonte: HYER (1993).

Ainda HYER (1993) diz que outros componentes de revestimento são os formadores de filme, utilizado para ligar as fibras individuais juntas como um carretel. A grande maioria dos revestimentos em fibras de vidro utiliza o poliacetato de vinila (PVA) como formador de filme. PVA é uma forma de partículas em suspensão aquosa média. Fotos micrográficas de um carretel mostraram que o PVA é depositado na forma de glóbulos sobre e entre as fibras e que no carretel são mantidas juntas por estes glóbulos formando pontes de uma fibra para a outra. O inconveniente do uso de PVA como formador de filme, é que é uma adição não bem vinda ao material compósito. O PVA permanece nas fibras depois de impregnadas com resina, levando a uma perda das propriedades mecânicas do material compósito. Plastificantes são adicionados às emulsões de PVA (8 a 20\%) para aumentar à flexibilidade e reduzir o amolecimento à temperatura, sendo os plastificantes mais comuns utilizados os: Ftalatos, Fosfatos e Poliésteres. O plastificante poliéster tem um interesse particular às fibras de vidro como reforço nas indústrias de compósitos devido sua maior 
compatibilidade com resinas epóxi e poliéster. Lubrificantes são adicionados às fibras em concentrações de $(0.2$ a $2 \%)$ e sua maioria são agentes ativos de superfície catiônicos, eles serão carregados com cargas negativas normalmente presentes na superfície da fibra. Um grupo catiônico normalmente utilizado é a amina no qual um ácido graxo é impregnado.

A energia estática presente nas fibras de vidro é consequência do atrito nos roletes durante o processo de fabricação ou do deslizamento entre elas mesmas. As cargas estáticas aumentam até a perda de a condução ser balanceada pela taxa na qual a carga é gerada. Uma técnica para controlar a eletricidade estática é realizar o processo num ambiente úmido, controlando a umidade em $70 \%$. Se esta técnica não for possível, agentes antiestáticos podem ser utilizados para conduzir a eletricidade estática ao longo da fibra.

Tabela 10 - Formulação típica para revestimento da fibra de vidro.

\begin{tabular}{|ll|}
\hline Componente & $(\%)$ \\
\hline Agente de acoplamento & $0,3-0,6$ \\
Formador de filme & $3,5-15,0$ \\
Lubrificantes & $0,1-0,3$ \\
Agente de superfície ativa & $0-0,5$ \\
Agente antiestático & $0-0,3$ \\
Água destilada & $83,3-96,1$ \\
\hline
\end{tabular}

Fonte: HYER (1993).

\subsection{FORMATO DA MECHA}

Um carretel de fibra de vidro é composto por uma mecha de fios de vidro. Nos EUA os filamentos de vidro são codificados por uma letra que define o diâmetro nominal da mecha. A tabela a seguir mostra a codificação destas mechas. 
Tabela 11- Diâmetro das mechas comerciais.

\begin{tabular}{ccc}
\hline Letra do código & Diâmetro em mícrons & $\begin{array}{c}\text { Diâmetro } \\
1 / 1000.000 \text { polegadas }\end{array}$ \\
\hline $\mathrm{K}$ & 13 & $50-55$ \\
$\mathrm{M}$ & 16 & $60-65$ \\
$\mathrm{~T}$ & 23 & $90-95$ \\
\hline \hline
\end{tabular}

CODIFICAÇÃO DA MECHA

Fonte: ALMACO (2008).

A mecha é composta de vários filamentos de fibra. A composição de 200 a 4000 filamentos é chamada de "strand". A coleção de dois ou mais strands é chamado de "Roving”. O peso em relação à unidade de comprimento das mechas de roving no enrolamento é descrito com tex ou yield. Tex peso em gramas de 1000 metros de roving $(\mathrm{g} / \mathrm{km})$. Yield número de jardas de uma mecha por uma fibra de roving. Um roving de 250 yield terá 250 jardas de roving em uma libra (y/lb) (ALMACO 2014).

\subsection{CARACTERÍSITCAS DA TENSÃO-DEFORMAÇÃO ELÁSTICA LINEAR DOS MATERIAIS REFORÇADOS POR FIBRAS}

Para entender o comportamento de um material compósito reforçado por fibras, HYER (1993) sugere o posicionamento de um material laminado em um sistema de coordenadas ortogonais e isola um pequeno elemento como ilustra a figura 23 , e a orientação dos eixos neste elemento. A orientação 1 é alinhada à orientação da fibra e é chamada de direção da fibra ( $\sigma)$. A orientação 2 e 3 são orientações perpendiculares à orientação da fibra e são chamadas direção da matriz ou direção transversal $(T)$. Os termos direção da matriz e direção transversal é um tanto ambíguo, pois se encaixam em qualquer uma destas descrições. HYER (1993) adota direção da matriz. 
Figura 23 - Sistema de coordenada do material.

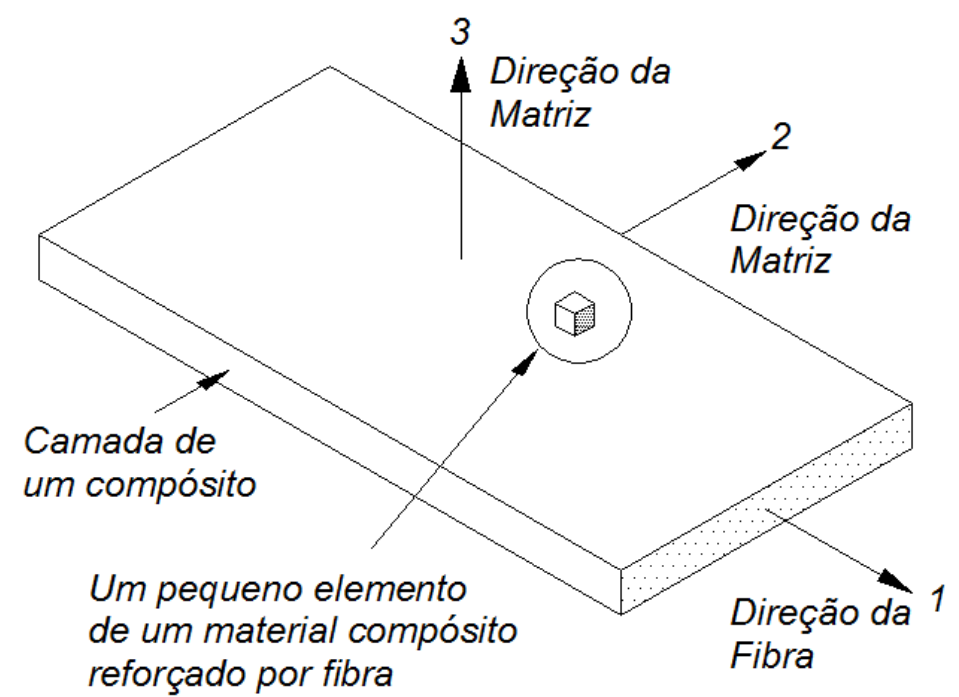

Fonte: HYER (1993).

De acordo com HYER (1993), o estudo da tensão-deformação de uma única camada do material compósito reforçado por fibra é equivalente a determinar as relações entre a tensão aplicada às superfícies delimitadas da camada e às deformações da camada como um todo. A tensão em uma fibra individual ou no elemento matriz não pode ser levada em consideração como análise do todo. Dois elementos, matriz e fibras são entendidos como um único material homogêneo. Embora considerado homogêneo, o material apresenta propriedades diferentes nas três direções. Força e rigidez na direção 1 são mais altas que nas direções 2 e 3 . 0 material que apresenta estas características, propriedades mecânicas diferentes nas direções, é chamado ortotrópico. Já um material que apresenta propriedades iguais em todas as direções é chamado isotrópico. Algumas literaturas adotam ortotrópico como anisotrópico. A figura 24 ilustra as tensões agindo em um pequeno elemento. 
Figura 24 - Ação da tensão em um pequeno elemento de um material reforçado por fibra.

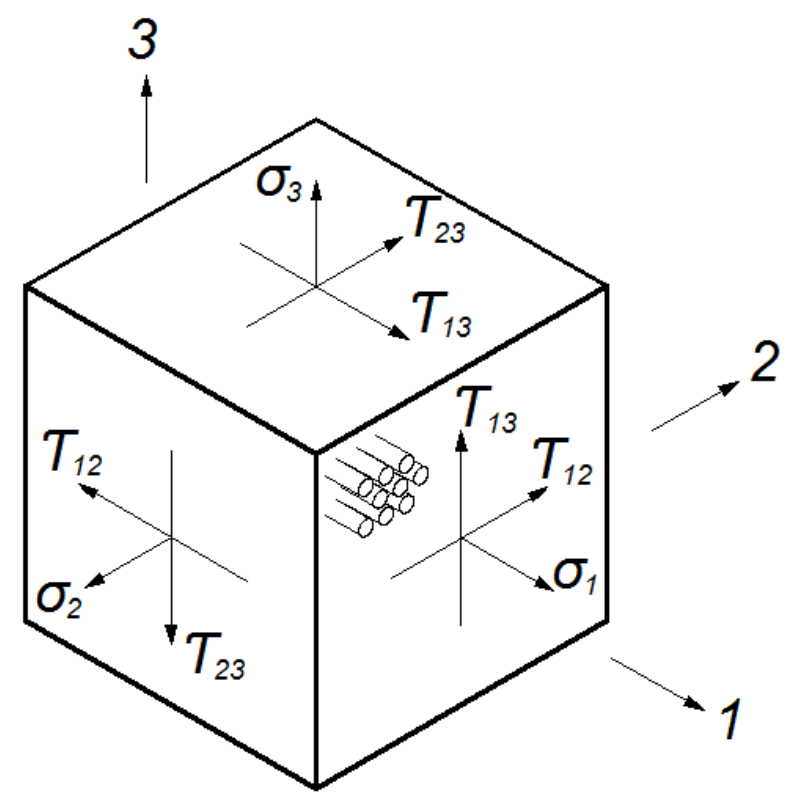

Fonte: Adaptado de HYER (1993).

Da figura 24, a tensão normal agindo na face do elemento na direção 1, é denotado por $\sigma 1$, a tensão de cisalhamento agindo na direção 2 é denotado por T12 e a tensão de cisalhamento agindo na direção 3 é denotada por T13. As respostas das deformações axiais nas direções 1,2 e 3 são denotadas por $\varepsilon 1$, $\varepsilon 2$ e $\varepsilon 3$ enquanto que as tensões de cisalhamento são denotadas por $\gamma 1$, $\gamma 2$ e $\gamma 3$. A relação tensãodeformação de um pequeno elemento do material é construída considerando a resposta do elemento em cada uma das seis componentes de tensão. A tensão normal $\sigma 1$ causa um alongamento do material na direção 1, e devido ao efeito Poisson, contração nas direções 2 e 3 . Não existe razão para acreditar que a contração será a mesma nas direções 2 e 3.

A deformação axial na direção 1 está relacionada com a tensão normal de elasticidade no sentido da direção 1 (tração), ou alongamento, o módulo do material no sentido das fibras. A relação entre essas grandezas é dada por:

$$
\begin{aligned}
& \varepsilon_{1}=\frac{\sigma_{1}}{E_{1}} \\
& \text { O raio de Poisson pode ser calculado por: }
\end{aligned}
$$


$\mathrm{v}_{12}=-\frac{\varepsilon_{2}}{\varepsilon_{1}}$

Então:

$\varepsilon_{2}=-\mathrm{v}_{13} \varepsilon_{1}=-\mathrm{v}_{12} \frac{\sigma_{1}}{E_{1}}$

Por convenção, a contração na direção 3 está relacionada ao alongamento na direção 1 dada por $v_{13}$.

$\mathrm{v}_{13}=-\frac{\varepsilon_{3}}{\varepsilon_{1}}$

Esta equação pode ser escrita por:

$$
\varepsilon_{3}=-v_{13} \varepsilon_{1}=-v_{13} \frac{\sigma_{1}}{E_{1}}
$$

A figura 25 ilustra a ação da tensão $\sigma 1$ agindo no plano 1 vista pelos demais planos e em perspectiva isométrica.

Figura 25 - Deformação de um elemento devido a ação de $\boldsymbol{\sigma} 1$.

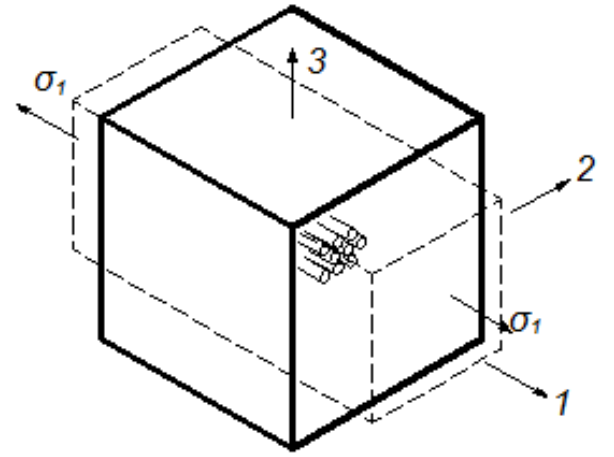

Perspectiva

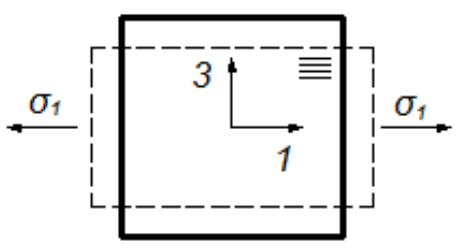

Vista pelo plano 1-3

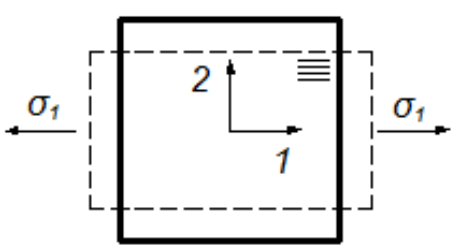

Vista pelo plano 1-2

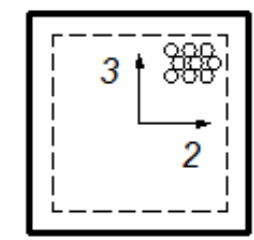

Vista pelo plano $2-3$

Fonte: HYER (1993). 
Se a tensão de alongamento aplicada na direção 1 fosse aplicada na direção 2, as deformações que ocorreriam no elemento teriam um comportamento diferente. Devido a anisotropia do material, o alongamento seria maior na direção 2 que na direção 1. A rigidez das fibras tendem a resistir o efeito de Poisson, a contração na direção 1 seria mínima. Em contraste a contração na direção 3 seria grande. Com o carregamento aplicado na direção 2, o módulo de alongamento pode ser escrito por:

$$
\varepsilon_{2}=\frac{\sigma_{2}}{E_{2}}
$$

Devido à tensão estar sendo aplicada na direção perpendicular das fibras, $\varepsilon_{2}$ seria muito menor $\varepsilon_{1}$. Pela convenção do raio de Poisson, a contração na direção 1 é relacionada ao alongamento na direção 2 , dado pela equação:

$$
\mathrm{v}_{21}=-\frac{\varepsilon_{1}}{\varepsilon_{2}}
$$

Então:

$$
\varepsilon_{1}=-\mathrm{v}_{21} \varepsilon_{2}=-\mathrm{v}_{21} \frac{\sigma_{2}}{E_{2}}
$$

De maneira similar, a contração na direção 3 está relacionada ao alongamento na direção 2 por $\vee_{23}$ dado pela equação:

$$
\mathrm{v}_{23}=-\frac{\varepsilon_{3}}{\varepsilon_{2}}
$$

Rearranjando estas equações, pode ser escrita por:

$$
\varepsilon_{3}=-\mathrm{v}_{23} \varepsilon_{2}=-\mathrm{v}_{23} \frac{\sigma_{2}}{E_{2}}
$$

A figura 26 ilustra a ação da tensão $\sigma 2$ agindo no plano 2, vista pelos demais planos e em perspectiva isométrica.

Figura 26 - Deformação de um elemento devido a ação de $\mathbf{\sigma} 2$. 


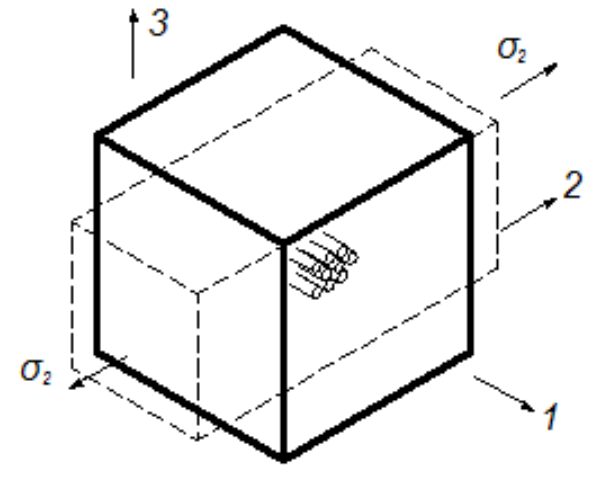

Perspectiva

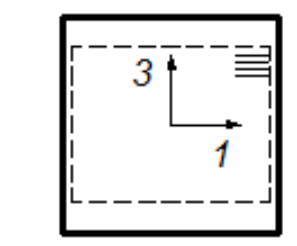

Vista pelo plano 1-3

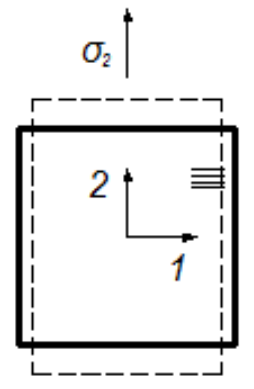

$\sigma_{2}$

Vista pelo plano 1-2

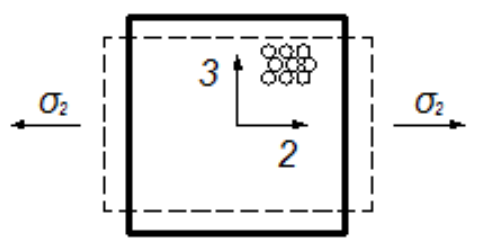

Vista pelo plano 2-3

Fonte: HYER (1993).

Se a tensão normal de alongamento fosse aplicada na direção 3, a deformação nas três direções seria dada por:

$$
\begin{aligned}
& \varepsilon_{3}=\frac{\sigma_{3}}{E_{3}} \\
& \varepsilon_{2}=-v_{32} \varepsilon_{3}=-v_{32} \frac{\sigma_{3}}{E_{3}} \\
& \varepsilon_{1}=-v_{31} \varepsilon_{3}=-v_{31} \frac{\sigma_{3}}{E_{3}}
\end{aligned}
$$

A figura 27 ilustra a ação da tensão $\sigma 3$ agindo no plano 2, vista pelos demais planos e em perspectiva isométrica. 
Figura 27 - Deformação de um elemento devido a ação de $\boldsymbol{\sigma} 3$.

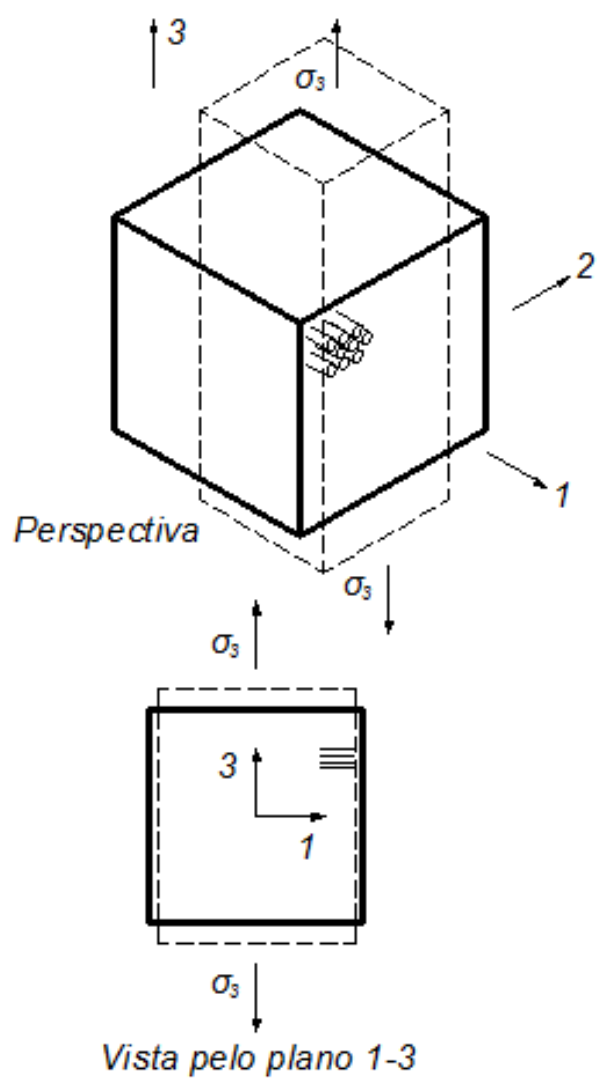

HYER (1993).

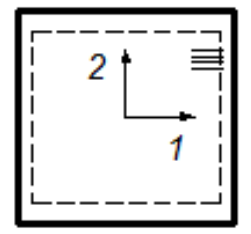

Vista pelo plano 1-2

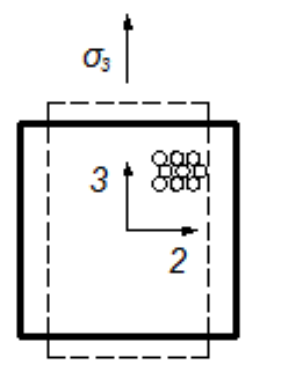

$\sigma_{3}$

Vista pelo plano 2-3

Fonte:

A deformação em qualquer direção sob a ação dês três tensões aplicadas simultaneamente pode ser escrita pela matriz a seguir. HYER (1993).

$$
\left\{\begin{array}{l}
\varepsilon_{1} \\
\varepsilon_{2} \\
\varepsilon_{3}
\end{array}\right\}=\left[\begin{array}{ccc}
\frac{1}{E_{1}} & \frac{-v_{21}}{E_{2}} & \frac{-v_{31}}{E_{3}} \\
\frac{-v_{12}}{E_{1}} & \frac{1}{E_{2}} & \frac{-v_{32}}{E_{3}} \\
\frac{-v_{13}}{E_{1}} & \frac{-v_{23}}{E_{2}} & \frac{1}{E_{3}}
\end{array}\right]\left\{\begin{array}{l}
\sigma_{1} \\
\sigma_{2} \\
\sigma_{3}
\end{array}\right\}
$$

\subsubsection{TEORIA DE FALHA EM MATERIAIS REFORÇADOS POR FIBRAS: CRITÉRIO DE TSAI WU.}

Materiais compósitos se diferem dos materiais metálicos em alguns aspectos como densidade, processo de fabricação e comportamento mecânico. Materiais 
metálicos são considerados isotrópicos, possuem o mesmo comportamento em qualquer direção onde seja aplicada um força. Já materiais compósitos são geralmente anisotrópicos, com orientações aleatórias, não apresentam o mesmo comportamento quando a força é aplicada em várias direções.

O critério de von Mises introduzido na resistência de materiais é descrito pela equação:

$$
\frac{1}{2}\left(\frac{1}{\sigma^{y}}\right)^{2}\left[\left(\sigma_{1}-\sigma_{2}\right)^{2}+\left(\sigma_{1}-\sigma_{3}\right)^{2}+\left(\sigma_{2}-\sigma_{3}\right)^{2}\right]=1
$$

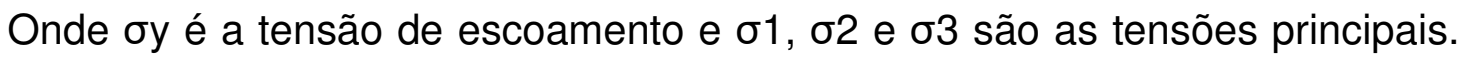
Esta equação pode ser escrita por:

$$
F\left(\sigma_{1}, \sigma_{2}, \sigma_{3}\right)=1
$$

De acordo com Von Mises se o resultado da equação for menor que 1, não há escoamento do material.

$$
F\left(\sigma_{1}, \sigma_{2}, \sigma_{3}\right)<1
$$

De acordo com HYER (1998) esta abordagem do critério de falha pode ser estendida aos materiais compósitos, considerando como um material ortotrópico no sistema de coordenadas principal, assumindo a equação:

$$
F\left(\sigma_{1}, \sigma_{2}, \sigma_{3}, \tau_{23}, \tau_{13}, \tau_{12}\right)=1
$$

Pode ser usada para representar a condição de falha de um compósito, enquanto que a condição de não falha é dada por:

$$
F\left(\sigma_{1}, \sigma_{2}, \sigma_{3}, \tau_{23}, \tau_{13}, \tau_{12}\right)<1
$$

Segundo HYER (1998) compósitos se diferem dos metais convencionais, assim, para determinar a forma específica (F) agindo em um compósito não seria possível a utilização do mesmo critério utilizado para os metais. Vinco de fibra em compressão, fratura da fibra na tração e falha da interface fibra-matriz no cisalhamento ou tensão na direção perpendicular da fibra. Extender os conceitos utilizados em metais para compósitos, porém se a generalização é vista como uma hipótese para 
ajustar os dados e ela é razoável, então a hipótese fornece um indicador que pode ser usado no estudo da falha.

Para o estado plano de tensão, se a força do componente de tensão é mantido, a equação geral de $\mathrm{F}$ é dado por:

$$
\begin{aligned}
& F\left(\sigma_{1} \sigma_{2} \tau_{12}\right)=F_{1} \sigma_{1}+F_{2} \sigma_{2}+F_{6} \tau_{12}+F_{11} \sigma_{1}^{2}+F_{22} \sigma_{2}^{2}+F_{66} \tau_{12}^{2}+ \\
& 2 F_{12} \sigma_{1} \sigma_{2}+2 F_{16} \sigma_{1} \tau_{12}+2 F_{26} \sigma_{2} \tau_{12}
\end{aligned}
$$

Onde F1, F2, F6, F11, F22, F66, F12, F16 e F26 são constantes. Todas componentes de tensão são representadas na primeira e segunda força e todo o produto das tensões estão representados. As constantes F12, F16 e F26 se referem a interação das constantes e a magnitude de seus valores serão dedicados ao grau de interação entre seus componentes. A interação entre a tensão normal $\sigma_{1}$ e $\sigma_{2}$ e a tensão de cisalhamento $\tau_{12}$ é incluída em virtude das constantes F16 e F26 e a interação entre as componentes normais de tensão $\sigma_{1}$ e $\sigma_{2}$ incluído com o termo F12.

Dada estas considerações, o critério de falha é encontrado por:

$$
\begin{aligned}
& F_{1} \sigma_{1}+F_{2} \sigma_{2}+F_{6} \tau_{12}+F_{11} \sigma_{1}^{2}+F_{22} \sigma_{2}^{2}+F_{66} \tau_{12}^{2}+2 F_{12} \sigma_{1} \sigma_{2}+ \\
& 2 F_{16} \sigma_{1} \tau_{12}+2 F_{26} \sigma_{2} \tau_{12}=1
\end{aligned}
$$

Este critério foi postulado por Tsai e Wu como a forma do plano de tensão (HYER 1998).

E a condição de não falha é dada por:

$$
\begin{aligned}
F_{1} \sigma_{1}+F_{2} \sigma_{2}+F_{6} \tau_{12}+F_{11} \sigma_{1}^{2}+F_{22} \sigma_{2}^{2}+F_{66} \tau_{12}^{2}+ \\
2 F_{12} \sigma_{1} \sigma_{2}+2 F_{16} \sigma_{1} \tau_{12}+2 F_{26} \sigma_{2} \tau_{12}<1
\end{aligned}
$$

As constantes $\mathrm{F} 1$...F66 foram determinadas pelos resultados de um simples teste de falha com material compósito reforçado por fibra. Considerando um elemento de um material compósito tensionado somente na direção da fibra, então temos: 


$$
\begin{gathered}
\sigma_{1} \neq 0 \\
\sigma_{2}=0 \\
\tau_{12}=0
\end{gathered}
$$

A função $F\left(\sigma_{1}, \sigma_{2}, \tau_{12}\right)$ é reduzida para a equação:

$$
F\left(\sigma_{1}, \sigma_{2}, \tau_{12}\right)=F_{1} \sigma_{1}+F_{11} \sigma_{1}^{2}
$$

A tensão $\sigma_{1}$ aplicada na direção 1 , a falha por tração ocorre quando:

$$
\sigma_{1}=\sigma_{1}^{T}
$$

O critério de falha deve ser a unidade do valor da $\sigma_{1}$, dada por:

$$
F_{1} \sigma_{1}^{T}+F_{11}\left(\sigma_{1}^{T}\right)^{2}=1
$$

A tensão $\sigma_{1}$ em compressão, falha quando:

$$
C=\sigma_{1}^{C}
$$

O critério de falha deve ser a unidade do valor da $\sigma_{1}$, dada por:

$$
F_{1} \sigma_{1}^{C}+F_{11}\left(\sigma_{1}^{C}\right)^{2}=1
$$

Das equações 19 e 21 resultante dos dois testes de falha na direção da fibra fora obtidas as equações para calcular $F_{1} e F_{11}$. A figura blabla ilustra a ação da tensão $\sigma 1$ na direção da fibra.

$$
F_{1}=\frac{1}{\sigma_{1}^{T}}+\frac{1}{\sigma_{1}^{C}} \text { e } F_{11}=\frac{1}{\sigma_{1}^{T}}+\frac{1}{\sigma_{1}^{C}}
$$

Figura 28 - À esquerda falha por tração na direção 1. À direita falha por compressão. Ambos pelo critério de Tsai wu.

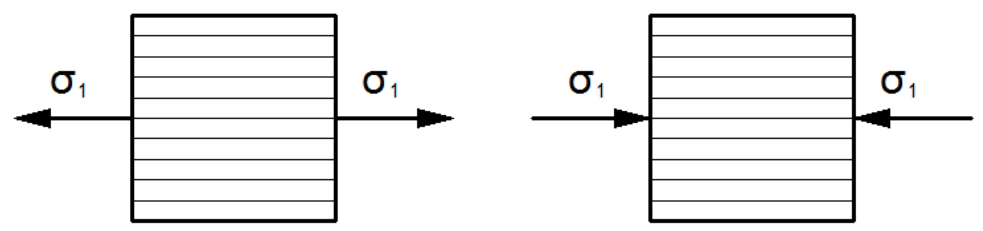


Fonte: HYER (1993).

Numa aproximação similar, mas com a tensão e compressão aplicada na direção 2 do material, temos:

$$
\begin{gathered}
\sigma_{1}=0 \\
\sigma_{2} \neq 0 \\
\tau_{12}=0
\end{gathered}
$$

A função $F\left(\sigma_{1}, \sigma_{2}, \tau_{12}\right)$ é reduzida para a equação:

$$
F\left(\sigma_{1}, \sigma_{2}, \tau_{12}\right)=F_{2} \sigma_{2}+F_{22} \sigma_{2}^{2}
$$

A tensão $\sigma_{2}$ aplicada na direção 2, a falha por tração ocorre quando:

$$
\sigma_{2}=\sigma_{2}^{T}
$$

O critério de falha deve ser a unidade do valor da $\sigma_{2}$, dada por:

$$
F_{2} \sigma_{2}^{T}+F_{22}\left(\sigma_{2}^{T}\right)^{2}=1
$$

A tensão $\sigma_{2}$ em compressão, falha quando:

$$
\sigma_{2}=\sigma_{2}^{C}
$$

O critério de falha deve ser a unidade do valor da $\sigma_{2}$, dada por:

$$
F_{2} \sigma_{2}^{C}+F_{22}\left(\sigma_{2}^{C}\right)^{2}=1
$$

Das equações 27 e 29 resultante dos dois testes de falha na direção da fibra fora obtidas as equações para calcular $F_{2} e F_{22}$. A figura 29 ilustra a ação de $\sigma 2$ agindo no plano perpendicular às fibras.

$$
F_{2}=\frac{1}{\sigma_{2}^{T}}+\frac{1}{\sigma_{2}^{C}} \text { e } F_{22}=\frac{1}{\sigma_{2}^{T}}+\frac{1}{\sigma_{2}^{C}}
$$


Figura 29 - À esquerda falha à tração na direção 2 pelo critério de Tsai Whu. À direita falha à compressão pelo critério de Tsai Whu.
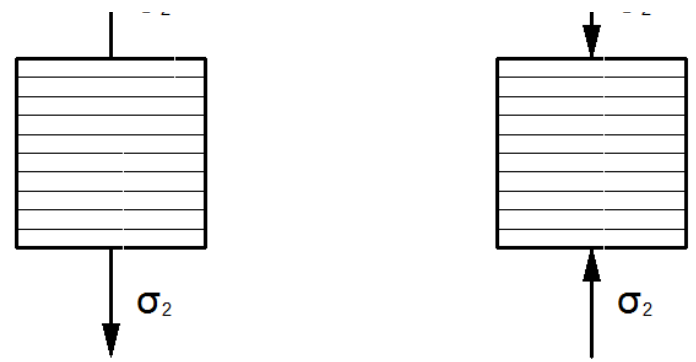

Fonte: HYER (1993).

Para o teste de falha por cisalhamento o carregamento utilizado foi:

$$
\begin{gathered}
\sigma_{1}=0 \\
\sigma_{2}=0 \\
\tau_{12} \neq 0
\end{gathered}
$$

A função $F\left(\sigma_{1}, \sigma_{2}, \tau_{12}\right)$ é reduzida para a equação:

$$
F\left(\sigma_{1}, \sigma_{2}, \tau_{12}\right)=F_{6} \tau_{12}+F_{66} \tau_{12}^{2}
$$

Se a tensão $\tau_{12}$ é positiva, a falha ocorre quando:

$$
\tau_{12}=\tau_{12}^{F}
$$

e

$$
F_{6} \tau_{12}^{F}+F_{66}\left(\tau_{12}^{F}\right)^{2}=1
$$

Se a tensão $\tau_{12}$ é reversa, falha quando:

$$
\tau_{12}=-\tau_{12}^{F}
$$

e 
$-F_{6} \tau_{12}^{F}+F_{66}\left(-\tau_{12}^{F}\right)^{2}=1$

Das equações 37 e 39 leva à:

$$
F_{6}=0 \text { e } F_{66}=\left(\frac{1}{\tau_{12}^{F}}\right)^{2}
$$

F6 é basicamente zero no sistema principal de coordenadas do material a falha não é sensitiva ao sinal da tensão de cisalhamento. Neste ponto o critério de falha de Tsai Wu se torna:

$$
\begin{aligned}
& \left(\frac{1}{\sigma_{1}^{T}}+\frac{1}{\sigma_{1}^{C}}\right) \sigma_{1}+\left(\frac{1}{\sigma_{2}^{T}}+\frac{1}{\sigma_{2}^{C}}\right) \sigma_{2}+\left(-\frac{1}{\sigma_{1}^{T} \sigma_{1}^{C}}\right) \sigma_{1}^{2}+\left(-\frac{1}{\sigma_{2}^{T} \sigma_{2}^{C}}\right) \sigma_{2}^{2}+\left(\frac{1}{\tau_{12}^{F}}\right)^{2} \tau_{12}^{2}+ \\
& 2 F_{12} \sigma_{1} \sigma_{2}+2 F_{16} \sigma_{1} \tau_{12}+2 F_{26} \sigma_{2} \tau_{12}=1
\end{aligned}
$$

A figura 30 ilustra o critério de falha por cisalhamento.

Figura 30 - À esquerda falha devido ao cisalhamento positivo, à direita falha devido ao cisalhamento reverso. Critério de Tsai Whu.
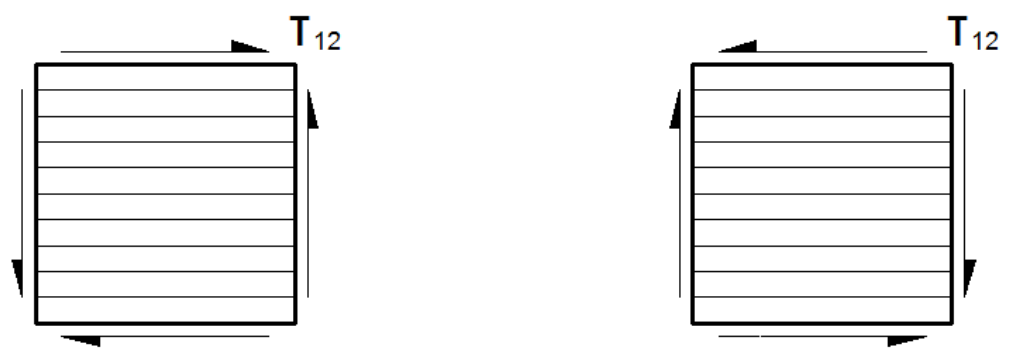

Fonte: HYER (1993).

\subsection{PROCESSOS DE FABRICAÇÃO EM COMPÓSITOS}

Segundo GUTOWSKY (1997) embora haja muitos tipos de processos para fabricar materiais compósitos, todos tem alguns passos básicos em comum. Por exemplo, todos compósitos reforçados por fibras requerem a fabricação de estrutura de uma rede de fibras intricadas específica para uma geometria ou microestrutura. 
Esta estrutura de fibra deve ser umedecida e infiltrada na matriz e a matriz em volta, deve ser solidificada, enquanto a peça apoiada, de alguma forma, se torna rígida.

Existem vários processos de manufatura para obtenção de materiais compósitos, cada processo tem sua vantagem e aplicação. Aqui são listados alguns processos de manufatura para obtenção de materiais compósitos: Fabricação por Centrifugação, Fabricação por compressão, Laminação continua, Filament Winding, Hand Lay up, Injeção, Reinforced reaction injection Molding - RRIM (Moldagem por mistura e injeção), Resin transfer molding - RTM (Moldagem por transferência de resina), Spray up (Moldagem a pistola). Além dos processos de manufatura do componente final existem processos intermediários tais como: Prepregs (préimpregnados), Preforms (pré-formados), BMC - Bulk molding compound, SMC Sheet molding compound; pultrusão.

\subsubsection{CENTRIFUGAÇÃO}

Este processo serve para a fabricação de peças ocas de revolução como tubos, postes, tanques, etc. O processo consiste em depositar a resina em uma manta (ou tecido) de fibra dentro de um molde cilíndrico oco no formato externo da peça final, pela força centrífuga.

O molde em movimento de rotação em torno do seu próprio eixo com o tecido em seu interior recebe a resina injetada através de um dosador. Pela ação da força centrífuga a resina penetra no tecido removendo o ar contido dentro do mesmo. A resina depositada pela ação da força centrífuga produz uma camada contínua e uniforme. A figura blabal ilustra o processo de centrifugação.

Neste tipo de processo a cura pode ser realizada pela temperatura ambiente ou em estufa. Este processo é indicado para peças cujo propósito não exija propriedades homogêneas.

Figura 31- Processo de centrifugação. 


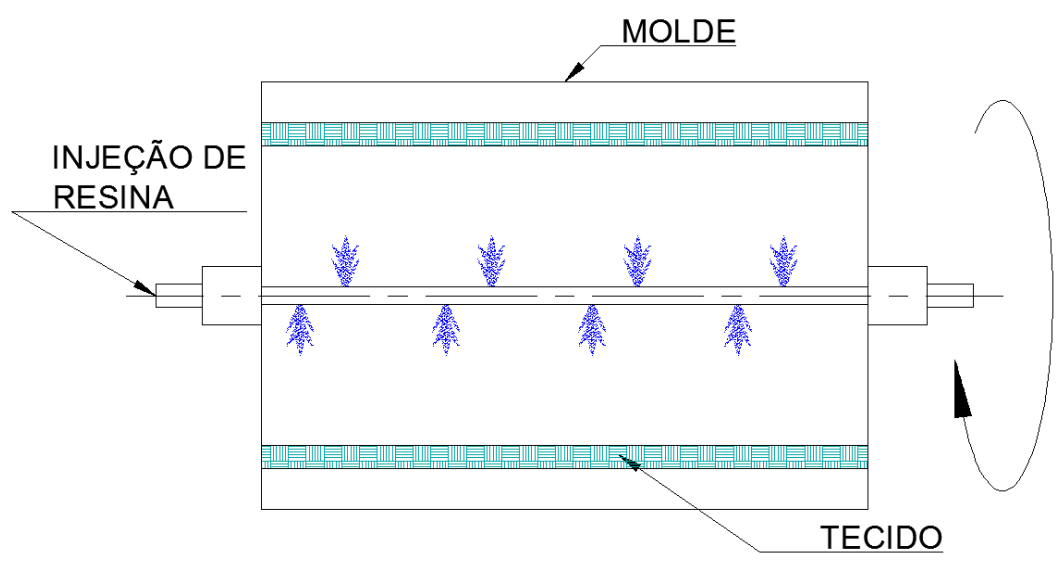

Fonte: Adaptado de NETO (2006).

\subsubsection{PROCESSO POR COMPRESSÃO OU MOLDAGEM POR COMPRESSÃO}

Neste processo, o material de reforço pode ser uma folha pré-impregnada, a granel, pré-formados ou por lâminas de termoplásticos reforçados por fibras. Folhas pré-impregnada é conhecida como sheet molding compound (SMC), a granel é conhecido por bulk molding compound (BMC) e pré-formados é conhecido por preform. NETO (2006).

Este processo tem o princípio semelhante ao de conformação de metais numa prensa. Uma vez o material acomodado dentro do molde, geralmente na parte fêmea na posição horizontal, a outra parte do molde, ou o macho, é movido em direção contra a fêmea, acomodando o material na fêmea e dando forma ao reforço embebido em matriz.

O processo de cura normalmente ocorre no próprio molde. Este processo garante bom acabamento superficial e dimensional, as indústrias automobilísticas são um exemplo das que utilizam este processo. É necessário salientar que a experiência mostra que a qualidade superficial e a precisão dimensional do produto a ser obtido dependem da qualidade superficial do molde e de um controle da contração do produto. 
A figura 32 ilustra o processo de fabricação de uma sheet molding compound. A figura 33 ilustra o processo de fabricação pelo método de compressão utilizando sheet molding compound.

Figura 32 - Produção de Sheet Molding Compound.

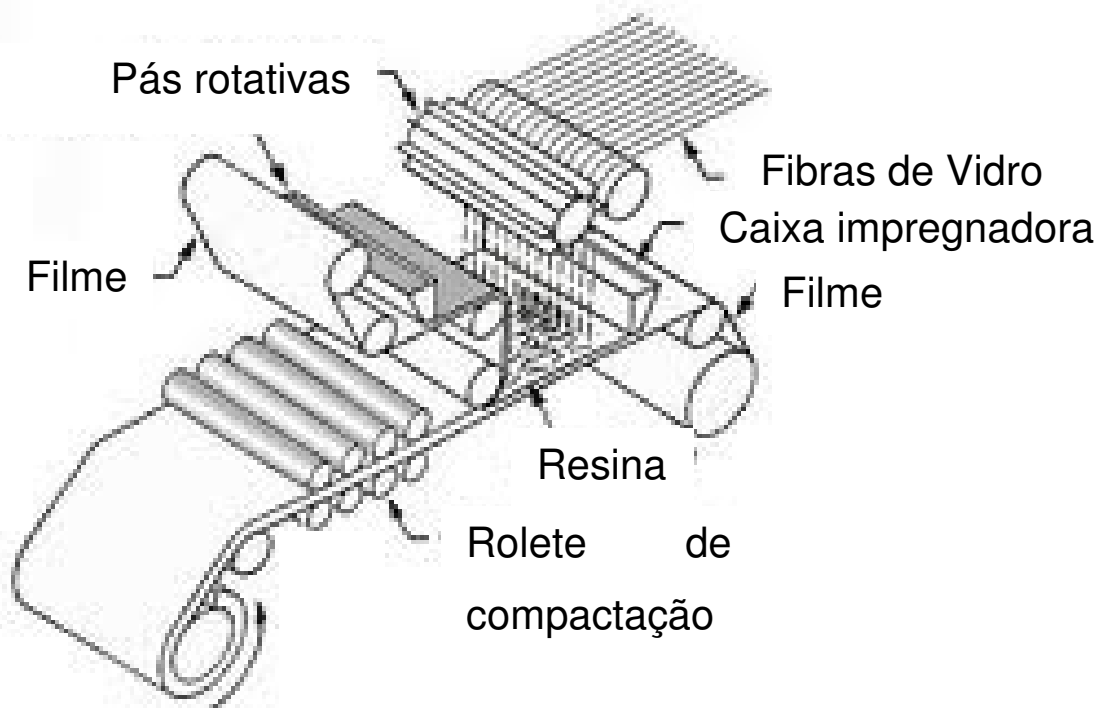

Fonte: NETO (2006).

Figura 33 - Processo de compressão com sheet molding compound.
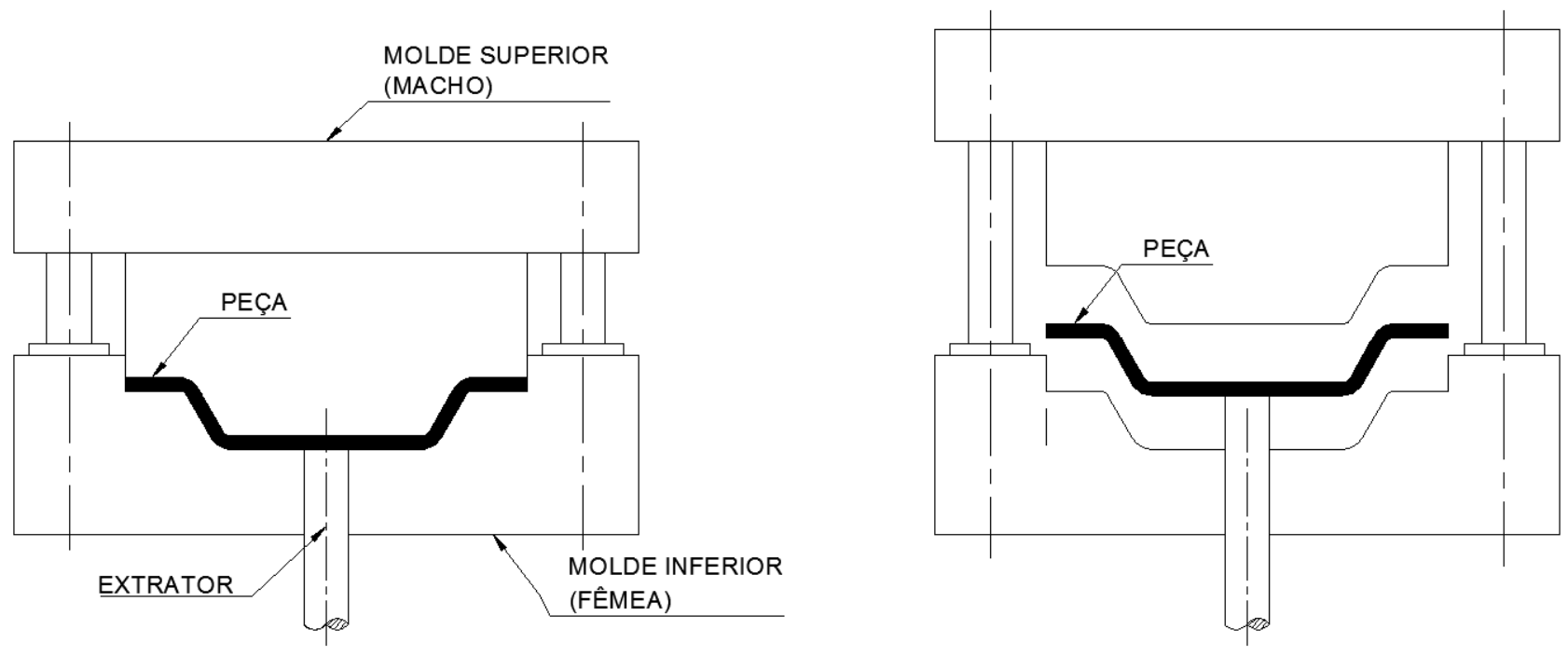

Fonte: Adaptado de NETO (2006). 


\subsubsection{LAMINAÇÃO CONTÍNUA}

Este processo é utilizado para fabricação de materiais compósitos em formatos de placas, lâminas ou chapas. Estas peças podem ser planas, normalmente executadas em máquinas para dimensão de largura de até $3 \mathrm{~m}$ ou no formato ondulado de coloração translucida normalmente executado em máquinas para dimensão de largura de até $2 \mathrm{~m}$. As peças podem ser coloridas ou pigmentadas variando de 0,8 a $3 \mathrm{~mm}$ de espessura com velocidades de produção entre 3 a $5 \mathrm{~m}$ por minuto.

Este processo consiste em colocar o reforço (fibras) entre dois filmes e mergulhá-los em um banho de resina. As lâminas tomam sua forma através de rolos e a resina catalisada e tem sua cura acelerada ao passar por uma fonte de calor.

O laminado é posto para curar em uma estufa em temperaturas entre $90^{\circ} \mathrm{C} \mathrm{e}$ $150^{\circ} \mathrm{C}$ entre zonas de aquecimento. Após a cura o produto é cortado e rebarbado nas dimensões desejadas. A figura 34(a) ilustra o processo de fabricação por laminação contínua e a figura 34(b) ilustra um produto obtido por laminação contínua.

Figura 34 - (a) Processo de fabricação de compósitos por laminação contínua. (b) Placa de fibra de vidro ondulada.
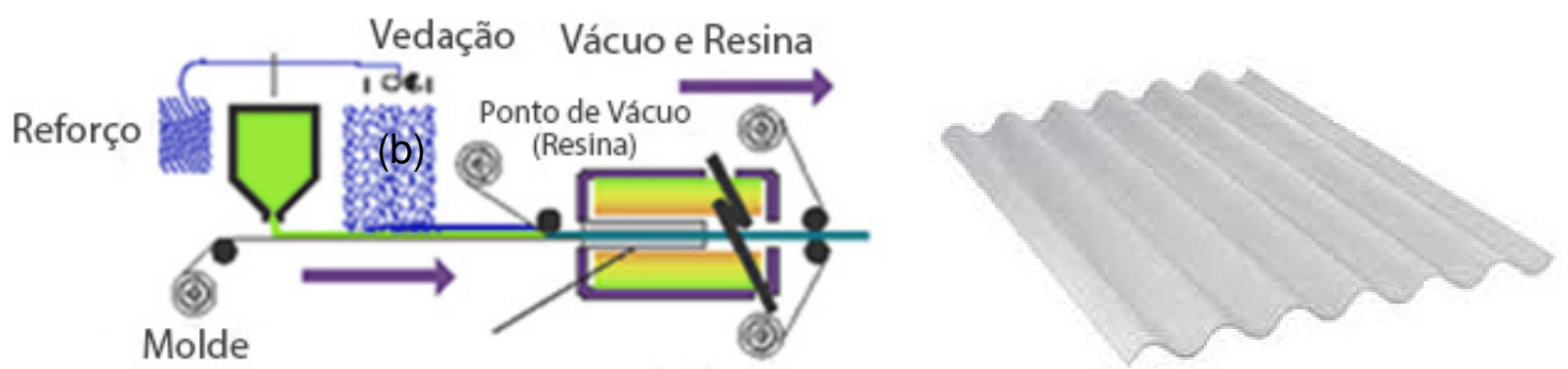

Filme Plástico

Fonte: CPIC FIBERGLASS (2012).

\subsubsection{HAND LAY UP (MOLDAGEM MANUAL)}

GUTOWSKI (1997) define este processo como o mais importante na produção aeroespacial, hand lay up de pré-impregnados e curados em autoclave. O processo é 
utilizado devido ser extremamente flexível e sua capacidade de fazer uma larga variedade de geometrias. Este processo pode incluir cerca de 50 passos para concretizar um material compósito, devido ser um processo lento, tedioso e que podem englobar uma variedade de geometrias, sua automação é difícil. Uma produção típica pode tomar cerca de $0,5 \mathrm{~kg}$ por hora para ser obtido. Devido suas limitações de tempo (lento e tedioso) o processo pode passar pelas mãos de vários operadores até a finalização, o que podem influenciar na maneira com que é feito e consequentemente em suas propriedades.

AEROSPACE COMPOSITES (2008) cita que os compósitos aeroespaciais devem suportar cargas críticas e em sua grande maioria era processado por hand lay up com pré-impregnados de matrizes termorrígidas curadas em autoclave. Neste processo, camadas de pré-impregnados são cortadas e acomodadas individualmente em um molde aberto. Dependendo do número de camadas, os cortes destas camadas podem sofrer modificação em seu tamanho em ordem de redução, isto geralmente ocorre após a quarta camada. Essa redução é necessária para evitar que bolhas ou gases da resina fiquem presos no laminado e o tornem fraco.

Neste processo, uma combinação do reforço em forma de fibras picadas, mantas ou tecidos podem ser usados como reforço. Este reforço é acomodado em um molde aberto, devidamente revestido com desmoldante. A matriz é posta no molde impregnado as fibras. Durante o processo de cura, que pode ser realizado com o auxílio de sacos de vácuo para amenizar a formação de vazios e garantir uma melhor impregnação da resina na fibra, o material compósito assume a forma do molde.

A figura 35 ilustra o processo de fabricação por Hand Lay Up.

Figura 35 - Processo de Hand Lay Up. 


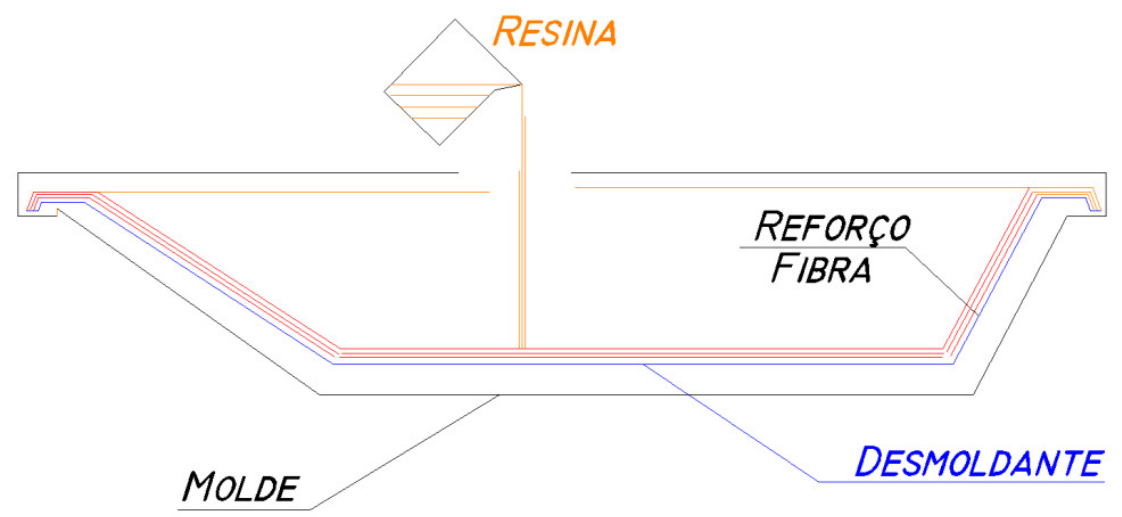

Fonte: Adaptado de NETO (2006).

\subsubsection{PROCESSO POR INJEÇÃO}

Neste processo o material termorrígido ou termoplástico é misturado com fibras picadas num sistema de rosca sem fim. Neste ponto do processo, a matriz e o reforço estão sob temperatura controlada para manter a viscosidade da matriz. Na rosca sem fim, matriz e reforço são misturados e encaminhados a uma câmara onde um pistão, sob alta pressão injeta ambos num molde ou cavidade, fechado. São mantidos neste molde até o ponto de cura. Estes moldes possuem sistema de refrigeração indireta, em geral água sob temperatura ambiente, passa por cavidades do molde, sem contato com o material injetado, fazendo uma troca de temperatura, promovendo a cura do material e a refrigeração do molde. A figura 36 ilustra o processo de fabricação por injeção com o molde e a rosca dosadora em uma injetora.

Quando o molde é aberto, o material compósito assumiu a forma das cavidades, tendo uma contração, e um pino ou punção extrator remove o produto do molde. Estes moldes antes de receberem o material injetado, recebem uma camada de material desmoldante.

Figura 36 - Processo de injeção. 


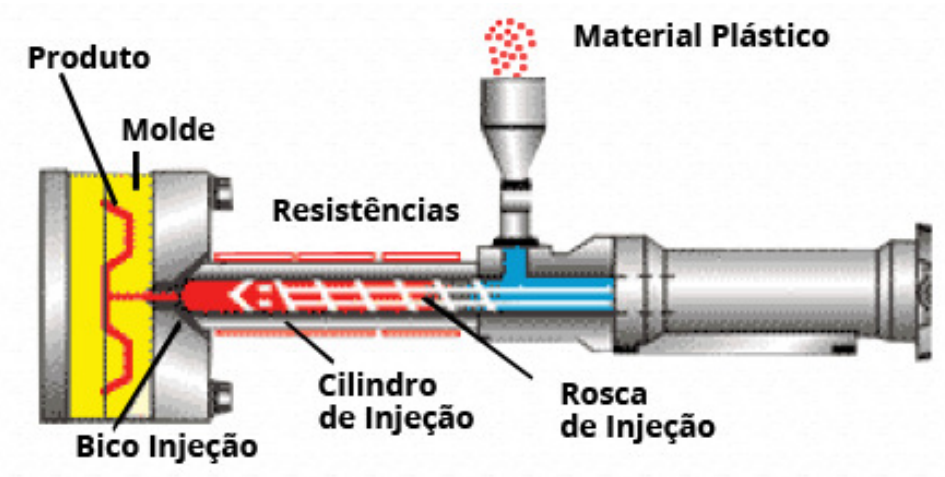

Fonte: TECPLAS (2012).

\subsubsection{REIFORCED REACTION INJECTION MOLDING - RRIM (MOLDAGEM POR MISTURA E INJEÇÃO)}

Neste processo o reforço (fibras picadas) é adicionado à resina e em seguida a resina é misturada ao catalisador e injetada na cavidade de um molde bi-partido, onde ocorre a reação, finalizando a cura dentro do molde e dando a forma final à peça em compósito como mostrado. Quando o molde é aberto à peça em seu estado final é liberada do molde.

Este processo também é conhecido por Reaction Injection Molding (RIM) onde não há introdução de reforço. Neste processo, dois componentes líquidos são injetados numa cavidade e a reação química entre estes dois líquidos resultam em um componente polimérico solidificado. Os materiais mais comuns deste método são tipicamente poliuretanos onde os dois líquidos são isocianato e poliol, ou diciclopentadiene (DCPD) onde os dois líquidos são monômeros. O isocianato (ISO) chamado de lado A é o catalizador e o poliol chamado de lado B, determina as propriedades físicas, como resistência ao impacto, densidade, módulo de flexão e cor da peça produzida. Outras propriedades podem ser obtidas ou melhoradas com a adição de aditivos ao poliol.

Quando os componentes A e B são combinados, eles reagem com a hidroxila presente no Poliol para formar um polímero poliuretano termofixo. Isto é uma reação exotérmica e exige um controle de temperatura, que é realizado através do fluxo de água refrigerando as cavidades do molde indiretamente, ou seja, através de troca de 
temperatura sem com que haja contato da água com a peça sendo manufaturada. A figura 37 ilustra o processo de fabricação por RIM.

Alguns dos materiais utilizados em RIM incluem elastômeros sólidos, espumas estruturais, os reforçados por fibras - RRIM, estruturas RIM - SRIM, Injeção de fibras longas (LFI) e DCPD. ROMEORIM (2014).

Figura 37 - Processo de fabricação por RIM.

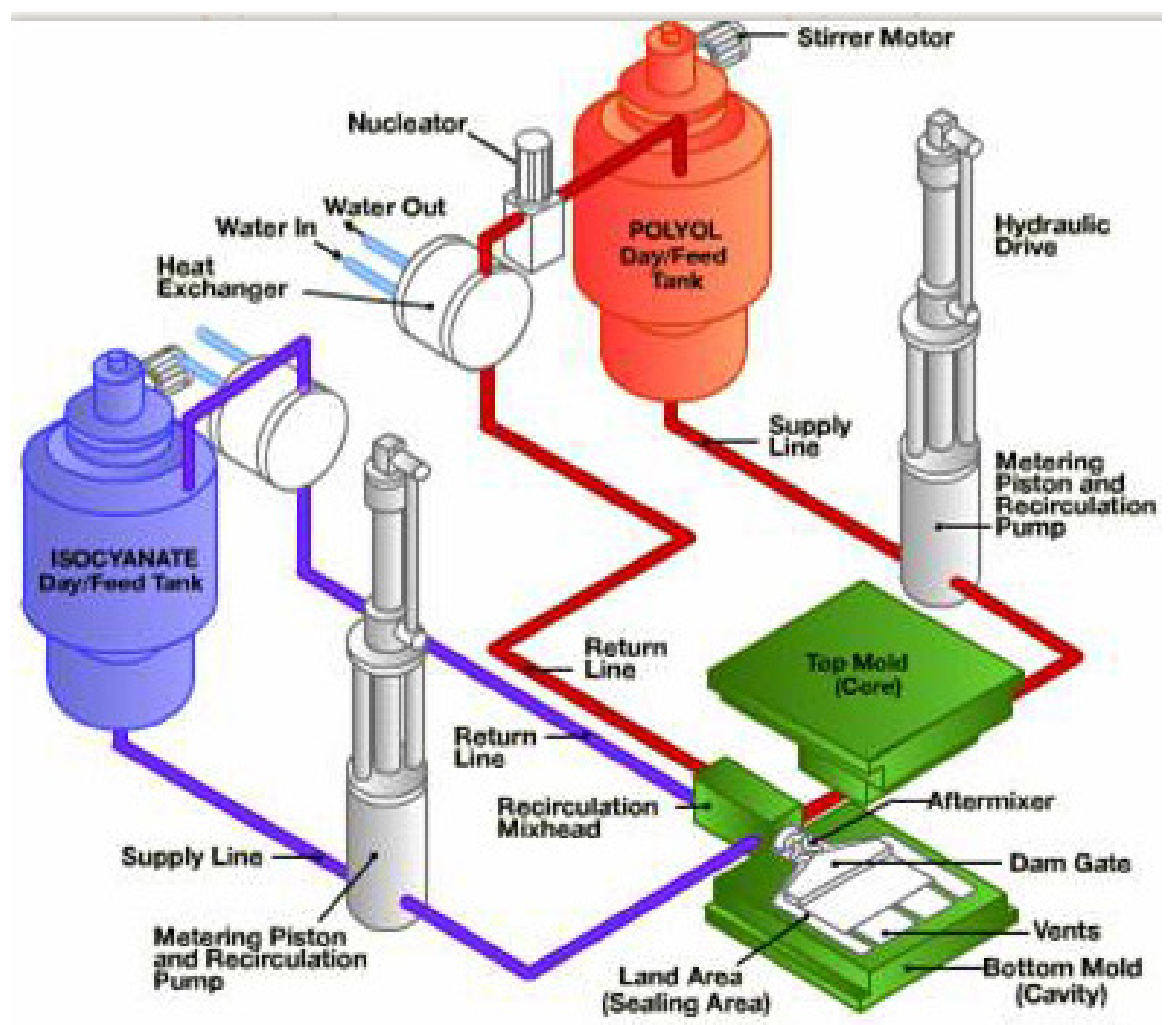

Fonte: ROMEORIM (2012).

\subsubsection{RESIN TRANSFER MOLDING (RTM)}

Este processo é parecido com o processo de injeção. Neste processo o molde deve receber uma camada de gel para melhorar a superfície da peça final. $O$ tecido (reforço) é posicionado no molde. A resina de baixa viscosidade é injetada dentro do molde sob pressão (sem bomba de vácuo no processo) ou sob baixa pressão com o auxílio de bomba de vácuo para que a resina impregne toda a peça e remova todo ar do sistema. Alguns moldes são aquecidos para facilitar o fluido da resina e após a 
cura da peça no molde o mesmo é aberto e o produto final é removido. A figura 38 ilustra o processo de RTM.

Segundo GUTOWSKI (1997), este método é um grupo de processos que injetam a resina em fibras pré-formadas dentro de uma cavidade ou molde fechado. Estes processos podem ser realizados com tecidos processados como 2D trançado e tecelagem, com ou sem costura ou 3D trançado e processado por tecelagem. Préformados trançados e não trançados também podem ser estampados. A reação da resina pode ser iniciada com calor (pelas paredes do molde) ou pela mistura de um componente reagente priorizando a injeção. O processo de RTM em cavidades fechadas resulta em melhora da estabilidade dimensional, embora para isso implique em cavidades mais sofisticadas gerando mais custo. Este processo tem se mostrado mais interessante desde que avanços na fabricação de reforços em tecidos têm apresentado uma variedade de opções para a manufatura de peças que exijam o mais complexo desempenho das fibras. A figura 38 ilustra o processo de RTM.

Pesquisas mantém o foco no problema de enchimento do molde, o qual é crítico para o sucesso do processo de RTM. O custo com ferramental para este processo é geralmente alto e ferramentas fechadas protegem as pessoas da exposição ao processo de cura da resina. Uma característica mais atrativa deste processo é a habilidade para se produzir peças complexas que podem reduzir ou eliminar a necessidade de montagem. RTM é considerado o mais apropriado na manufatura de peças de volume pequeno e médio.

No setor aeroespacial RTM tem sua aplicação específica para componentes de aeronaves. A revista AEROSPACE COMPOSITES (2008) traz uma aplicação típica, iniciando com uma peça bipartida, combinada, num molde fechado, feito de metal ou material compósito. Resina e catalisador são fundidos e misturados e bombeados para dentro do molde sob pressão moderada (menor que 100 psi/ 6.89 bar), através das portas de injeção seguindo as trajetórias pré-definidas através das fibras. Resinas de extrema baixa viscosidade são usadas em aplicações de RTM para assegurar a saturação da fibra ou o banho e minimizar os vazios ou bolhas. Ambos o molde e resina podem ser pré-aquecidos para minimizar a duração do ciclo. Embora autoclave e sacos de vácuo sejam desnecessários, peças desmoldadas destinadas a aplicações de altas temperaturas geralmente são pós-curadas em forno. Geralmente tecidos 
secos em RTM são menos custosos que pré-impregnados por não necessitar de cuidados especiais para estocar. RTM pode produzir peças com geometrias próximas ou exatamente às que serão utilizadas como componente final dispensando o processo de usinagem. Também rendem uma boa estabilidade dimensional e acabamento superficial, ao contrário de molde aberto que proporciona acabamento liso em toda a superfície exposta. RTM também pode ser automatizado para produção em maior escala. O componente manufaturado por RTM pode sofrer influência na qualidade final em função da viscosidade da resina, temperatura, pressão, projeto do pré-formado, o número e posição dos furos de saída e entrada de resinas e ar, material do molde e força de travamento ou sujeição.

Figura 38 - Processo de RTM.
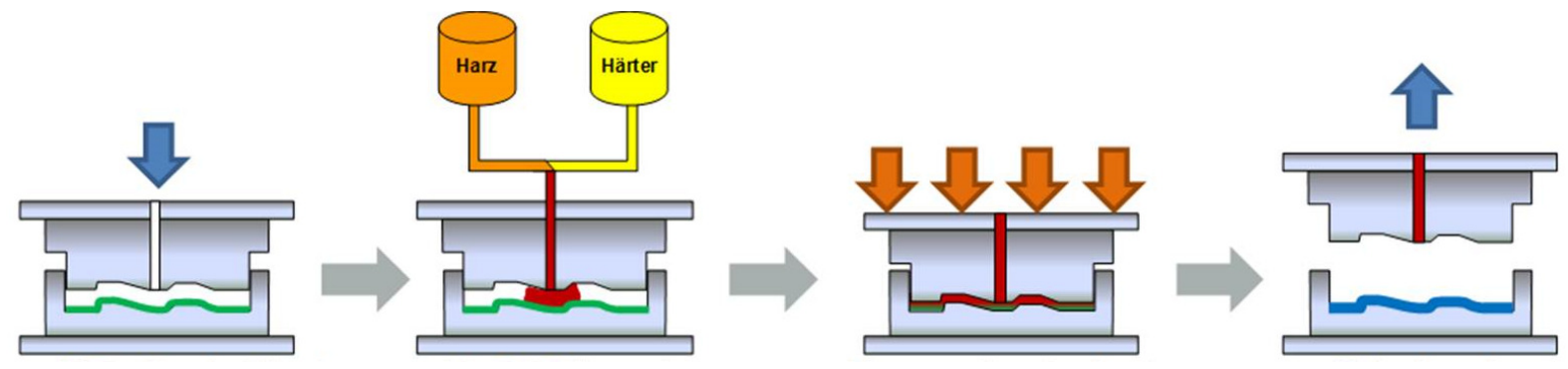

Fonte: FRAUNHOFER (2012).

\subsubsection{SPRAY UP}

Este processo é similar e muita vez combina-se com a modelagem manual. No Spray Up a fibra em forma fios contínua Roving é alimentada para uma pistola com um picador, que corta o fio com determinado tamanho. As fibras são lançadas com um jato de resina catalisada contra um molde aberto, este processo é ilustrado na figura 39. Este molde deve ter sua superfície polida para facilitar a remoção e melhorar o acabamento superficial do produto final. Além da superfície polida, desmoldantes como cera de carnaúba, são passados no molde antes da impregnação para facilitar a remoção do produto. Após a impregnação, matriz e reforço são uniformizados por roletes manualmente. A espessura da camada é realizada manualmente e os roletes ajudam a uniformizar a espessura da camada ao longo da superfície. 
Para peças de grande espessura, recomenda-se passar o rolete alternado entre as camadas para se uniformizara a superfície. As camadas onde os roletes serão passados devem ser definidas em uma estratégia. No boletim técnico da Fiber Center ver. 06.13 recomenda que a cada $4 \mathrm{~mm}$ de espessura sejam passados os roletes nestas camadas, este processo de passar os roletes serve para uniformizar a superfície, remover bolhas ou vazios e conformar o compósito à superfície. Ainda é recomendável que esta operação de passar roletes seja executada a partir do centro da peça para as bordas.

A cura destas peças pode ser realizada em temperatura ambiente ou em estufas. Os custos deste método são baixos comparados aos métodos de laminação manual e RTM onde o ferramental para execução do método encarece o processo.

Figura 39 - Processo de Spray Up.

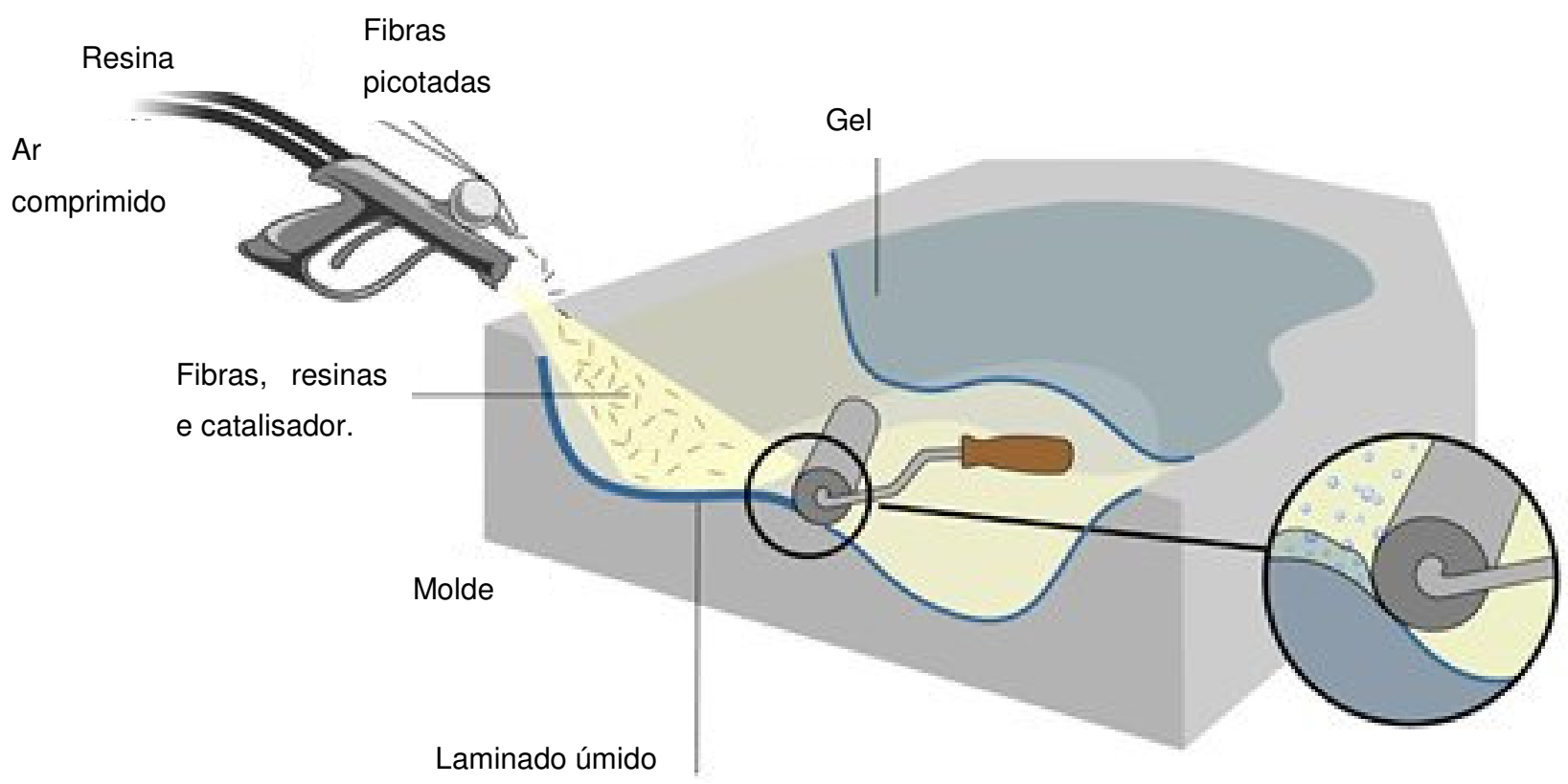

Fonte: Nuplex (2012).

\subsubsection{PREPREG (PRÉ-IMPREGNADOS)}

Trata-se de uma forma intermediária de compósito onde o reforço está impregnado pela resina, mas esta ainda não está curada. As placas de Prepregs são envoltas em filme plástico, e acondicionadas sob-refrigeração para assegurar sua durabilidade (shelf life), uma vez que a cura da resina necessita de calor. 
Peças feitas com prepreg podem ser feitas em moldes abertos ou fechados. Assim como nos métodos anteriores, a superfície do molde necessita ser de baixa rugosidade (preferencialmente polidas) e impregnadas com desmoldante para facilitar a remoção. A cura ocorre com a introdução de calor que pode ser do aquecimento do molde ou em estufa ou autoclaves.

Na fabricação de prepreg, uma lâmina de reforço (Fibras de carbono, vidro, etc.) é mergulhada em um banho contendo resina não acelerada (catalisada), sendo em seguida pressionado por dois rolos, recoberta por um filme plástico, cortado na medida desejada e armazenado sob-refrigeração.

Os pré-impregnados, ou prepreg, são definidos como fibras contínuas de reforço impregnadas com matriz polimérica, que no caso dos polímeros termorrígidos está parcialmente curada e no caso dos polímeros termoplásticos, solidificada. $\mathrm{O}$ material pré-impregnado é um produto intermediário, pronto para a moldagem e é recebido pelas indústrias de compósitos na forma de tecido ou tape (com fibra unidirecional), e durante a fabricação de peças em compósito, é realizada a colocação do prepreg diretamente no molde, e subsequente consolidação sem a necessidade da adição de resina durante o processamento. CALLISTER. ( 2008). 
Figura 40 - Processo de produção de Prepreg.

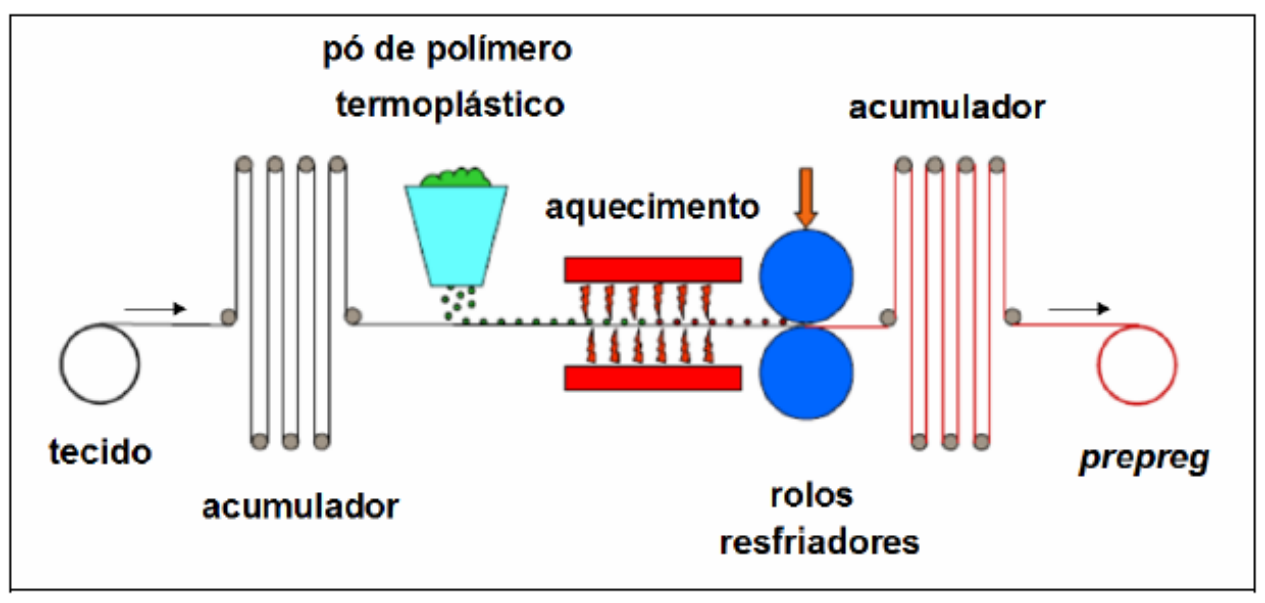

Fonte: SANTANA (2010).

\subsubsection{PREFORMS}

Os reforços por fibras podem ser encontrados de várias formas, carretel, picados, tecidos, etc. Um tipo comum é o tecido seco, ao contrário do prepreg, não vem com resina impregnada. As tramas destes tecidos são fabricadas em várias direções entre $0^{\circ}, 45^{\circ} \mathrm{e} 90^{\circ}$, bidirecionais $\left(0^{\circ} \mathrm{e} 90^{\circ}\right)$, para oferecer uma boa resistência em várias direções. As tramas também são entrelaçadas de maneira estratégica de modo a favorecer a resistência do tecido.

A resistência à tração nestes tecidos, entretanto, é comprometida em algum grau devido as fibras estarem cravadas umas sobre as outras durante o processo de tecelagem. Sobtensão de carregamento, estas fibras tendem a endireitar, causando tensão ao sistema da matriz. AEROSPACE COMPOSITES (2008).

Preforms é uma espécie de rede de reforço designado para peças particulares pelo empilhamento e conformação de camadas de tecidos unidirecional, bidirecional, multidirecional em um molde. Podem ser utilizados em processos RTM para a fabricação de peças complexas, com um grande número de camadas variando o tamanho e orientação das fibras. AEROSPACE COMPOSITES (2008).

Os pré-formados destinam-se na sua grande maioria ao processo final de fabricação de peças RTM. 


\subsubsection{BULK MOLDING COMPOUND (BMC)}

Trata-se de uma mistura de fios de fibras (reforço), resinas, catalisadores, cargas, pigmentos e aditivos específicos a cada aplicação. Esse material prémisturado tem a consistência de uma argila de modelagem, podendo ser injetado na cavidade de moldes ou colocado na base de moldes bipartidos e prensados para adquirir a forma final. A figura 41 (a) ilustra o processo de confecção de BMC e a figura 41 (b) ilustra o produto final obtido pelo processo de BMC.

Figura 41 - (a) Processo de manufatura de BMC. (b) Produto BMC.

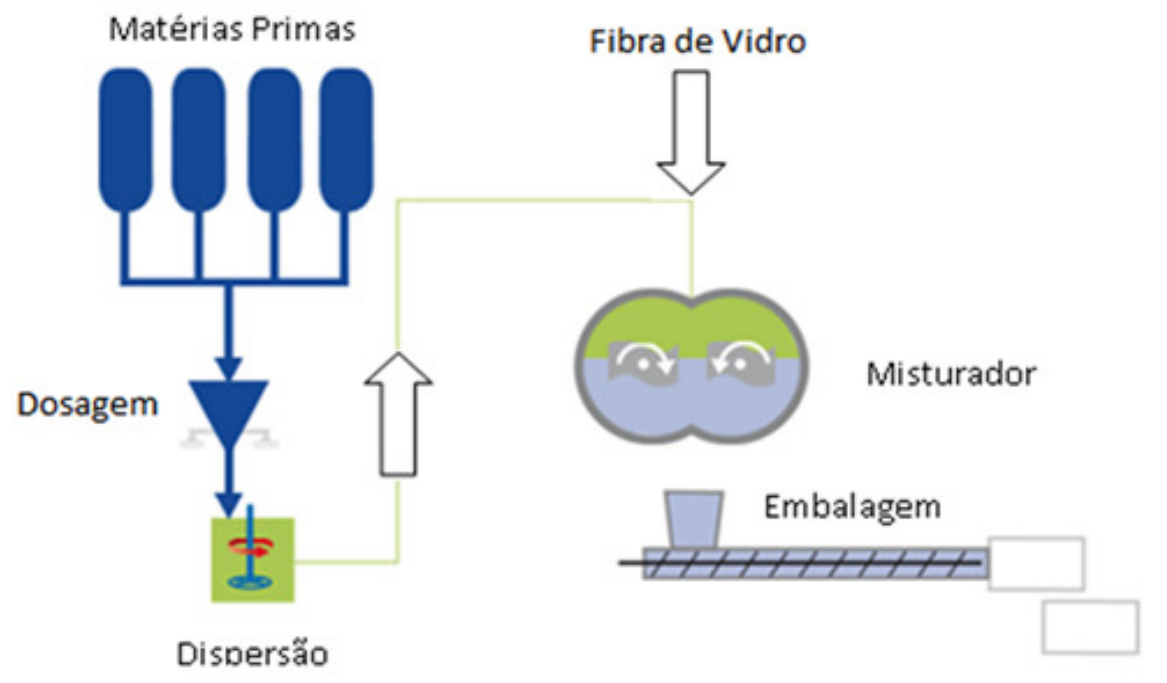




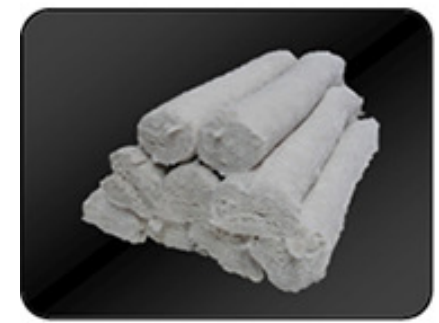

BMC “Extrudado"

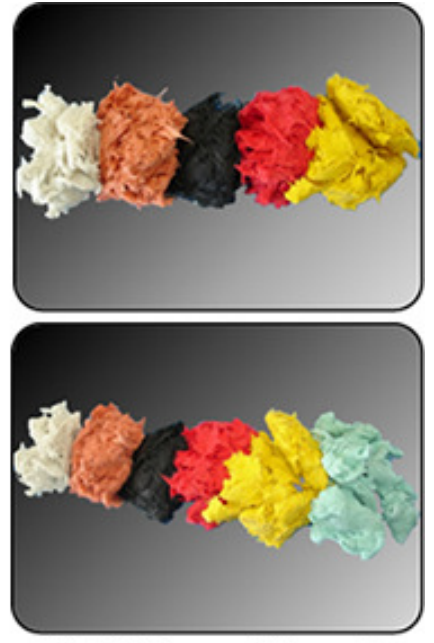

BMC “Forma Fibrosa”

Fonte: FBMIX (2012).

\subsubsection{SHEET MOLDING COMPOUND (SMC)}

Fios de fibras (reforço) são depositados sobre uma camada de massa, composta basicamente por resinas, catalisadores, cargas e aditivos específicos a cada aplicação. Em seguida outra camada de massa de resina é adicionada formando uma espécie de sanduíche. Só então essa mistura de resina e reforço será prensada em rolos laminadores, envolta em filme plástico para armazenagem. A figura 42 ilustra ao processo de fabricação de SMC. Durante o armazenamento a resina entra em processo de pré-cura, ou seja, adquire uma consistência similar ao couro, quando então está pronto para o uso.

Nesse estágio o material é cortado em tamanhos adequados e transformado na peça final pelo processo de compressão (RTM). 
Figura 42 - Processo de SMC.

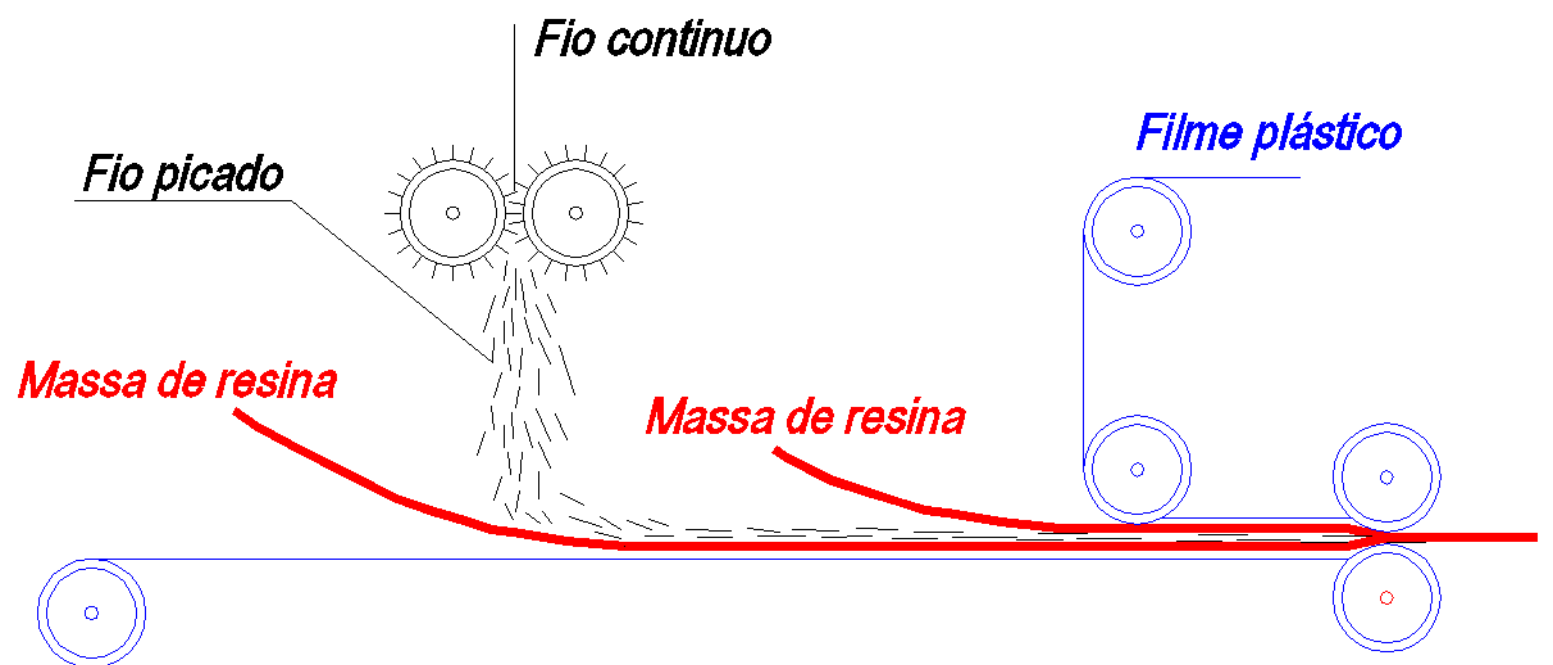

Fonte: Adaptado de NETO (2006).

\subsubsection{PULTRUSÃO}

Segundo GUTOWSKI (1997), o processo de pultrusão envolve puxar a fibra através de uma estação umedecida e conduzi-la a uma matriz aquecida onde a resina é curada. Após a cura a peça é cortada no comprimento desejado. Pultrusão é o processo mais apropriado para a confecção de peças de perfil constante, tais como trilhos para escada, seção de estruturas e membros estruturais. Peças de perfis com seção variável também podem ser manufaturados pelo processo de tracionar e moldar. O processo de pultrusão é relativamente produtivo e está entre os processos de menor custo em compósitos. Cuidados com a orientação das fibras e evitar o movimento das mesmas durante o processo são importantes. Ambas as resinas termoplásticas e termorrígidas podem ser utilizadas, embora maiores experiências tenham ocorrido com resinas termorrígidas da família poliéster. Em peças de elevado comprimento, problemas com linearidade e empenamento podem ocorrer, especialmente em peças de comprimentos longos e seções esbeltas. A figura 43 ilustra o processo de manufatura por pultrusão.

Pultrusão é um processo contínuo que produz perfis reforçados ocos ou maciços, de diferentes formatos. Dependendo do formato do perfil, a taxa de 
participação do reforço (Fibra de Vidro; Aramida, Naturais, Carbono etc.) pode variar de $30 \%$ a $70 \%$.

Os reforços são baseados principalmente nas fibras contínuas, os chamados Rovings, dispostos de maneira a proporcionar um reforço longitudinal, o qual é responsável pela resistência às tensões de tração e flexão. Além do reforço longitudinal o perfil também recebe uma manta de filamento contínuo responsável por suportar os esforços transversais.

Dando acabamento ao manufaturado, tem-se ainda uma camada externa rica em resina resistente à corrosão em ambientes severos, barreira contra exposição contínua a raios ultravioletas. As resinas (matrizes) podem ser de material termofixo ou termorrígido (poliéster, estervinilica, epóxi etc.) ou ainda resinas Termoplásticas (policetal, nylon, policarbonato, polipropileno, etc.).

O perfil obtido pela pultrusão caracteriza-se, por ser uma peça com um grande comprimento se comparado com sua seção transversal, podendo ser cortado no tamanho desejado após sua fabricação.

GUTOWSKI (1997) afirma que o processo de pultrusão ode ser considerado como uma combinação de procedimentos automatizados por pré-formados, impregnação dos pré-formados com resina e cura do pré-formado em um sólido aminado. Estes três processos são integrados e acontecem de forma contínua.

Figura 43 - Processo de pultrusão.

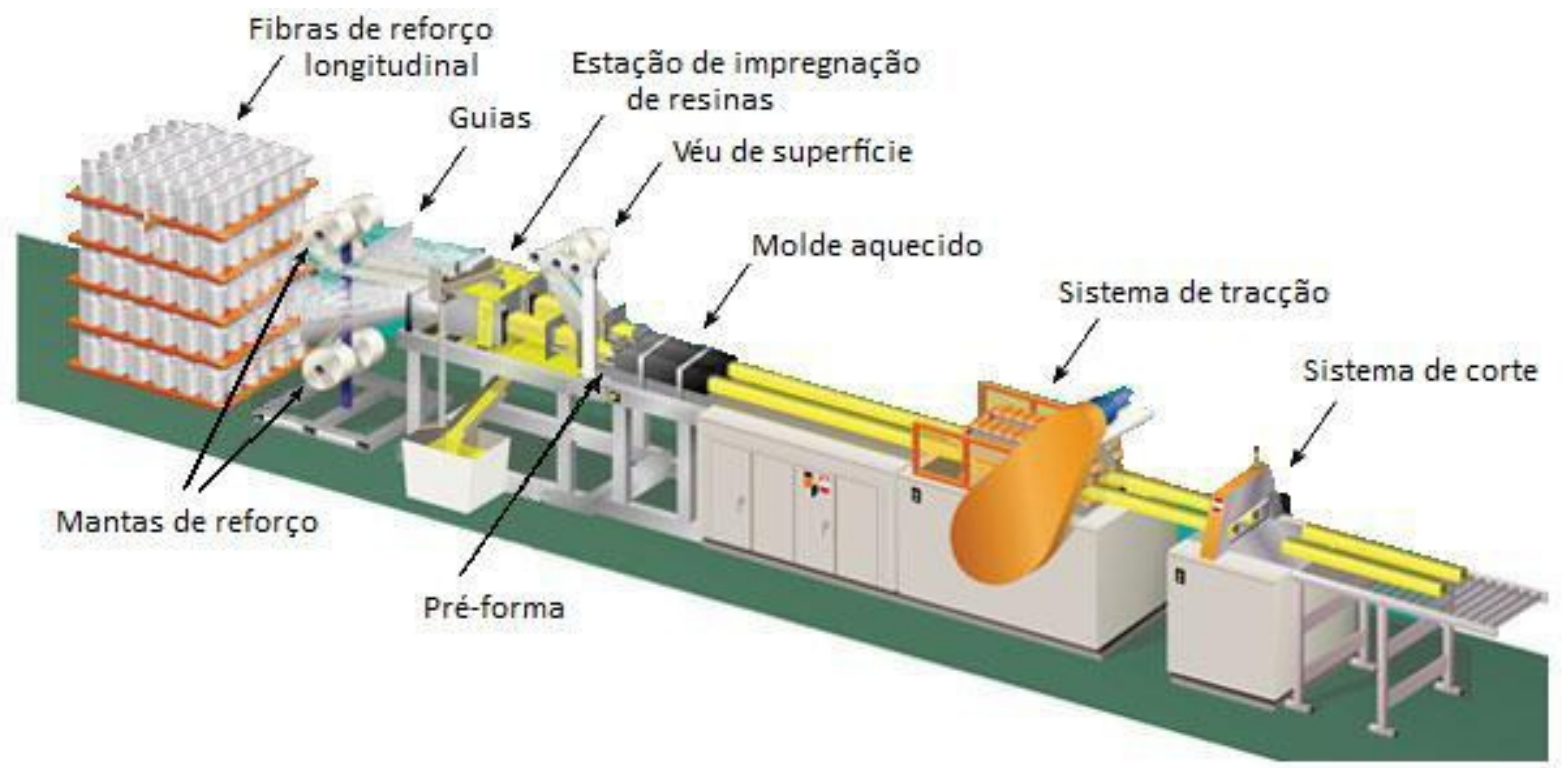




\subsection{FILAMENT WINDING}

De uma maneira geral, Filament Winding, enrolamento filamentar ou bobinamento filamentar, é um processo no qual a fibra é depositada em um mandril em revolução, seguindo uma trajetória previamente determinada juntamente com o mandril em rotação estabelecida, tendo as fibras tensão determinada, podendo ser estas secas ou umedecidas com resina (matriz). Muitos autores tem sua definição para este processo.

ABDALLA (2005) Filament winding emergiu como um processo primário para fabricação de estruturas cilíndricas de compósitos de baixo custo. Neste processo camadas de compósitos são enroladas em um mandril em rotação. A construção de um cilindro de material compósito reforçado por fibra consiste de três passos básicos. O primeiro passo é o projeto, onde abrange a seleção de materiais, geometria e orientação das fibras. O segundo passo é a deposição das fibras nas camadas, os meios mecânicos nos quais as fibras serão enroladas no mandril. $O$ terceiro passo é o controle do processo.

PETER (2011) Entre os anos de 1940 a 1980 as primeiras máquinas de Filament Winding não eram automatizadas, nem tinham aparato eletrônico para auxiliar no enrolamento. $O$ processo era controlado por caixas de engrenagens calculadas para desempenhar os ângulos de enrolamentos pré-determinados. Para cada ângulo de enrolamento o operador tinha de ajustar a caixa de engrenagens. $\mathrm{Na}$ era da computação, a empresa Entec foi uma das pioneiras a fabricar máquina de Filament Winding com integração computacional, software que para geração e controle de enrolamento em diferentes padrões de enrolamento. Além destas limitações enfrentadas neste período, peças de grande porte eram difíceis de serem manipuladas, montagem e desmontagem do produto no mandril e a montagem e a desmontagem do mandril na máquina eram feitos através de empilhadeiras ou pontes rolantes. A cura destas peças também eram difícil, eram realizadas em partes. Isto limitava o volume de produção. Filament winding foi ganhando espaço na indústria de óleo e gás na fabricação de tubos, isso contribuiu para o avanço na tecnologia de fabricação, especialmente em mandris que eram difíceis e de demorada extração, 
novos conceitos e extratores foram desenvolvidos para reduzir o tempo de extração do produto no mandril. A indústria de materiais esportivos também contribuiu para 0 avanço da tecnologia com a demanda por grande volume de produção de peças de pequeno porte. Por este tempo Filament Winding inovou com mais de um eixo para produção em uma mesma máquina como se pode observar na figura 44 .

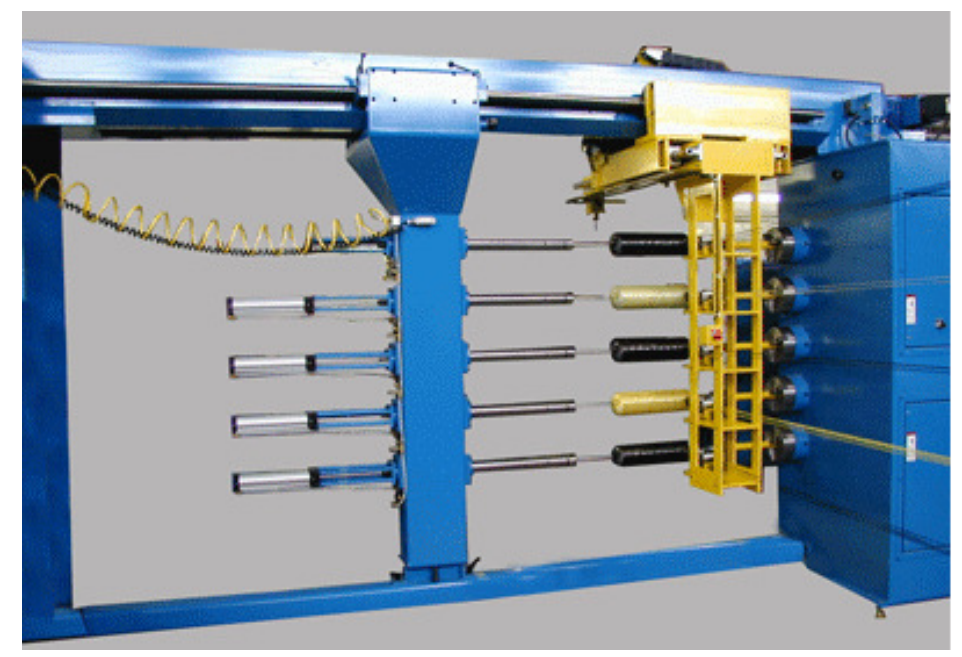

Fonte: ENTEC (2012).

Figura 44 - Máquina de filament winding 4 eixos.

No final de 1990, a demanda por tanques de propano (vasos de pressão) de baixo peso e alta resistência mecânica, contribuiu para a fabricação por processos automatizados que reduzissem custos e tempo de produção. Os fornos de cura também sofreram mudanças, fornos para cura através de vapor, líquido, alimentados por óleo, eletricidade, etc. Fornos para muitas peças juntas até fornos de cura em linha onde o produto entra por uma extremidade e é conduzido por compartimentos até a saída em outra extremidade do forno onde já se encontra curada.

SCHOLLIERS (1992) define o processo de filament winding como o processo de fabricação de compósitos estruturais reforçados por fibras, no qual o reforço contínuo impregnado com resina é esticado sob uma tensão controlada, através de um olho guia ao longo de um mandril em rotação e removível com trajetórias previamente determinadas como pode ser visto na figura 45. A tensão nas fibras 
fornece a pressão, necessária para compactar o laminado. A peça é curada depois que mandril e enrolamento são removidos.

Figura 45 - Desenho esquemático do filament winding.

\section{COMPACTAÇÃO}

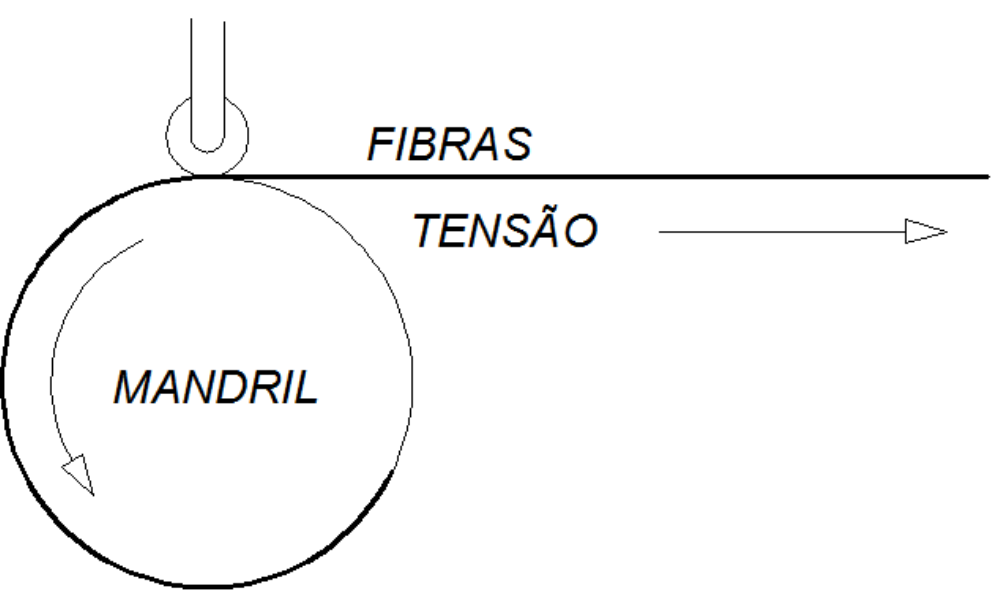

Adaptado de SCHOLLIERS (1992).

Fonte:

GUTOWSKY (1997) define que Filament Winding envolve o enrolamento (normalmente úmido) de fibras agrupadas sobre um mandril em rotação, ilustrado na figura 46. Muitas variações são utilizadas neste processo, tais como umedecimento da fibra durante o enrolamento, enrolamento pré-impregnado e enrolamento de termoplásticos com uma apropriada fonte de calor. Devido às fibras agrupadas serem tensionadas, deve seguir uma trajetória geodésica. Isto limita a orientação das fibras dispostas no processo. Por exemplo, o enrolamento circunferencial em um cone pode deslizar devido à curvatura geodésica desta trajetória. 
Figura 46 - Processo de filament winding.

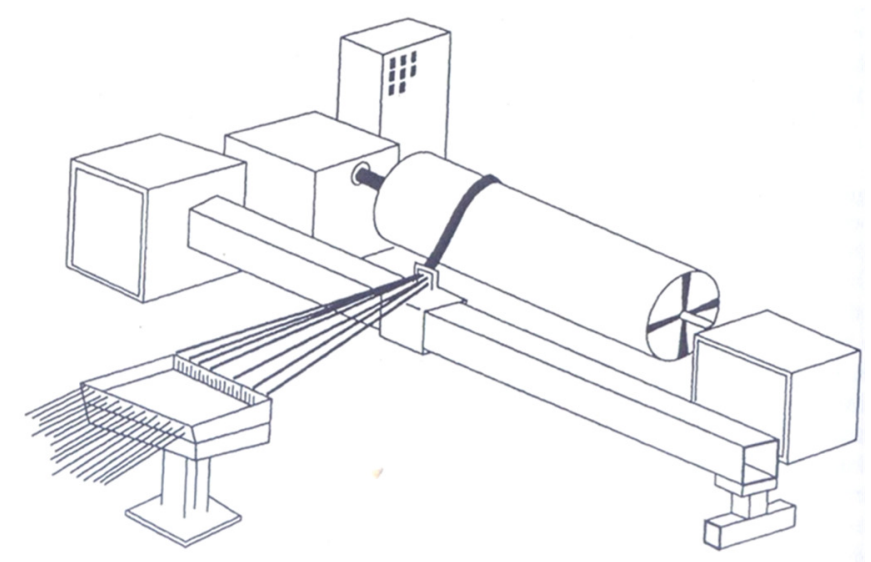

Fonte: GUTOWSKI (1997).

CARVALHO (1996) define o processo de filament winding como o processo de fabricação de compósitos estruturais reforçados por fibras, no qual o reforço contínuo impregnado com resina é esticado sob uma tensão controlada, através de um olho guia ao longo de um mandril em rotação e removível com trajetórias previamente determinadas, podendo a matriz ou resina, ser depositada nas fibras antes, durante ou depois do processo de filament winding.

Figura 47 - Dispositivos do processo de filament winding.

Deslocamento

transversal

mandril

banho de resina

carretel tensionador 


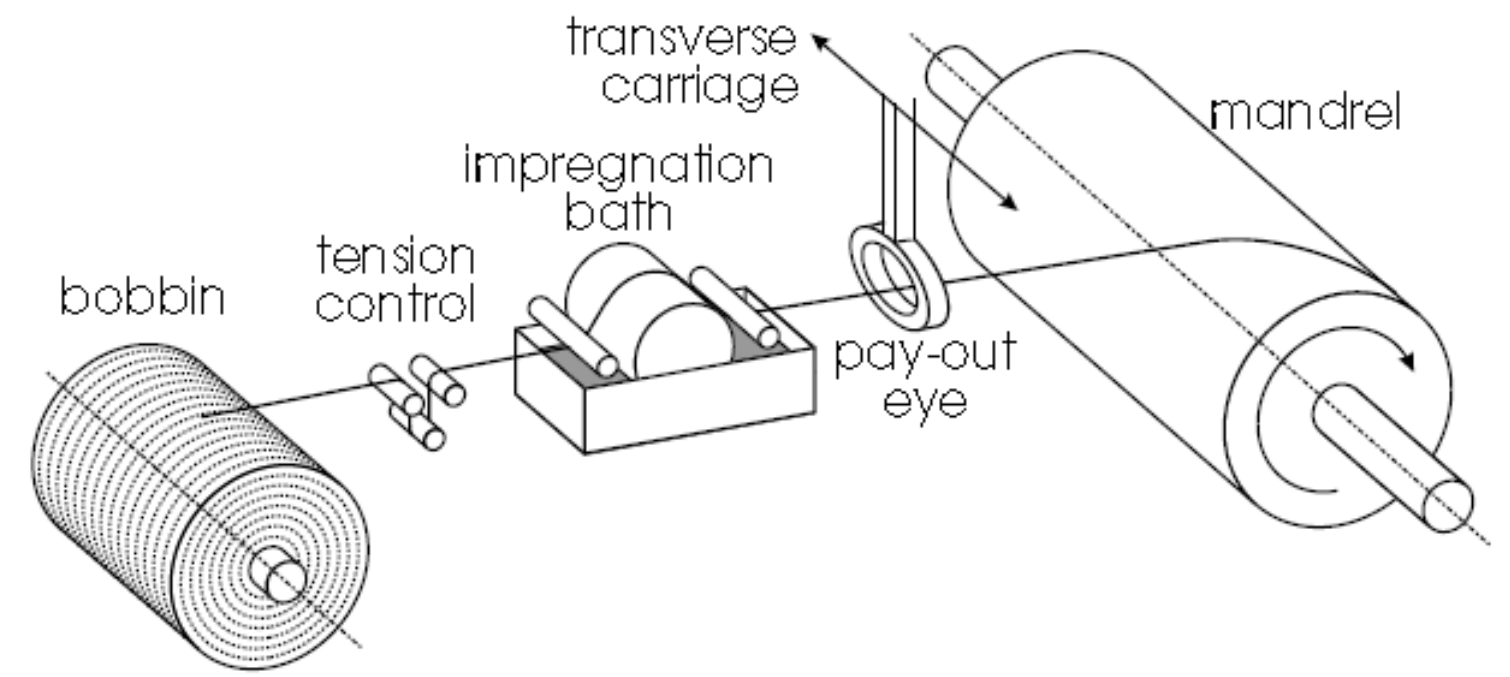

Fonte: CARVALHO (1996).

Segundo SILVA (2005), o processo de Filament Winding envolve a deposição de fibras em um mandril em rotação, sendo estas fibras fornecidas em carretéis, antes de chegarem ao mandril elas sofrem tensão para manter as mesmas esticadas no processo, são umedecidas em resina num dispositivo com resistência para melhorar a viscosidade da resina, dispositivo este chamado de Molhador, e são guiadas pelo olho guia no mandril, este sistema é ilustrado na figura 48. Estes movimentos de rotação e deslocamento do olho ao longo do comprimento do mandril são calculados e determinados por programas específicos que calculam estas trajetórias.

Segundo GUTOWSKY (1997), embora o processo de Filament Winding seja um processo mais apropriado para peças cilíndricas simétricas, é possível aplicar este processo em peças não simétricas ou conhecidas como irregulares. Algumas peças não simétricas que podem ser enroladas, como exemplo, vigas, cascos de navios e aerofólios. Entretanto estas peças requerem procedimentos especiais, assim como peças cônicas. Estes casos podem resultar em peças de espessuras diferentes ao longo do sua estrutura. Remover peças prontas do mandril também é uma atividade problemática que envolve soluções criativas, por exemplo, mandris quebradiços, solúveis e desmontáveis. As peças são normalmente curadas em fornos e resulta em peças com relativamente alto índices de vazios ou bolhas, cerca de $3 \%$ e um 
acabamento superficial insatisfatório. Estes problemas podem ser resolvidos utilizando sacos ou embrulhos de contração ou pressurização durante a cura.

Figura 48 - Dispositivo de impregnação de resina (matriz) nas fibras durante o processo de filament winding.

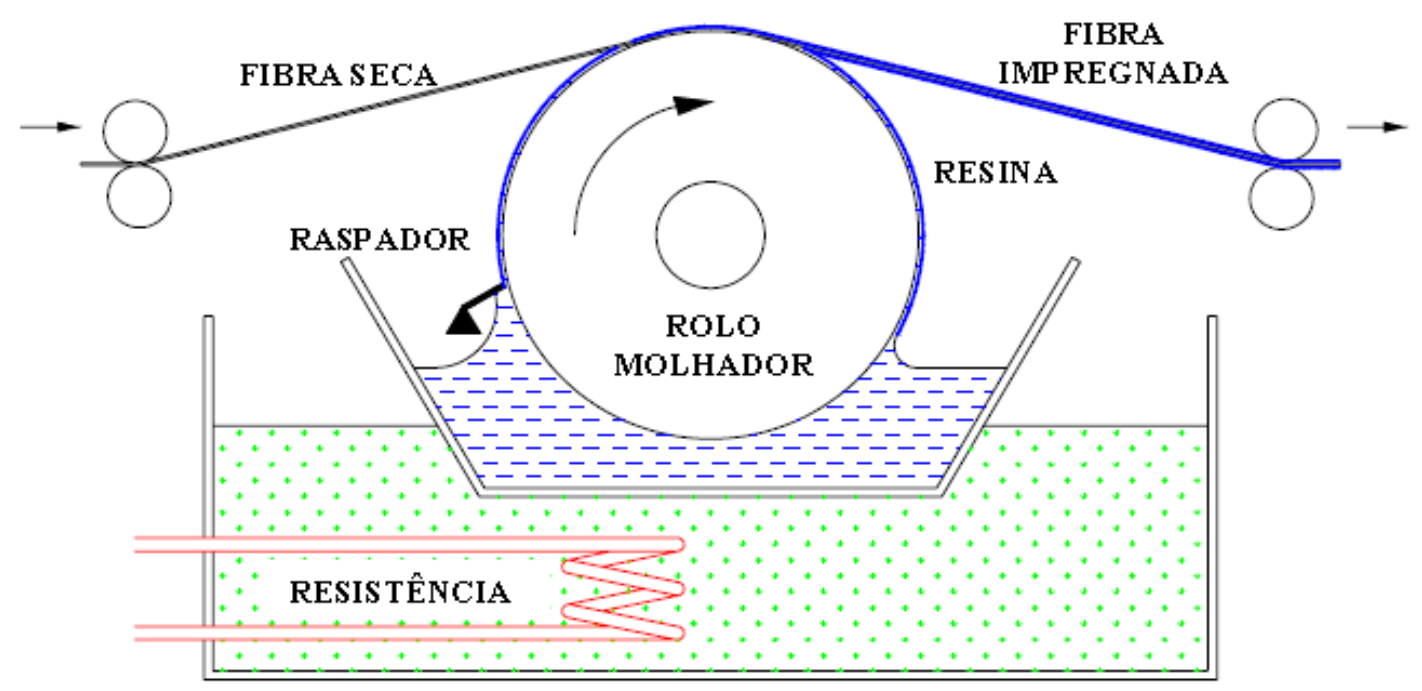

Fonte: SILVA (2005).

$\mathrm{Na}$ revista AEROSPACE COMPOSITES o processo de Filament Winding é um processo automatizado de alta repetibilidade, baixo custo e apropriado para a produção de ambas as estruturas tubulares abertas e fechadas com seção constante, tais como invólucro de foguetes e vasos de pressão. 
Segundo GUTOWSKY (1997) o processo de Filament Winding consiste de três etapas principais: (1) o projeto, inclui a seleção de materiais, geometria e orientação das fibras, (2) posicionamento da fibra, o meio mecânico pelo qual a fibra será acomodada no mandril na devida posição e (3) seleção e controle das condições que serão mantidas durante o processo de manufatura. As principais variáveis a serem controladas neste processo são a temperatura, tensão da fibra e velocidade do revestimento. A temperatura do processo pode ser realizada na temperatura ambiente, abaixo ou acima, mas o processo de cura envolve calor e pode ser realizado no próprio mandril inserido em um forno ou autoclave. Para um determinado conjunto dessas variáveis de processo (para determinada velocidade de enrolamento, a tensão da fibra e histórico de temperatura) o modelo de processo fornece as seguintes informações como função da posição e do tempo:

- Temperatura dentro do compósito e do mandril

- Grau de cura dentro do compósito

- Viscosidade dentro do compósito

- Posição das fibras

- Tensão e deformação dentro do compósito e do mandril

- Porosidade dentro do compósito

- Enrolamento e tempo de cura

CARVALHO (1996) define algumas vantagens e desvantagens no processo de Filament Winding. As vantagens são:

- Alto grau de repetibilidade e precisão na deposição da fibra no mandril (de camada para camada e peça para peça).

- A capabilidade, embora limitada, de depositar reforço com fibras contínuas nas direções apropriadas.

- O alto grau de automação que pode ser obtido, levando a um baixo custo de manufatura e larga taxa de produção.

- Baixo custo relativo de material desde que fibra e resina possam ser usadas no estado bruto como pré-impregnados. 
As desvantagens inerentes ao processo de Filament Winding são:

- Necessidade de um mandril, cuja fabricação pode ser difícil e cara. A geometria do mandril deve favorecer a remoção depois do processo na maioria das aplicações.

- Dificuldade de enrolamento em peças côncavas devido a problemas com a perda de contato entre fibra e mandril.

- Limitação no projeto da trajetória das fibras, onde problemas de deslizamento podem limitar severamente a liberdade para posicionar as fibras na direção apropriada. Também a dificuldade para mudar a direção da fibra ao longo da mesma peça torna difícil o enrolamento de peças assimétricas.

- Baixa qualidade da superfície externa.

Outras vantagens que podem ser levadas em consideração no processo de Filament Winding é o fato de poder alternar o ângulo da fibra em relação ao eixo do mandril entre as camadas ou ao longo do corpo, definir estratégias de início de enrolamento, ilustrado na figura 49 e por ser um processo relativamente simples. Outras desvantagens podem ser listadas como a dificuldade do controle de tensão da fibra e do banho de resina nas fibras e as extremidades do mandril sempre terão uma espessura excessiva de material.

Figura 49 - Estratégia de enrolamento.

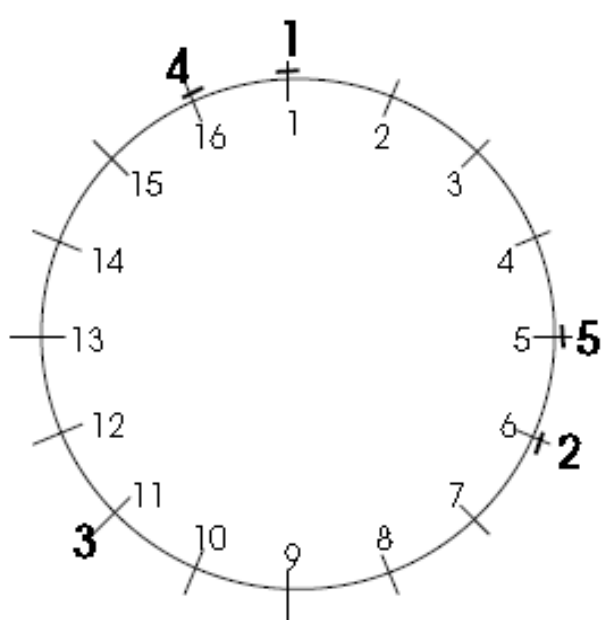

Fonte: CARVALHO (1996). 


\subsubsection{ESTRATÉGIAS DE ENROLAMENTO}

O processo de Filament Winding em geral adota três estratégias para revestimento do mandril. A seleção de um ou mais padrões pode ser usado em uma mesma peça respeitando as limitações da máquina, geometria do mandril e enrolamento desejado.

As trajetórias individuais das fibras devem ser combinadas de tal maneira que todo o mandril seja revestido. Uma série de duas consecutivas trajetórias é chamada winding circuit (circuito de enrolamento): O primeiro trajeto da fibra atravessa o mandril através de uma extremidade inicial até a extremidade oposta, o segundo trajeto atravessa o mandril da extremidade oposta até a extremidade inicial. $O$ segundo circuito é similar ao primeiro, mas deslocado ao longo da circunferência do mandril. A sequência do tempo de deposição da fibra em uma seção transversal do mandril é chamada de sequência de enrolamento (winding sequence) e é denotado como a razão de dois inteiros: $\frac{m}{n}$ (m e $\mathrm{n}$ não podem ter um divisor comum). SCHOLIERS (1992). Esta sequencia é ilustrada na figura 50.

Existem duas abordagens, dependendo ou não a largura de banda é levada em conta. A primeira considera a largura da fita $\frac{m_{1}}{n_{1}}$. O denominador é igual a $n_{p}$ o número global de caminhos de fibra ao longo da circunferência. O segundo circuito é deslocado ao longo de uma fracção de $\frac{m_{1}}{n_{1}}$ da circunferência com respeito ao primeiro circuito.

Figura 50 - Sequencia de enrolamento.

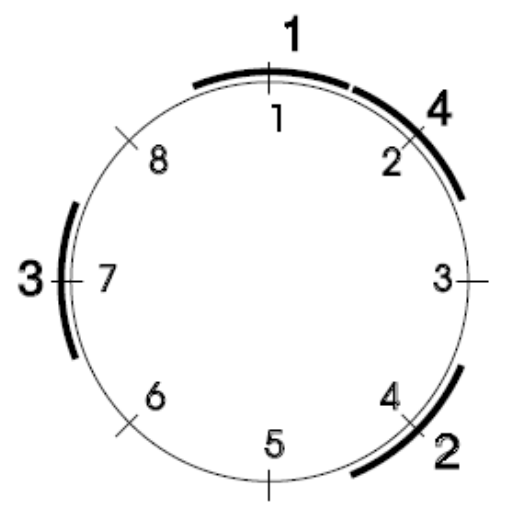


Fonte: SCHOLIERS (1992).

\section{REVESTIMENTO POLAR (POLAR WINDING)}

Neste caso a trajetória das fibras vai ao longo de um plano tangencial para ambos os polos abertos do mandril. O mandril avança uma largura da banda da fita para cada novo ciclo, resultando em um enrolamento onde cada fita é posta adjacente a anterior. A figura 50 (a) ilustra este tipo de enrolamento. A principal vantagem deste método é a simplicidade e a possibilidade de manter a velocidade regular. Fornece um método ideal de alta velocidade para fabricação de formatos esféricos.

\section{REVESTIMENTO HELICOIDAL (HELICAL WINDING)}

A rotação do mandril e a alimentação da fibra são sincronizadas na direção em que o ângulo desejado está sendo gerado. Como resultado, os diferentes ciclos de enrolamento não são adjacentes, resultando em um enrolamento caracterizado por fibras que transpõe umas às outras ao longo do mandril. Apesar da sua complexidade ligeiramente maior, é mais versátil que o enrolamento polar, devido à combinação de diâmetros (entre camadas), comprimento e ângulos que podem ser enrolados. A figura 50 (b) ilustra este tipo de enrolamento. O conceito deste método pode ser estendido a enrolamentos não geodésicos utilizando o conceito de não deslizamento das fibras. Entretanto algoritmo especial para determinar uma sequencia adequada, são necessários se peças mais complexas são enroladas.

\section{RESVESTIMENTO TIPO ARO (HOOP WINDING)}

Revestimento tipo aro ou circunferencial é basicamente um revestimento helicoidal com ângulo próximo a $90^{\circ}$, isto é, as fibras são acomodadas quase que perpendicularmente ao eixo do enrolamento. A figura 50 (c) ilustra este tipo de enrolamento. A cobertura do mandril é realizada no sincronismo com a alimentação da fibra, o deslocamento na direção do eixo de enrolamento ocorre à largura da fita a cada volta do mandril, ou seja, o passo da hélice é a largura da fita. 
Figura 51- Fstratégias de enrolamento.

(a)

(b)

(c)

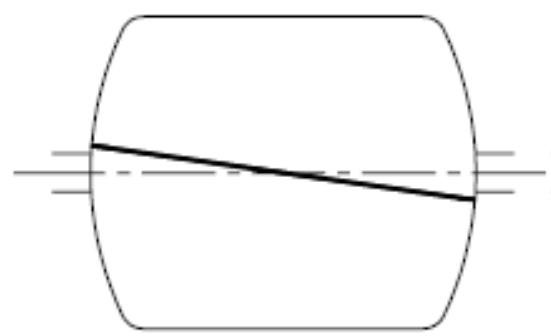

REVESTIMEHTO POLAR

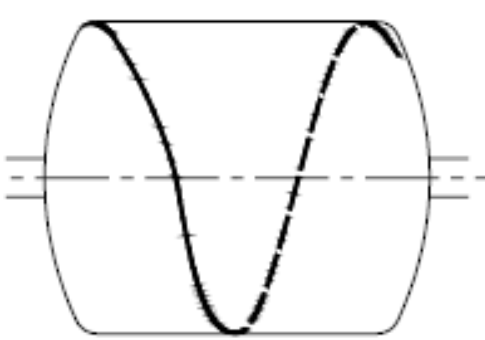

REVESTIMENTO HELICOIDAL

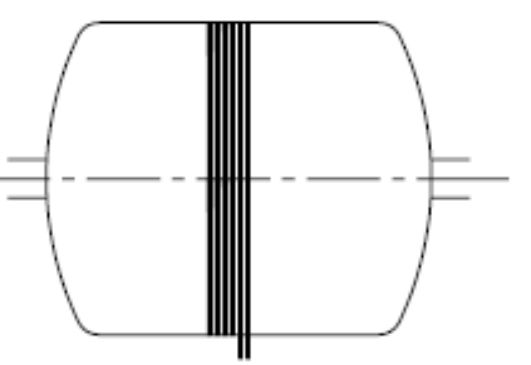

REVESTIMEHTO CIRCULAR

Fonte: Adaptado de CARVALHO (1996) e SILVA (2005).

ROUSSEAU (1998) a estratégia de enrolamento nas extremidades do tubo define a forma de desenho das fibras na superfície do mandril. A figura 51 ilustra esta forma de acordo com a estratégia.

Figura 52 - Estratégia de enrolamento e resultado superficial.

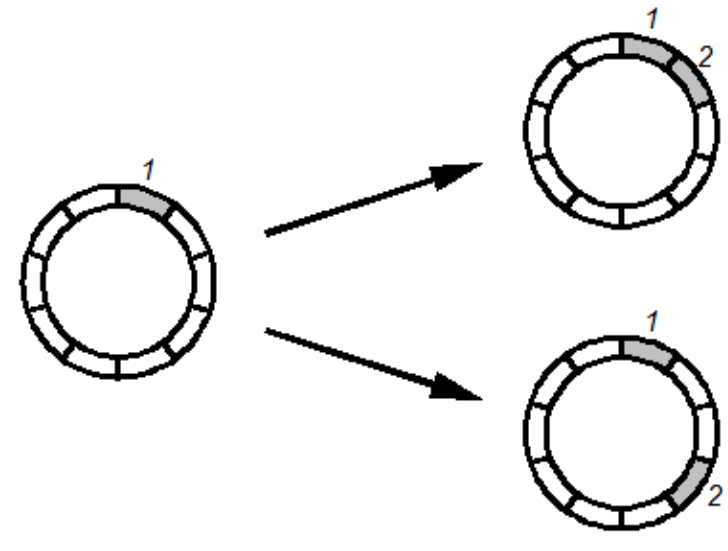

ESTRATÉGIAS
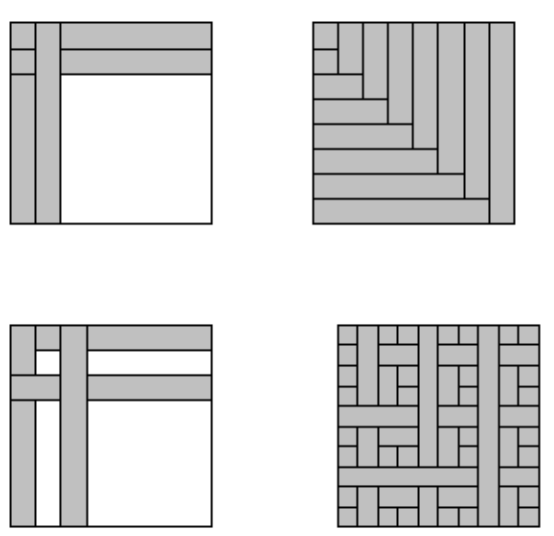

PADRÃO NA SUPERFÍCIE 
Fonte: ROUSSEAU (1998).

De acordo com LI (2005) o projeto das trajetórias das fibras é baseado em dois critérios: cobertura uniforme e resistência ideal. Em ordem de obter trajetórias que atendam os requisitos de cobertura e resistência ideal do compósito, as trajetórias das fibras precisam estar dentro dos requerimentos técnicos do processo de filament winding evitando problemas tais como deslizamento e descolamento, cobertura de toda a superfície e retorno do olhal.

\subsubsection{TRAJETÓRIA DAS FIBRAS}

No processo de Filament Winding um grande desafio é o cálculo da trajetória da fibra ao longo do mandril. Segundo CARVALHO (1996) devido às limitações impostas pelo processo de Filament Windign, o ângulo ideal das fibras não pode sempre ser encontrado e as trajetórias viáveis desviarão das desejadas. Programas são desenvolvidos considerando estas restrições em ordem de garantir estas trajetórias.

Segundo LI (2007), para cobrir o mandril uniformemente, as trajetórias das fibrs devem ser executadas em certo padrão, este padrão é chamado de padrão de enrolamento, o qual é definido pela combinação de uma trajetória adjacente da fibra e a determinação do desempenho mecânico do produto.

Segundo SCHOLIERS (1992), a força externa que age na fibra no momento do enrolamento, é a força de tensão que é aplicada na fibra com o fim de mantê-la esticada. Esta força de tensão na fibra $\overrightarrow{f_{t}}$ leva a uma força resultante $\overrightarrow{f_{r}}=\frac{d \overrightarrow{f_{t}}}{d_{s}}$ por unidade de comprimento na superfície do mandril, o qual é dirigido para o centro da curvatura da trajetória da fibra. Esta força resultante pode ser dividida em duas componentes: a força normal $\overrightarrow{f_{n}}$ perpendicular à superfície e à força transversal $\overrightarrow{f_{b}}$ tangente à superfície do mandril. Estas forças são ilustradas na figura 52. 
Figura 53 - Forças que atuam na fibra durante o enrolamento.

Fonte:

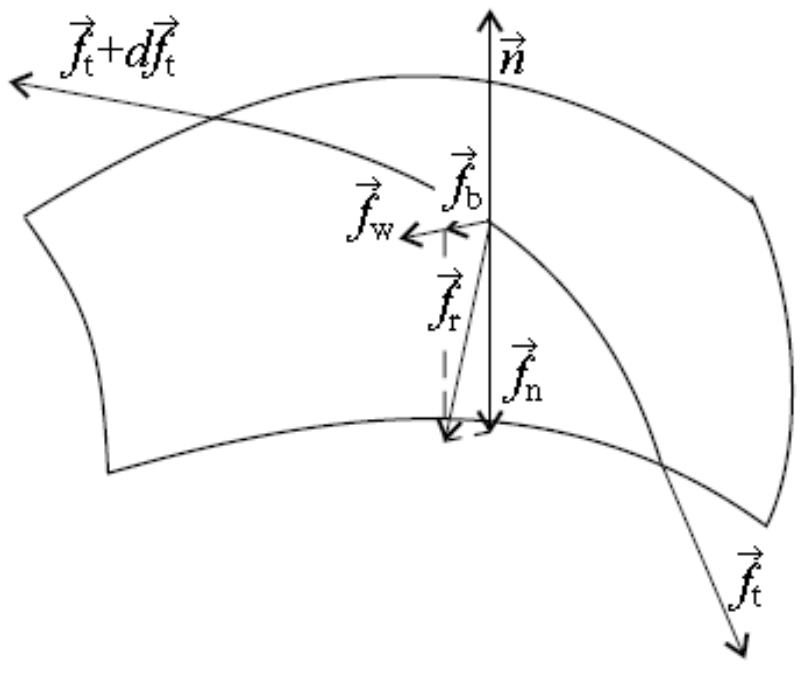

SCHOLIERS (1992).

Com a finalidade de obter precisão e repetibilidade no acomodamento da fibra na superfície do mandril, a fibra não deve deslizar na superfície do mandril. O ângulo de deslizamento $\beta$ é definido como o ângulo entre as forças $\overrightarrow{f_{r}}$ e $\overrightarrow{f_{n}}$ e a tendência ao deslizamento $\lambda$ como a razão entre a força transversal $\overrightarrow{f_{b}}$ e a força lateral $\overrightarrow{f_{n}}$.

$$
|\lambda|=|\tan \beta|=\frac{\left\|\overrightarrow{f_{b}}\right\|}{\left\|f_{n}\right\|}
$$

A fibra pode deslizar se a força transversal $\overrightarrow{f_{b}}$ for maior que a força de atrito entre a fibra e a superfície abaixo da fibra (mandril ou uma camada de fibra).

A força de atrito $\overrightarrow{f_{w}}$ é dada por:

$$
\left\|\vec{f}_{w}\right\|=\mu\left\|\vec{f}_{n}\right\|
$$

Sendo $\mu$ o coeficiente de atrito.

A condição de estabilidade:

$$
\left\|\vec{f}_{b}\right\| \leq\left\|\vec{f}_{w}\right\|
$$

pode ser escrito como:

$$
\left\|\vec{f}_{b}\right\|=|\lambda|\left\|\vec{f}_{n}\right\| \leq \mu\left\|\vec{f}_{n}\right\|
$$


Se a força transversal é zero $\left(\vec{f}_{b}=\overrightarrow{0}\right)$ a força resultante $\vec{f}_{r}$ na superfície é normal à superfície. A trajetória da fibra corresponde então a uma geodésica. Uma geodésica é definida como uma curva no qual a derivada de segunda ordem é perpendicular à superfície. Por exemplo: Uma geodésica em uma esfera corresponde ao círculo meridiano, em um plano para uma linha reta, em um cilindro para uma hélice. Se geodésicas são utilizadas para o enrolamento, então o termo geodesic winding (enrolamento geodésico) é usado, por outro lado, se as trajetórias são permitidas desviar da geodésica, o termo non-geodeisc-winding (enrolamento não geodésico) ou semi-geodesic-winding (enrolamento semi geodésico) é usado. A restrição às geodésicas simplifica os cálculos das trajetórias das fibras, mas reduz a liberdade do projeto. Enrolamento a seco permite alto coeficiente de atrito em relação ao enrolamento úmido. Na prática o deslizamento da fibra é suscetível a ser imprevisível. Sistemas pré-formados tem, devido a sua maior aderência, um alto coeficiente de atrito em relação ao sistema umedecido com resina, permitindo um grande desvio das geodésicas. SCHOLIERS (1992).

A força normal $\overrightarrow{f_{n}}$ fornece a pressão interlaminar $p i$ a qual é necessária para compactar o laminado.

$$
p i=\frac{\vec{f}_{n}}{w}=\frac{T k_{c}}{w}
$$

Onde: $\mathrm{w}$ - largura da fita

$$
\begin{aligned}
& k_{c} \text { - curvatura da trajetória da fibra } \\
& \mathrm{T} \text { - tensão da fibra }
\end{aligned}
$$

Se uma pressão de consolidação é aplicada no ponto de contato, muitos desvios podem ser feitos da geodésica. A pressão previne o deslizamento da fibra no ponto acomodado. A condição de estabilidade tem de ser válida para cada fita do carretel e para as bordas exteriores do enrolamento. $O$ requisito de que as fibras na borda da banda não pode escorregar limita a largura de fita do carretel. A largura da 
fita é em função da curvatura normal do mandril na trajetória da fibra. SCHOLIERS (1992).

A largura máxima da fita para uma trajetória geodésica é dada por:

$$
w_{\max }=\frac{2}{k_{g}} \arctan \mu
$$

Onde kg é a curvatura na direção normal para a trajetória da fibra.

O diâmetro do mandril também interfere na escolha da largura da fita. Deve ser considerado o perímetro da seção circular menor do mandril em relação à largura da fita, por exemplo, um mandril cônico onde o diâmetro maior seja muito maior que o diâmetro menor. A quantidade de fibra que será depositado neste diâmetro menor será muito maior que o diâmetro maior, consequentemente vai obter uma espessura maior no diâmetro maior. Outro aspecto importante é que se o diâmetro do mandril for muito pequeno e a largura da fibra for muito grande comparado ao perímetro do diâmetro do mandril, com duas ou três passadas o mandril será todo revestido podendo até uma largura da fita sobrepor uma camada como está ilustrado na figura 53.

Figura 54 - Ilustração da sobreposição da fita.

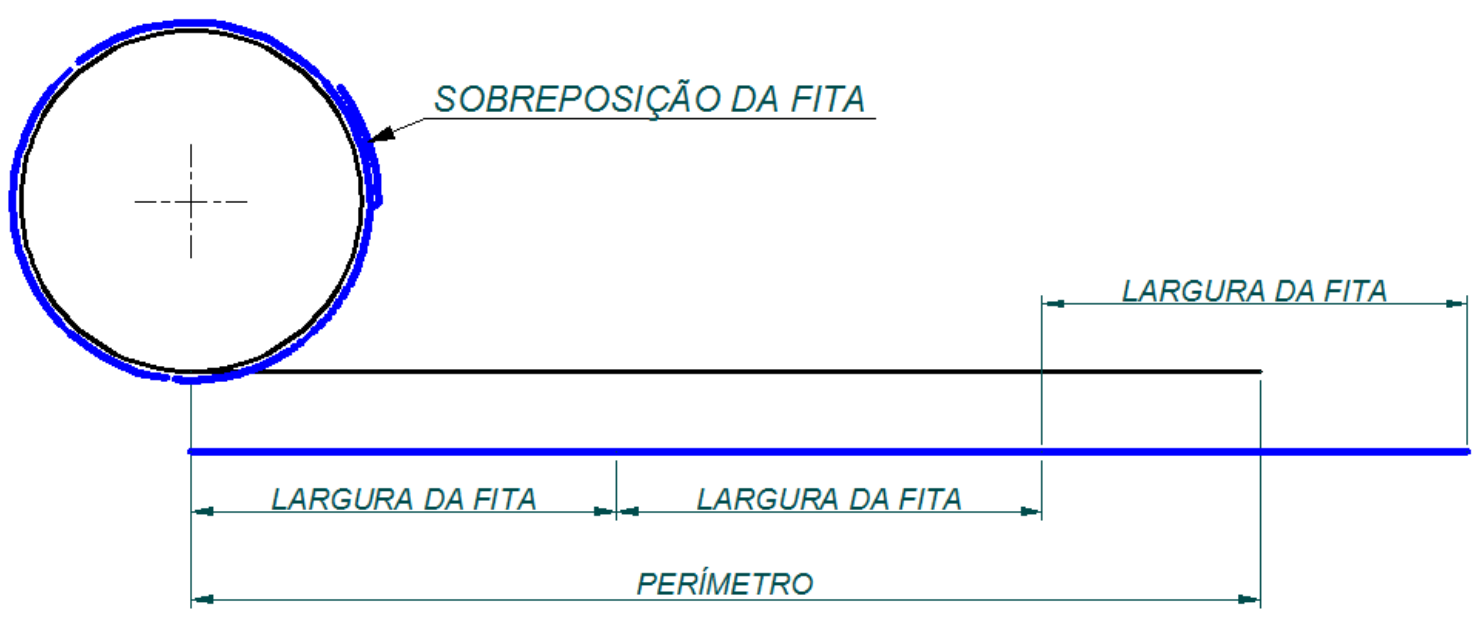

Fonte: Próprio autor.

Esta sobreposição deve ser considerada na estratégia de enrolamento, pois influenciará no acabamento da superfície da última camada. 
A trajetória da fibra em superfícies assimétricas é caracterizada pelo winding angle $\alpha$ (ângulo de enrolamento $\alpha$ ), isto é, o ângulo entre a tangente da trajetória da fibra e a geratriz da superfície de revolução, medida na tangente do plano à superfície, ilustrado na figura 54. SCHOLIERS (1992).

Figura 55 - Ângulo de enrolamento na superfície de revolução.

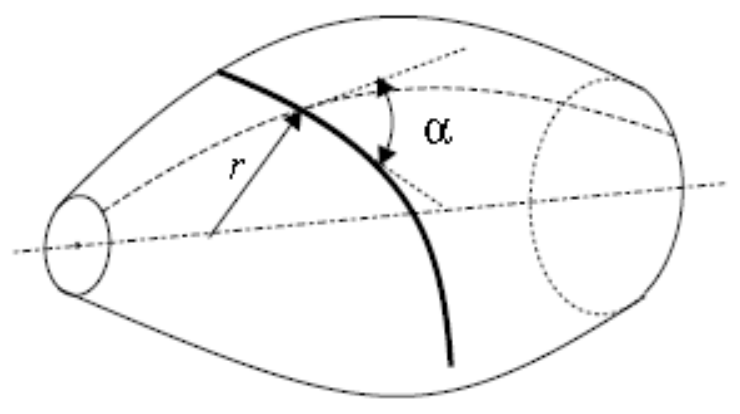

Fonte: SCHOLIERS (1992).

Para as trajetórias geodésicas das fibras numa superfície de revolução, a equação de Clairaut é utilizada.

$r \sin \alpha=C_{c}$

Onde $r$ é o raio da superfície, a o ângulo de enrolamento e $C_{c}$ é a constante para a geodésica.

\subsubsection{TRAJETÓRIA HELICOIDAL}

A trajetória da fibra de passo constante por camadas no mandril formam uma trajetória helicoidal na superfície do mandril. Nas estratégias de revestimento citadas por CARVALHO (1996), as estratégias de revestimento helicoidal e revestimento circular, ambas formam uma espira helicoidal na superfície do cilindro. A diferença entre elas está no passo da hélice. O passo da hélice é uma relação de deslocamento na superfície em relação ao eixo de revolução e do diâmetro da superfície. O deslocamento a cada volta representa o passo da hélice. A figura 56 ilustra o desenho da trajetória helicoidal no espaço tridimensional.

Figura 56 - Trajetória helicoidal. 


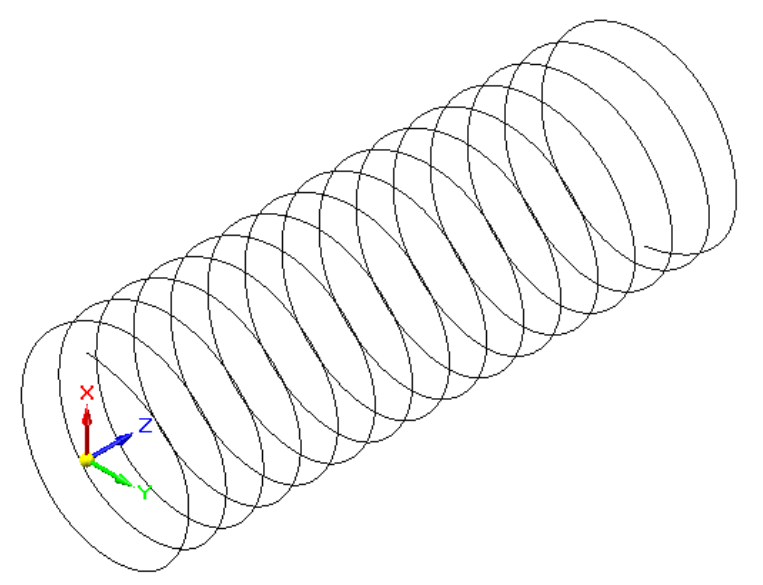

Fonte: Próprio autor (2015).

A trajetória da fibra ao redor da superfície cilíndrica com diâmetro constante ao longo do comprimento pode ser visto na figura 57 ,

Figura 57 - Trajetória da fibra em uma superfície cilíndrica e os dados construtivos da mesma.
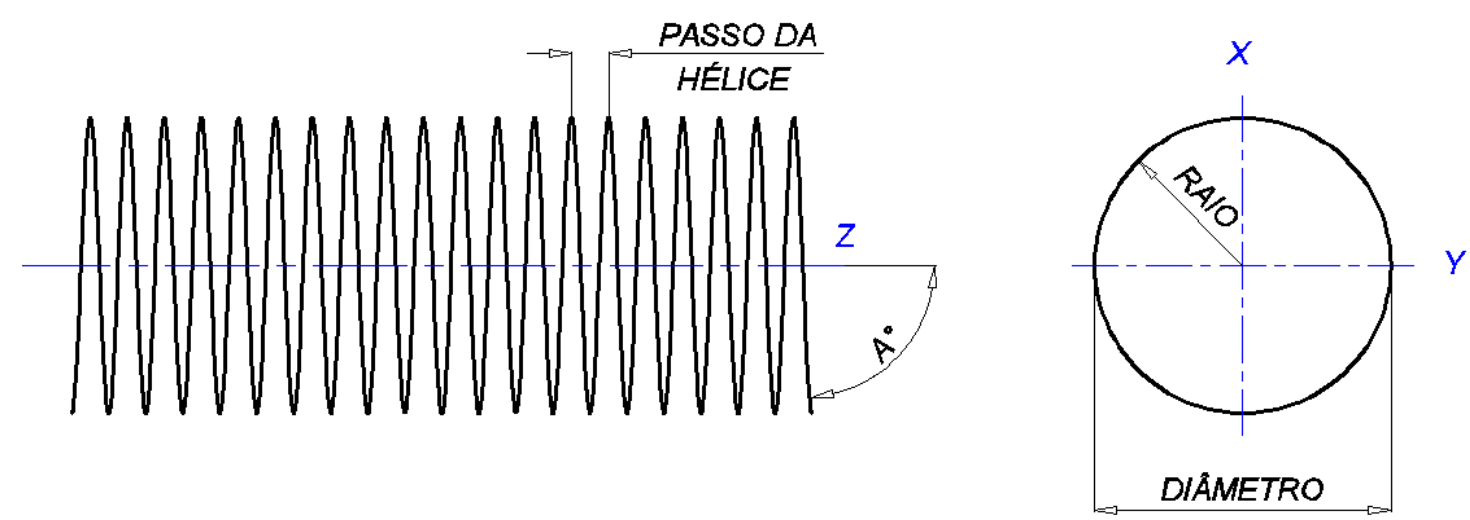
Fonte: Próprio autor (2015).

No revestimento circular, o passo é a largura da fita ou ajuntamento das fibras. No revestimento helicoidal, se o passo da hélice for muito baixo ele se aproxima do revestimento polar, se o ângulo da hélice for muito alto, ele se aproximará do revestimento circular.

$$
\begin{aligned}
& \text { Para o cálculo da hélice a equação usada é: } \\
& x=\text { raio. } \cos t \\
& y=\text { raio. } \sin t \\
& z=n \\
& t=z / b \\
& b=P_{h} / 2 . \pi \\
& \alpha=t . \frac{180}{\pi}
\end{aligned}
$$

Onde: $X$ valor da posição no eixo $X, Y$ valor da posição no eixo $Y, Z$ valor da posição no eixo $Z$, $t$ variável de construção para os valores de $X$ e $Y$, b variável para construção de t em função do ângulo da hélice e $\alpha$ ângulo formado entre a posição e o eixo $X$.

$O$ valor de $Z$ é adotado segundo a necessidade. Por exemplo, $Z=0,1,2,3 \ldots n$, $Z=0,0.5,1,1.5,2,2.5,3 . . n, Z=0,0.25,0.5,0.75,1,1.25,1.5,1.75,2 \ldots n, Z=0,2$, 4, 6...n. Esta escolha influencia na definição da hélice quanto a visualização no software CAD. 


\subsection{MÁQUINAS PARA FILAMENT WINDING}

As máquinas para o processo de filament winding são basicamente compostas de um ou mais eixos árvore para prender o girar o mandril, barramento horizontal para deslocamento longitudinal do mandril (fixado por dispositivos mecânicos ao eixo árvore), contraponto, sistema de guia ou orientação das fibras (olhal), sistema de tensionamento das fibras e sistema de controle para os movimentos do eixo árvore (um ou mais), sistema de guia, sistema de tensionamento e eventualmente outros acessórios como sistema de aquecimento da resina, controle de braços robóticos, etc.

Segundo SKINNER (2006) o processo de filament winding passa por um crescimento novamente, após anos de estagnação. Uma grande parcela deste crescimento se deve ao crescimento e interesse dos mercados asiáticos e norte americano, isto impulsionou o desenvolvimento de máquinas mais sofisticadas para filament winding tais como máquinas a seis eixos, controladas por computador, etc. Um exemplo destas evoluções pode ser vista na figura 58 , uma máquina de filament winding desenvolvida pelo Indian Institute of Technology (IIT), controlada por CNC Siemens ${ }^{\circledR}$ 840D. O software para operação desta máquina é o Cadfil® para peças de geometria assimétrica e não assimétrica tais como tubos e tubos com curvaturas.

Figura 58 - Máquina de filament winding com CNC. 


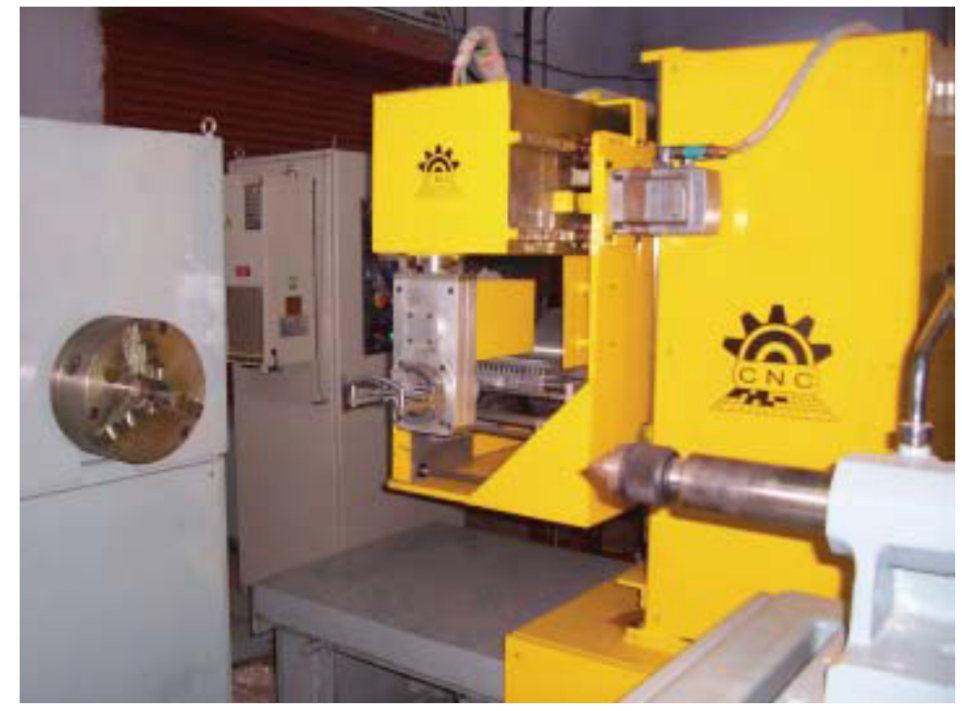

Fonte: SKINNER (2006).

\subsubsection{MAQUINAS COMERCIAIS PARA FILAMENT WINDING}

Vários fabricantes de máquinas têm ofertado máquinas para filament winding no mercado, entre eles é possível destacar alguns renomeados no mercado como: ENTEC, EHA, McClean Anderson e Korthfiber. A empresa norte americana ENTEC produz máquinas para determinados tipos de aplicações em filament winding.

- FW SERIES FILAMENT WINDER - um único eixo árvore, para peças com comprimento entre 1,2 a 3,7 metros (4 a 12 pés), com diâmetro máximo de $600 \mathrm{~mm}$, limite de rotação a 280 rotações por minuto, com Sinumerik Controller Siemens $\AA$, software para trajetórias FiberGrafix, controle de tensão e baho de resina. Estas máquinas, ilustradas na figura 59(a), são destinadas a vasos de pressão, tubos, componentes tubulares e equipamentos esportivos.

- PS SERIES FILAMENT WINDER - esta máquina pode ter até 10 eixos de enrolamento, para peças com comprimento entre 1,2 a 7,3 (4 a 24 pés), com diâmetro máximo de $864 \mathrm{~mm}$, limite de rotação a 150 rotações por minuto, com Sinumerik Controller Siemens $\AA$, software para trajetórias FiberGrafix, controle de tensão e baho de resina. Estas 
máquinas, ilustradas na figura 59(b), são destinadas a vasos de pressão, domos para foguetes e equipamentos esportivos.

- 5K SERIES FILAMENT WINDER - esta máquina é dedicada a construção de peças aeronáuticas, principalmente domo de foguetes e vasos de pressão. Com um único eixo árvore, para mandris com comprimento entre 3,6 a 12,3 (12 a 60 pés), com diâmetro máximo 3,7m, limite de rotação a 125 rotações por minuto, com Sinumerik Controller Siemens ${ }^{\circledR}$, software para trajetórias FiberGrafix, controle de tensão e baho de resina. A figura 59(c) ilustra essa máquina.

Além destas máquinas comerciais, a Entec disponibiliza máquinas especiais para fabricação de tubulações de material compósito para altas pressões (entre 1000 a 3000 psi) e diâmetros elevados (até 1500 mm) e máquinas customizadas como para a fabricação de pás eólicas.

Figura 59 - Máquinas para filament winding fabricadas pela empresa Entec.
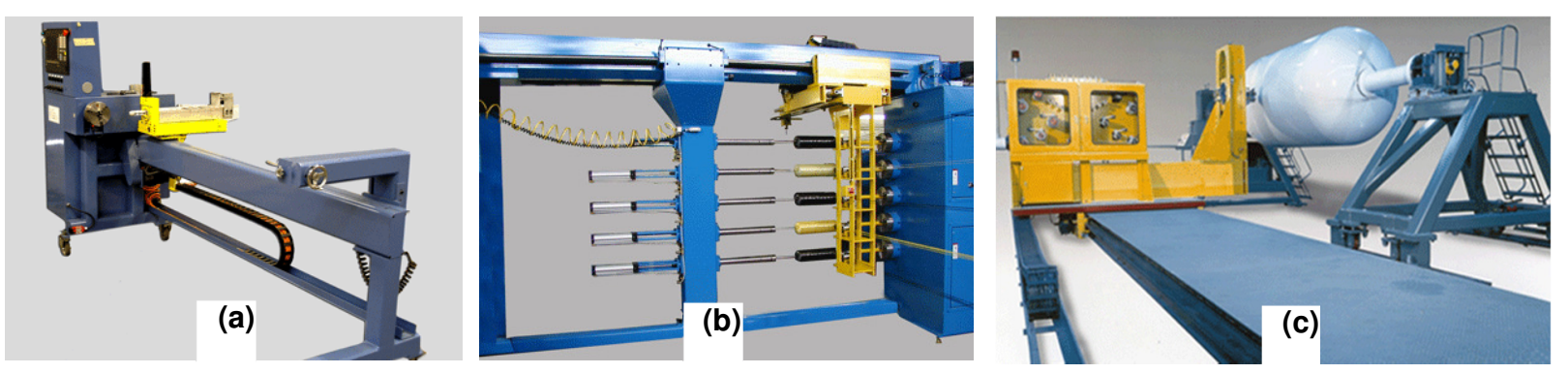

Fonte: Entec (2012).

Outro fabricante de máquinas de filament winding conceituada é a EHA (Engineering High-tech Assets) localizada em Steffenberg - Alemanha. A EHA fornece não somente a máquina para filament winding, mas acessórios para a fabricação. Assim como a Entec as máquinas da EHA dispõe de sistema de tensionamento, banho de resina, mais de um eixo para fixação de mandril. As máquinas comerciais disponibilizadas são as BS WINDER nos modelos TYPE 1, TYPE 2 e TYPE 5 ilustradas na figura 60(a), 60(b) e 60 (c) respectivamente. Máquinas estas destinadas a fabricação de vasos de pressão, vasos para gás comprimido, tubos e aplicações especiais. O fabricante não disponibiliza os softwares para o controle e cálculo das trajetórias das fibras. 
Além das máquinas a EHA fornece a célula de produção para filament winding. Estas células visam à produtividade, segurança, ergonomia e eficiência na produção. llustrada na figura 61, estas células se destinam a produção em larga escala.

Figura 60 - Máquinas para filament winding fabricadas pela EHA.
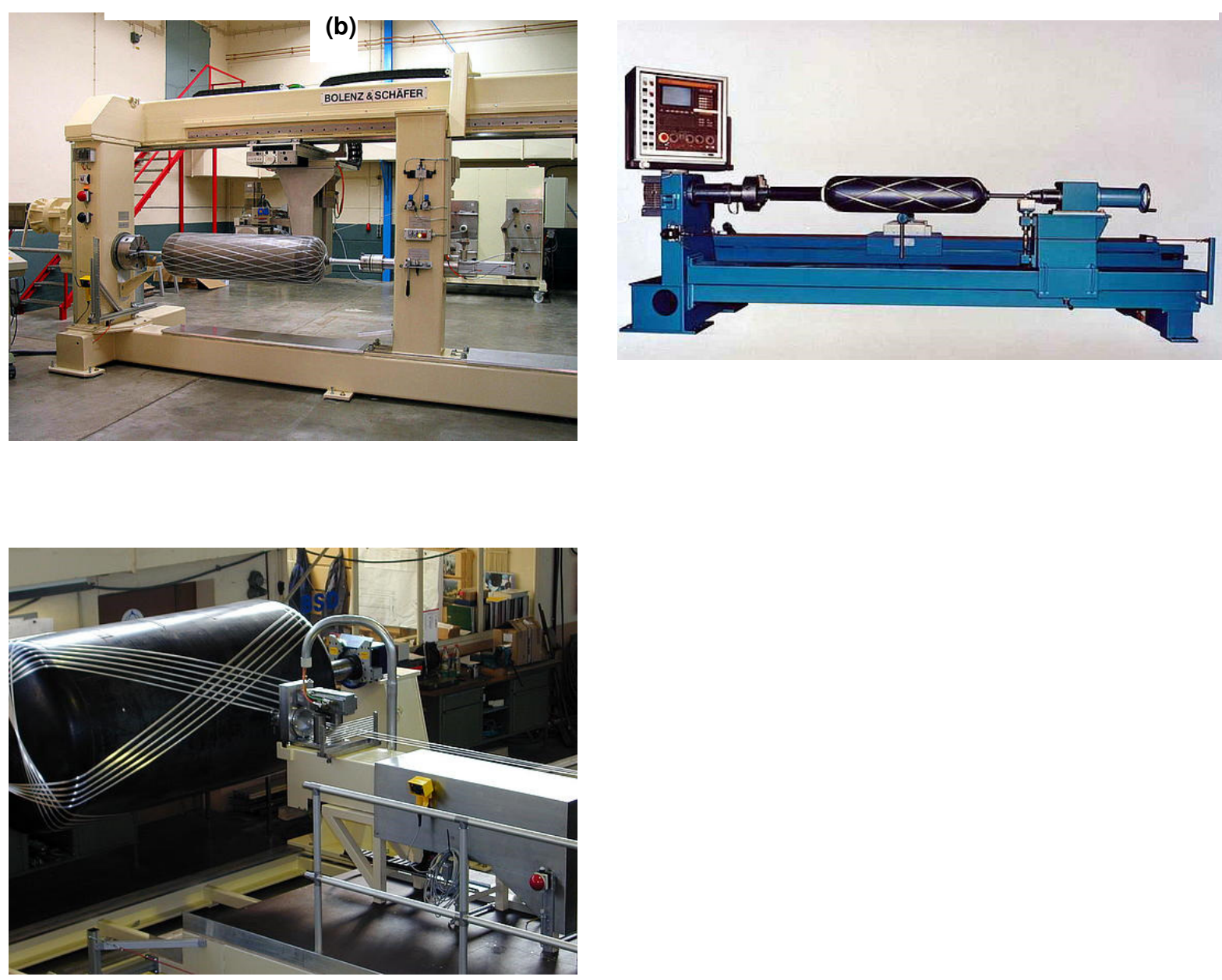

Fonte: EHA (2012). 
Figura 61 - Célula de produção para o processo de filament winding desenvolvido pela empresa EHA.

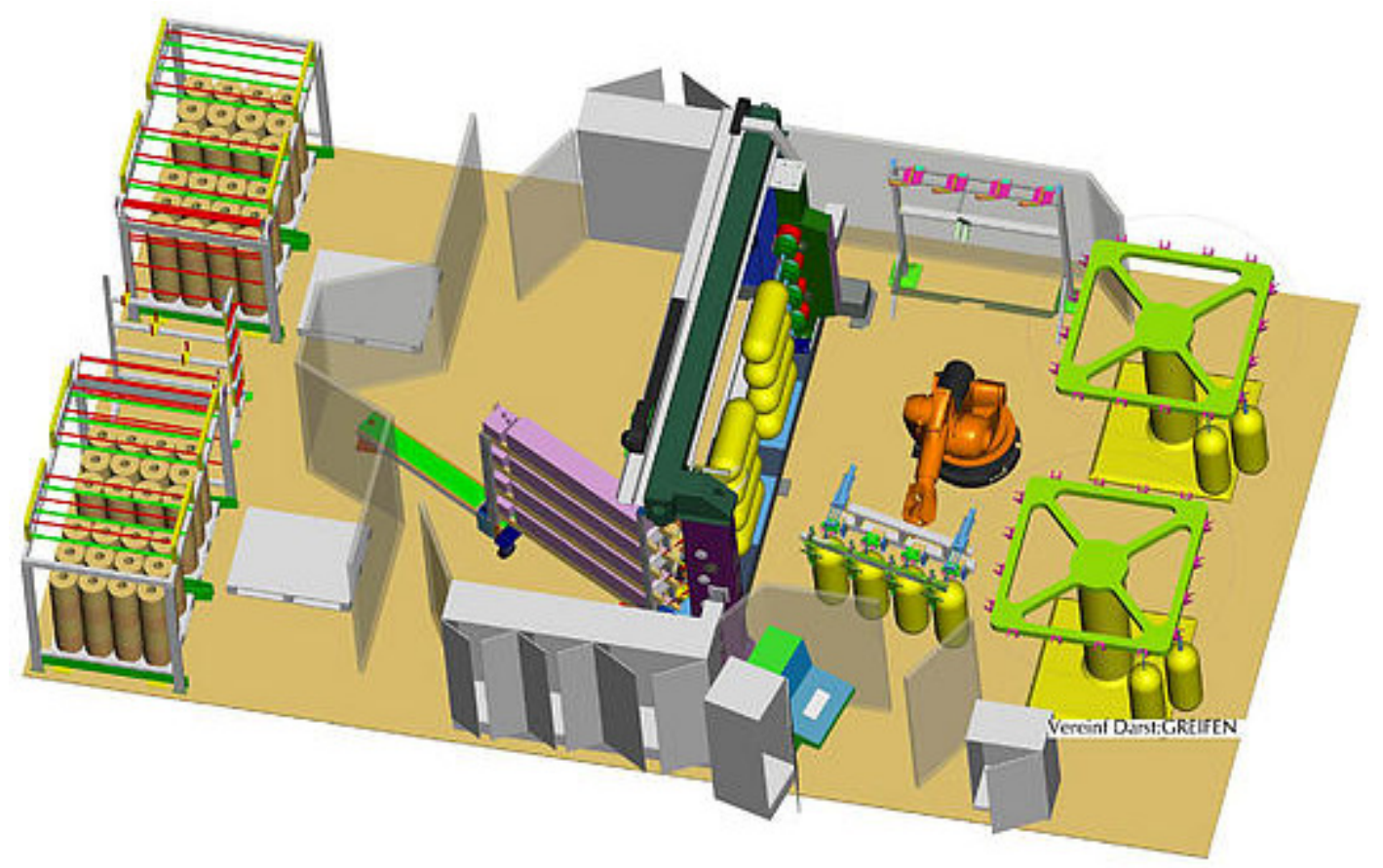

Fonte: EHA (2012).

Outro fabricante renomeado no mercado é McClean Anderson®, produz máquinas para filament winding para várias dimensões e aplicações. Faz restrições quanto às dimensões e o peso das peças a serem produzidas. Dentre as máquinas 
comerciais fornecidas estão: Little Hornet, Super Hornet, Spider, Ciclone, Titan e Raptor. Dentre as máquinas comerciais fornecidas pela empresa, é ilustrada na figura 62 a Little Hornet, disponível com um eixo de rotação para mandril. A empresa também fornece equipamentos controladores de tensão e banho de resina. Os softwares disponíveis para as máquinas são: Flexwind que permite a configuração das trajetórias nas camadas, Composite Designer que permite a criação de um formato geométrico bidimensional e o SimWind específico para domos.

Figura 62 - Máquina para filament winding comercial.

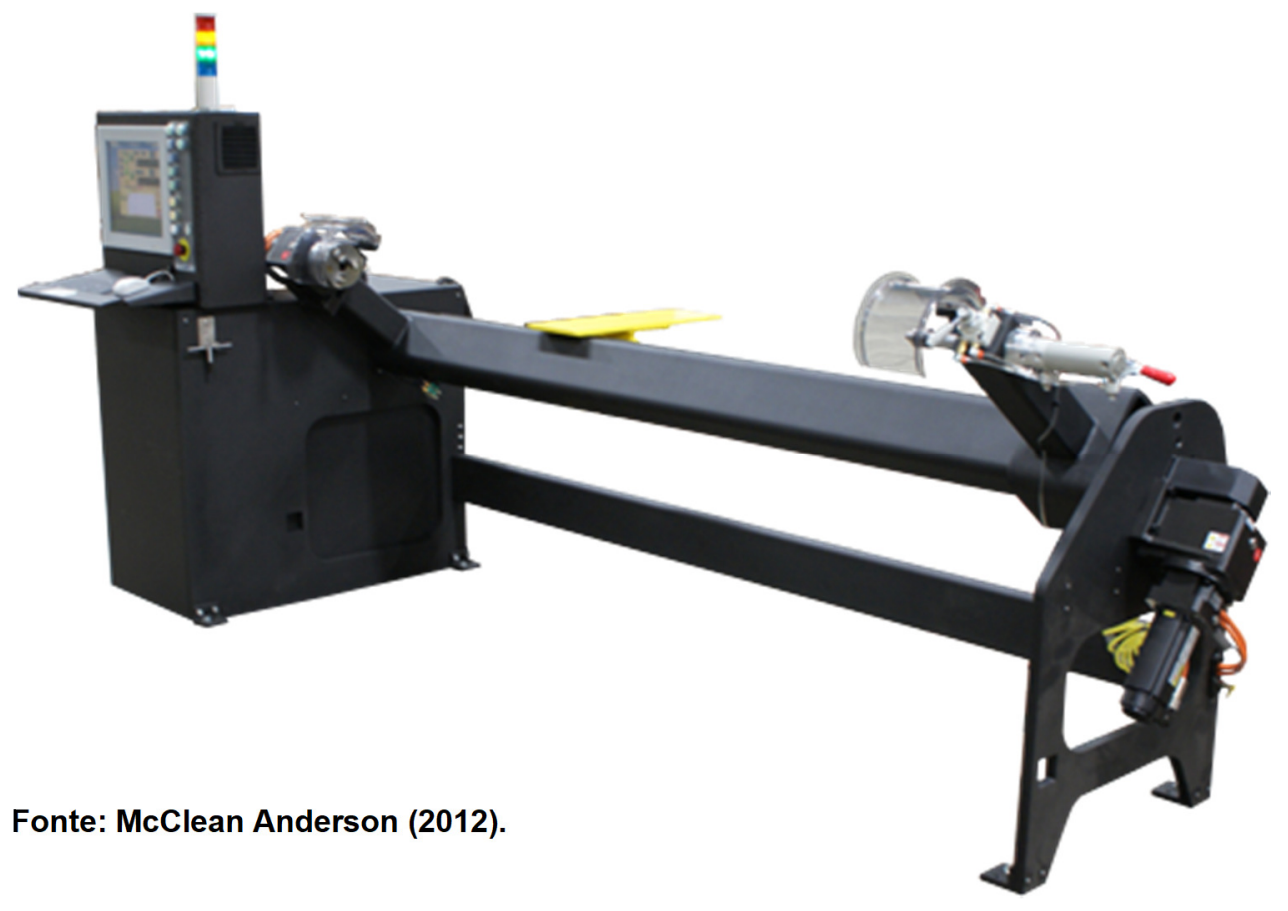

As máquinas para filament winding trabalham com olhal e mesa de deslocamento no longitudinal em relação ao mandril para acomodação das camadas, mas é possível ao invés de trabalhar com olhal e mesa de deslocamento, trabalhar com robô ou braço robótico. 
CARRINO (2003) um sistema robotizado de filament winding é composto de um robô industrial, equipado com sistema de deposição e alimentação, e uma máquina com o mandril preso ao eixo árvore. As coordenadas relativas aos movimentos das partes envolvidas (robô e mandril) descrevem uma trajetória tridimensional para o revestimento do mandril com as fibras. Este sistema pode produzir peças assimétricas e com geometrias mais complexas que as máquinas convencionais, respeitando os limites do grau de liberdade do robô ou braço robótico. Com o robô ou com o braço robótico a máquina se torna mais flexível para uma mudança na geometria da peça.

AMRC (2013) o uso de robôs pode oferecer mais flexibilidade, embora os ajustes de máquinas (setup) sejam parecidos com os das máquinas convencionais. $O$ sistema pode operar com o tradicional filament winding interagindo os dispositivos para o processo. O processo é indicado para vasos de pressão, rotor, eixo de torção, barra de suspensão, pás eólicas (limitada ao comprimento), etc. A figura 63 ilustra uma célula robótica para filament winding.

Uma limitação deste tipo de processo é com relação ao comprimento e diâmetro da peça a ser produzido ser mais limitada em função do braço do robô em relação às máquinas tradicionais. Em uma máquina com mais de um eixo árvore, trabalhando com célula robótica, as peças produzidas nos mandris são todas de mesma geometria e estratégia de revestimento. A máquina de filament winding com robô é caro comparado às máquinas tradicionais.

Figura 63 - Célula robótica e peça produzida pela célula.

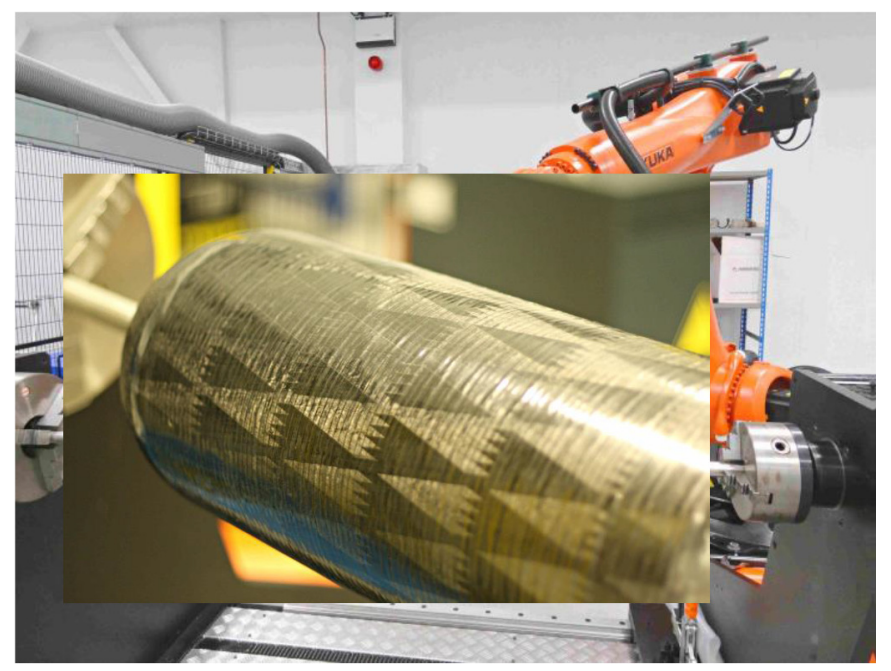

Fonte: AMRC (2013). 


\subsubsection{MAQUINAS ACADÊMICAS PARA FILAMENT WINDING}

As máquinas comerciais tem finalidade para fabricação de peças em larga escala, com geometria e dimensões pré-definidas. Quando há alterações de geometria e/ ou dimensões nas peças, as mesmas são executadas em lotes de produção, sendo que cada lote é formado por peças de mesma dimensão e geometria.

As máquinas acadêmicas não são voltadas para a produção em larga escala, mas tem o seu objetivo a fabricação de peças em menor escala para estudos acadêmicos voltados para análise do produto, processo, equipamentos, etc.

ABDALLA (2005) utilizou uma máquina de filament winding para fins acadêmicos, ilustrada na figura 64 , para fabricar peças de seus estudos em cima do processo de filament winding. ABDALLA descreve a máquina em partes de submontagem. São elas: a unidade montada de rotação que compreende os mancais, caixa de engrenagens e o dispositivo que sustenta e segura o mandril, o sistema de tensionamento das fibras compreendidos desde o dispositivo que aplica tensão nas fibras até o olhal por onde as fibras são depositadas no mandril e a unidade de controle que compreende a unidade elétrica e eletrônica da máquina. As peças produzidas pela máquina desenvolvida por ABDALLA (2005) são ilustradas na figura 65.

Figura 64 - Máquina de filament winding usada por ABDALLA para fins acadêmicos.

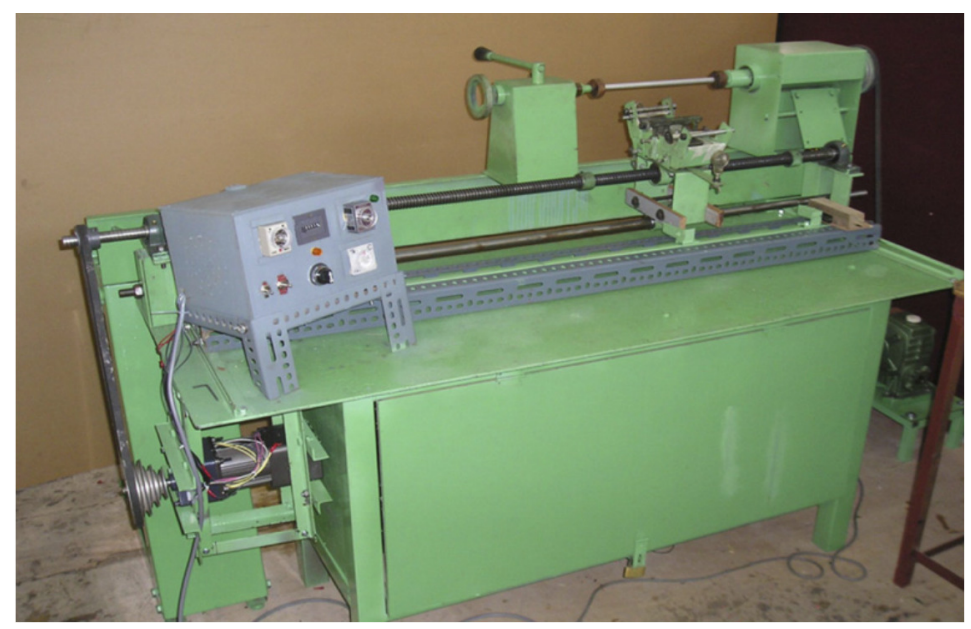

Fonte: ABDALLA (2005). 
O processo de fabricação de peças nesta máquina foi dividido em cinco etapas:

- Fixação do mandril, este poderia ser de alumínio ou PVC.

- O preparo do banho de resina (ABDALLA utilizou resinas epóxis MW 215 TA e MW 215 TB).

- Carregamento das fibras no banho de resina até os pinos no mandril.

- Ajuste da rotação do eixo árvore e do ângulo de revestimento.

- Deixar a peça em rotação na máquina por 3 horas para evitar que a resina respingasse.

Figura 65 - Peças produzidas por ABDALLA (2005).
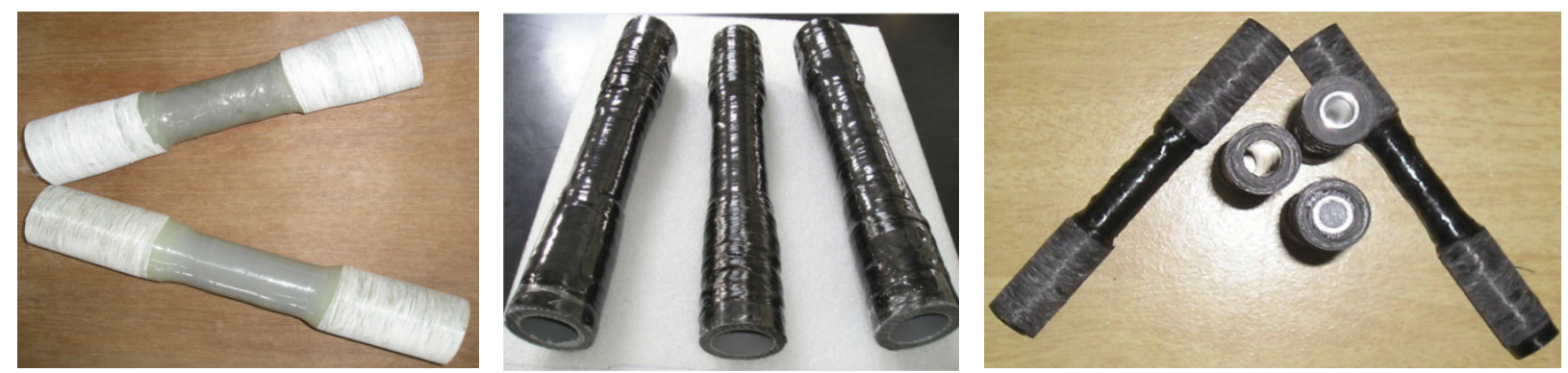

Fonte: ABDALLA (2005).

Apesar das máquinas de filament winding no mundo acadêmico não serem voltadas para produção em larga escala, elas sofrem estudos a respeito do assunto e isto gera mudanças, inovações, seja no processo, no produto ou na própria máquina.

Durante o processo de filament winding, as mechas das fibras são desenroladas de um ou mais carretéis, as mechas podem ser pré-impregnadas (prepreg) ou impregnadas durante o processo (wet winding), CHAN (1996). Esta mudança embora pareça sutil, faz diferença no processo, algumas destas mudanças causam preocupação com o aquecimento da resina, proteções contra respingos, dispositivo para impregnar as fibras, etc.

Para peças de geometria e padrões de enrolamentos mais complexos, o posicionamento do olhal requer mais flexibilidade. Esta flexibilidade pode ser alcançada por meio de controladores de eixos independentes, tais como controlados numericamente $(\mathrm{CNC})$. Estas máquinas podem produzir peças de geometrias mais complexas tais como pás eólicas, tubos em formato de $\mathrm{T}$, fuselagem aeronáutica, etc. Máquinas equipadas com CNC normalmente possuem dois eixos, um usado para 
acionar o mandril e o outro para controlar o movimento de translação do olhal por onde a fibra será depositada no mandril, isto pode ser visto na figura 66 . Outros eixos podem ser

Figura 66 - Componentes de uma máquina para filament winding com CNC.

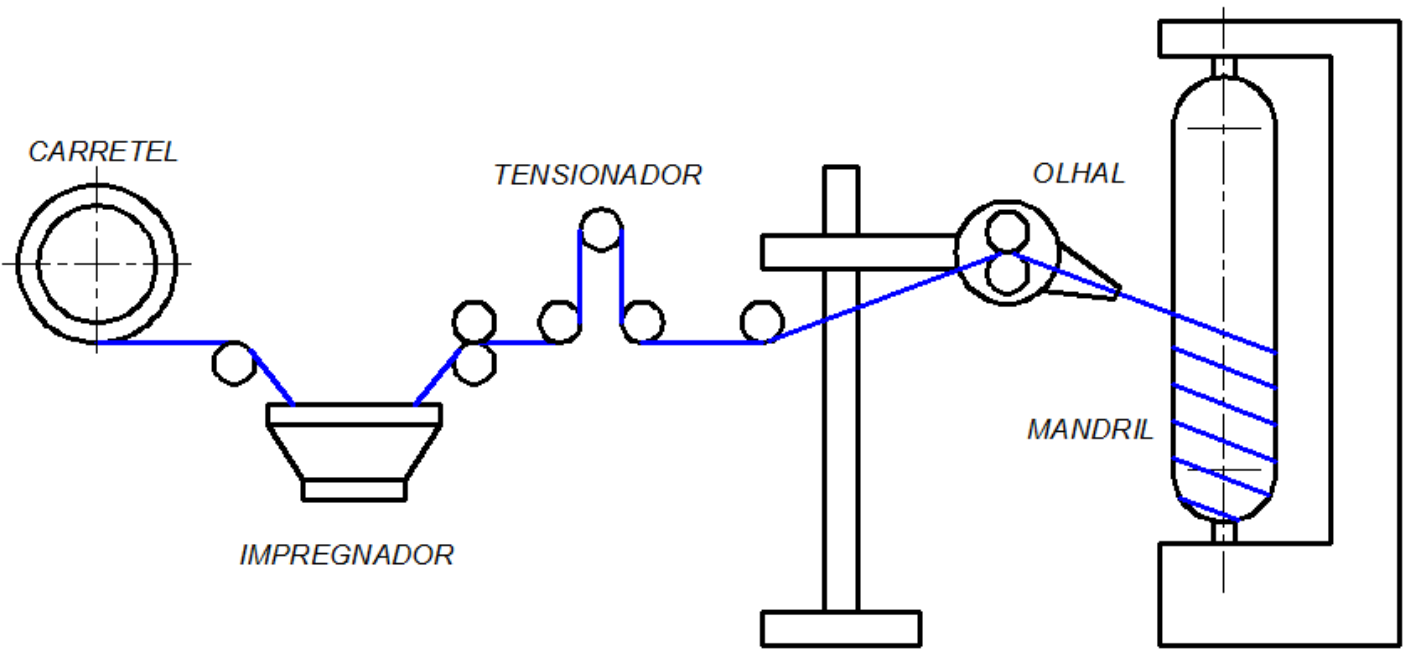

adicionados e controlados por microprocessadores baseado no sistema de controle no qual é capaz de controlar ambos, movimentos lineares e não lineares. CHAN (1996).

Fonte: CHAN (1996).

Em 1996 MARKOV e CHENG propuseram uma máquina de filament winding onde as fibras seriam depositadas por meio de um olhal estático e um braço robótico e as mesas ao redor fariam os movimentos responsáveis pelo processo de filament winding. $O$ desenho esquemático desta proposta pode ser visto na figura 67.

Figura 67 - Design de uma proposta para máquina de filament winding. 


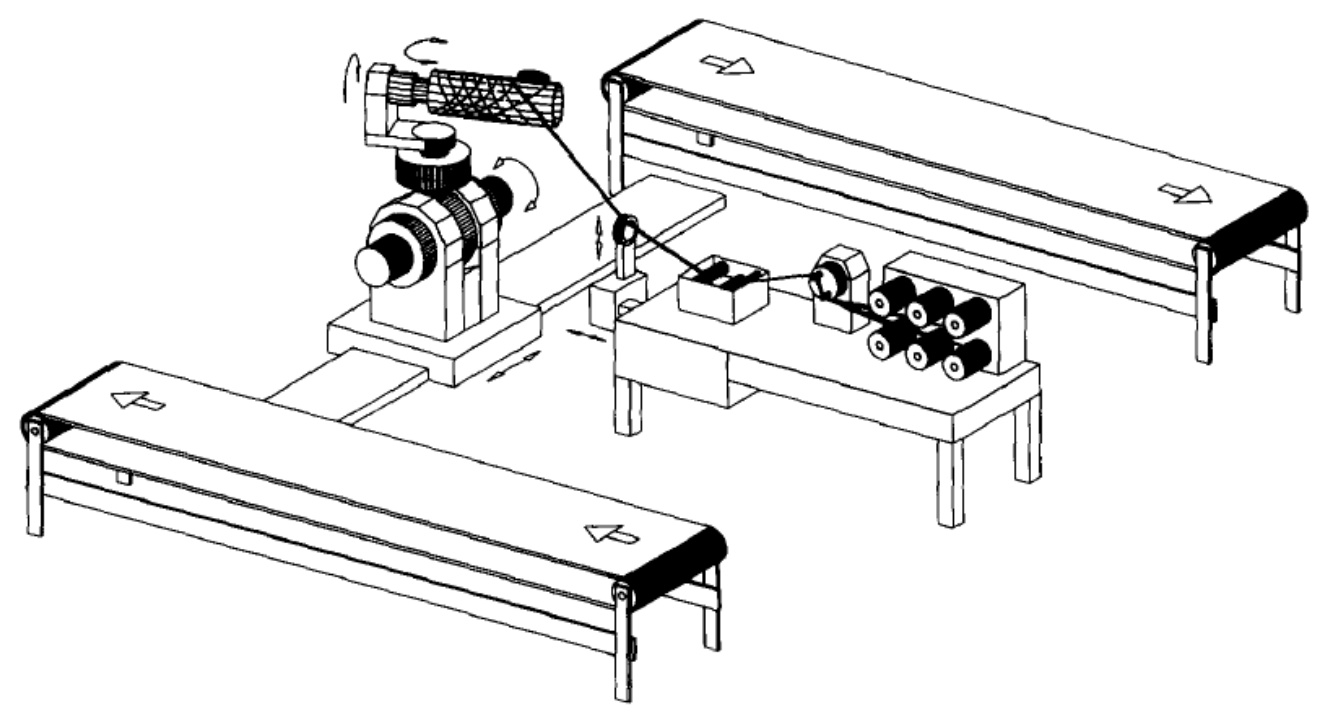

Fonte: MARKOV e CHENG (1996).

CARRINO (2003) propôs um sistema de filament winding onde o mandril, tensionador, olhal e um sistema de alimentação de fibras estivessem acoplados em um único dispositivo e este fixado a um robô que executaria as trajetórias das fibras. A figura 68(a) e 68(b) ilustram este sistema.

Figura 68 - (a) Robô com dispositivo para filament winding. (b) Dispositivo com tensionador, olhal, mandril e sistema de tensionamento das fibras.
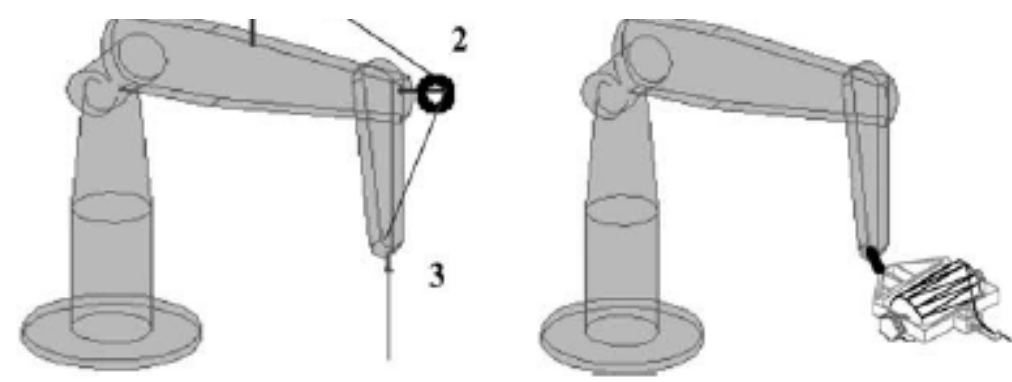

(a) 


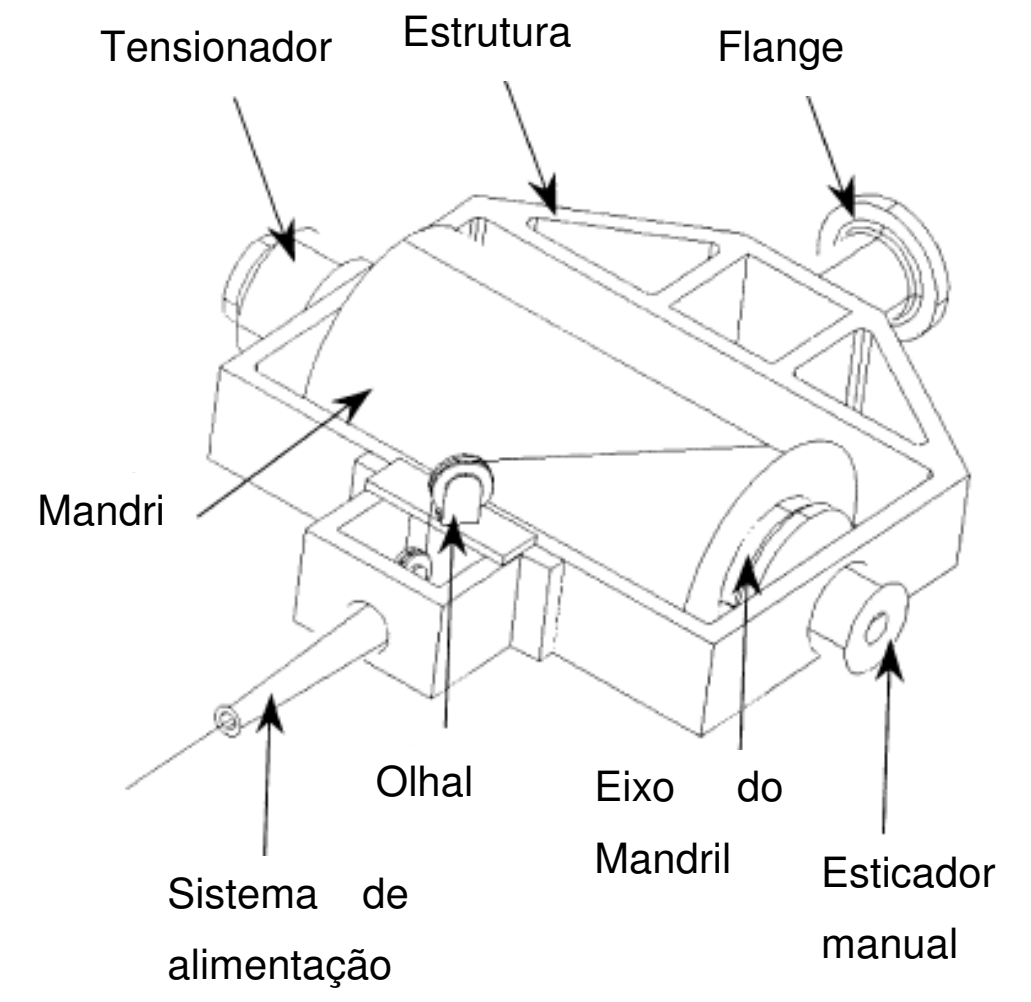

(b)

Fonte: CARRINO (2003).

\subsubsection{SISTEMA DE TENSIONAMENTO DAS FIBRAS}

O controle da tensão das fibras é importante no processo de filament winding. Segundo WANG (2009) o ângulo de enrolamento definido inicialmente pode desviar se não for aplicada tensão nas fibras. Se a tensão for instável durante o processo poderá ocorrer perda de qualidade e produtividade.

IMAMURA (1999) realizou um experimento com um uma máquina de filament winding composta, basicamente, de mandril, estrutura e um sistema de rolos de aperto (nip roll) para provocar tensão nas fibras. Dois sistemas de medição foram adaptados, um no mandril e outro no sistema de rolos de aperto. O desenho esquemático da máquina utilizada por IMAMURA pode ser vista na figura 69. 
Figura 69 - Máquina de filament winding con controle de tensão nas fibras.

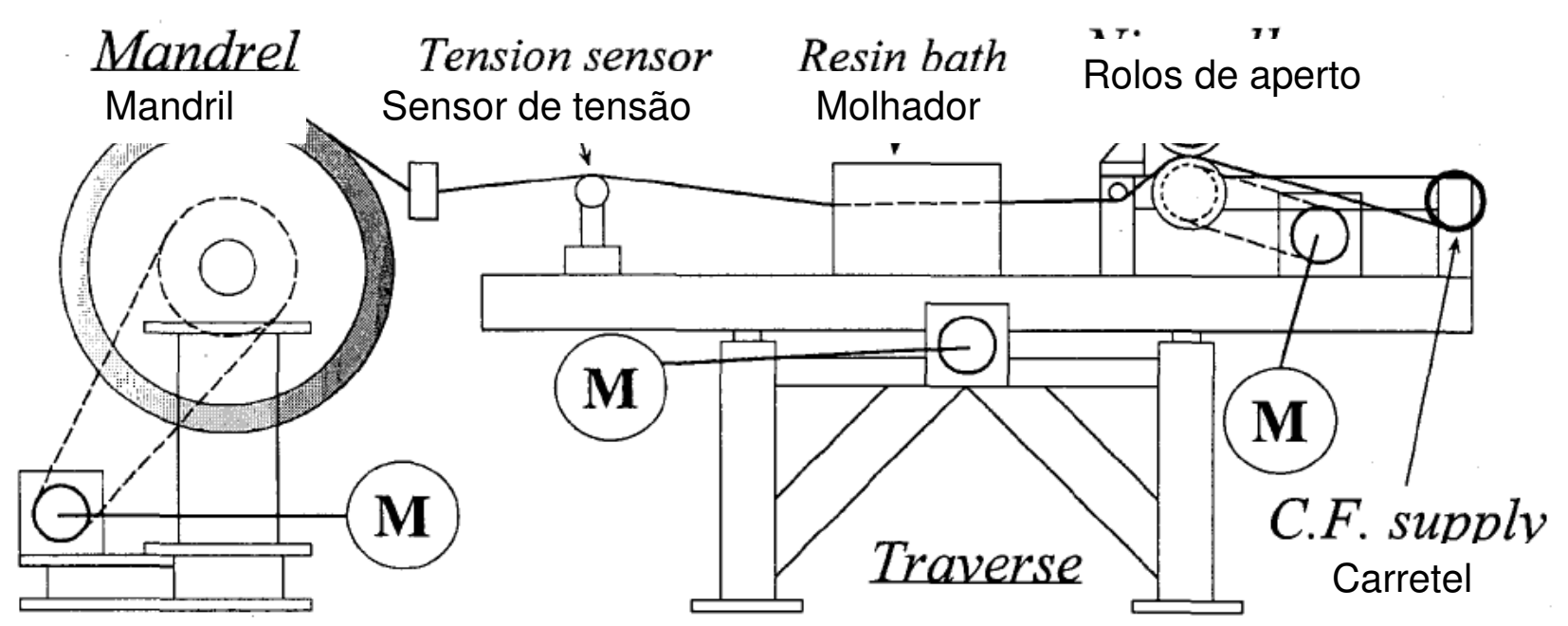

Fonte: IMAMURA (1999).

IMAMURA (1999) usou servomotores no mandril, no banho de resina e no sistema de aperto por rolos, a tensão aplicada foi ajustada em $50 \mathrm{~N}$ e $100 \mathrm{~N}$. Na primeira etapa IMAMURA controlou a tensão através do torque do servomotor do mandril, numa segunda etapa o controle de tensão se deu variando as velocidades entre o mandril e o sistema de aperto por rolos. A conclusão obtida pelo autor foi que o sistema de diferença de velocidades foi o melhor para controlar a tensão nas fibras. Esta conclusão ele obteve analisando características das peças produzidas, tais como quantidade de resina, inspeção das camadas, etc.

REN (2010) uma tensão apropriada e estável aplicada nas fibras durante o enrolamento, pode aumentar a resistência a pressão interna e a resistência à fadiga do componente enrolado. Pesquisas têm mostrado que tensões inapropriadas e instáveis no processo de filament winding tem resultado em componentes com perdas de resistência da ordem de 20 a 30\%.

AKKUS (2008) projetou e construiu um sistema para tensionar as fibras durante o processo de filament winding por meio de servomotor. Segundo AKKUS (2008) o controle de tensão é imprescindível para evitar o deslizamento das fibras e com isso a alteração da trajetória predefinida da mesma. A figura 70 ilustra o desenho esquemático do controlador de tensão.

Figura 70 - Sistema de controle de tensão do processo de filament winding. 


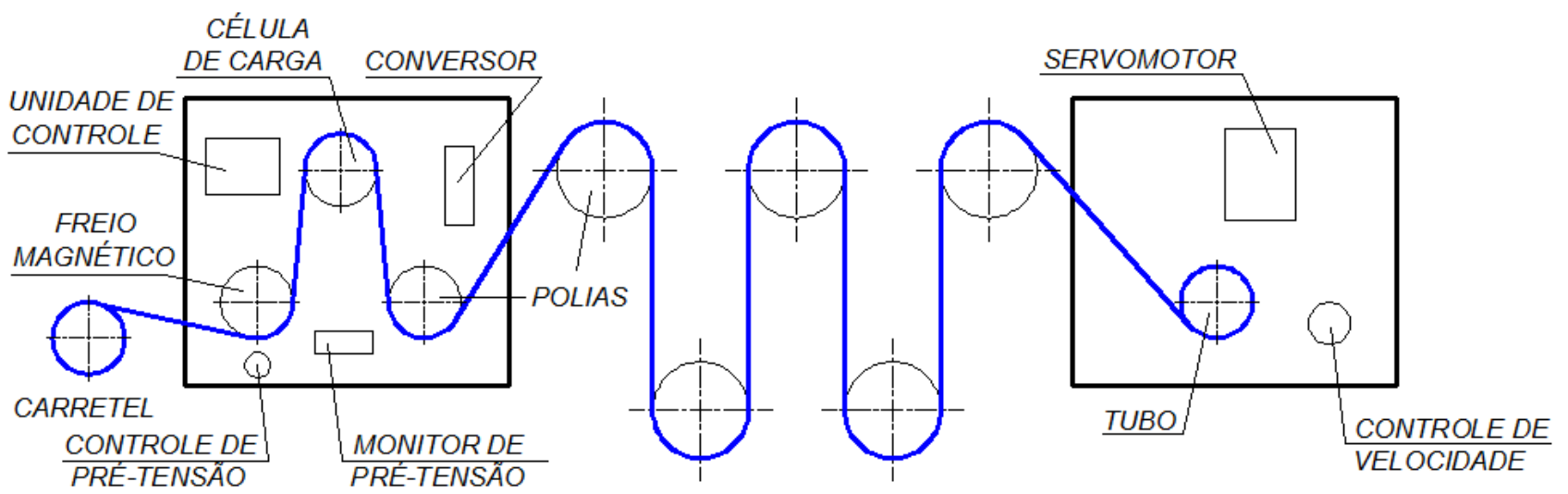

Fonte: Adaptado de AKKUS (2008).

O controlador de tensão projetado por AKKUS (2008) foi desenhado para manusear fibras de carbono para processo de altas velocidades mantendo a tensão uniforme ao longo do processo, porém o controlador pode ser usado em outras fibras sintéticas contínuas. Os resultados foram:

- Uma variação da tensão da ordem de $10 \%$, aceitável para o propósito de AKKUS (008).

- Menor perda de matéria prima durante o processo.

- Aumento da velocidade de produção, consequentemente da produtividade.

- Melhoria na qualidade do produto.

SCHOLLIERS (1992) a tensão aplicada nas fibras é um parâmetro crítico na impregnação e consolidação do processo de filament winding. A tensão das fibras no mandril fornece a pressão interlaminar a qual determina a integridade monolítica da peça manufaturada. Mudança na pressão interlaminar pode afetar o fluxo de resina e causar variações na distribuição da mesma.

Segundo SCHOLLIERS (1992) não há um consenso entre os fabricantes, qual seria a tensão ótima a ser aplicada nas fibras durante o processo, há uma variação nos valores entre um e outro fabricante. Ainda SCHOLLIERS (1992) afirma que se a tensão aplicada nas fibras for alta, resultará em um alto volume de fração das fibras, baixo índice de vazios na peça, um alinhamento melhor das fibras e a peça apresentará baixa densidade e alta resistência mecânica. Por outro lado, o risco de danos à fibra aumenta, resultando em baixa resistência mecânica, a migração da 
resina de dentro para fora das nas camadas aumenta causando rugas nas camadas internas e deformações no mandril.

SCHOLLIERS (1992) a tensão nas fibras deve ser mantida baixa antes do banho com resina para prevenir contra danos por abrasão nas fibras secas e a tensão pode ser aumentada após o banho. SCHOLLIERS (1992) usou um sistema de braços e servomotor para controlar a tensão aplicada nas fibras. A figura 71 ilustra o desenho esquemático do sistema de tensionamento das fibras.

Figura 71 - Sistema de tensinamento utilizado por SCHOLLIERS.

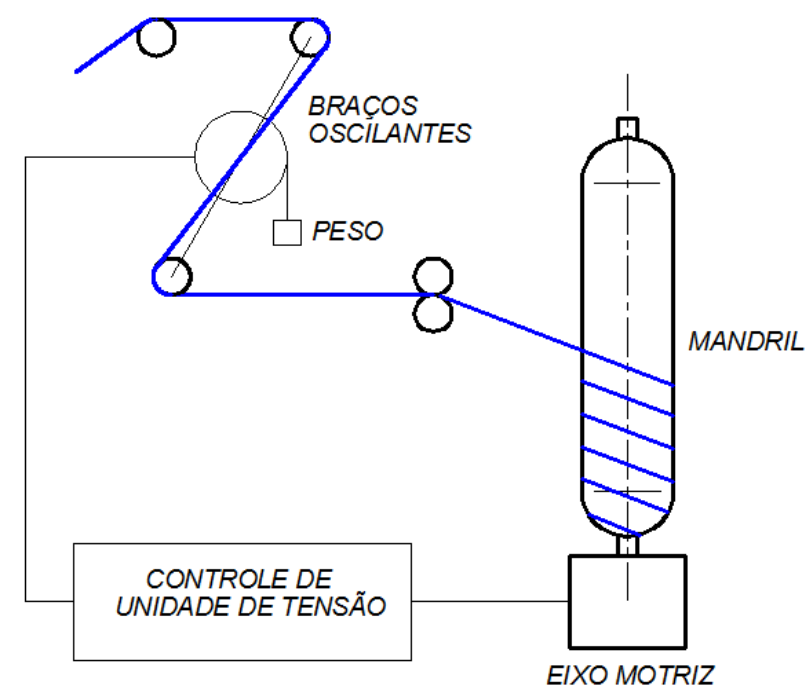

Fonte: Adaptado de SCHOLLIERS (1992).

\subsubsection{SISTEMA IMPREGNAÇÃO DAS FIBRAS}

A impregnação ou banho de resina é um fator importante no processo de filament winding, a quantidade de resina impregnada, viscosidade da resina e temperatura para aumentar a viscosidade da resina influenciam na peça manufaturada. Cuidados por onde as fibras impregnadas com resina passam é outro fator a ser considerado, pois as mesmas podem respingar das fibras.

COPMACO (2012) Recomenda a viscosidade da resina para o processo de filament winding entre 500 a 1000 cps já com catalisadores e aceleradores. Viscosidade acima de 1000 cps pode resultar em bolhas e dificuldade de 
impregnação. A distância entre o sistema de banho de resina e o mandril deve ser o menor possível devido aos respingos.

COPMACO (2012) sugere o uso de três tipos de banho de resina: Funil, Banheira com rolos e Sistema de tambor.

- Funil: Neste sistema de banho, as fibras passam por um banho em um funil com resina e no fundo do funil elas passam por uma tampa de polietileno segura por uma mola. As fibras são impregnadas e a tampa funciona como um raspador eliminando o excesso de resina. Vantagens: simplicidade e sem partes móveis. Desvantagens: difícil colocação das fibras e permite um excesso de resina no mandril. A figura 72 ilustra 0 sistema de impregnação funil.

Figura 72 - Sistema de impregnação tipo Funil.

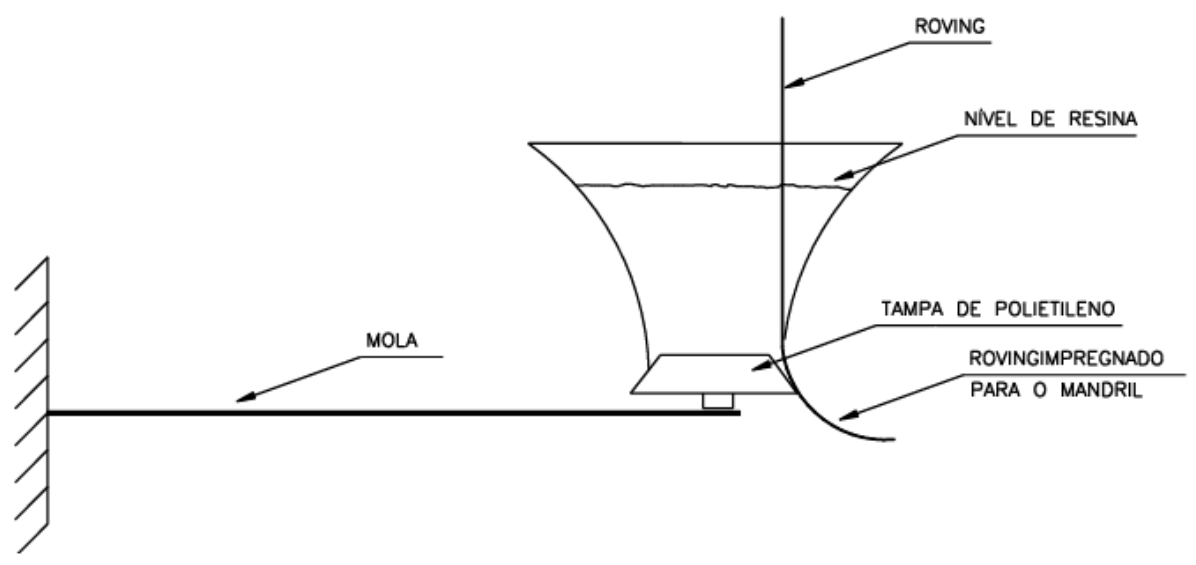

Fonte: COPMACO (2012).

- Banheira com rolos: neste sistema de banho, as fibras são direcionadas para dentro de um reservatório com resina, por meio de

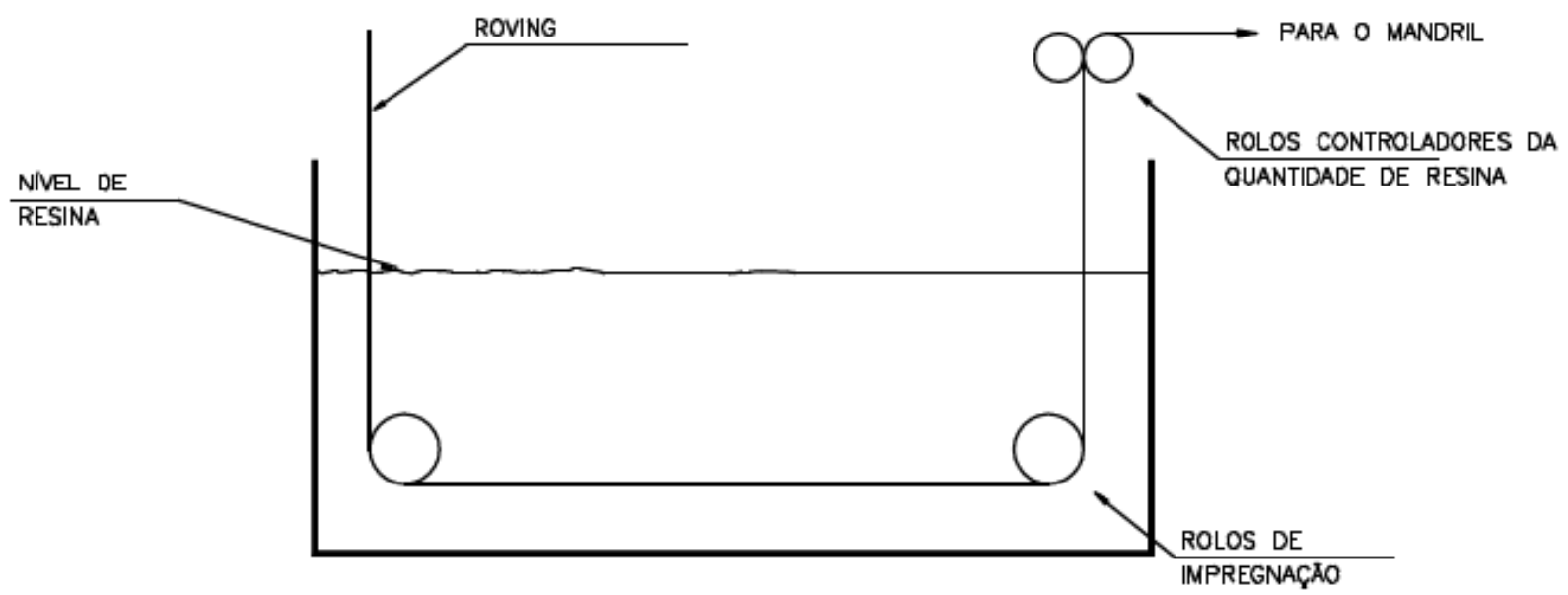


rolos. Na saída do reservatório, dois rolos removem o excesso de resina fazendo com que o excesso caia dentro do reservatório. Vantagem: Maior tempo das fibras em contato com a resina, facilitando a impregnação. Desvantagens: difícil colocação das fibras no sistema e filamentos quebrados enrosca nos rolos dificultando a limpeza e impedindo os rolos de girarem. A figura 73 ilustra o sistema de impregnação tipo banheira com rolos.

Figura 73 - Sistema de impregnação tipo Banheira com rolos.

Fonte: COPMACO (2012).

- Sistema de tambor: neste sistema de banho, as fibras são conduzidas a um reservatório por meio de rolos, um tambor impregna as fibras com resina e uma lâmina restringe o excesso de resina no tambor. Após a impregnação dois rolos removem o excesso de resina das fibras. Vantagens: Boa impregnação das fibras, fácil colocação das fibras e bom controle da impregnação. Desvantagens: possibilidade das fibras embaraçar e com a viscosidade muito alta o sistema pode requerer um acionador independente. A figura 74 ilustra o sistema de impregnação tipo tambor.

SCHOLLIERS (1992) uma vez que as fibras são produzidas separadamente da matriz, a matriz deve ser combinada com as fibras em certo estágio do processo de filament winding de tal maneira que a resina fique totalmente integrada com as fibras e o ar entre elas seja expulso. A impregnação deve ser homogênea.

Figura 74 - Sistema de impregnação tipo tambor. 


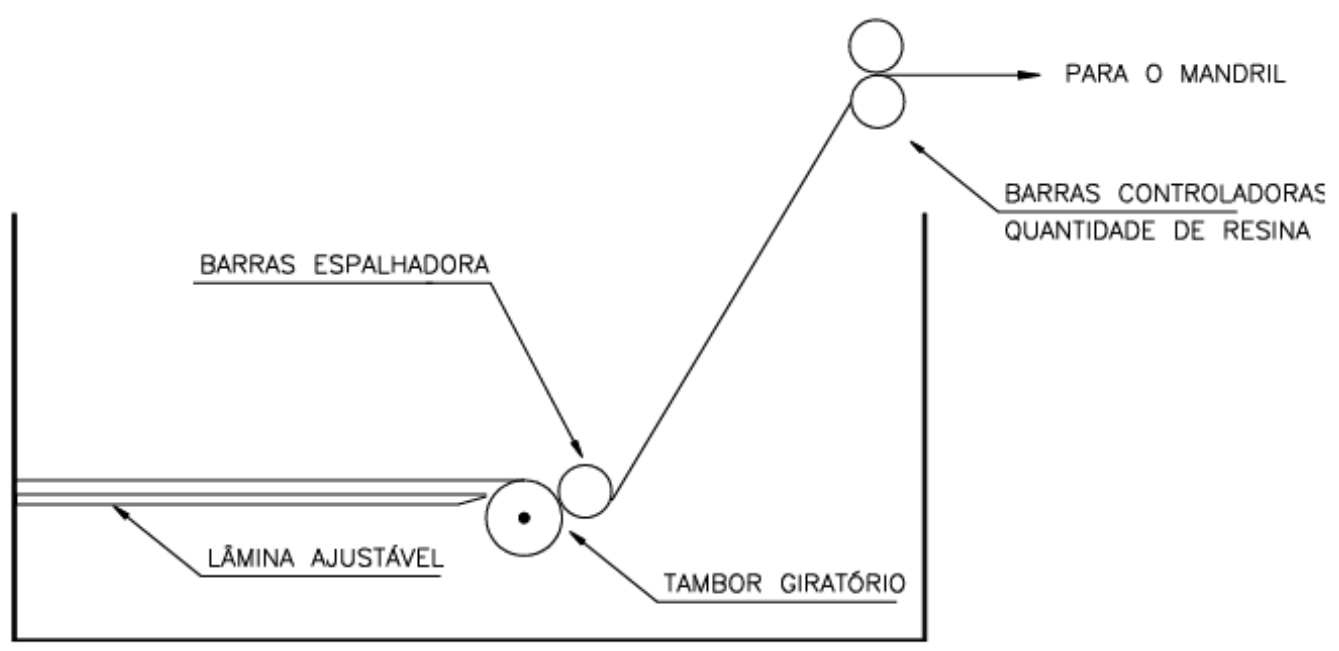

Fonte: COPMACO (2012).

\subsubsection{SISTEMA DE ORIENTAÇÃO DAS FIBRAS}

Entre o sistema de impregnação das fibras e o mandril, um sistema de orientação é inserido para guiar as fibras no mandril ao longo da trajetória desejada. Este sistema pode ser de deposição onde o dispositivo tem contato direto com o mandril, como no caso do Fiber Placement ou permite que as fibras tenham grau de liberdade para se acomodar no mandril, neste caso um olhal guia as fibras nas trajetórias desejadas, mas não tem contato direto com o mandril.

$\mathrm{Na}$ figura $68(\mathrm{~b})$ o olhal tem grau de liberdade para girar e as fibras provocam este giro para se acomodar no mandril. Na figura 67 o olhal é fixo e as fibras tem a liberdade de deslizar pela superfície do olhal. Neste sistema recomenda-se olhal polido para minimizar o atrito com as fibras e evitar ruptura dos filamentos.

\subsubsection{MANDRIL}

O mandril define a geometria da peça a ser manufaturada em filament winding. O mandril pode ser removido ou fazer parte da peça ao final do processo. No caso de mandril que faz parte da peça temos vasos de pressão. 
Vários materiais podem ser utilizados para manufatura dos mandris. GALE (2012) após o processo de filament winding o mandril é removido da peça, mas em casos o mandril não é removido e fará parte da peça final.

Mandris que serão removidos devem ser polidos e revestidos com material que evite com que a resina entre contato com o mandril sendo difícil ou prejudicial a peça a sua remoção. Pode se passar no mandril material desmoldante ou embrulhar 0 mandril em papel apropriado para este tipo de aplicação.

A tabela XXX apresenta os diferentes tipos de material para mandril.

Tabela 12 - Sistema de mandris utilizados em filament winding.

\begin{tabular}{|c|c|c|}
\hline Sistema de mandril & Visão geral & Comentários \\
\hline Aço cilíndrico & Mandril reutilizável & $\begin{array}{c}\text { Custo } \\
\text { relativamente baixo }\end{array}$ \\
\hline Papelão & Mandril barato & $\begin{array}{l}\text { Baixo custo de } \\
\text { ferramental }\end{array}$ \\
\hline Solúvel em água & Mandril removível & \multirow{3}{*}{$\begin{array}{c}\text { Mandril que pode } \\
\text { ser extraído }\end{array}$} \\
\hline Segmentado & $\begin{array}{l}\text { Mandril } \\
\text { desmontável }\end{array}$ & \\
\hline Capaz de desinflar & Mandril inflável & \\
\hline Integrado & $\begin{array}{l}\text { Mandril não } \\
\text { reutilizável }\end{array}$ & $\begin{array}{l}\text { Mandril que não } \\
\text { pode ser extraído }\end{array}$ \\
\hline
\end{tabular}

Fonte: GALE (2012). 


\subsection{MÁQUINAS CNC}

\subsubsection{HISTÓRICO}

"Homens tem sido descrito como uma ferramenta de uso animal. Entre as características que distingue ele de outras espécies é a habilidade de construir dispositivos complexos que magnífica ou estendem suas capacidades. Estes dispositivos, os quais chamaram de máquinas, tem governado a taxa do progresso do homem com materiais através da história. A evolução da máquina pode ser atribuída à propagação inerente do poder. A existência de ferramentas torna possível a manufatura das mais avançadas ferramentas nos quais em torno serve para acelerar o processo de evolução." PRESSMAN and WILLIAMS (1997).

Acredita-se que as primeiras máquinas ferramenta que foram construídas tenha sido desenvolvida há mais de 2500 anos atrás. Estes primeiros dispositivos de rotação permitiam os artesões produzir formas circulares com materiais como madeira. Por volta do século XIV uma evolução das máquinas já permitia a manufatura de peças relativamente complexas.

Durante a revolução industrial surgiram as primeiras máquinas controladas por cartões numéricos. Em 1650 na Holanda uma máquina de tocar tambores comandados por tambor com pinos foi construída, mais tarde este princípio se aplicou em caixinhas de música. O primeiro tocador automático de piano, patenteado por $\mathrm{M}$. Fourneaux em 1863 utilizava um grande rolo de papel com 12 polegadas de largura, perfurado de modo que 0 ar pudesse passar pelos furos para ativar teclas apropriadamente. No inicio de 1700 , M. Falcon inventou uma máquina de tricotar controlada por cartões perfurados. Cada um dos muitos cartões era sincronizado em uma sequência para atuar na máquina de tricotar. Cada furo em um dado cartão atuava um acoplamento mecânico o qual impulsionava uma agulha associada com uma coluna particular no cartão para puxar uma linha colorida através do tecido naquele certa posição. Fonte: Mundo CNC. A máquina de fiar desenvolvida por M. Falcon é ilustrada na figura 75. 
Figura 75 - Máquina de fiar controlada por cartão perfurado.

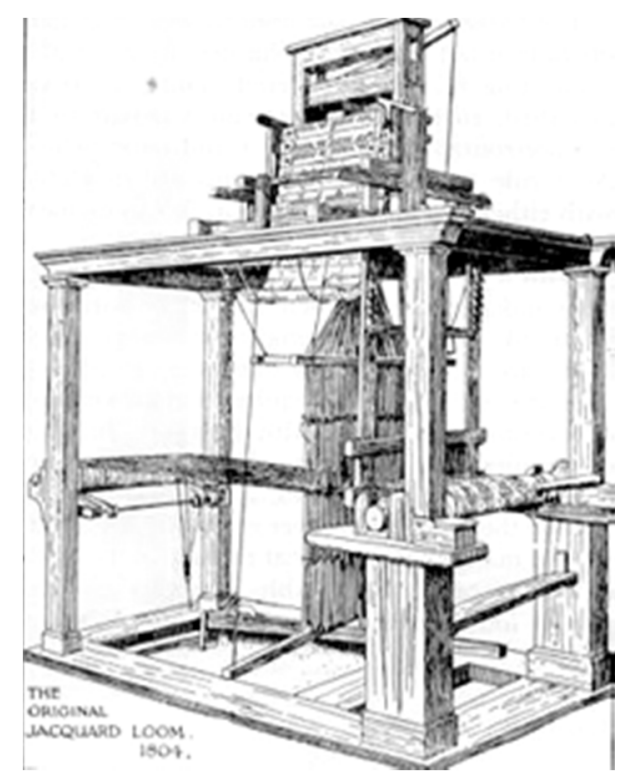

Fonte: PRESSMAN and WILLIANS (1997).

Nos primórdios de 1900 Hermam Hollerith desenvolveu um sistema armazenamento de dados para cartões perfurados para o departamento de recenseamento dos EUA. Durante a segunda guerra mundial, John Von Neumann projetou o computador de programas armazenados digitalmente o qual se tornou uma peça essencial para o comercio e indústria complexa. Em 1949, a força aérea norteamericana estava certa que máquinas ferramentas convencionais manuais não poderiam ser confiáveis para manter lado a lado as frequentes mudanças e ao mesmo tempo prover adequada produção de componentes de aviões em uma emergência. Baseado na experiência de uma pequena empresa fabricante hélices e rotores de helicópteros na época a "Parsons Corporation", que em 1947 havia experimentado colocar uma forma rudimentar de controle por números em uma máquina de usinagem convencional, ligando esta máquina a um computador que era alimentado por informações via cartões perfurados, a Força Aérea Americana então ao reconhecer um possível avanço na fabricação de aviões e material bélico, contratou a Parsons e patrocinou estudos e desenvolvimento do controle numérico, e assim planejaram e executaram as adaptações de controle numérico para uma máquina ferramenta convencional da Cincinnati (fabricante na época de máquinas ferramenta convencionais), e deste modo criaram o protótipo de uma máquina $\mathrm{CN}$ que foi 
demonstrado em 1953 no MIT Instituto de Tecnologia de Massachusetts. Estes estudos foram estendidos para incluir o desenvolvimento de sofisticadas rotinas de computadores por fitas perfuradas e os estudos da evolução do controle numérico. Os resultados foram excepcionais e demonstraram uma mudança revolucionária nas indústrias de transformação. O ímpeto dado pela força aérea americana permitiu um rápido desenvolvimento de uma variedade de controle de máquinas e sistema de armazenamento de dados. Muitos formatos diferentes foram aplicados, fita magnética, cartão perfurado, fita perfurada, e mais atualmente disquetes e sistemas de dados centralizados. O culminar das três tecnologias (Máquinas ferramenta, Automação, Informática), e a ansiedade evolutiva humana trouxeram hoje as possibilidades de construir peças e insumos de extrema complexidade e precisão, é possível, por exemplo, perceber a evolução nos design dos automóveis que há vinte anos tinham formas rudimentares que de certo modo nos dava a impressão de sobra de materiais. Como exemplo desta evolução, no interior de um bom automóvel, as formas são bonitas e variadas, tem se a impressão nítida de mais conforto, mais espaço, a ergonomia dos acentos, pedais e manoplas são impecáveis. Sem quase perceber em tudo isso esta implícita a evolução do CNC e as ferramentas afins, como os CAD/CAMs e máquinas ferramentas. Fonte: Mundo CNC.

As máquinas CNC são voltadas para a área de usinagem, sua precisão, alta velocidade de trabalho e elevado grau de repetibilidade na usinagem de peças fazem delas uma necessidade na manufatura em produção. Muito comum em máquinas ferramentas totalmente mecânicas, ou controladas por cames, serem reformadas e modificadas para serem controladas por CNC. Máquinas controladas por cames, dispositivos copiadores, ou qualquer controlador mecânico dedicado, não possuem a flexibilidade para produzirem diversas geometrias. Um torno copiador, por exemplo, é limitado a usinar o perfil do copiador, se houver uma mudança não muito significativa na geometria, um novo perfil deve ser usinado e inserido no copiador, porém se a mudança for significativa, pode até ocorrer a substituição de todo o copiador. Um torno acionado por cames, por sua vez, há a necessidade da construção de um novo came, ou a troca do mesmo, para a execução de uma nova geometria. No torno CNC, para cada nova geometria ou mudança da mesma, basta chamar ou escrever um novo programa, não há a necessidade da construção de novos dispositivos mecânicos. Em todos estes tornos, porém, pode ou não haver a necessidade de um ajuste de 
ferramentas e preparação da máquina (pré-set) dependendo da mudança de geometria. A figura 76 ilustra exemplos de tornos com copiador, came e CNC.

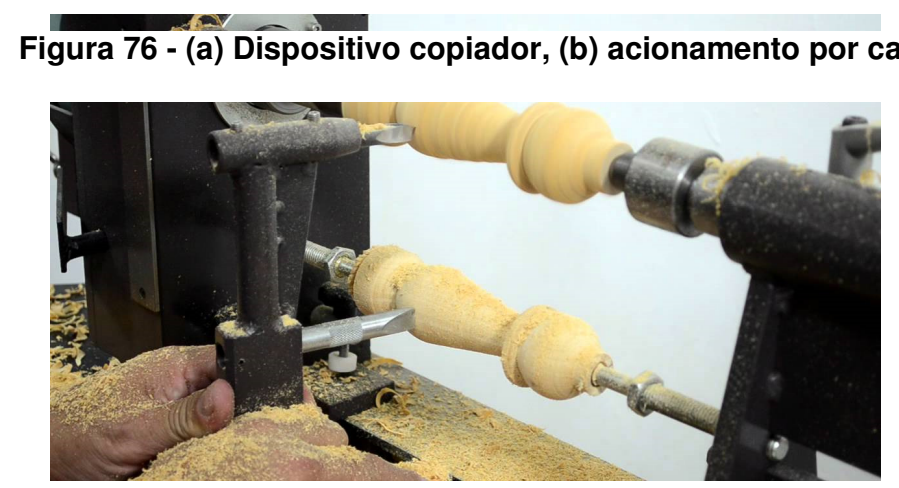

(a) :) torno CNC.

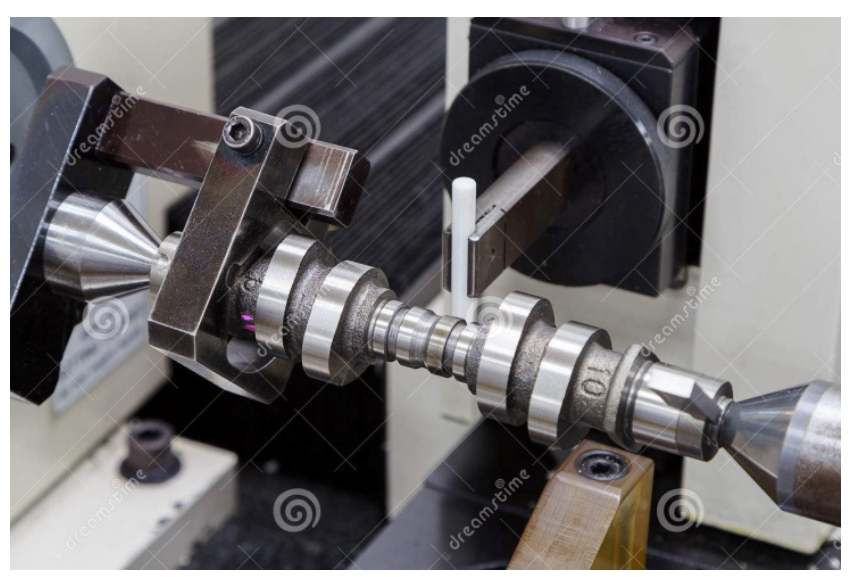

(b)

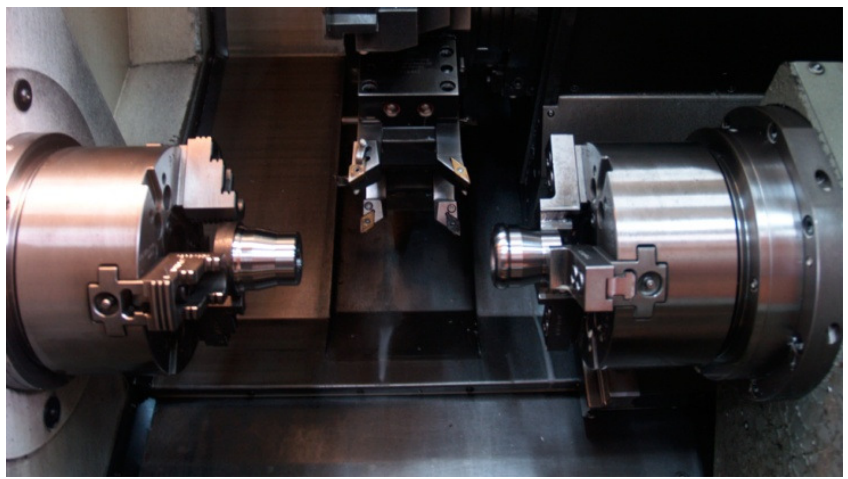

(c)

Fonte: (a) Mega Turn Woodturning Lathe (2012). (b) Dreamstime.com. (c) Macro-moldes. 


\subsubsection{COORDENADAS}

As máquinas CNC trabalham com coordenadas, sendo estas podendo ser programadas de modo absoluto, incremental e polar. Na coordenada absoluta, uma vez definido o ponto zero, também chamado de zero peça, todas as trajetórias e posições que a ferramenta executará parte do zero pré-definido. Na coordenada incremental, o zero peça serve apenas para o início do deslocamento, a partir deste ponto a trajetória e posição da ferramenta será determinado em função de um novo zero a cada deslocamento realizado, ou seja, o zero é flutuante. Na coordenada polar o deslocamento da ferramenta é feito em função de um raio e ângulo programado. A figura 77 ilustra o gráfico para coordenadas cartesianas nos planos $\mathrm{X}$ e $\mathrm{Y}$.

Figura 77 - Coordenadas cartesianas. Plano X e Y. Divisão em mm, cada divisão equivale a 10mm.

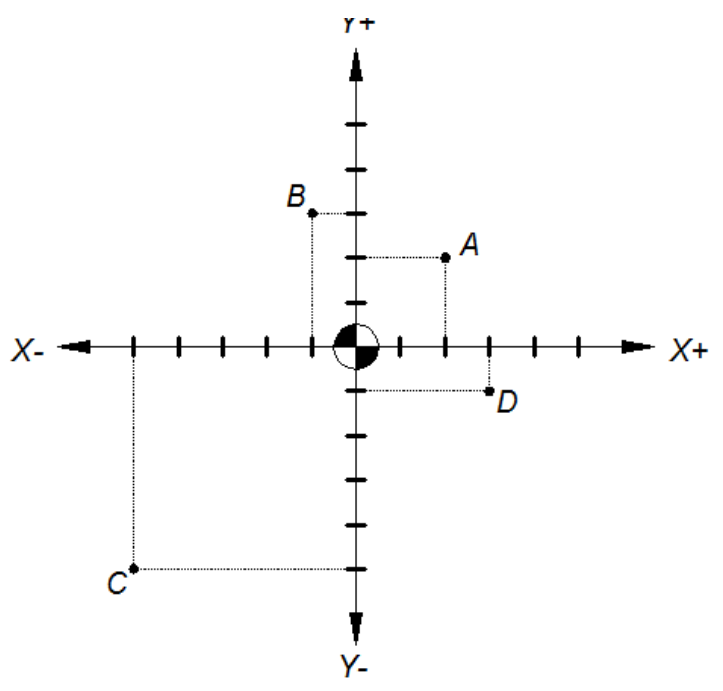

Fonte: Próprio autor (2015).

As coordenadas acima servem para centro de usinagem, cujo eixo $Z$ é o eixo perpendicular aos eixos $\mathrm{X}$ e $\mathrm{Y}$. No caso de torneamento os eixos utilizados são $\mathrm{X}$ e $Z$, com X para diâmetro e Z para deslocamento longitudinal.

A tabela 13 ilustra as coordenas cartesianas da figura 77 em coordenadas absolutas e incrementais. 
Tabela 13 - Coordenadas absolutas e incrementais.

\begin{tabular}{|c|c|c|c|c|c|}
\hline \multicolumn{2}{|c|}{ COORDENADAS ABSOLUTAS } & \multicolumn{3}{c|}{$\begin{array}{c}\text { COORDENADAS } \\
\text { INCREMENTAIS }\end{array}$} \\
\hline PONTO & EIXO X & EIXO Y & PONTO & EIXO X & EIXO Y \\
\hline$A$ & 20 & 20 & $A$ & 20 & 20 \\
\hline$B$ & -10 & 30 & $B$ & -30 & 10 \\
\hline$C$ & -50 & -50 & $C$ & -40 & -80 \\
\hline$D$ & 30 & -10 & $D$ & 80 & 40 \\
\hline
\end{tabular}

Fonte: Próprio autor (2015).

A utilização de CNC apresenta muitos recursos na programação, um destes recursos é a possibilidade de trabalhar com coordenadas polares, onde é possível dar valores para raios e ângulos. A figura 78 ilustra as coordenadas polares e a tabela 14 os valores para as coordenadas da figura 78 .

Figura 78 - Coordenadas polares.

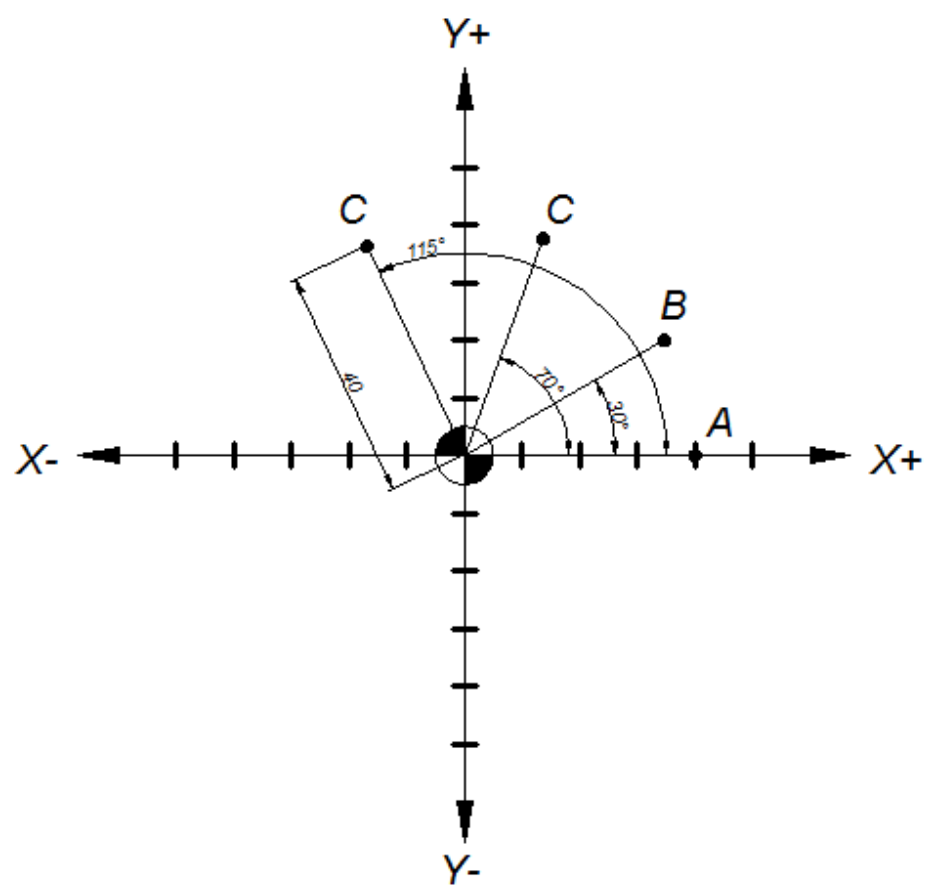

Fonte: Próprio autor (2015). 
Tabela 14 - Coordenadas polares.

\begin{tabular}{|c|c|c|}
\hline \multicolumn{3}{|c|}{ COORDENADAS POLARES } \\
\hline PONTO & RAIO & $\hat{A N G U L O}$ \\
\hline A & 40 & $0^{\circ}$ \\
\hline B & 40 & $30^{\circ}$ \\
\hline C & 40 & $70^{\circ}$ \\
\hline D & 40 & $115^{\circ}$ \\
\hline
\end{tabular}

Fonte: Próprio autor (2015).

\subsubsection{MÁQUINAS CNC}

As máquinas CNC trabalham em um ambiente tridimensional ou bidimensional conforme a necessidade.

Tornos CNC com dois eixos são comandados pelos eixos: $X$ que define 0 diâmetro e eixo $Z$ que define o comprimento da peça a ser usinada. $\mathrm{O}$ eixo $\mathrm{C}$ define a posição da placa. O eixo A define a posição da torre ou magazine de ferramentas.

Centro de torneamento, também denominado como torno multitarefa, é uma máquina-ferramenta de alto rendimento que conta com um elevado grau de automatização, possibilitando controlar diversos eixos lineares e circulares e utilizar tanto ferramentas fixas como acionadas, com o objetivo de usinar peças complexas com elevada precisão por completo. Centro de torneamento conta com um quarto eixo, denominado em algumas máquinas de Y. Esta máquina além das operações de torneamento, contam com um dispositivo de fresamento.

Estes tornos também podem vir equipados com alimentador automático dispensando o tempo do operador em alimentar a máquina com matéria prima.

Centro de Usinagem CNC é uma máquina destinada à produção seriada e à usinagem de superfícies e geometria complexas. Esta máquina trabalha com ferramentas de corte para movimentos circulares como fresas, brocas, alargadores, machos, etc. Também pode ser usadas ferramentas para abertura de chavetas. Nesta 
máquina a ferramenta executa o movimento circular horário ou anti-horário na direção vertical e o movimento da mesa ocorrem na direção horizontal no sentido da direita, esquerda, frontal e para trás. A combinação destes movimentos resulta em peças das mais variadas geometrias. A figura 79 ilustra um torno e um centro de usinagem.

Figura 79 - Máquinas CNC. Torno e Centro de usinagem.
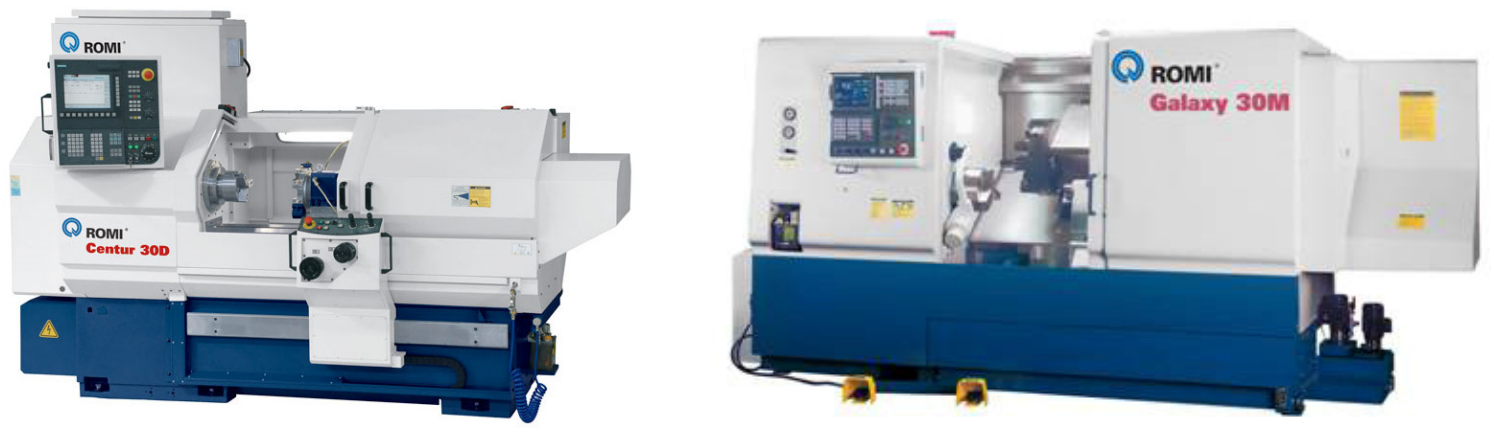

Fonte: Romi (2013).

No centro de usinagem o ambiente em geral é comandado por três eixos: $X$ deslocamento da mesa na esquerda e direita, eixo $Y$ movimenta a mesa para frente $e$ para trás e eixo $Z$, o eixo árvore, movimenta a ferramenta na direção vertical perpendicular a mesa.

Nestas máquinas podem ainda ser adicionados o quarto e quinto eixos para a manufatura de peças de maior complexidade.

Além do Torno e Centro de Usinagem existe outra máquina CNC como eletroerosão a fio, puncionadeira, etc. Algumas máquinas convencionais podem ser reformadas ou modificadas para receber o comando CNC. É o caso, por exemplo, de empresas que possuem tornos convencionais e sofrem reformas e são adaptados para o CNC. Estas máquinas aumentam sua produtividade e flexibilidade. 
As máquinas CNC trabalham com fuso de esferas ao invés de varão roscado. O posicionamento é feito através de servos-motores e incoders ou réguas graduadas que garantem a posição da mesa ou ferramenta na posição programada. $O$ uso do fuso de esferas dá a liberdade da máquina de usinar em qualquer direção ou em sentido concordante ou discordante, ao contrário das fresadoras convencionais onde o fresamento é realizado sempre no sentido discordante.

\subsubsection{LINGUAGEM ISSO DE PROGRAMAÇÃO EM CNC}

As máquinas $\mathrm{CNC}$ tem sua própria linguagem de programação conforme cada fabricante. Por exemplo, Siemens tem o próprio comando Siemens, Mazak tem a linguagem Mazatrol. Mas para que isso não fosse um problema, todas estas máquinas vêm equipadas com a linguagem ISO, uma linguagem universal também conhecida como linguagem $\mathrm{G}$ ou código $\mathrm{G}$. Na linguagem $\mathrm{G}$ os códigos "Gs" são as funções preparatórias da máquina, para ciclos, mudança de interpolação, etc. Os códigos "Ms" são as funções miscelâneas, ligam e desligam óleo, ligam eixo árvore no sentido horário ou anti-horário, abrem e fecham porta, etc. Os parâmetros de usinagem estão nas letras S e F.

Abaixo segue um exemplo de programação de um torno Galaxy 10 ROMI comando Fanuc.

O0001 (EXEMPLO DE PROGRAMAÇÃO);

N10 G21 G40 G90 G95;

N20 G0 G53 X0 Z0;

N30 T0101 (FERRAMENTA DE DESBSTE);

N40 G54;

N50 G96 S150;

N60 G92 S2500 M3;

N70 G0 X25 Z3 M8; 
N80 G74 X18 Z-50 P2000 Q53000 R2 F.35;

Esta é uma operação de desbaste em torneamento paralelo. As linhas de programa são separadas em blocos designados pela nomenclatura N10, N20...Nnn. No bloco N10 ocorre uma função preparatória para a máquina, selecionando as características de trabalho: trabalho com milímetros, descompensação do raio da ferramenta, avanço em milímetros por volta e coordenadas absolutas.

No bloco N60 a função miscelânea M3 indica o sentido horário de giro para o eixo árvore e no bloco seguinte a função M8 liga o óleo refrigerante. Já no bloco N80, um ciclo de torneamento automático é acionado, $X$ e $Z$ são as coordenadas finais do torneamento, $P$ e $Q$ são incrementos de corte, $R$ afastamento da ferramenta e $F$ o avanço da ferramenta.

\subsubsection{LINGUAGEM DE PROGRAMAÇÃO C}

A linguagem de programação C foi desenvolvida entre os anos de 1969 e 1973, foi batizada de linguagem $C$ devido ao desenvolvimento dela surgir a partir da linguagem $B$. A primeira notícia que se tem do uso da linguagem $C$ fora do ambiente acadêmico foi por volta de 1983. Na década de 70 a linguagem $C$ começou a substituir a linguagem Basic na programação de microcomputadores e durante os anos 80 começou a ser utilizada em PC's IBM, quando começou a se tornar popular.

A linguagem C\# faz parte do conjunto de ferramentas oferecidas na plataforma .NET e surge como uma linguagem simples, robusta, orientada a objetos, a fim de permitir que uma mesma aplicação possa ser executada em diversos dispositivos de hardware, independentemente destes serem PCs, handhelds ou qualquer outro dispositivo móvel.

C\# ou C Sharp como é conhecida surgiu como necessidade às novas necessidades da programação. Os desenvolvedores reconheceram a necessidade de software que fosse acessível para qualquer um e disponível por meio de praticamente qualquer tipo de dispositivo.

Após uma evolução da linguagem $C$, com o surgimento do C\#, imaginava-se que a nomenclatura da linguagem seria $\mathrm{C}++++$, porém decidiu-se por $\mathrm{C \# ,} \mathrm{com} \mathrm{O}$ 
símbolo sustenido (\#), sendo uma alusão ao símbolo que aumenta em meio tom uma nota musical.

O C\# é uma linguagem de programação visual dirigida por eventos e totalmente orientada a objetos. Permite um grau de intercâmbio entre linguagens (componentes de software de diferentes linguagens podem interagir). Os desenvolvedores podem empacotar até software antigo, para trabalhar com novos programas C\#. Os aplicativos C\# podem interagir pela Internet usando padrões do setor, como SOAP (protocolo de acesso a objetos simples) e XML (linguagem de marcação extensível).

O C\# tem raízes em $\mathrm{C}, \mathrm{C}++$ e Java, adaptando os recursos de cada linguagem e acrescentando novas capacidades próprias. Ele fornece os recursos que são mais importantes para os programadores, como programação orientada a objetos,strings, elementos gráficos, componentes de interface com o usuário gráfica (GUI), tratamento de exceções, múltiplas linhas de execução, multimídia (áudio, imagens, animação e vídeo), processamento de arquivos, estruturas de dados pré-empacotadas, processamento de banco de dados, redes cliente/servidor com base na Internet e na World Wide Web e computação distribuída.

\subsection{SOFTWARE PARA FILAMENT WINDING}

Segundo SILVA (2005), existem vários programas para o processo de Filament Winding, que calculam as trajetórias das fibras na superfície do mandril. Estes programas possuem pacotes que podem gerar trajetórias tanto para peças simétricas quanto assimétricas. Alguns diferenciais destes programas são os recursos que oferecem como visualização 3D, geração de imagem em tempo real, análise CAE, possibilidade de mudança de trajetória ao longo do mandril, etc.

Dentre os programas para o cálculo das trajeórias das fibras para filament winding, temos programas comerciais e acadêmicos. Os programas comerciais normalmente são "caixas pretas", o usuário possui liberdade para mudanças como geometria da peça, trajetórias nas camadas, entre outras, restrita ao que o fabricante oferece, estes programas estão mais voltados à produção seriada. No caso de uma mudança que necessite uma alteração no programa, o suporte técnico é a saída. 
Programas acadêmicos podem ou não ser aberto à comunidade e estão mais voltados às pesquisas que ao volume de produção.

\subsubsection{PROGRAMAS COMERCIAIS \\ CADFIL ${ }^{8}$}

Desenvolvido pela Crescent Consultants Limited, uma empresa que atua no segmento de compósitos manufaturados por Filament Winding desde 1983, CADFIL® é um software desenvolvido para para máquinas para Filament Winding com Comando Numérico (NC). O próprio fabricante dispõe em seu site a versatilidade do programa e a opção de desenvolver o programa para situações específicas.

O programa CADFIL® é subdividido em softwares específicos para cada aplicação:

- Cadfil Axsym - enrolamento de peças simétricas.

- Cadfil Lite - uma versão com mais recursos visuais que o Cadfil Axsym.

- Cadfil Sphere - específico para o enrolamento de perfis esféricos.

- Cadfil Ewbow Windign - enrolamento de perfils como cotovelos.

- Cadfil Pipe-winder - enrolamento de tubos.

- Cadfil Finite Elements Interface - programa para análise de elementos finitos.

- Tube Stress Analysis - programa para análise de tensão em tubos.

- Pole Design Module - programa para o cálculo da deformação de flexão em polos cônicos ou mastros manufaturados por Filament Winding.

A figura 80 (a) ilustra os parâmetros requeridos pelo Cadfil e a figura 80 (b) ilustra a tela de operação do Cadfil Lite, programa voltado à peças simétricas como vasos de pressão. 
Figura 80 - Parâmetros requeridos pelo software Cadfil.

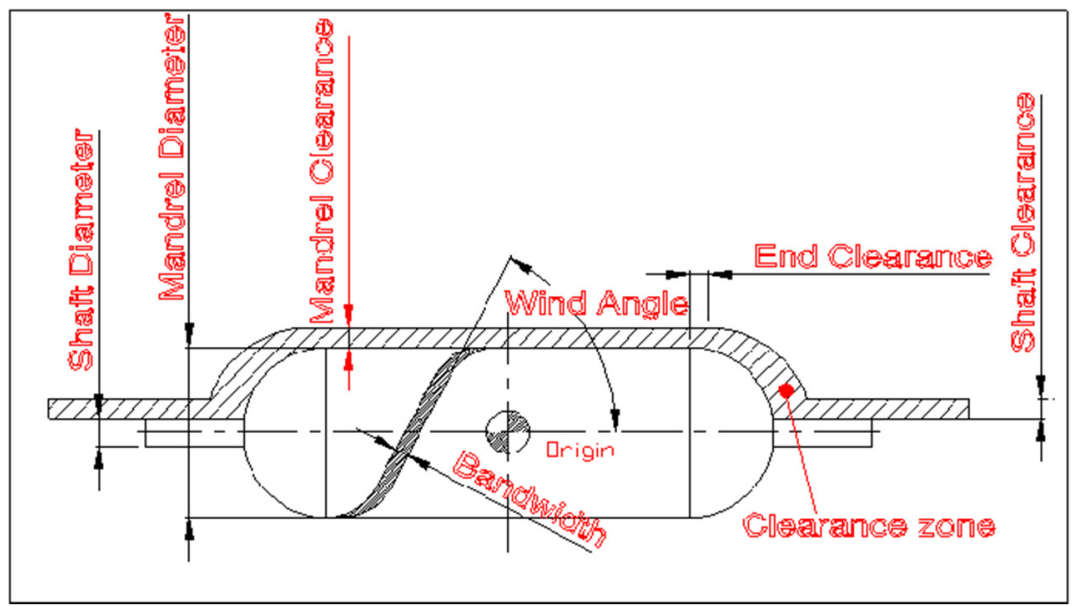

(a)

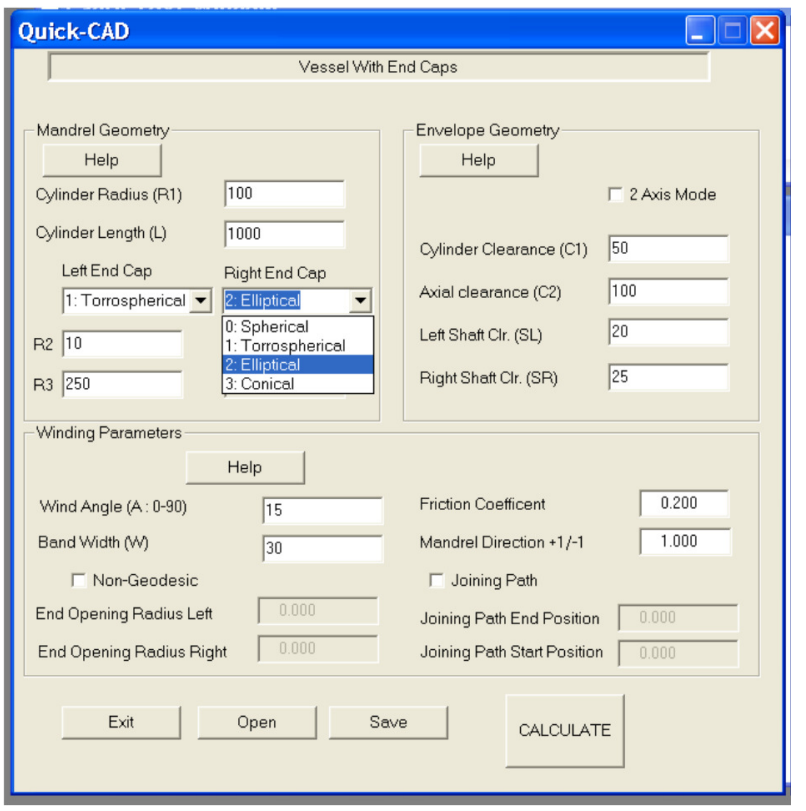

(b)

Fonte: Crescent Consultants Limited (2012).

\section{FIBER GRAFIX®}

Desenvolvido pela ENTEC Composites Machines, Inc do gupo Toray, Fiber Grafix® é um programa capaz de calcular as trajetórias das fibras para peças das mais variadas geometrias, importar desenhos a partir do sistema CAD, capaz de criar, 
modificar e organizar as camadas de revestimento, coordenar os movimentos dos eixos das máquinas, gerar visualizações 3D e fazer análise de elementos finitos.

Este grupo também fabrica máquinas para Filament Winding, tensionadores das fibras, equipamentos para o banho das fibras, etc.

Fiber Grafix® módulo Winding Simulation: ilustrado na figura 81 , se destina à criação e modificação do mandril onde as fibras serão enroladas, gerenciamento de projeto, trajetórias das fibras na superfície do mandril e definição de parâmetros.

Figura 81 - Tela do software Fiber Grafix®.

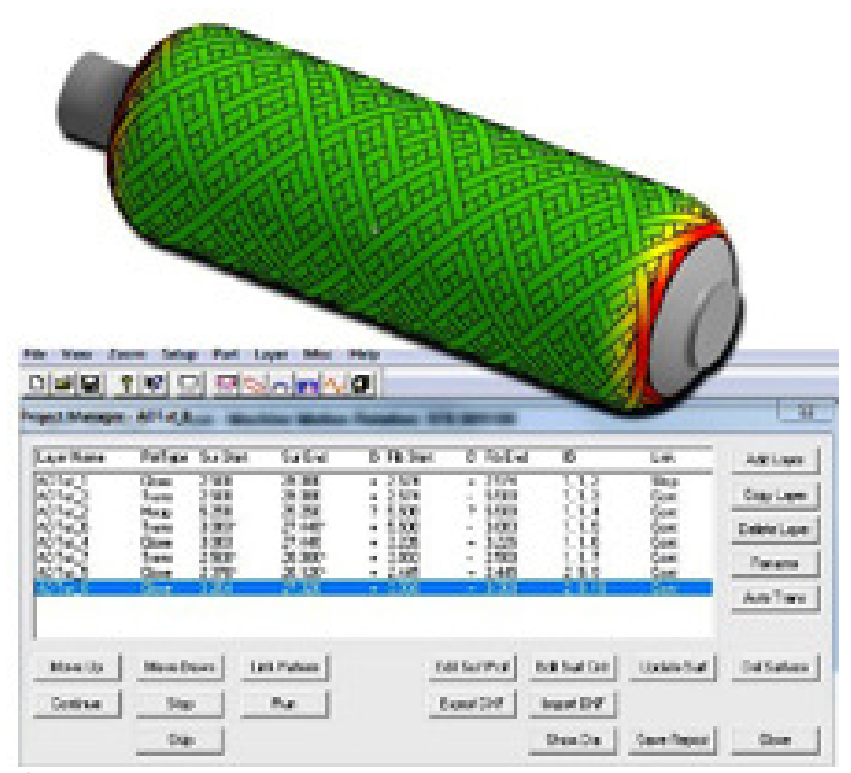

Fonte: ENTEC (2012).

Módulo Machine Simulation: ilustrado na figura 82, este módulo gerencia os servos de acionamento da máquina e exibe o gráfico de simulação de máquina.

Figura 82 - Fiber Grafix®, módulo de simulação de máquina.

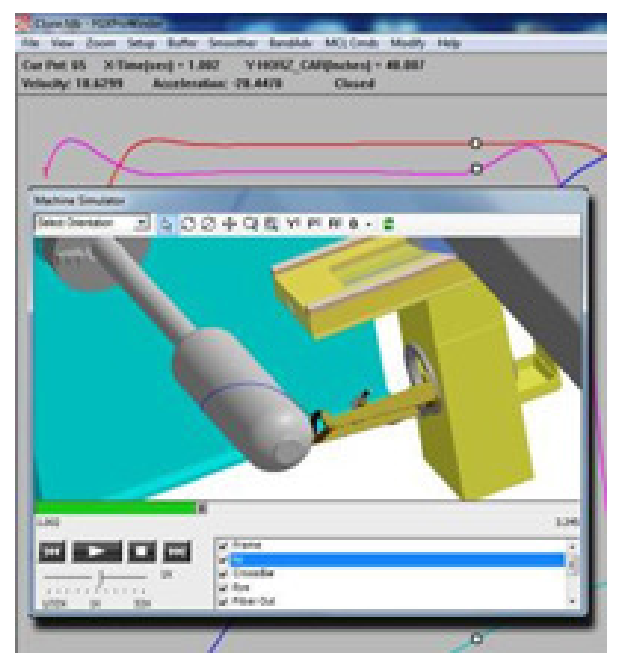


Fonte: ENTEC (2012).

Módulo ANALISYS: este último módulo ilustrado na figura 83, faz interface com análises oriundas de análise em CAE. Permite alterações no projeto da peça em confecção.

Figura 83 - Tela do módulo de análise.

Fonte: ENTEC (2012).

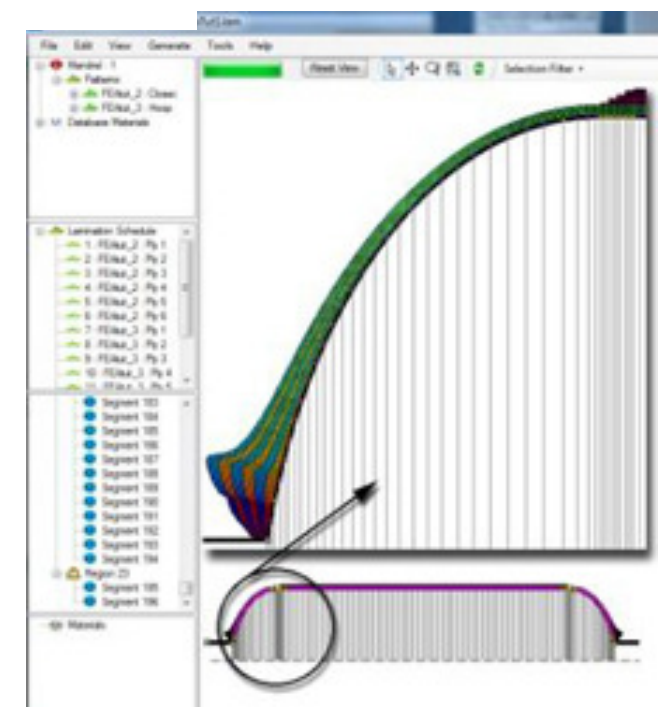

\section{CADWIND®}

Desenvolvido pela Netamax Engineering, CADWIND® é um dos programas que pode ser baixado numa versão experimental. Este programa é voltado para o cálculo das trajetórias e simulação de movimentos. No módulo de simulação, é possível verificar o atrito entre fibra e mandril.

CADWIND® também analisa o movimento dos eixos, disponibilizando uma visualização do gráfico de desempenho dos eixos.

Uma das telas operacionais do CADWIND® pode ser visto nafigura 84. 
Figura 84 - Tela operacional do CADWIND®.

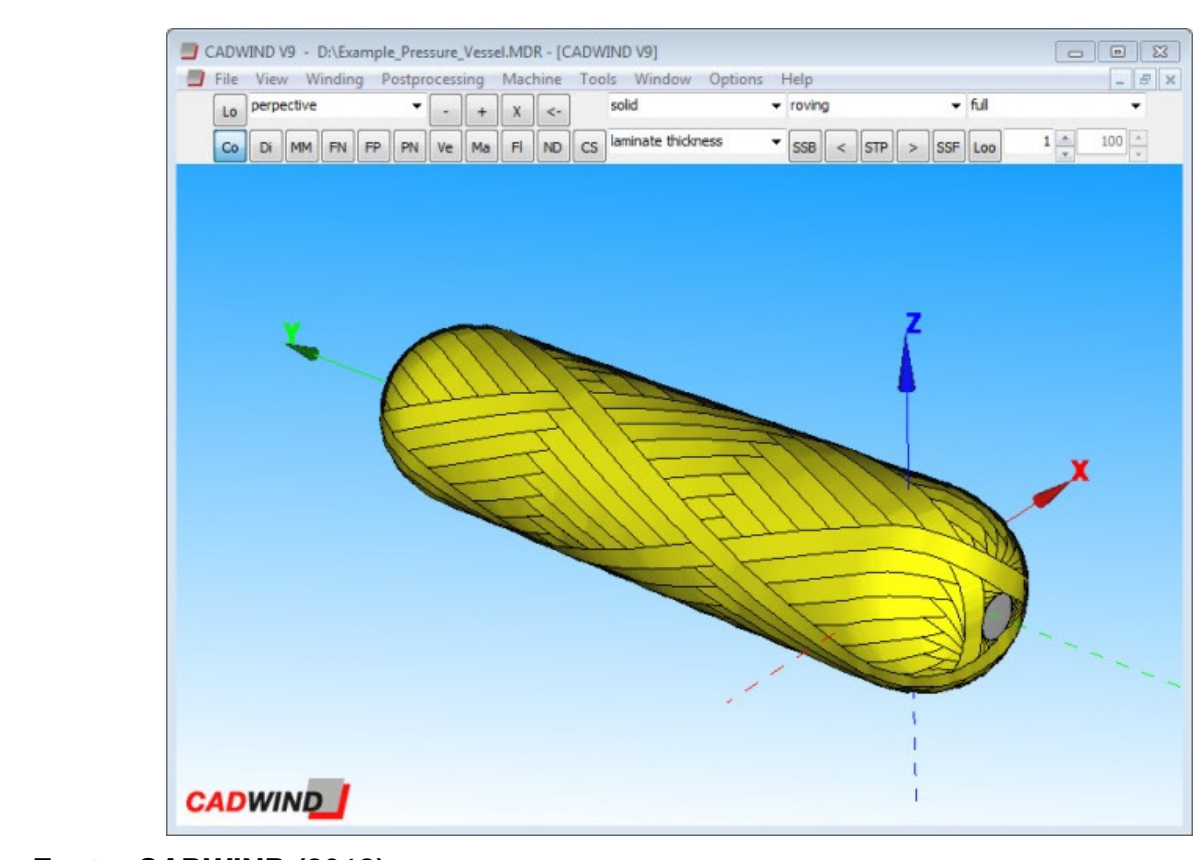

Fonte: CADWIND (2012).

\subsubsection{PROGRAMAS ACADÊMICOS}

Alguns programas para filament winding forma desenvolvidos nos meios acadêmicos e se tornaram comerciais, outros são usados apenas no ambiente acadêmico e alguns trabalhos usam softwares comerciais para realizar seus trabalhos.

HEITKOETTER (2009) realizou uma simulação computacional para motores de foguetes utilizando o processo de filament winding. Para seu experimento o software CadWind® foi utilizado. A simulação avaliou ângulos de bobinagem e padrões de enrolamento para verificar qual o melhor padrão de enrolamento para ancoragem e distribuição das fibras na construção de motores de foguete.

Este é um exemplo de utilização de software para filament winding comercial no meio acadêmico para pesquisas.

XU (2006) sistema aberto de controle numérico de máquinas para manufatura de materiais compósitos reforçados por fibras para a fabricação de tubos pelo processo de filament winding é composto por um computador industrial e um controlador de movimento sincronizado. XU desenvolveu um modelo matemático para 
controladores de transmissão e velocidade não uniforme, algoritmo de controle de posição de volta, posição do eixo árvore e método de interpolação. O software de desenvolvimento utilizado por $\mathrm{XU}$ foi o Visual $\mathrm{C}++6.0$ baseado na plataforma Windows 2000.

SCHOLLIERS (1992) desenvolveu um programa em linguagem C para o cálculo das trajetórias das fibras no processo de filament winding. O programa batizado de CAWAR foi usado, mais tarde, por CARVALHO (1996) para implementar novas rotinas para o problema de deslizamento da fibra da trajetória previamente calculada.

JOHANSEN (1998) desenvolveu um trabalho com estratégias para padrão de enrolamentos em filament windign. Em seu trabalho JOHANSEN utilizou o programa CADPath desenvolvido por B.S. Johansen, M.T. e Jensen, para o cálculo das trajetórias. Este programa estava disponível na rede para download como usuário sem o código fonte para pesquisas. 


\section{CAPÍTULO 3}

\section{MATERIAIS E MÉTODOS}

Com o objetivo de elaborar um programa para filament winding e validar o mesmo, o desenvolvimento deste trabalho ocorreu em três fases distintas. A primeira fase consistiu no desenvolvimento de um programa de computador para calcular os valores das trajetórias das fibras em uma superfície cilíndrica de comprimento e diâmetro constantes e determinados, a segunda fase consistiu em projetar dispositivos e acessórios que auxiliassem a validação do programa. Estes dispositivos e acessórios foram projetados, manufaturados, montados e testados. Finalmente a terceira fase consistiu em validar o programa. O programa gerou um código NC para um torno CNC, os dispositivos e acessórios manufaturados foram montados no torno e próximos à máquina e um mandril de formato tubular foi enrolado com fibras para validar o programa.

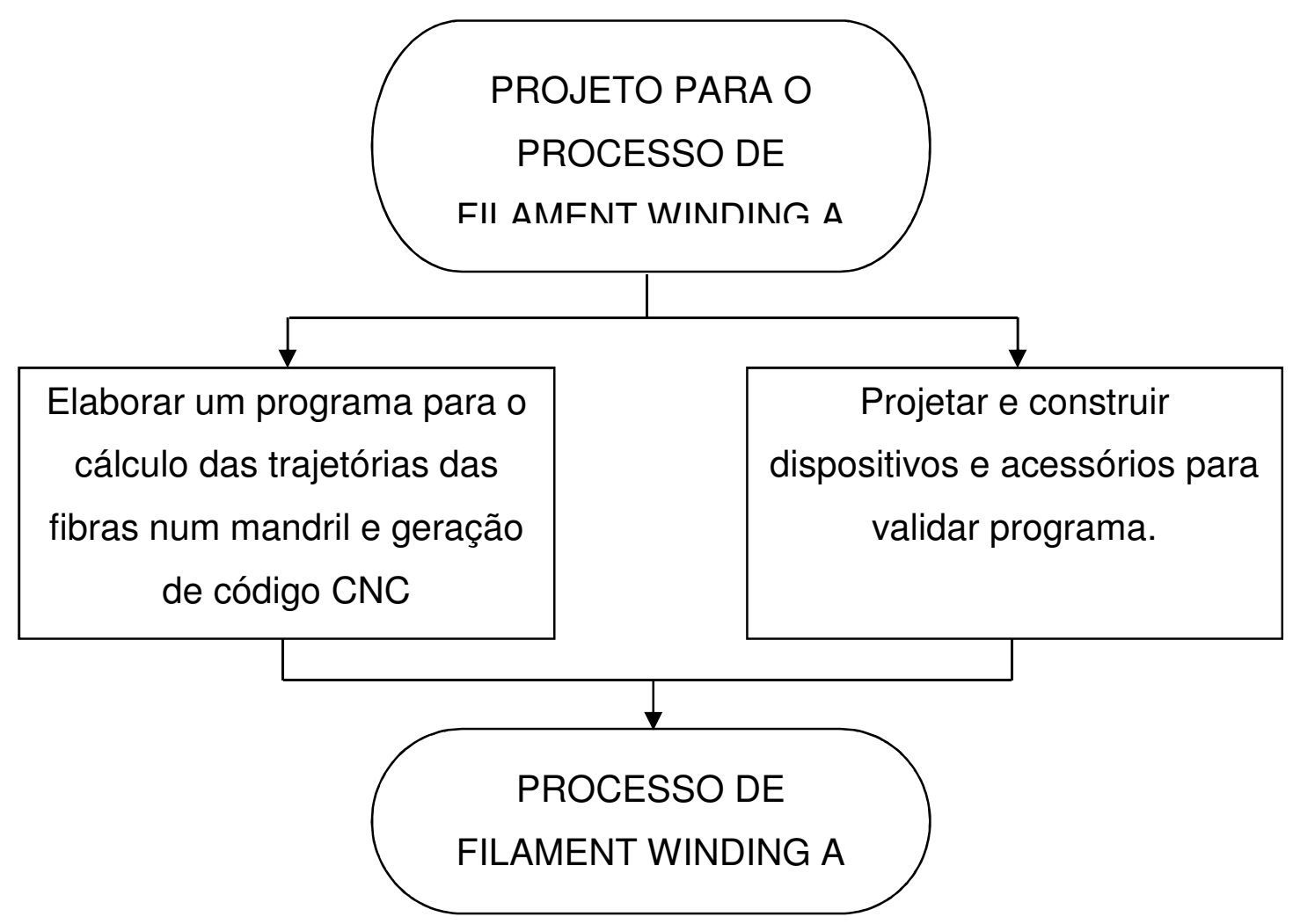

O programa é baseado nos programas existentes onde o usuário fornece os dados para o processo de filament winding e o programa retorna dados para manufatura do produto projetado. 
Para o projeto mecânico, dispositivos e acessórios, que validem o programa, a metodologia de desenvolvimento de produto (PDP) de ROZENFELD (2006) foi utilizada como base neste trabalho. A figura 85 ilustra a metodologia do desenvolvimento.

Figura 85 - Metodologia para desenvolvimento de produto.

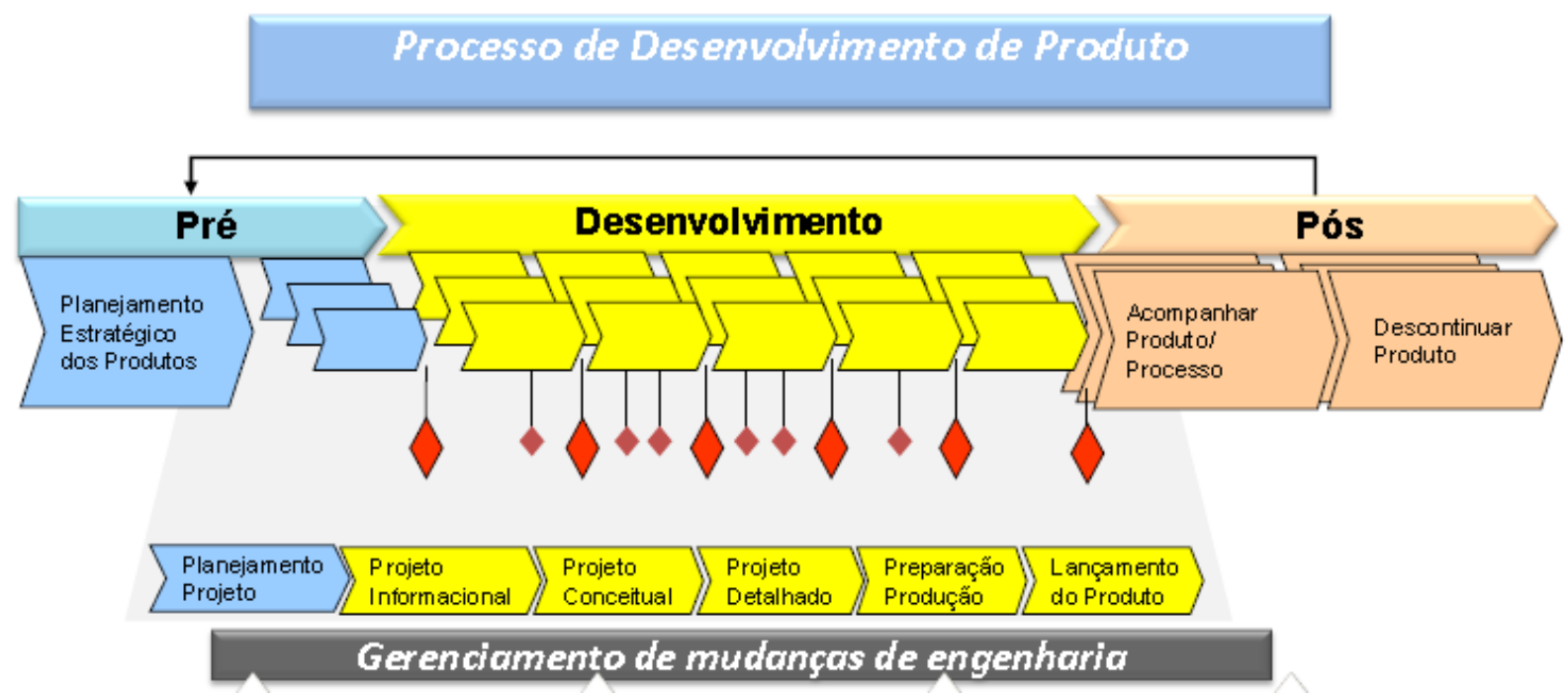

Fonte: ROZENFELD (2006).

Pré-Desenvolvimento: requisitos e necessidades do projeto.

Desenvolvimento: Projeto conceitual e detalhado.

Pós: testar, validar, sugerir melhorias. 


\subsection{O PROGRAMA}

Dos programas pesquisados, os comerciais são de código fonte fechado não sendo permitido ao portador da licença alteração no código fonte. Embora alguns deles como o caso do Cadfil@ ser possível baixar uma versão DEMO.

Os programas acadêmicos são voltados para máquinas automatizadas, como robôs, controle de servo-motores, etc. Nas pesquisas não foram encontrados programas que utilizassem o programa $\mathrm{CNC}$ de uma máquina comercial utilizando a linguagem ISO ou linguagem $G$ de programação em CNC para executar os movimentos do processo de filament winding.

Nas pesquisas foram encontrados programas elaborados na linguagem C. Para este trabalho optou-se utilizar a linguagem C\# do programa Microsoft Visual Studio 2010. Um programa que pode ser baixado gratuitamente do site do fabricante, desde que utilizado para fins acadêmicos.

A ideia inicial deste trabalho era um programa capaz de ler superfícies provenientes de modelos elaborados em programas CAD 3D nos protocolos IGES e STL e através desta superfície desenvolver as trajetórias das fibras na superfície do modelo CAD.

O motivo pelo qual a ideia foi posta de lado foi de que num primeiro momento o programa iria executar apenas superfícies cilíndricas com comprimento e diâmetros pré-estabelecidos. Diante desta tornou-se mais vantajoso o próprio programa ser capaz de gerar as trajetórias sem a necessidade de um programa CAD para gerar a superfície. Outro motivo que levou a deixar a ideia inicial de lado, mas não fora dos planos numa etapa futura, foi uma limitação encontrada no formato STL. As trajetórias das fibras teriam de ser elaborado com base nos vértices dos triângulos gerados pelo protocolo STL o que levaria obrigatoriamente a passar por pontos da superfície nem sempre desejados e desviaria do proposto.

O programa para a finalidade deste trabalho deveria ser capaz de ler os dados fornecidos pelo usuário, gerar curvas das trajetórias das fibras em cima de uma superfície cilíndrica, gerar dados em planilhas de Excel para leitura e análise das curvas em programa CAD (Solidedge escolhido para este trabalho) e por fim gerar um 
código CNC para manufatura de um tubo pelo processo de filament winding. A figura 85 ilustra o fluxograma da proposta do programa.

Figura 86 - Fluxograma da proposta do programa.

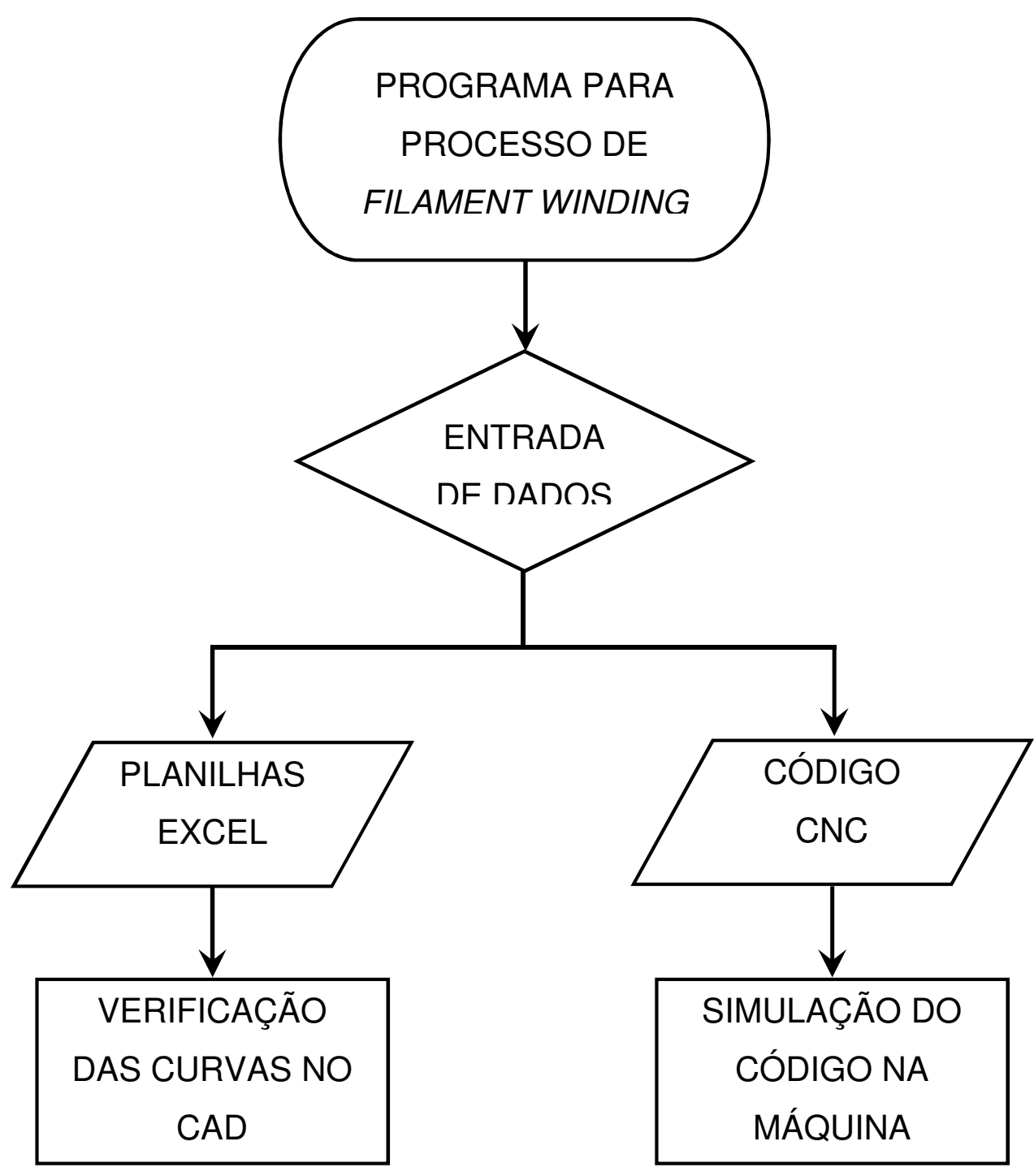

Fonte: Próprio autor (2014).

O programa foi elaborado para trabalhar em telas de trabalho que conduzem o usuário de maneira interativa a preencher os dados necessários para o que se deseja realizar.

O programa solicita dados para a construção da trajetória, como diâmetro do mandril, comprimento, largura da mecha, ângulo das trajetórias, camadas, etc. A figura 86 ilustra o fluxograma com o funcionamento do programa. 
Figura 87 - Fluxograma do programa para Filament Winding.

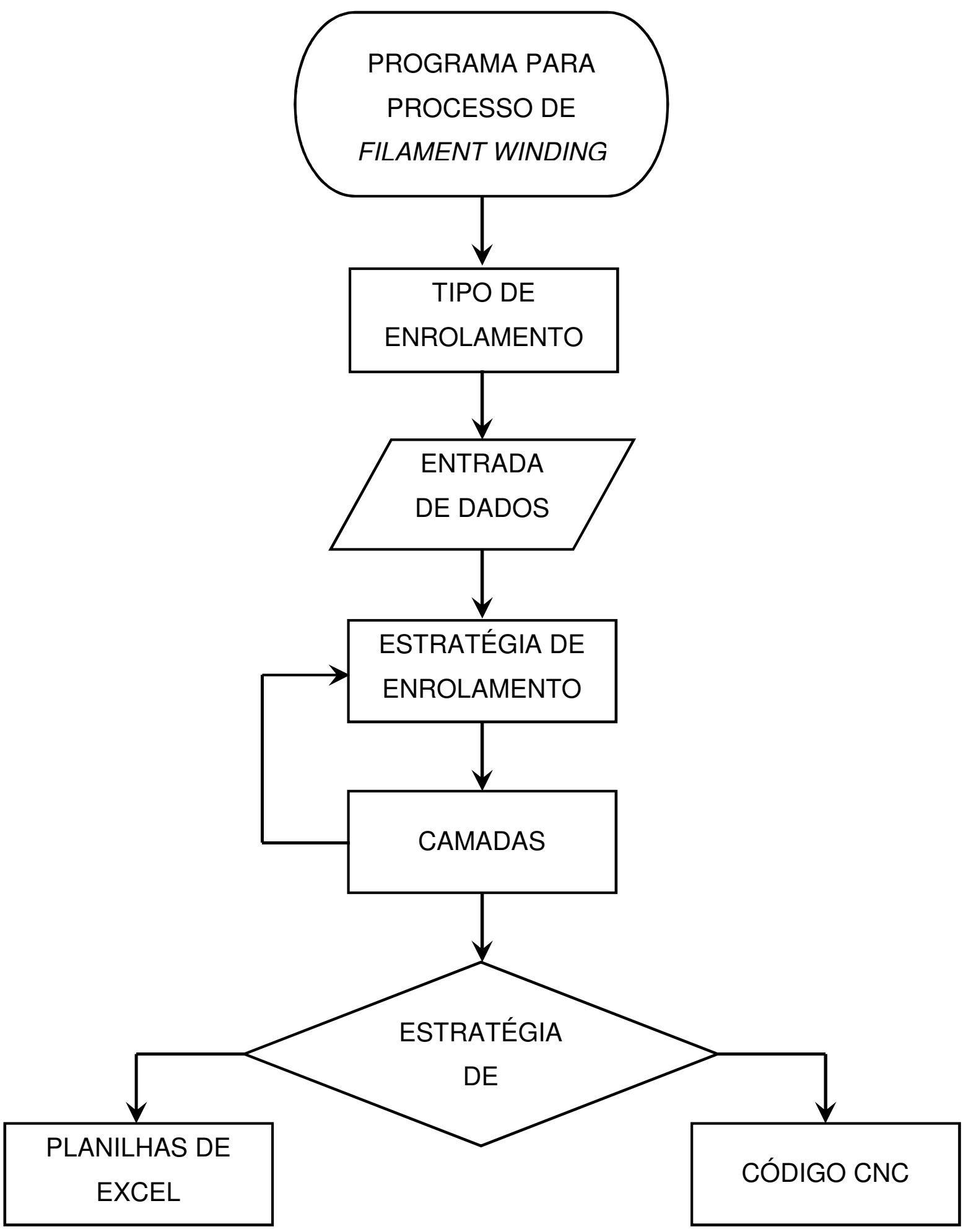

Fonte: Próprio autor (2014).

As planilhas geradas pelo programa são pontos espaciais com coordenadas $X$, Y e Z. Estes dados são calculados pelas equações 53, 54, 55, 56, 57 e 58 são alocados em uma planilha de Excel. Estes dados geram curvas espaciais em formato 
de hélice, estas curvas podem ser vistas num programa CAD, neste trabalho utilizouse o programa CAD SolidEdge.

As planilhas geradas pelo programa utilizam uma biblioteca destinada a trabalhos com Excel. O programa Visual Studio deixa a biblioteca desabilitada quando o mesmo é inicializado, a biblioteca Excellibrary.SpreadSheet e ExcelLibrary.CompoundDocumentFormat. Com estas bibliotecas as planilhas geradas pelo programa são gravadas diretamente no drive $\mathrm{C}$.

$\mathrm{O}$ código CNC é gerado em bloco de notas, um arquivo texto. Este arquivo tem de ser convertido em extensão mpf para que o software da máquina CNC possa ler.

A partir dos dados inseridos, o programa pode gerar planilhas e um arquivo texto em bloco de notas, contendo o código CNC para a manufatura em um torno CNC comercial. Neste trabalho o torno utilizado foi o torno CNC Centur 30D da Romi, comando Siemens ${ }^{\circledR}$.

O código CNC é inserido na máquina através de um cartão de comunicação. Este código gera movimentos nos eixos $\mathrm{X}, \mathrm{Z}$ e $\mathrm{C}$ de maneira a reproduzir as trajetórias das fibras a partir dos dados inseridos pelo usuário. Este código pode ser executado a partir do próprio cartão ou ser copiados para o hardware da máquina. Uma vez copiados para a máquina é possível simular testes para procurar erros de sintaxe, visualizar o gráfico de movimentos dos eixos na própria máquina e rodar em modo Dry Run e normal antes de manufaturar o produto.

No código CNC desenvolvido pelo programa, a estratégia de enrolamento é definida pelo usuário, porém alguns parâmetros são definidos internamente pelo programa. Estes parâmetros iniciam e finalizam o processo. No início do processo antes de iniciar o enrolamento, o mandril gira $360^{\circ}$ para garantir o contato inicial da fibra com o mandril e posiciona o mandril no ângulo inicial definido pelo usuário. No final do enrolamento o mesmo giro de $360^{\circ}$ se repete finalizado o processo. 


\subsection{PROJETO MECÂNICO}

O projeto mecânico para validar o programa foi dividido em submontagens para facilitar o trabalho. As submontagens se dividiram em dispositivos para o produto (mandril), transporte das fibras (guias) e tensionamento das fibras (dispositivo tensionador).

\subsubsection{MANDRIL}

Pré: O mandril é responsável pelo formato do produto, deve estar centrado na linha de centro do torno e sua superfície deve ser lisa o suficiente para a remoção do produto.

Desenvolvimento: O mandril por receber as fibras e possivelmente resina num futuro e ser manuseado manualmente, decidiu-se por utilizar alumínio comercial, devido sua baixa densidade comparado ao aço e por resistir à oxidação.

O mandril em função de garantir centralização no eixo árvore da máquina e devido ao seu comprimento necessitar de contra ponto, necessita de acessórios que garantam sua centralização. Com a finalidade de diminuir o peso do mandril, foi usinado a partir de um tubo com $\varnothing 2 "$ x $410 \mathrm{~mm}$ de comprimento. Em suas extremidades, para garantir a centralização, é necessário acessórios que sejam adaptados ao contra ponto do torno e da placa.

As castanhas da placa designada para este trabalho com o fim de garantir a centralização, são utilizadas castanhas torneáveis ou castanhas mole. Estas castanhas podem ser usinadas na medida desejada garantindo a centralização da peça a ser presa quando a peça tenha a mesma medida ou dimensão pouco inferior ao dimensional usinado nas castanhas.

Para a centralização no contra ponto basta um furo com broca de centro. $\mathrm{Na}$ extremidade do mandril voltada ao contra ponto é necessário um acessório para a furação, devido ao tubo não ter material para este furo.

$\mathrm{Na}$ outra extremidade do mandril é necessária a fixação na placa. O mandril teria de ter um corpo com diâmetro pré-determinado para prender na placa. Assim como na extremidade do lado do contra ponto, um acessório pode auxiliar a 
centralização. Ao invés de fixação direta na placa, a fixação ocorre por um cone similar ao cone do contra ponto, sendo este cone um acessório fixado às castanhas por meio de um corpo cilíndrico. Para garantir o movimento de rotação do mandril com a placa, um sistema de arraste é necessário. O projeto do mandril ilustrado na figura 88 mostra as extremidades do tubo e a fixação dos acessórios.

Figura 88 - Ilustração do mandril com os acessórios nas extremidades.
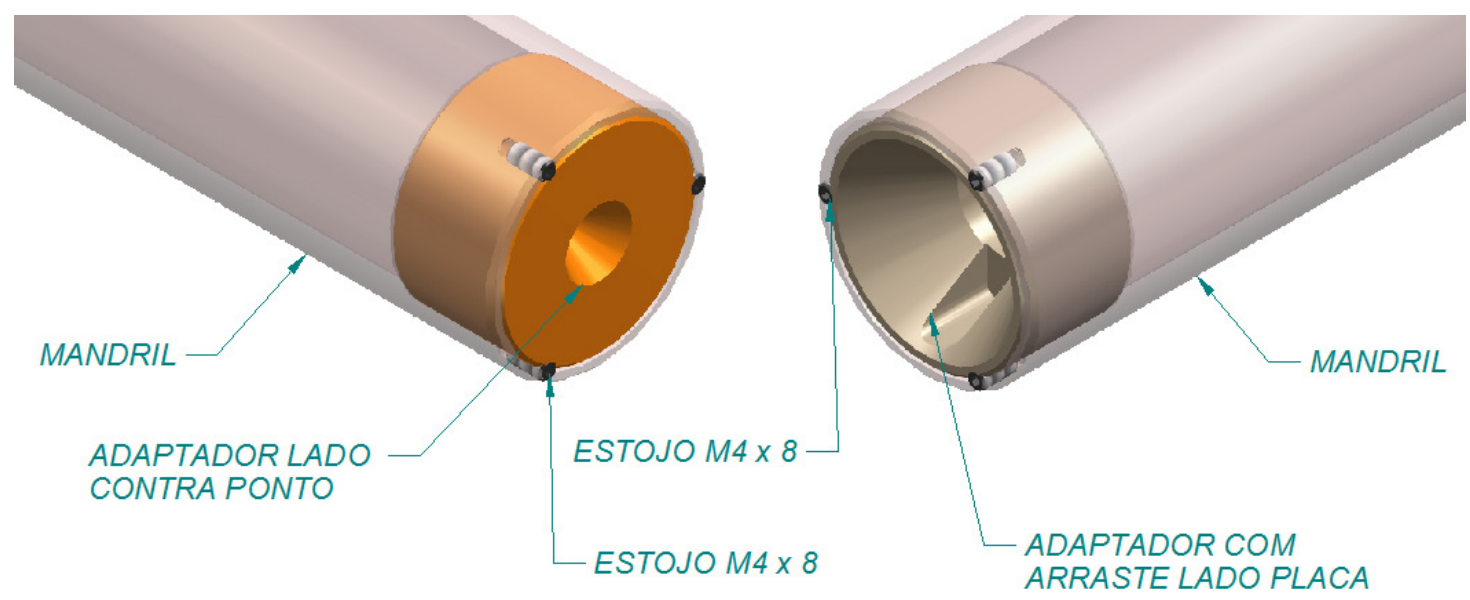

Fonte: Próprio autor (2105).

Os acessórios do mandril foram construídos em alumínio comercial trefilado. A fixação dos mesmos ocorreu por meio de parafusos estojo M4. Furos e roscas usinados nas extremidades do mandril sendo metade do furo e rosca na parede do mandril e a outra metade no acessório. Esta fixação evitou o movimento longitudinal e de rotação dos acessórios no mandril. 
O acessório com o lado voltado para a placa necessita de arraste para realizar o movimento de rotação. O acessório fixo na placa onde o mandril será indexado, chamado de ponto, necessita de um cone para garantir a centralização e para garantir o arraste é necessário um sistema de transmissão de movimento como chaveta ou entalhe ou outro sistema de transmissão. Em virtude de o ponto ser cônico, um sistema com chaveta seria difícil de usinar tanto no ponto quanto no acessório do mandril. Entalhado seria de alto custo e tempo de usinagem. Um sistema com pino no ponto e encaixe no acessório do mandril foi o mais rápido, prático e de menor custo para usinar. A figura 89 ilustra o ponto para o arraste do mandril.

Figura 89 - Ponto para arraste do mandril.

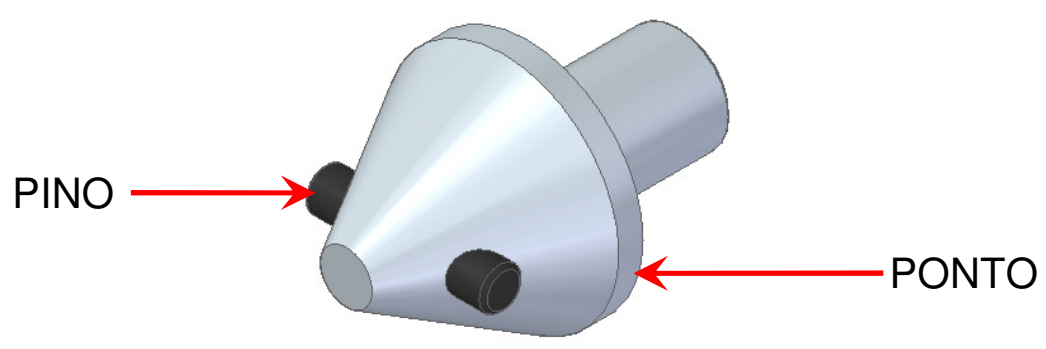

Fonte: Próprio autor (2015).

Pós: $O$ ponto foi montado na placa com castanhas torneadas e o mandril montado no ponto e contra ponto. Visualmente a centralização foi garantida, o arraste conseguiu fazer o mandril girar. O mandril foi polido para facilitar a remoção do produto ou das fibras quando necessário. Durante o movimento de rotação não foi verificado folga em caso de reversão de rotação, mesmo em estática, o mandril estava justo no ponto e contra ponto não tendo folga para girar quando a placa estivesse parada. A colocação e remoção do mandril no torno não apresentaram problemas com a centralização. A figura 90 ilustra o mandril montado no torno.

Figura 90 - Mandril montado no torno com acessórios.

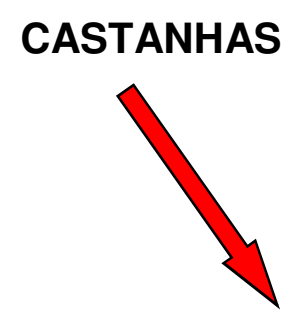

MANDRI

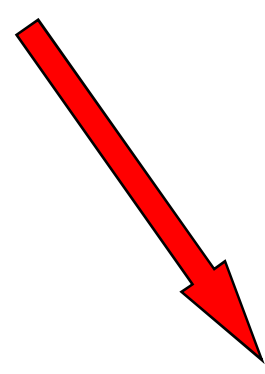

CONTRA

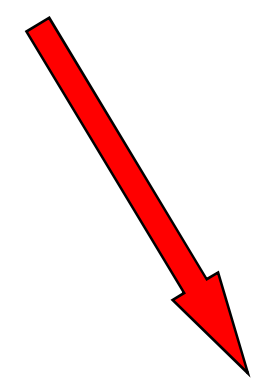




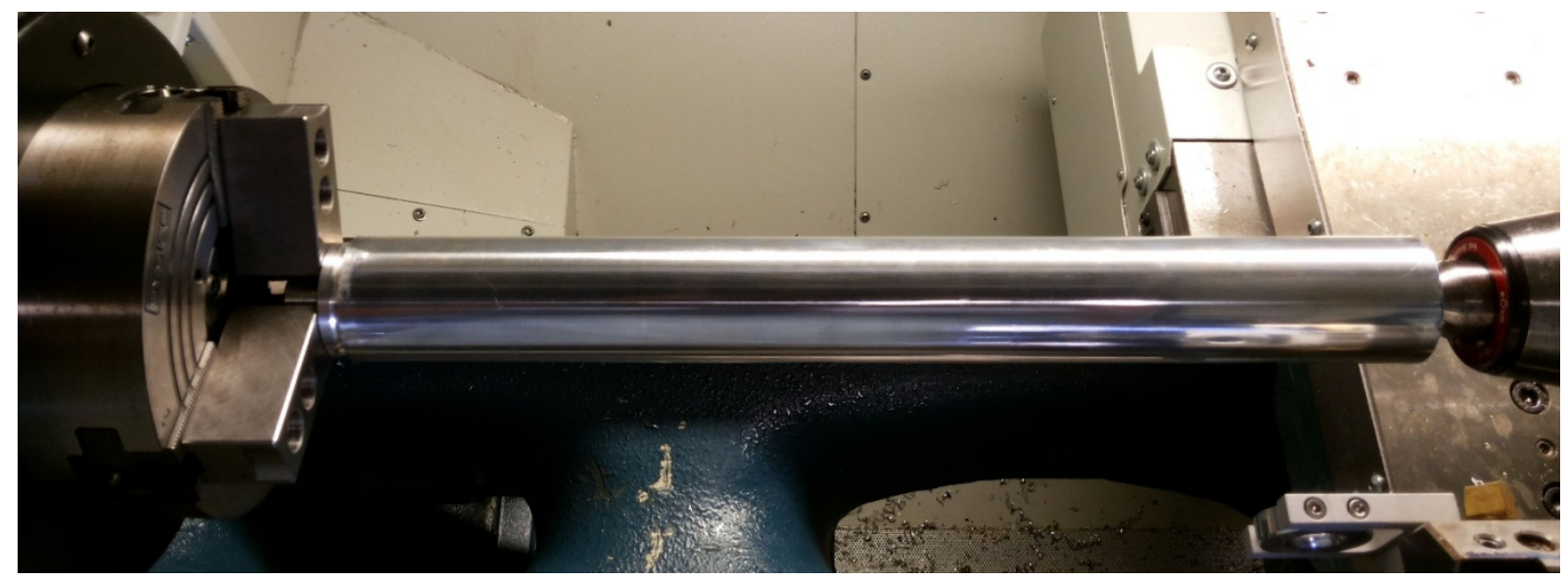

Fonte: Próprio autor (2015).

\subsubsection{GUIAS}

Responsável pelo movimento longitudinal das fibras ao longo do mandril, as guias ou olhais, no movimento combinado com a rotação do eixo árvore aloca as fibras na trajetória pré-determinada.

Pré: As fibras devem ter liberdade para deslizar nas guias. Em razão deste deslizamento das fibras nas guias, as mesmas devem ser polidas para evitar a ruptura de filamentos das fibras durante a passagem das fibras. Os olhais devem garantir que as fibras não tenham contato com o magazine de ferramentas do torno. Para evitar qualquer alteração na geometria do magazine, as guias deverão ser montadas no magazine de ferramentas por meio de parafusos aproveitando as roscas existentes no próprio magazine.

Desenvolvimento: As guias foram construídas em alumínio comercial o que evita a oxidação. As guias foram usinadas com perfil arredondado e polido para facilitar o deslizamento das fibras. Para as guias foram construídos suportes que permitissem sua fixação no magazine mantendo as mesmas afastadas do magazine, assim as fibras não teriam contato algum com o magazine de ferramentas. 
O movimento das fibras tem a liberdade de deslizar no diâmetro interno do olhal (polido) conforme o magazine movimenta ao longo do eixo $Z$ (longitudinal) e movimenta em direção ao mandril pelo movimento de rotação do eixo árvore.

As guias são montadas em suportes fixados ao magazine de ferramentas. Estes suportes são fixados por meio de parafusos Allen DIN 912 M5 x 10. Os olhais são fixados nos suportes por meio parafusos Allen DIN 912 M4 X 8 .

Pós: Os suportes são encaixados no magazine e parafusados no mesmo. 0 encaixe dos suportes no magazine possui uma folga pequena de $0,05 \mathrm{~mm}$ o que garante uma boa precisão no posicionamento dos suportes. Os olhais encaixam no suporte com a mesma folga e são fixados por meio de parafusos. Foram construídos dois olhais e dois suportes para alinhar as fibras de maneira paralela ao magazine. Os suportes são fixados no magazine de maneira que as fibras tenham liberdade de movimento restrito nos eixos $X$ e $Y$ para evitar o contato com o magazine de ferramentas.

Afigura 91 ilustra os suportes e os olhais em alumínio comercial. A figura xxx ilustra os olhais e suportes montados no magazine de ferramentas do torno.

Figura 91 - Olhais e suporte.

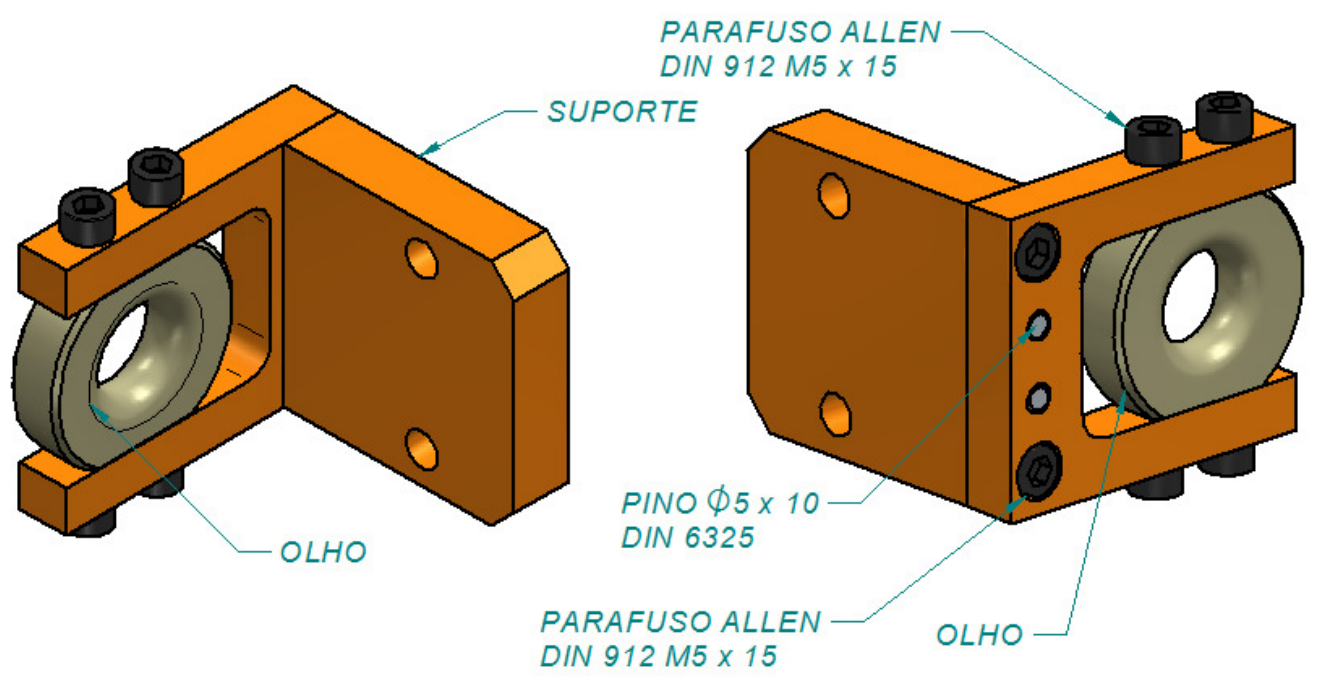

Fonte: Próprio autor (2015).

Figura 92 - Olhais e suporte fixados no magazine de ferramentas do torno. 


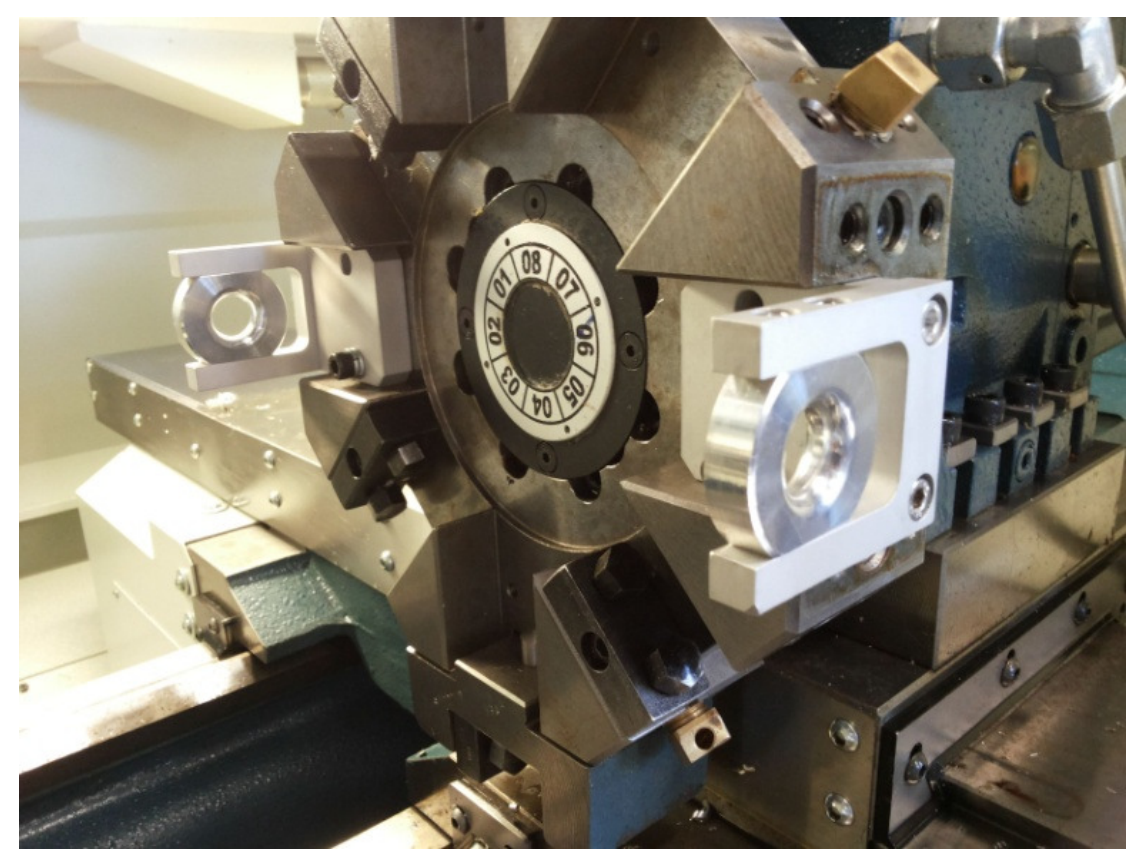

Fonte: Próprio autor (2015).

\subsubsection{DISPOSITIVO TENSIONADOR}

O dispositivo tensionador é o responsável por manter as fibras com tensão determinada para evitar com que a fibra fique "solta" durante o processo e saia da trajetória determinada. Diversos tipos de dispositivo para tensionar as fibras foram desenvolvidos e são abordados no capítulo 2. A proposta para este trabalho é um dispositivo mecânico que cause tensão nas fibras e desenrole as mesmas do carretel. As propostas de tensionadores pesquisadas mostraram sua precisão e complexidade. Para a validação do programa neste trabalho, uma proposta de um tensionador mecânico sem a necessidade de recursos eletrônicos para os testes, foi abordada e concretizada.

Pré: As fibras vêm em carretel e necessitam ser desenroladas para serem tensionadas e direcionadas ao mandril. A tensão nas fibras deve ser controlada de tal maneira que evite com que as fibras fiquem "bambas" ou "soltas" durante o processo. $\mathrm{O}$ dispositivo deve permitir o direcionamento das fibras às guias fixadas no magazine de ferramentas do torno. 
Desenvolvimento: Para desenrolar ou remover as fibras do carretel 0 dispositivo necessita de um rolo por onde as fibras são sujeitas e sofrem tensão. $O$ direcionamento das fibras é realizado por meio de olhais fixos em suporte. Todo o conjunto é fixado em uma base de alumínio comercial.

O rolo é sustentado por meio de mancais e estes são fixados em suportes fixos na base por meio de parafusos Allen DIN 912 M8. O rolo é construído de tubo de PVC o que alivia o peso e reduz o custo de fabricação, os flanges em alumínio comercial foram colados no rolo. A sustentação deste rolo nos mancais é feito por meio de eixos e flanges. Suporte e eixos foram construídos em alumínio comercial. A figura 93 ilustra a montagem do rolo, flanges, eixos, suportes e mancais na base.

Os eixos são parafusados nos flanges por meio de parafusos Allen DIN 912 M4. De um lado o eixo é montado no mancal de rolamento comercial SKF®, em outra extremidade o eixo além de ser montado no mancal de rolamento, sustenta o sistema de tensionamento das fibras.

O sistema de tensionamento das fibras é composto por dois dispositivos: um freio e um dispositivo para tensionar as fibras. $O$ dispositivo para tensionar as fibras funciona em conjunto com o freio. Um tambor e um flange construídos em alumínio comercial são montados no eixo de sustentação do rolo. $O$ tambor e o flange acomodam uma mola comercial tipo caracol. $O$ eixo onde o tambor e flange são montados tem a liberdade de girar no eixo. Para evitar o desgaste prematuro do eixo e do tambor, buchas de bronze grafitado CuSnC com boa propriedade de lubrificação, foram montadas evitando o contato direto entre as peças.

Figura 93 - Montagem do rolo e acessórios na base.

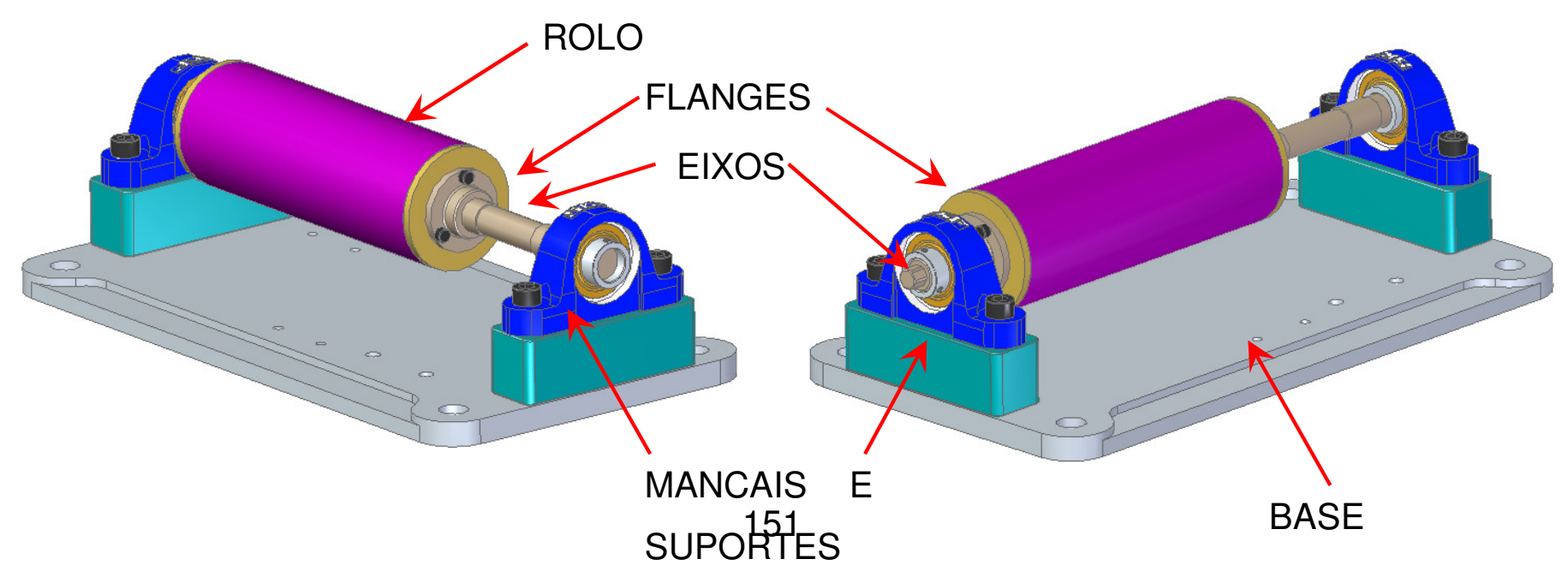


Fonte: Próprio autor (2015).

A mola caracol é fixada no tambor e no eixo. No tambor por meio de um pino, no eixo por meio de parafuso de Allen DIN 912 M4. A figura 94 ilustra o tambor, mola, flange e eixo montados.

Toda vez que o eixo faz o movimento de rotação, faz com que o conjunto tambor, mola e flange girem juntos. No flange fixado ao tambor, é fixado um disco de freio construído em aço Inox 306L. Um dispositivo de freio contendo dois pinos de celeron que são montados contra as faces do disco de freio, sobtensão de uma mola ajustada por meio de parafusos estojo M10, causam atrito no disco resistindo ao movimento de giro. Estes pinos, molas e parafusos são sustentados por meio de mancais fixados em um suporte, este fixado a base. Estes mancais e suporte foram construídos em alumínio comercial. A figura 95 ilustra este dispositivo de freio.

O tensionamento das fibras ocorre quando o mandril puxa as fibras para serem enroladas. As fibras saem do carretel, passam pelos olhais do dispositivo tensionador, são enroladas no tambor para girarem o mesmo com o atrito das fibras, as fibras passam pelo segundo olhal do dispositivo tensionador e passam pelos olhais fixados no magazine do porta ferramentas do torno e finalmente são enroladas no mandril.

Figura 94 - Dispositivo para tensionar as fibras.
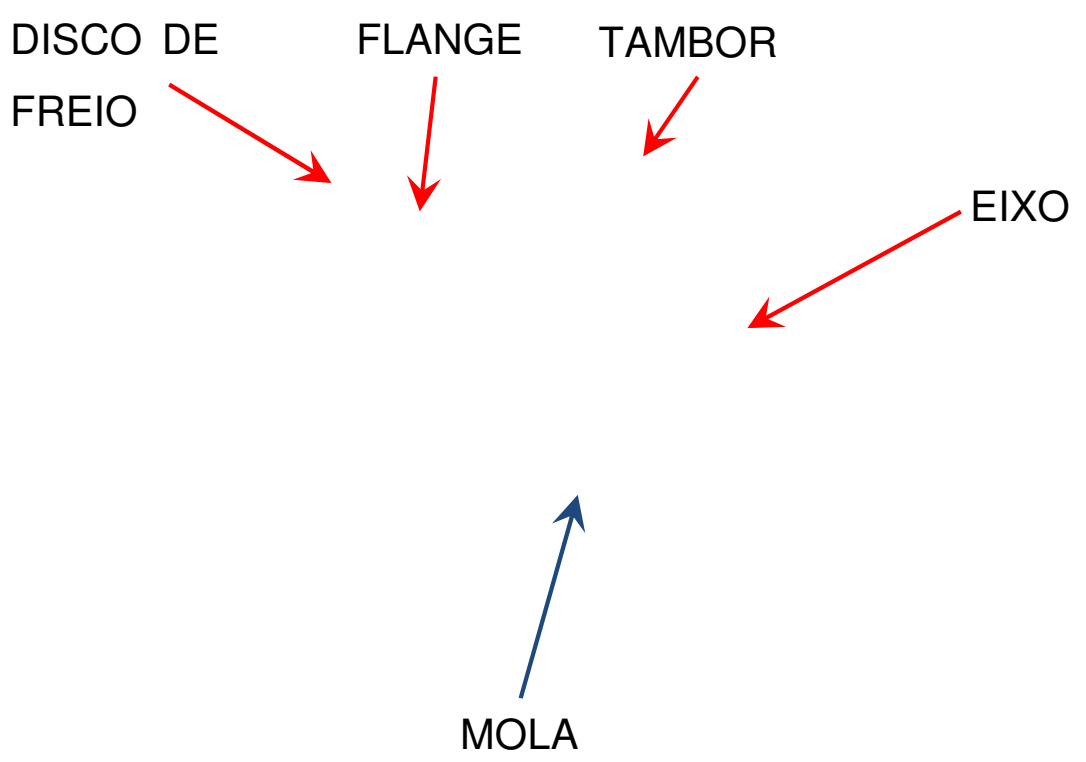


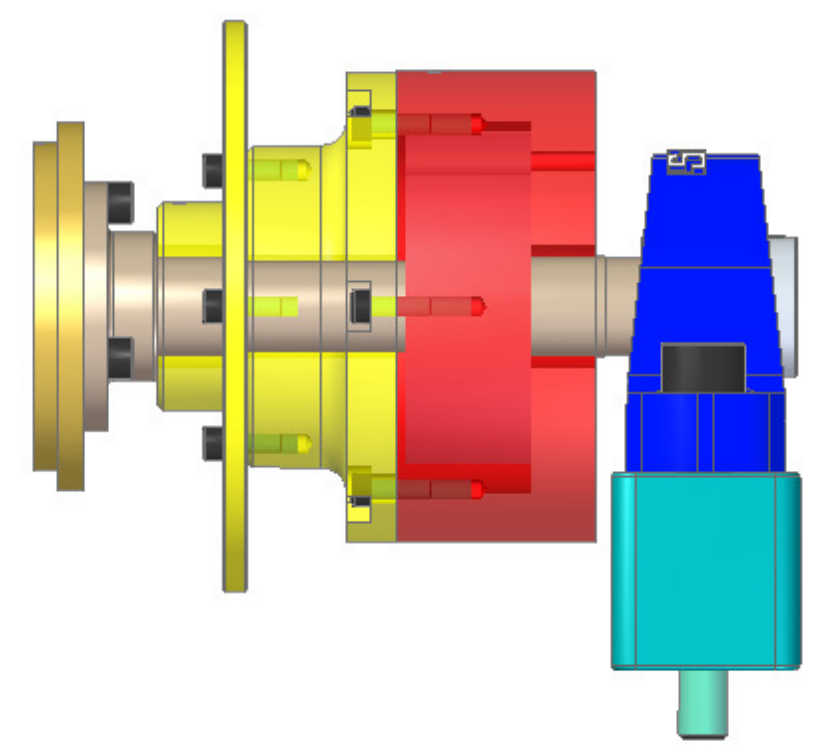

Fonte: Próprio autor (2015).

A passagem das fibras pelo rolo provoca o giro do mesmo pelo atrito das fibras, este giro é resistido pelo dispositivo de freio causando tensão nas fibras. Esta tensão é causada divido a resistência causada pelos pinos de celeron atritando com o disco de freio, isto causa uma torção na mola caracol entre o eixo e tambor/ flange no qual o disco de freio está fixado. Quando a força para girar o rolo vence a força de torção da mola, o conjunto gira sob tensão da mola.

A força de atrito dos pinos de celeron no disco de freio pode ser ajustada por meio de parafusos estojo M10 nos mancais de suporte dos pinos, molas helicoidais comerciais, tudo montado em guia para os pinos. Ao apertar o parafuso o mesmo exerce uma força contra a mola que exerce força sobre os pinos de celeron que atritam contra o disco. A mola serve para evitar o contato direto do parafuso com os pinos facilitando o ajuste da força aplicada no disco e absorve irregularidades da geometria durante o movimento. $\mathrm{O}$ dispositivo tensionador das fibras é ilustrado na figura 96. 
Figura 95 - Dispositivo de freio.
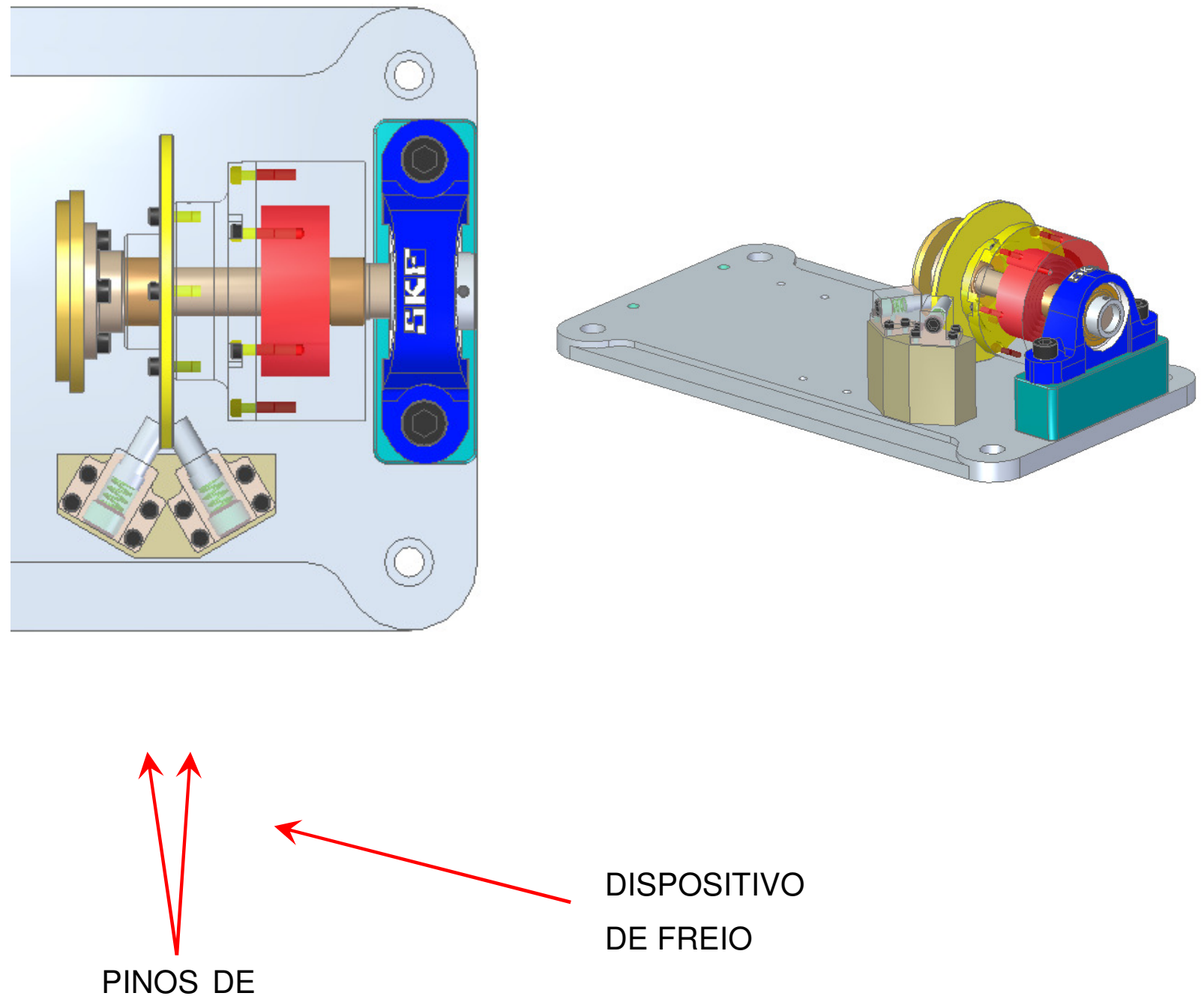

CELERON

Fonte: Próprio autor (2015). 
Figura 96 - Dispositivo tensionador para fibras.
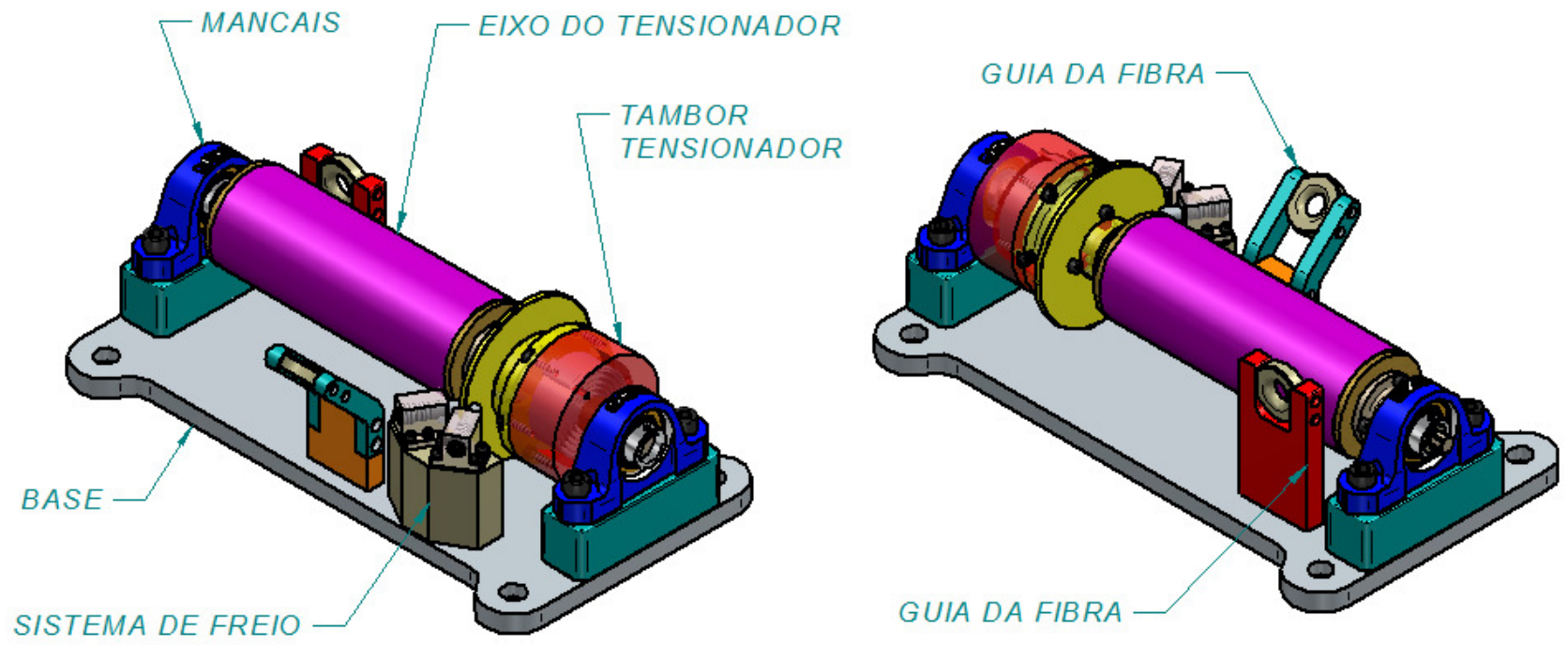

Fonte: Próprio autor (2015).

\subsection{MATERIAL COMPÓSITO}

Os materiais utilizados para a manufatura do material compósito neste trabalho foram:

- Fibra de vidro 1200 TEX.

- Resina Araldite LY 1564 Huntsman.

- Catalisador Aradur 2963 BR Huntsman.

\subsection{PESQUISA POR PATENTES}

Solicitado patente de programa para filament windign. Aguardando documentação. 


\section{CAPÍTULO 4}

\section{IMPLEMENTAÇÃO}

O processo de implementação visa à funcionalidade do programa, dispositivos e resposta do torno CNC. O programa deve gerar um executável que possa ser executado em computadores com plataforma Windows. Os resultados gerados pelo programa devem ser conferidos por um programa CAD, neste trabalho optou-se pelo Solid Edge da Siemens ${ }^{\circledR}$, os dados devem gerar trajetórias helicoidais com diâmetro, comprimento, passo e cobertura total do madril a partir dos dados inseridos no programa.

O mandril deve ser montado no torno, rotacionado e verificada a concentricidade entre mandril e eixo árvore da máquina. Para esta avaliação não necessita ter muito rigor, não há a necessidade de instrumento de medição para verificar a excentricidade do mandril, como o uso de relógio apalpador para verificar o batimento. A inspeção visual é o suficiente para verificar a concentricidade do mandril. 
As guias ou olhais fixados no magazine de ferramentas devem ser montadas de tal maneira a não ser necessária alteração na geometria do magazine e as fibras quando puxadas pelo mandril não devem tocar no magazine.

O dispositivo tensionador deve exercer tensão nas fibras evitando com que as mesmas fiquem frouxas ou bambas durante a passagem pelos olhais fixados no magazine e deve permitir o desenrolar das fibras do carretel.

\subsection{FLUXOGRAMA DE IMPLEMENTAÇÃO}

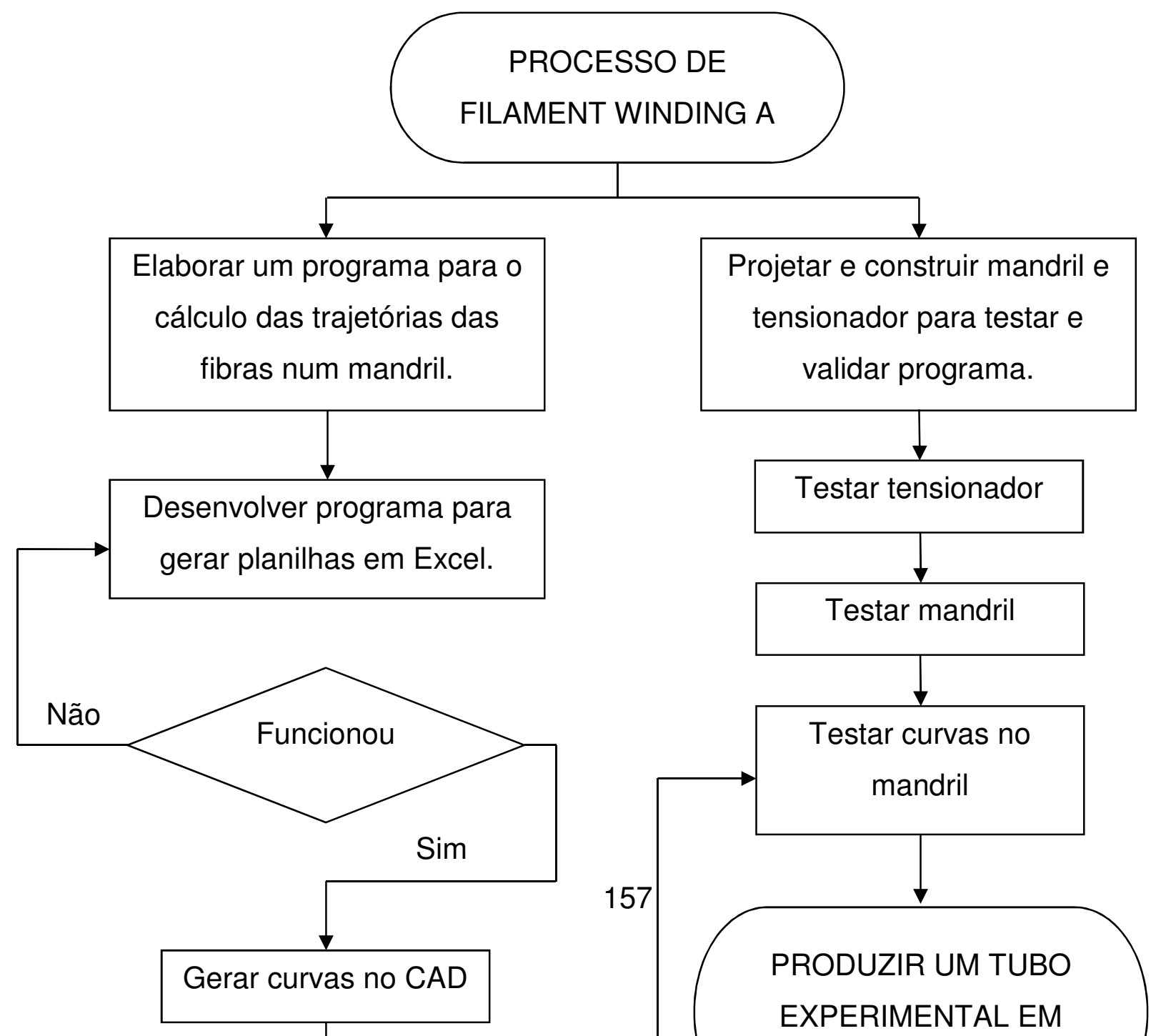




\subsection{PROGRAMA}

O programa desenvolvido em C\# com o software VisualStudio 2010. O programa foi desenvolvido e testado na plataforma Windows. O programa foi elaborado para trabalhar com janelas com informações e solicitações de dados que interagem com o usuário de tal maneira que a partir das informações do mesmo o programa forneça direções, dados e resultados.

O executável do programa funciona como executáveis convencionais da mesma plataforma, acionado pelo hardware de entrada (mouse ou teclado). A janela inicial abre ao usuário as opções do programa. Neste trabalho foi desenvolvida somente a opção de tubos cilíndricos com diâmetro e passo constantes. A figura 97 ilustra a tela inicial do programa. Acionada a opção de diâmetro e passo constantes, o programa leva a uma nova janela onde o usuário deve informar dados iniciais onde o programa avalia a possibilidade de realizar os cálculos. A figura 98 ilustra a janela onde o usuário deve informar os dados iniciais.

Figura 97 - Tela de abertura do programa. 


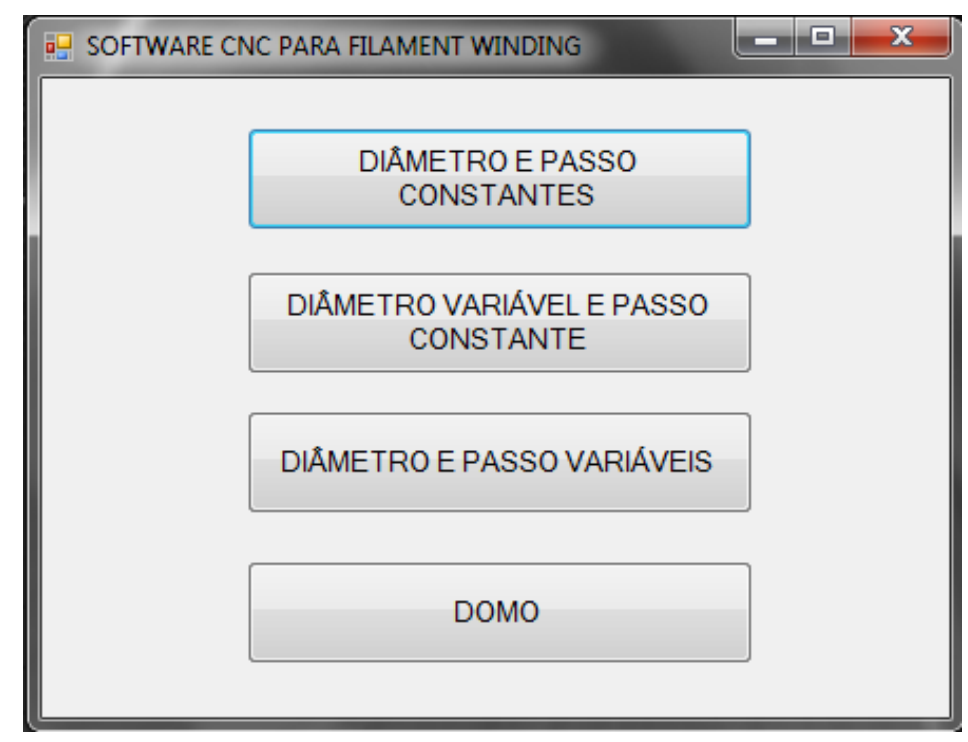

Fonte: Próprio autor (2015).

Estes dados são diâmetro e comprimento do mandril a ser revestida, largura da mecha (fita), número de rotações por minuto (RPM) e sentido de giro do mandril (horário ou anti-horário). Estes dados são validados pelo programa se poderão ser validados ou não. A validade destes dados está determinada internamente no programa, sendo necessária alteração na programação para alterar estes valores, como usuário não é possível alterar o mesmo. Esta validação foi pré-determinada com o fim de obter um mandril e enrolamento compatível com a capacidade da máquina.

As restrições para esta etapa do programa são: diâmetro do mandril entre $30 \mathrm{e}$ $100 \mathrm{~mm}$, comprimento entre 150 e $500 \mathrm{~mm}$ e largura da mecha inferior ou igual a oitava parte do perímetro do diâmetro do mandril em milímetros, o que garante um revestimento com pelo menos oito ciclos por camada (com exceção da camada $90^{\circ}$ ) entre ida e volta ao início e fim do comprimento do mandril. A figura 98 ilustra a tela para validação e geração de camadas, planilhas e código CN.

Se algum dos valores informados pelo usuário não for aceito pelo programa, uma mensagem de erro é emitida e os dados são apagados para nova digitação. 


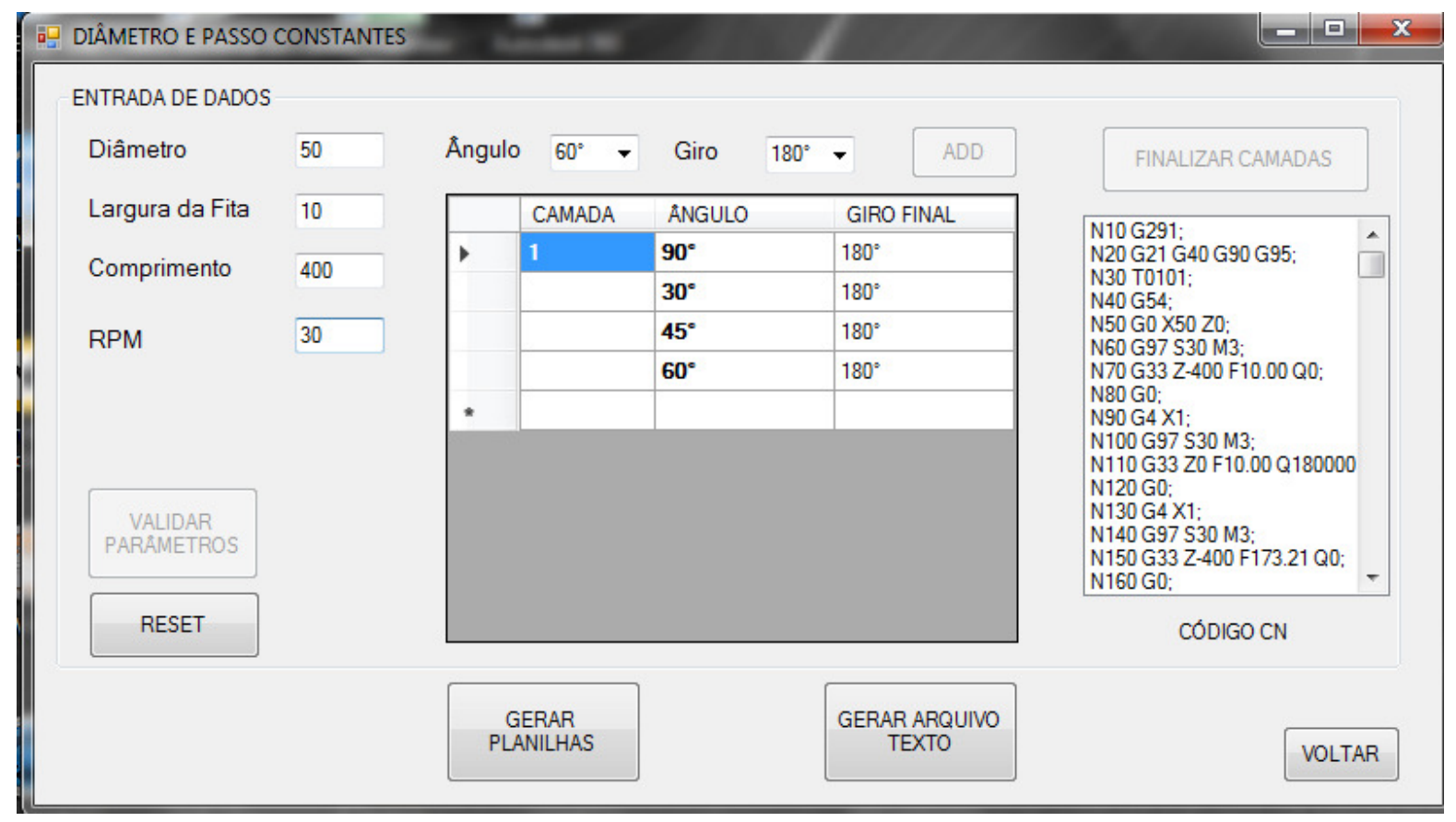

Fonte: Próprio autor (2015).

Após os dados serem validados, o programa libera ao usuário a realização da estratégia de revestimento em camada por camada. O programa foi restrito internamente para ângulos de $90^{\circ}, 60^{\circ}, 45^{\circ}$ e $30^{\circ}$, podendo ser alterado internamente para aumentar, diminuir ou modificar os ângulos para estratégia de revestimento.

À medida que o usuário insere os ângulos de revestimento o programa disponibiliza uma prévia do código $\mathrm{CN}$ ao lado da tabela de revestimento. É disponibilizado ao usuário que decida o ângulo no final do mandril para o giro antes do retorno do ciclo. Estes ângulos, assim como os ângulos da estratégia de revestimento só podem ser alterados internamente pelo programador, são eles: $180^{\circ}$, $360^{\circ}$ e $540^{\circ}$. 
Ao encerrar as camadas, o usuário deve acionar o botão FINALIZAR e dois outros botões são habilitados pelo programa: Gerar planilhas e gerar arquivo texto. As planilhas permitem ao usuário visualizar as trajetórias por meio de um programa CAD. A figura 99 ilustra um exemplo de visualização no SolidEdge. Estas planilhas contem valores para as coordenadas $\mathrm{X}, \mathrm{Y}$ e $\mathrm{Z}$ que geram uma trajetória helicoidal em função dos dados (diâmetro, mecha, comprimento e estratégia) fornecidos pelo usuário.

Figura 99 - Trajetória helicoidal gerada pelas planilhas resultantes do programa.

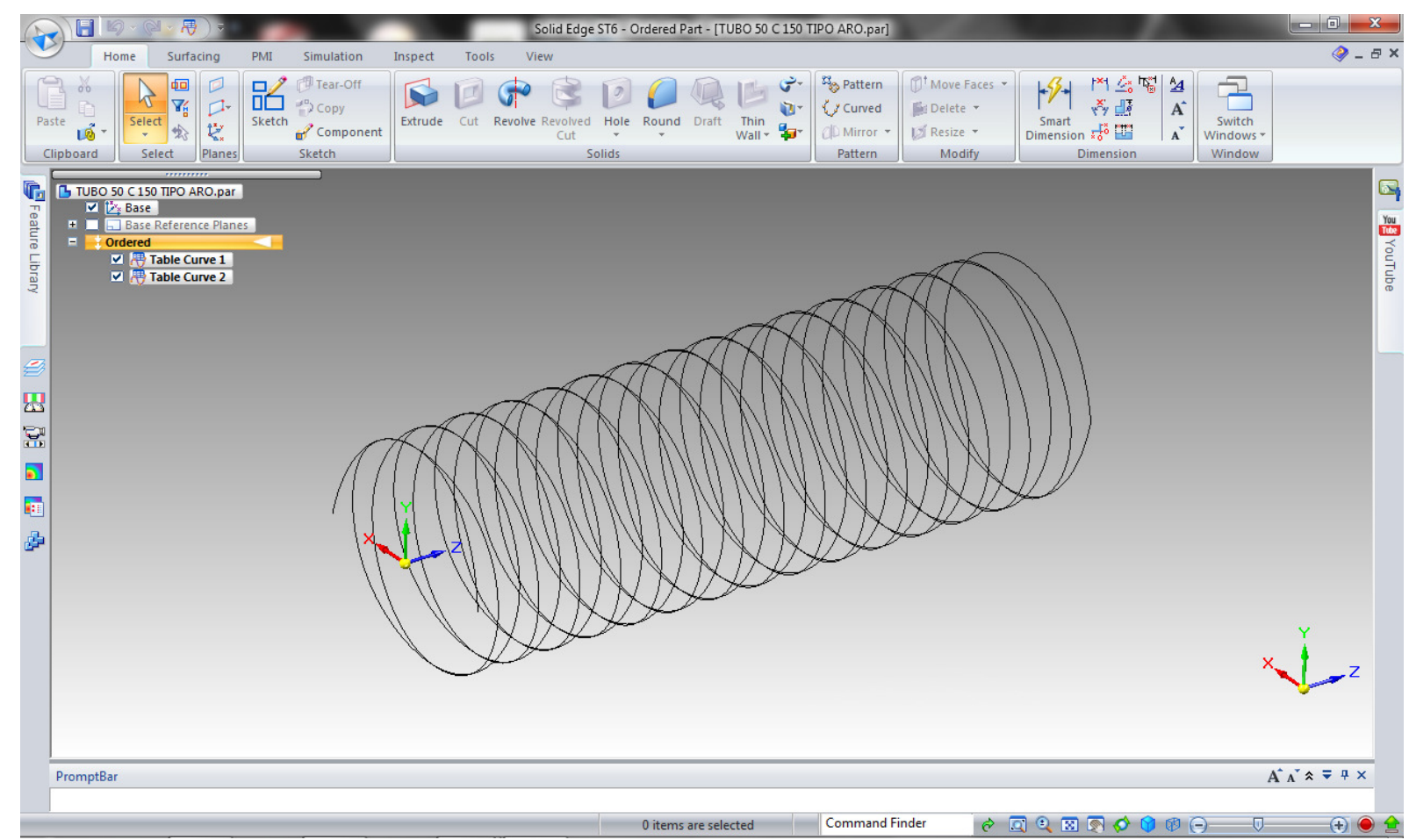

Fonte: Próprio autor (2015).

$\mathrm{O}$ arquivo gerado pelo programa é em formato texto com extensão txt. $\mathrm{O}$ software do torno CNC não é capaz de ler e executar os movimentos com arquivos desta extensão. Com o próprio Explorer da plataforma Windows é possível alterar esta extensão para mpf, extensão esta que a máquina consegue ler e realizar os movimentos necessários. Por exemplo, um arquivo denominado Mandril1.txt, não é possível realizar o processo, convertendo o arquivo para Mandril1.mpf é possível realizar o processo. A seguir um exemplo de arquivo texto gerado pelo programa. 
N10 G291;

N20 G21 G40 G90 G95;

N30 T0101;

N40 G54;

N50 G0 X50 Z0;

N60 G97 S60 M3;

N70 G33 Z-300 F5.0 Q0;

N80 G0;

N90 G4 X1;

N100 G97 S60 M3;

N110 G33 Z0 F5.0 Q180000;

N7890 G4 X1;

N7900 G0 X60;

N7910 M30;

$\mathrm{O}$ arquivo após ser convertido para extensão $\mathrm{mpf}$ pode ser transferido à máquina por meio de cartão de comunicação, USB ou wi-fi, isto depende do hardware da máquina, neste trabalho foi utilizado cartão de comunicação. $O$ cartão é conectado a um adaptador que possui portas USB e seriais, estas por meio de cabo se comunica com computador e hardware da máquina.

O programa foi inserido no torno e copiado para sua memória interna, o que se torna vantajoso para realização de dois testes: um virtual, onde um gráfico ilustra os movimentos dos eixos e um físico para prevenir colisões entre o magazine de ferramentas, mandril e placa. O teste físico praticado pelos programadores de CNC é conhecido como dry run, uma rotina das máquinas CNC que permite ao usuário ou operador, realizar os movimentos dos eixos sem ou com a peça fixada, estes 
movimentos simulam a usinagem real da peça em modo rápido, esta velocidade de realização pode ser controlada pelo usuário pelo potenciômetro da máquina.

\subsubsection{TESTE FÍSICO DO PROGRAMA}

Após a inserção do programa, um teste virtual visualizando o gráfico de movimento dos eixos foi realizado. Este gráfico é muito útil na usinagem de peças, pois permite a visualização da geometria da peça. No caso do processo de filament winding somente linhas retas aparecem, ilustrando o movimento da ferramenta ao longo do eixo $\mathrm{Z}$.

O olhal foi ajustado (pré set) como se fosse uma ferramenta de usinagem. Valores para as coordenadas ao longo dos eixos $X$ e $Z$ foram ajustados. Para o eixo $X$ (diâmetro) o olhal foi afastado em torno de $15 \mathrm{~mm}$ da superfície do mandril e assumiu o valor do diâmetro do mandril. Dependendo do número de camadas, o que determina o diâmetro final do tubo, a distância do olhal à superfície do mandril pode ser maior ou menor para facilitar a liberdade de movimento das fibras e evitar com que o olhal toque nas fibras na superfície do mandril durante o enrolamento.

Para o eixo $Z$ o olhal foi posicionado próximo a uma das extremidades do mandril de tal modo que o percurso de enrolamento ficasse no ajustado no centro do comprimento do mandril, permitindo que o enrolamento acontecesse na superfície do mandril e não chegasse aos extremos do mesmo.

Para verificar a possibilidade de colisões o dry run foi executado sem o mandril e não ocorreu colisão com a placa, em seguida o mandril e contraponto foram posicionados e um novo teste foi realizado para verificar colisões. Não ocorreram colisões e os movimentos ocorreram como planejados.

Antes de executar o processo de filament winding com as fibras na superfície do mandril, um teste físico foi realizado com o auxílio de uma caneta para marcador de quadro branco, fixada no olhal, a ponta da mesma foi ajustada para tocar no mandril, o programa foi executado as trajetórias das fibras foram reproduzidas na superfície do mandril, as marcas deixadas pelo marcador foram medidas e conferidas, tanto comprimento quanto passo da hélice, estava nas dimensões esperadas. A figura 
100 ilustra as marcas deixadas pelo marcador na superfície do mandril que foram usadas como referência.

O teste também serviu para verificar a cobertura da superfície do mandril e os ângulos de entrada nas extremidades do mandril.

Figura 100 - Teste com marcador realizando as trajetórias das fibras na superfície do mandril.
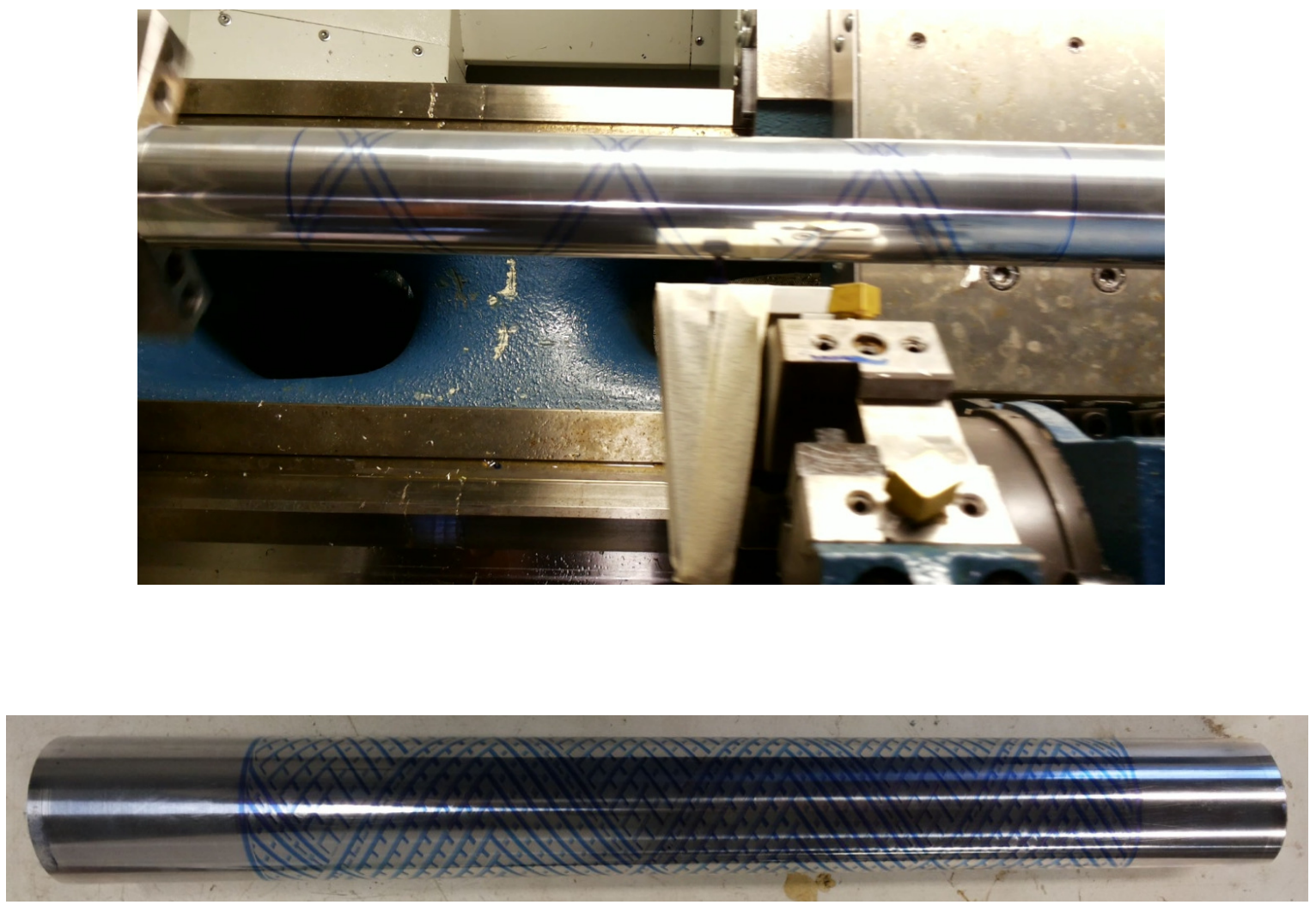

Fonte: Próprio autor (2015).

\subsection{MANDRIL}

O mandril é composto por dois adaptadores nas extremidades e por um tubo, tudo em alumínio comercial. A fixação é feita por meio de parafusos estojo M4x5 DIN 913. O mandril é responsável pela geometria do produto. O mandril construído em tubo de alumínio comercial foi polido para facilitar a remoção do produto.

A fixação do mandril no torno ocorre por meio dos adaptadores nas extremidades do tubo. O adaptador voltado para o lado da placa do torno possui um cone com inclinação a $60^{\circ}$ e um rasgo para que possa acontecer a transmissão de 
movimento circular ao mandril. $\mathrm{Na}$ placa do torno, as castanhas comerciais convencionais são de aço temperado e o contato entre elas e o material a ser fixado é feito de tal maneira que o material fixado fica com marcas das castanhas. Nesta situação a centralização pode apresentar variações ao sair da linha de centro do eixo árvore.

A fixação de peças por castanhas torneáveis possibilita a usinagem da mesma com o mesmo diâmetro da peça a ser fixada nas castanhas, permitindo uma pequena folga, este procedimento garante concentricidade entre peça fixada e linha de centro do eixo árvore.

Um ponto cônico usinado em alumínio comercial foi construído e fixado nestas castanhas usinadas com o mesmo diâmetro deste ponto. Para garantir que o movimento giratório do eixo árvore seja transmitido ao mandril, um pino foi inserido neste ponto para transmitir o movimento ou fazer o arraste do mandril. A figura 101 ilustra o ponto preso na placa. A conicidade entre o adaptador e o ponto garante a boa centralização do mandril com relação ao eixo árvore.

No lado do contra ponto, aproveitando o contraponto do próprio torno, o adaptador do mandril construído em alumínio comercial possui um furo de broca de centro para centralização com o contraponto. O mandril foi fixado no torno e seu diâmetro externo foi torneado e polido, garantido centralização e dimensional do mesmo. A figura 102 ilustra o mandril, placa, pontos e contrapontos montados no torno CNC.

Figura 101 - Ponto fixado na placa por meio de castanhas torneáveis. 


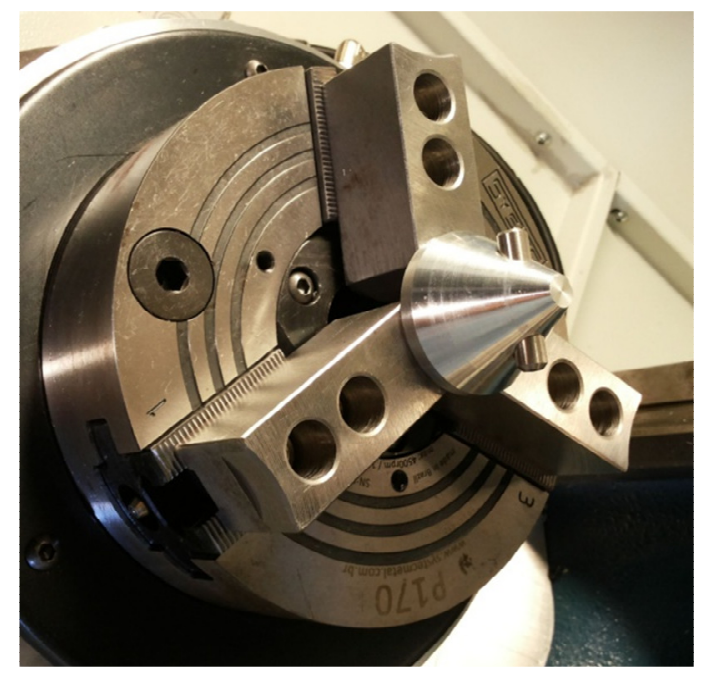

Fonte: Próprio autor (2015).

A rugosidade medida na superfície do mandril onde as fibras serão depositadas foi medida e o resultado foi:

Ra 0,08um, comprimento de medição 5,6mm, Cut-off 0,8mm, Rq 0,12, Rz 0,5, Rt 0,7, Rg 0,6 e SM 329. Instrumento Taylor-Robson Surtronic 3+.

Figura 102 - Mandril e acessórios montados no torno CNC.

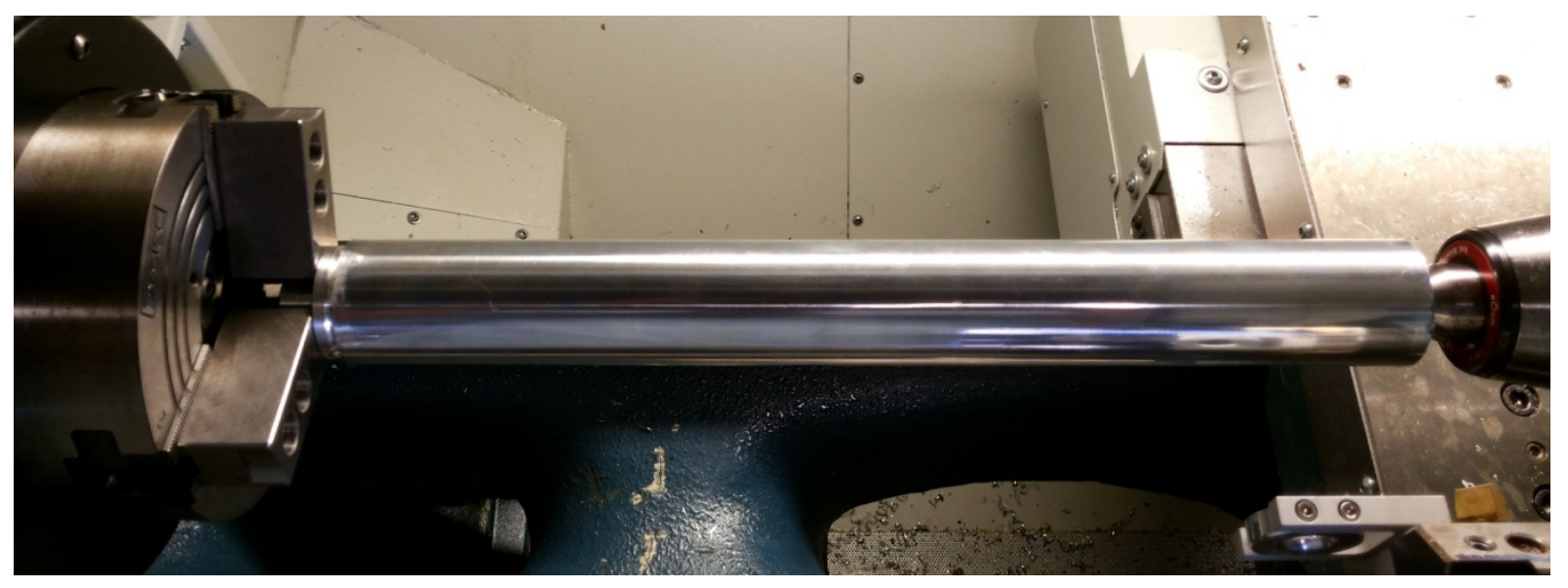

Fonte: Próprio autor (2015).

\subsection{GUIAS DAS FIBRAS}

As guias são compostas por suportes e olhais, todos construídos em alumínio comercial. Os olhais foram polidos para evitar que as fibras desfiem ou haja a ruptura 
dos filamentos durante o processo. Os olhais são fixados aos suportes por meio de parafusos Allen DIN $912 \mathrm{M} 4 \times 10$ e os suportes são fixados ao magazine de ferramentas do torno por meio de parafusos Allen DIN 912 M5 x 10. A figura 92 ilustra a montagem das guias no magazine de ferramentas.

O par de guias conduzem as fibras ao mandril e evita com que as mesmas toquem no magazine de ferramentas. Por meio destas guias e o movimento linear ao longo do eixo $\mathrm{Z}$, as guias conduzem às fibras ao mandril durante o processo de filament winding.

Os olhais possuem geometria circular e o furo por onde as fibras passam foram arredondados e polidos de forma a permitir liberdade às para se movimentarem durante o processo e evitar a ruptura de filamentos por atrito. A figura 103 ilustra o desenho técnico do olhal.

Figura 103 - Desenho técnico do olhal.
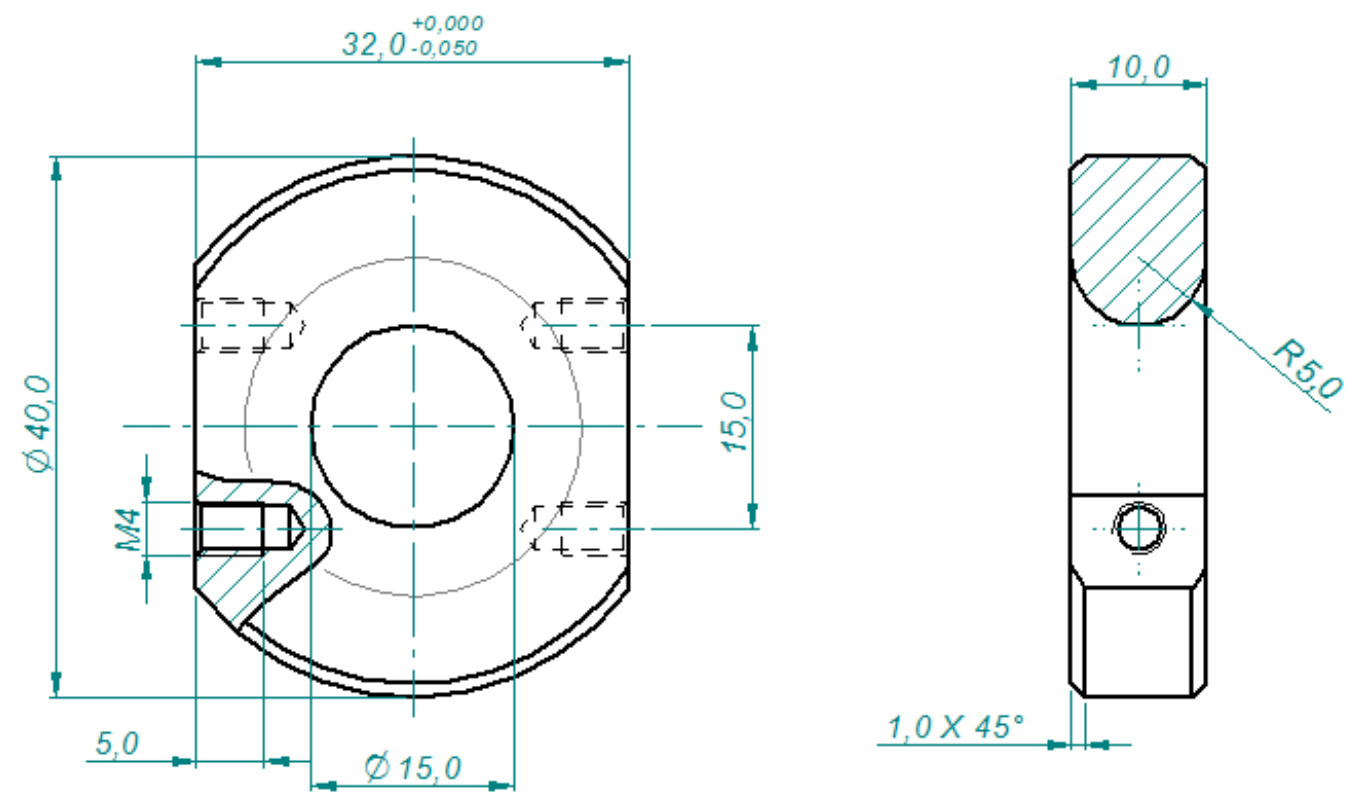

Fonte: Próprio autor (2015).

\subsection{DISPOSITIVO TENSIONADOR}

O propósito do dispositivo tensionador é manter as fibras tensionadas durante o processo ajudando com que a trajetória projetada para as fibras seja realizada. As fibras são fornecidas enroladas em carretéis, para desenrolar as mesmas dos 
carretéis e depositar na superfície do mandril, o dispositivo tensionador sofreu alterações para que pudesse não somente tensionar as fibras, mas desenrolar do carretel à medida que o mandril tracionasse a fibra pelo movimento de rotação do mesmo.

O dispositivo foi fixado a uma mesa, cuja altura ficou próxima à altura do magazine de ferramentas. O dispositivo foi fixado por meio de grampos em sua base e à mesa. A figura 103 ilustra o dispositivo fixado na mesa e o carretel posicionado abaixo do dispositivo.

O carretel foi posto em uma placa sobre o piso evitando o contato direto com o piso. As fibras forma desenroladas do carretel e conduzidas pelo olhal ao cilindro do dispositivo, ilustrado na figura 104.

Figura 104 - Fixação do dispositivo tensionador, posição do carretel e fibras conduzidas pelo olhal.
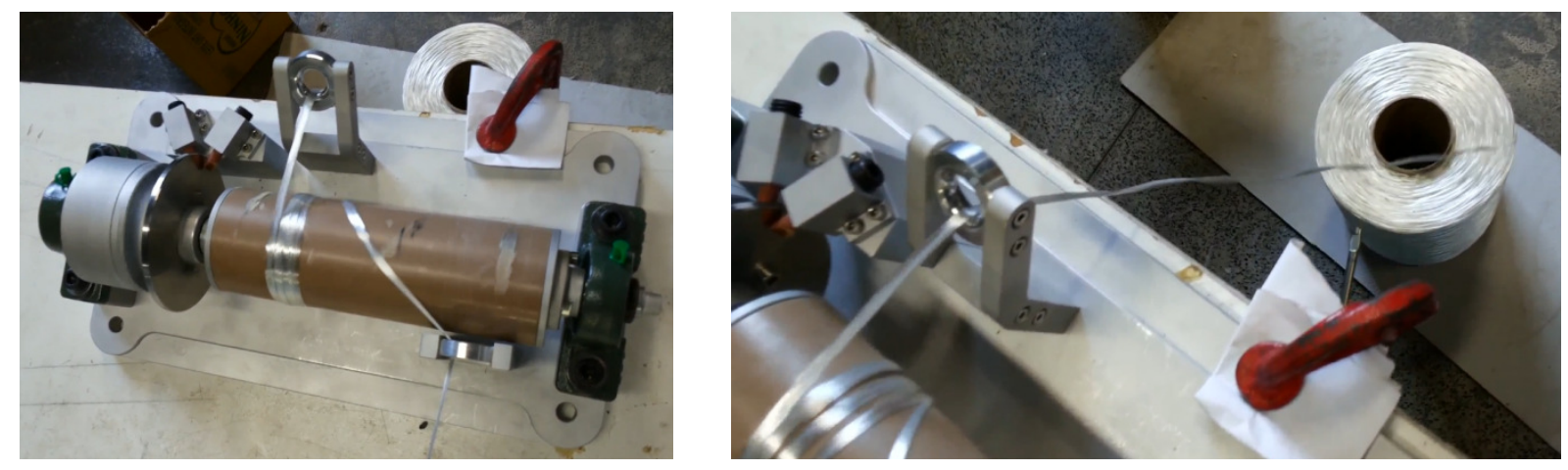

Fonte: Próprio autor (2015).

O dispositivo foi posicionado de maneira com que as fibras que passavam pelo olhal de saída do dispositivo (ver figura 96 e 104) ficassem posicionadas próximas aos olhais fixados no magazine de ferramentas, estes posicionados com seu centro coincidindo como o centro do mandril, entre as extremidades do mesmo.

O freio do dispositivo foi ajustado de tal maneira que o cilindro pudesse ser girado com as mãos com uma leve resistência, resistência esta a ser ajustada durante o ciclo do processo de filament winding. Esta resistência ao movimento de giro manteve a fibra tensionada quando puxada em direção ao mandril. A resistência ao 
movimento foi determinada pela combinação das forças exercidas pelos pinos de celeron contra o disco de freio e da mola caracol.

Num primeiro momento o dispositivo tensionador era composto não por um cilindro por onde as fibras passavam, mas por um eixo, isto resultou numa força excessiva para puxar as fibras do carretel para o mandril. A figura 105 ilustra 0 dispositivo tensionador com eixo ao invés de cilindro.

Neste primeiro projeto o dispositivo também contava com duas molas caracol com dimensões de espessura e largura inferiores às encontradas comercialmente. Nesta configuração o sistema de freio se encontrava numa posição diferente do utilizado no trabalho. Em função de ser inviável a construção de duas molas caracol o projeto foi adaptado a uma mola caracol comercial, a mesma encontrada em braços articuláveis das fresadoras e furadeiras de bancada. A figura 105 ilustra o sistema de freio e molas no primeiro projeto mecânico do dispositivo tensionador.

Figura 105 - Primeiro projeto do dispositivo tensionador.

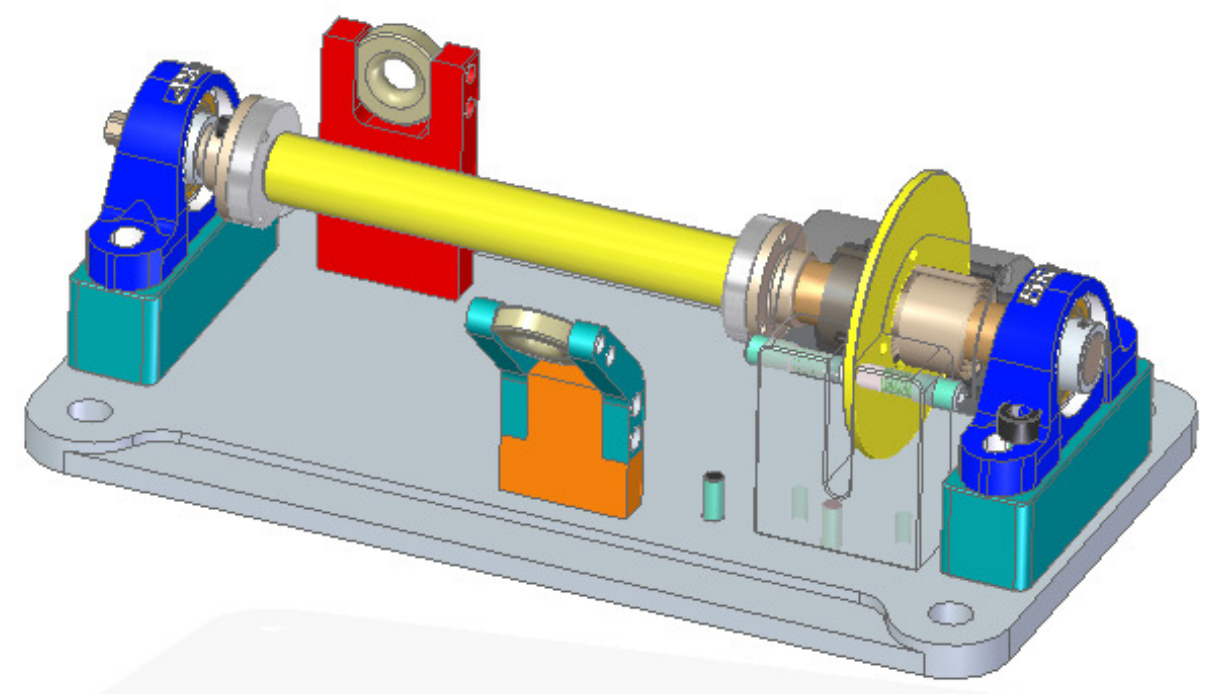

Fonte: Próprio autor (2014).

Em função da limitação da obtenção das molas caracol, o dispositivo foi adaptado para apenas uma mola caracol comercial, consequentemente o sistema de 169 
freio teve de ser alterado e em função da dificuldade para tracionara as fibras, o eixo foi removido e um cilindro foi posto em seu lugar. Estas mudanças impactaram no dispositivo e sua mudança resultou em uma configuração que é ilustrada na figura 96.

As fibras eram removidas do carretel, passavam pelo olhal de entrada do dispositivo, davam uma volta em torno do cilindro e eram direcionadas ao olhal de saída. Notou-se nesta configuração que as fibras deslizavam no cilindro sem fazer com que o mesmo girasse pelo atrito.

Utilizou-se então uma folha de lixa de fina granulação, 600 , o resultado foi rompimento dos filamentos. A lixa foi removida e ao invés de uma volta no cilindro, às fibras foram enroladas três voltas no cilindro, o que fez com que o mesmo tivesse de girar quando as fibras passassem por estes. 


\section{RESULTADO E DISCUSSÃO}

\subsection{AVALIAÇÃO DAS TRAJETÓRIAS NO CAD}

O programa elaborado em C\# conduz o usuário às opções para o processo de filament winding. Neste trabalho apenas tubos de diâmetro e comprimento constante estão implementados. O programa solicita ao usuário os dados para o cálculo das trajetórias das fibras na superfície de um mandril cilíndrico de perfil constante. Esta trajetória é calculada de camada em camada conforme o usuário solicita as mesmas.

Os dados fornecidos pelo usuário (diâmetro, comprimento e largura da fita) são avaliados pelo programa para validação interna. Esta validação são limitações impostas internamente no programa, como diâmetro mínimo e máximo para o mandril dado à limitação da máquina, comprimento mínimo e máximo limitado pela capacidade da máquina e do comprimento do barramento da mesma, largura da mecha, esta limitando a ser no mínimo oito vezes menor que o perímetro do diâmetro mínimo a ser revestido. A quantidade de camadas também foi limitada a vinte e uma camadas, sendo que esta última pode ser alterada internamente por um programador, repeitando o diâmetro máximo que a máquina pode realizar.

A limitação da largura da fita que foi restrita a um valor máximo de largura da fita de um oitavo do perímetro em cima do diâmetro fornecido pelo usuário. Por exemplo, um diâmetro de $80 \mathrm{~mm}$ a fita ou mecha teria uma largura limitada a um quarto do perímetro da circunferência, ou seja, $31,41 \mathrm{~mm}$. Esta limitação foi decidida para que o enrolamento em camadas com ângulo diferente de $90^{\circ}$ ocorresse ao menos oito vezes para revestir toda a superfície. Uma vez que o programa valida estes dados, a opção para ângulo de enrolamento é habilitada no programa, sendo limitado a 21 camadas.

Uma vez que os dados são validados, o programa habilita uma janela para o usuário determinar o ângulo de enrolamento, a estratégia de enrolamento na extremidade do mandril e realiza os cálculos para as trajetórias das fibras na superfície do mandril. A cada camada que o usuário determina o enrolamento, o programa gera internamente uma planilha em Excel contendo os valores para os eixos X, Y e Z. Estes valores servem para a construção de curvas helicoidais que representam as trajetórias das fibras no mandril. 
Estas planilhas foram desenvolvidas de acordo com as limitações do programa CAD. O programa CAD escolhido foi o Solid Edge da empresa Siemens®. Uma limitação apresentada pelo programa foi o volume de dados de cada planilha. $O$ revestimento de uma camada resulta em volume muito alto de dados, o que o programa $C A D$ não consegue interpretar. A solução para esta imitação foi desmembrar a camada revestida em trajetórias de ida e volta às extremidades do mandril e o posicionamento no final de cada enrolamento. Assim varias planilhas são geradas de acordo com a largura da fita, quantidade de camadas e ângulo de enrolamento.

A quantidade de ciclos é gerada sobre o cálculo do perímetro da circunferência do diâmetro do mandril dividido pela largura da fita mais um. Sendo garantido um revestimento que cobrisse toda a superfície do mandril e mais um ciclo de ida e volta para finalizar o revestimento. No caso do enrolamento para ângulo $90^{\circ} \mathrm{o}$ enrolamento ocorre em dois ciclos: ida e volta à extremidade inicial do mandril, sendo que neste enrolamento o passo é a própria largura da mecha.

$n c=\frac{\pi \cdot d}{l f}+1$

Onde: $\quad n c=$ número de ciclos.

$$
\begin{aligned}
& \pi \cdot d \text { = perímetro da circunferência. } \\
& \text { If = largura da fita utilizada no enrolamento. }
\end{aligned}
$$

Os ângulos de revestimento disponíveis no programa são $30^{\circ}, 45^{\circ}, 60^{\circ}$ e $90^{\circ}$ (tipo aro). Estes ângulos foram pré-determinados para o desenvolvimento do programa por serem comuns no processo de filament winding.

O número de ciclos corresponde à ida e volta numa das extremidades do mandril, as planilhas geradas pelo programa foram subdivididas, para cada ciclo duas planilhas, uma de ida e uma de volta à extremidade do mandril. 
A figura 106(a) ilustra o revestimento a $90^{\circ}$ ou tipo aro, a figura 106(b) ilustra o revestimento a $60^{\circ}$, a figura 106 (c) ilustra o revestimento a $45^{\circ} \mathrm{e}$ a figura 106 (d) ilustra o revestimento a $30^{\circ}$.

Figura 106 - Revestimentos com vários ângulos.

(a)

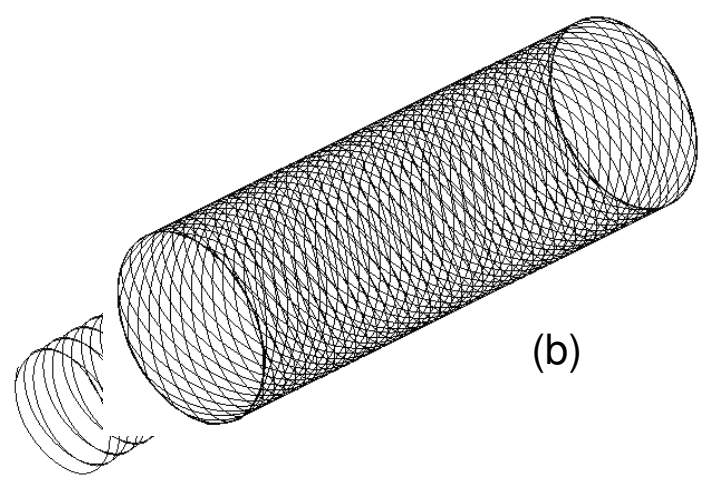

(c)
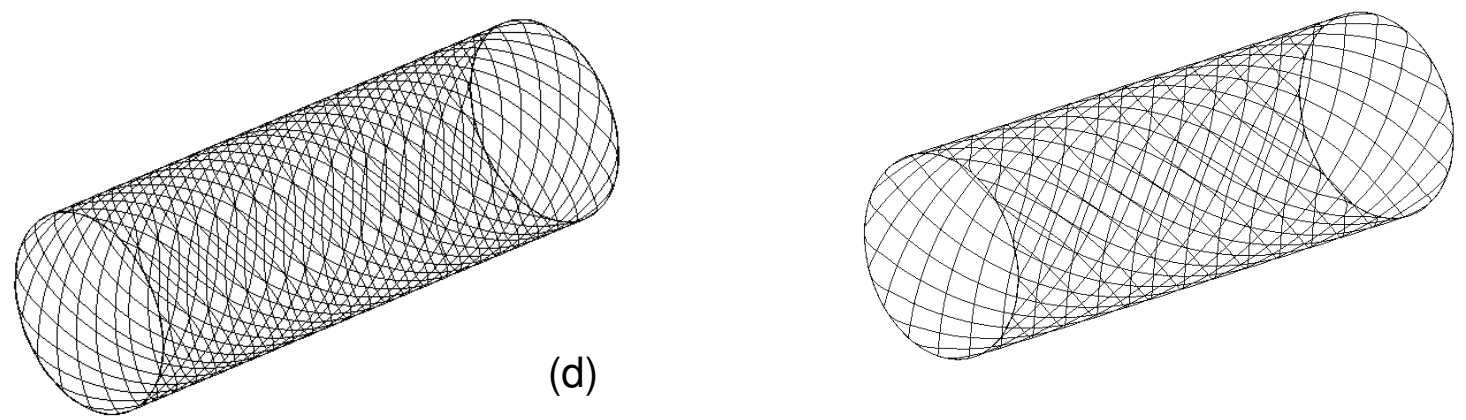

Fonte: Próprio autor (2015).

Outra limitação do programa CAD foi com relação às versões do programa, versões mais antigas, dependendo do diâmetro das curvas, as mesmas ficavam com segmentos de reta e não curvas, para resolver este problema a solução foi a resolução das curvas. Os dados para $X, Y$ e $Z$ são gerados com base no deslocamento do eixo $Z$ de $1 \mathrm{em} 1 \mathrm{~mm}$, abaixando este valor para $0,5 \mathrm{~mm}$ as curvas que apareciam como segmentos de reta apareceram como curvas. 
As curvas foram abertas no programa CAD SolidEdge® e verificada suas dimensões de acordo com a estratégia de enrolamento fornecida pelo usuário e as dimensões do mandril. Para verificação do dimensional das estratégias nos ângulos de $90^{\circ}, 60^{\circ}, 45^{\circ}$ e $30^{\circ} \mathrm{com}$ comprimento, diâmetro e largura de mecha definidos, foi gerado um cilindro sólido entre as curvas no diâmetro do mandril e verificado o dimensional.

A figura 107 ilustra o enrolamento tipo aro ou $90^{\circ}$ num mandril de diâmetro $50 \mathrm{~mm}$ por $150 \mathrm{~mm}$ de comprimento a largura da mecha $10 \mathrm{~mm}$.

Figura 107 - Enrolamento tipo aro, mecha largura 10mm.

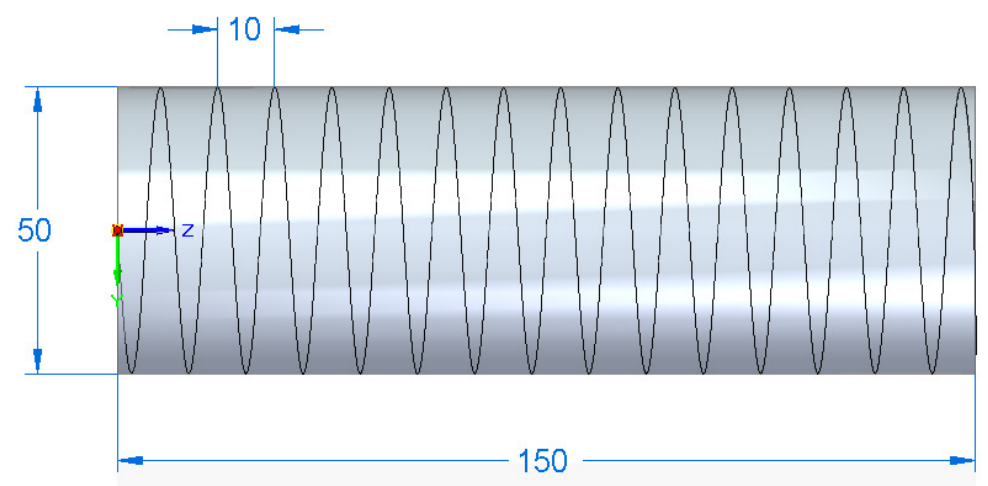

Fonte próprio autor (2015).

A figura 108 ilustra o enrolamento a $60^{\circ} \mathrm{com}$ mandril de diâmetro $50 \mathrm{~mm}$ e comprimento $150 \mathrm{~mm}$, a mesma mecha do enrolamento tipo aro, $10 \mathrm{~mm}$.

A figura 109 ilustra o enrolamento a $45^{\circ} \mathrm{com}$ mandril de diâmetro $50 \mathrm{~mm}$ e comprimento $150 \mathrm{~mm}$, a mesma mecha do enrolamento tipo aro, $10 \mathrm{~mm}$.

A figura 110 ilustra o enrolamento a $30^{\circ} \mathrm{com}$ mandril de diâmetro $50 \mathrm{~mm}$ e comprimento $150 \mathrm{~mm}$, a mesma mecha do enrolamento tipo aro, $10 \mathrm{~mm}$.

Figura 108 - Enrolamento a $60^{\circ}$. 


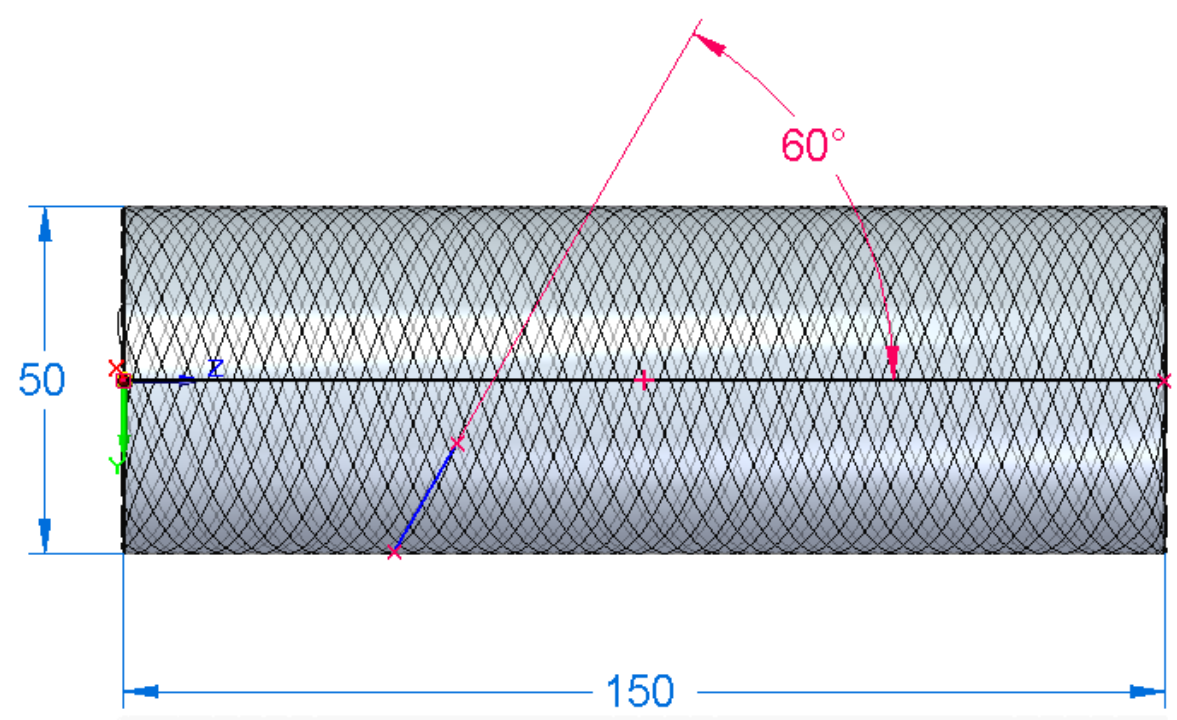

Fonte: Próprio autor (2015).

Figura 109 - Enrolamento a $45^{\circ}$.

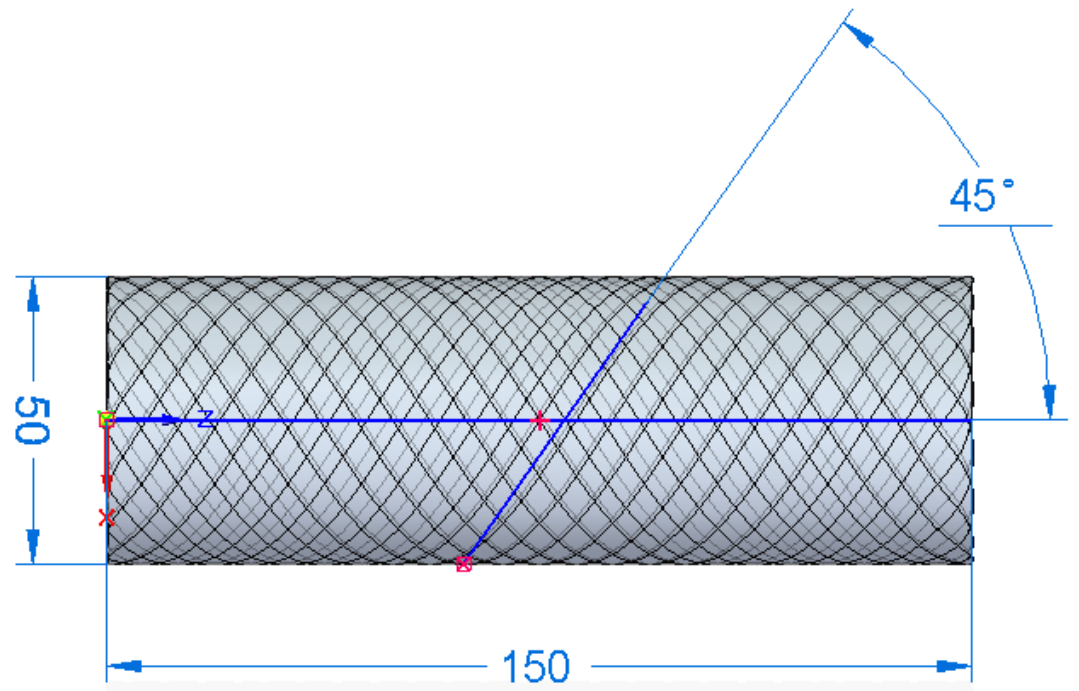

Fonte: Próprio autor (2015).

Figura 110 - Enrolamento a $30^{\circ}$. 


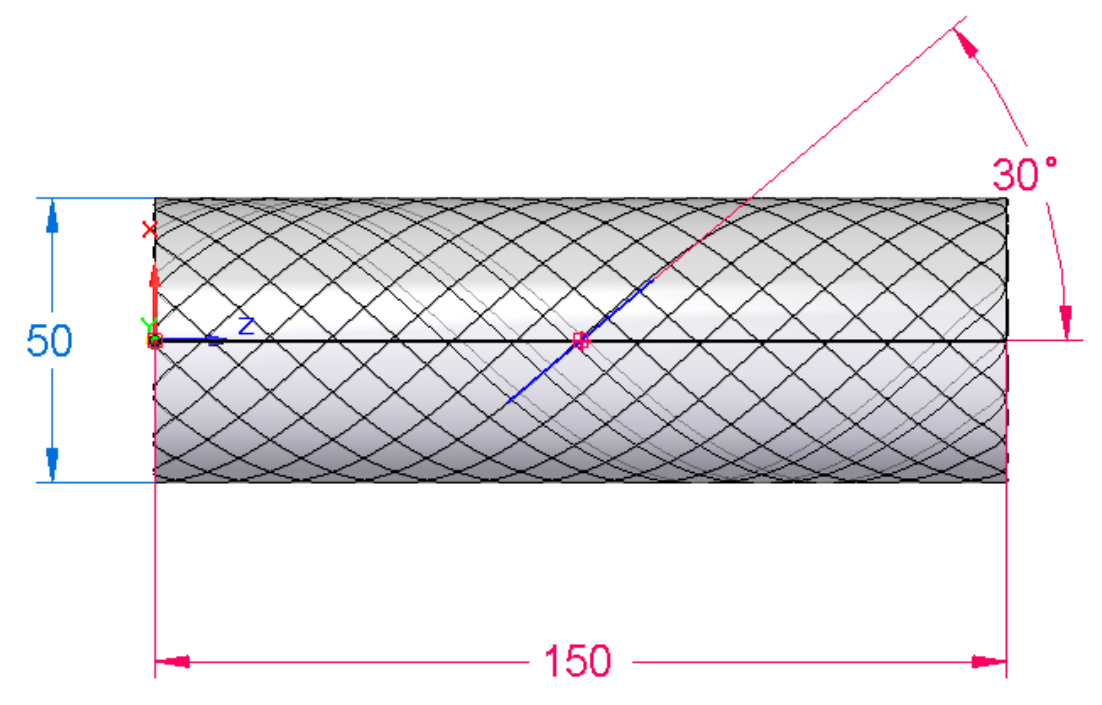

Fonte: Próprio autor (2015).

As curvas são difíceis de medir no CAD, é necessário projetá-las em ambiente de esboço (sketches) para poder mensurá-las. Visualmente pode se notar que as curvas estavam com formato de hélices e mantinham-se constantes ao longo do comprimento, atendendo o esperado das curvas no ambiente CAD tridimensional.

Ocultando algumas planilhas no ambiente $C A D$ foi possível perceber que os pontos de partida para um novo ciclo de enrolamento estava mantido conforme o programa foi designado, ou seja, a cada novo ciclo de enrolamento o havia um incremento em relação ao último ângulo enrolado. Neste trabalho não foi implementado a sequencia de enrolamento descrito por SCHOLLIERS (1992) visto na figura 50. A sequencia de enrolamento abordada neste trabalho é uma ordem sequencial, a cada novo ciclo de enrolamento, a largura da mecha é contada para o ângulo inicial, assim sucessivamente até a cobertura do perímetro.

A figura 111 ilustra a sequencia de enrolamento adotado neste trabalho.

Figura 111 - Sequencai de enrolamento. 


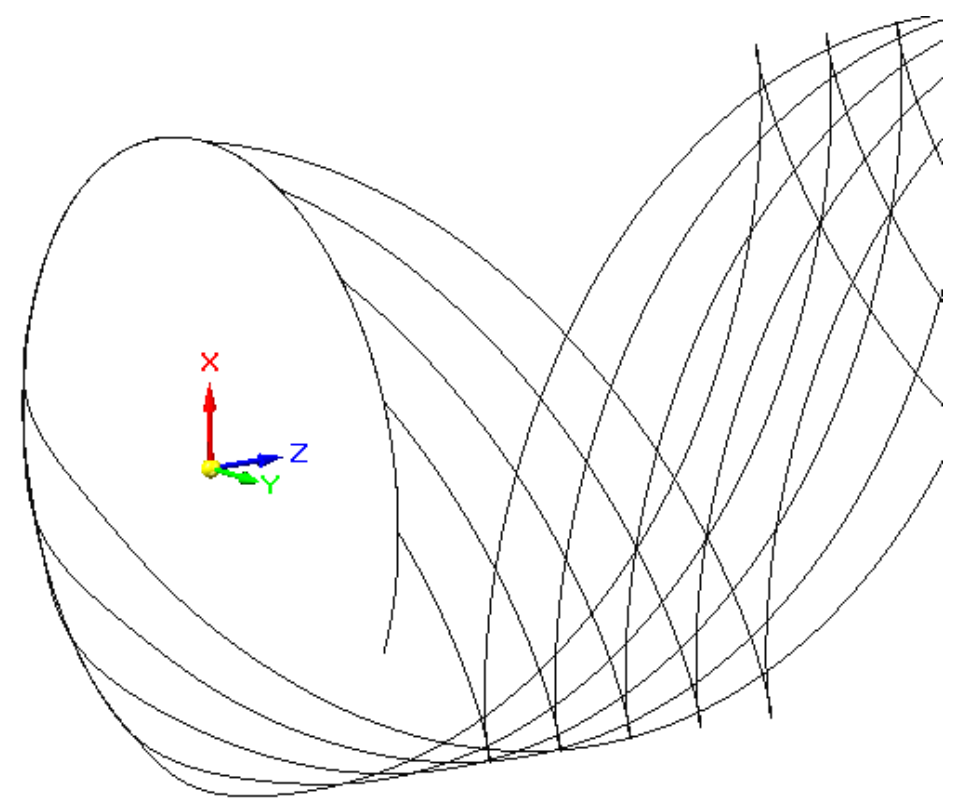

Fonte: Próprio autor (2015).

\subsection{TESTE DE PROGRAMA NO TORNO CNC}

O código escrito pelo programa é salvo no formato texto txt. Este código não é lido pelo compilador da máquina. O código é convertido em extensão mpf antes de ser enviado ou copiado ao hardware da máquina. Esta conversão é realizada no próprio Windows Explorer renomeando o arquivo, onde a alteração pode ou não ocorrer no nome do arquivo, mas que a extensão deve ser alterada para a extensão mpf.

A vantagem de copiar o programa para o hardware da máquina é a possibilidade de executar teste virtual com o gráfico do software da máquina e teste físicos com os eixos (dry run) em movimento visualizando e prevenindo contra possíveis colisões e a possibilidade de riscar o mandril como auxílio de um marcador para verificar as trajetórias ao longo do processo no mandril como ilustra a figura 100 no capítulo 4.

O código gerado pelo programa foi copiado do computador para um cartão de memória comercial, padrão para máquinas $\mathrm{CNC}$, por meio de um adaptador pela porta USB. O código foi transferido do cartão para a máquina novamente por meio do 
adaptador e comunicação por cabo de comunicação CNC padrão para o hardware da máquina.

Foram realizados testes de sintaxe para verificar possíveis erros no código, teste virtual verificando o gráfico gerado pelo software da máquina, teste em dry run para verificar possíveis colisões.

Para o teste com dry run a máquina precisou ter seus eixos $\mathrm{X}$ e $\mathrm{Z}$ ajustados (pre-set). Aproximando o olhal fixado no magazine de ferramentas, próximo ao mandril, foi determinado o diâmetro do enrolamento. Um ponto próximo ao contraponto foi determinado o Z0 ou o ponto inicial do enrolamento.

Realizado o teste em dry run, foi verificado que não havia risco de colisões, o enrolamento poderia acontecer sem risco de colisão entre mandril, olhal, placa e contra ponto. A distância entre o olhal e o mandril, deixava espaço o suficiente para que o enrolamento acontecesse sem que o olhal tocasse nas fibras nas últimas camadas do enrolamento.

Para verificar o comportamento das trajetórias na superfície do mandril, um marcador para quadro branco foi preso no olhal de maneira que tocasse na superfície do mandril. Um enrolamento com os três ângulos $30^{\circ}, 45^{\circ}$ e $60^{\circ}$ individualmente foi executado e as marcas deixadas na superfície do mandril foram mensuradas para verificar se as dimensões esperadas estavam acontecendo.

Numa primeira etapa, o código CNC gerado pelo programa controlava 0 movimento dos eixos $\mathrm{Z}$ e $\mathrm{C}$, onde $\mathrm{Z}$ é o eixo longitudinal do mandril e $\mathrm{C}$ o giro do eixo árvore onde o mandril está preso. Este primeiro código gerou dois problemas durante os ciclos. O primeiro problema era a impossibilidade de controlar a rotação por minutos (RPM) do eixo árvore, um parâmetro interno ajustava esta rotação de acordo com o deslocamento do eixo Z. O segundo problema era com relação ao deslocamento do eixo $Z$ durante o ciclo. No ciclo inicial, durante a saída do olhal da extremidade do contra ponto até a placa, as marcas deixadas pelo marcador na superfície do mandril estavam boas, durante o giro de $180^{\circ}$ quando o olhal estava na extremidade do lado da placa, o torno apresentou um problema em posicionar o ângulo do eixo árvore, uma trepidação que começava no posicionamento e durava até o final do ciclo. 
Esta trepidação era observada durante o enrolamento dos ângulos de $30^{\circ}, 45^{\circ}$ e $60^{\circ}$, no enrolamento tipo aro, ou o enrolamento onde o passo da hélice é o mesmo valor da largura da mecha das fibras, não ocorria às trepidações ao longo do ciclo, porém a rotação do eixo árvore por minuto (RPM) era alta, sendo possível reduzi-las apenas por meio do potenciômetro de rotação. A figura 112 ilustra as marcas deixadas pelo enrolamento tipo aro com o controle do eixo árvore (C).

Figura 112 - Enrolamento tipo aro controlando eixo C.

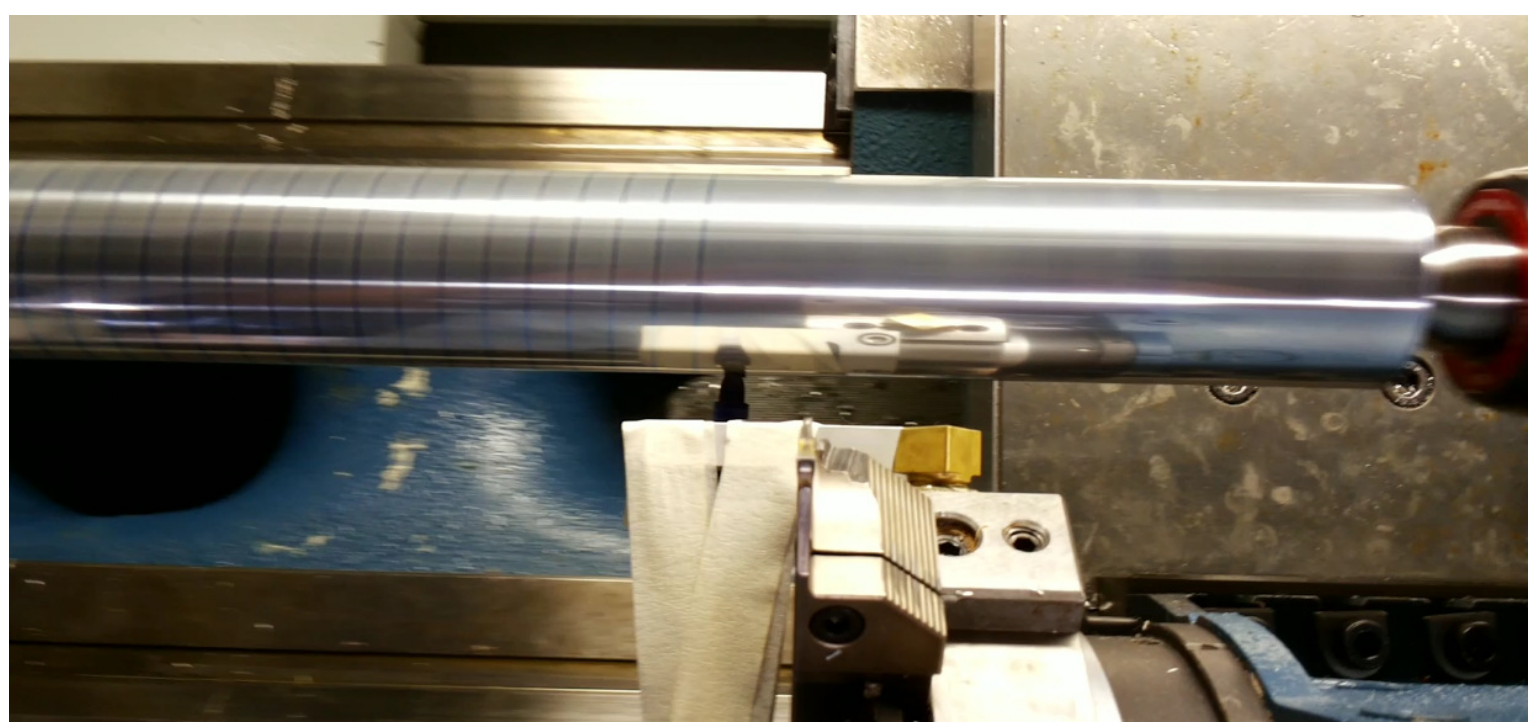

Fonte: Próprio autor (2015).

Essa trepidação apareceu de maneira clara nas marcas deixadas pelo marcador na superfície do mandril durante o retorno do olhal do eixo árvore ao contra ponto nos enrolamentos com ângulos $30^{\circ}, 45^{\circ} \mathrm{e} 60^{\circ}$. O código foi escrito com base nos eixos $\mathrm{X}, \mathrm{Z}$ e $\mathrm{C}$, sua codificação ficou da seguinte maneira:

G21 G40 G90 G95;

T0101;

G54;

G0 X (diâmetro) Z0 (ponto inicial do comprimento do tubo);

M19 (miscelâneas que aciona o eixo árvore); 
G0 C0 (posiciona o eixo árvore no ângulo zero);

G91 (aciona valores incrementais);

Z- (comprimento do tubo) C (ângulo formado pelo passo ao longo do comprimento);

C (giro no final do comprimento do tubo, no programa $180^{\circ}, 360^{\circ}$ ou $540^{\circ}$ );

Z0 (retorno ao início do tubo) C (valor do ângulo de giro no início do tubo mais o valor do incremento ou valor do ângulo formado pelo perímetro da mecha no diâmetro);

O resultado desta trepidação pode ser visto na figura 113, a primeira vez que o olhal se desloca do contra ponto em direção à placa, o desenho da hélice aparece de forma suave e constante, no retorno as trepidações se iniciam e estas permanecem durante todo o processo.

Figura 113 - Trepidações ocorridas durante o enrolamento com o controle do eixo árvore.

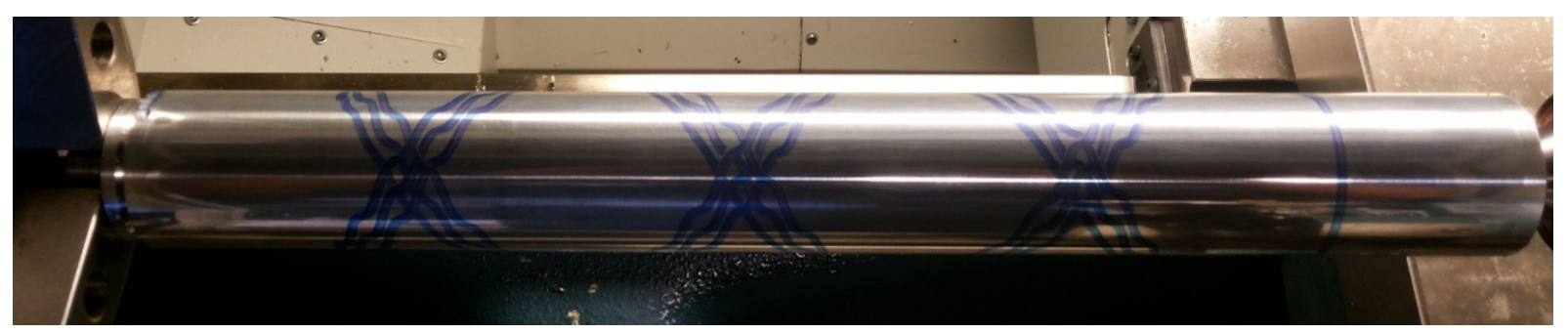

Fonte: Próprio autor (2015).

Para resolver este problema a ideia de trabalhar com ciclo de rosca foi pensado, porém o torno sempre tentaria reiniciar a rosca em sua mesma entrada e no retorno do olhal ao contra ponto não havia garantias de que o valor do passo seria mantido. Para solucionar este problema era necessário cancelar o ciclo de rosca a cada nova entrada ou deslocamento do olhal nas extremidades.

Um ciclo de rosca manual, o G33 da máquina, onde é possível controlar o ângulo de entrada do eixo árvore sem comprometer o desempenho do olhal durante os deslocamentos, deixando o movimento suave reproduzindo a geometria da hélice ao longo da superfície do mandril. Com este ciclo era possível controlar o ângulo de entrada da rosca ou o ângulo de início do enrolamento no início do ciclo. 
Para cada deslocamento do olhal entre sair do contra ponto e se deslocar até a placa e sair da placa e se deslocar até o contra ponto, um novo ciclo se iniciava, para o movimento descrito de ida e vinda temos dois ciclos de rosca controlando passo e ângulo de entrada.

Com este ciclo de rosca, era necessário cancelar o ciclo a cada ida e vinda e iniciar um novo ciclo de rosca alterando o ângulo de entrada. Este novo código permitiu controlar a rotação do eixo árvore de maneira programada e não mais pelo potenciômetro. A figura 114 ilustra o enrolamento com o ângulo de $60^{\circ} \mathrm{com}$ o novo código. As linhas das trajetórias ficaram mais suaves, mantiveram as medidas e não trepidaram.

Figura 114 - Enrolamento a $60^{\circ} \mathrm{com}$ novo código CN.

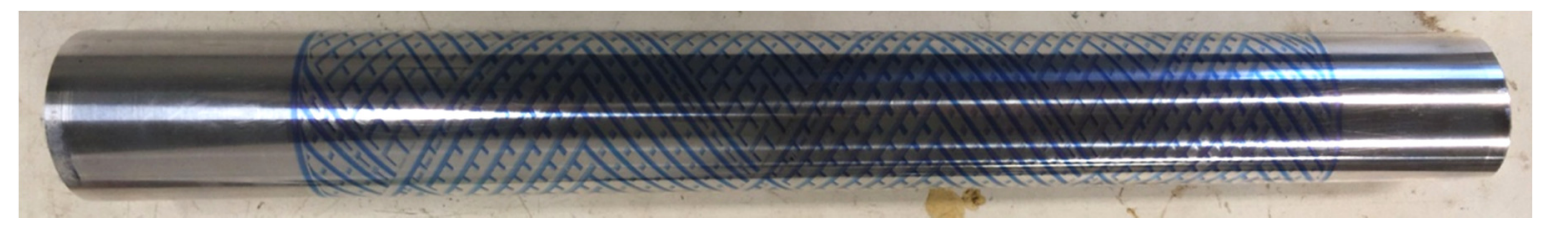

Fonte: Próprio autor (2015).

O ensaio com marcador após a mudança do código $\mathrm{CN}$ foi realizado nos quatro ângulos de revestimento, tipo aro ou $90^{\circ}$ onde o valor do passo da hélice é o mesmo valor da largura da mecha das fibras, $30^{\circ}, 45^{\circ}$ e $60^{\circ}$. Todos os enrolamentos tiveram o valor do passo da hélice medido nas marcas deixadas pelo marcador, estavam todos na dimensão programada por cada ângulo.

O novo código com a utilização do ciclo de rosca manual G33 ficou conforme descrito a seguir:

G291 - Programação em linguagem ISO ou linguagem G.

G21 G40 G90 G95 - Linha de segurança e parâmetros de trabalho.

T0101 - Número da ferramenta ou posição do magazine e seu corretor.

G54 - Função zero peça, pre set da ferramenta.

G0 X50 Z0 - Aproximação do olhal no mandril na posição inicial. 
G97 S30 M3 - Ajuste para rotação constante, valor da rotação (30rpm) e sentido de giro horário.

G33 Z-300 F10.00 Q0 - Ciclo de rosca manual, comprimento do enrolamento no mandril $(300 \mathrm{~mm})$, valor do passo da hélice $(10 \mathrm{~mm})$ e ângulo de entrada a $0^{\circ}$.

GO - cancela o ciclo.

G4 X1 - Tempo Dwell, tempo de parada de movimento do eixo Z, mas eixo árvore permanece girando com valor programado anteriormente $30 \mathrm{rpm}$.

G97 S30 M3

G33 Z0 F10.00 Q180000 - retorno do olhal ao contra ponto com ângulo de reentrada a $180^{\circ}$.

G0 - cancela ciclo.

Com este novo código foi possível realizar os enrolamentos em todos os ângulos previamente definidos, $90^{\circ}$ (tipo aro), $30^{\circ}, 45^{\circ}$ e $60^{\circ}$. A simulação realizada na superfície do mandril com cada um dos ângulos e com todos os ângulos em um só programa foram testados e validados, as marcas deixadas pelo marcador forma medidas e comprovadas as dimensões esperadas.

\subsection{DISPOSITIVO TENSIONADOR}

O dispositivo tensionador, à princípio, foi pensado como um eixo principal no qual seriam enroladas (ou bobinadas) as fibras. Estas seriam desenroladas do carretel do fabricante e enroladas no eixo principal do tensionador para serem desenroladas e enroladas novamente no mandril. A quantidade de fibras a ser enrolada no eixo principal do tensionador seria calculada em função das camadas que revestirão o mandril. Isto limitaria consideravelmente o número de camadas, comprimento e diâmetro do tubo a ser produzido. Este problema também levaria a um tempo bem maior de execução devido ao desenrolamento das fibras do carretel e o enrolamento das fibras no dispositivo e do desenrolamento das fibras do dispositivo para 0 
enrolamento no mandril, além disto, o problema com a ruptura de filamentos durante os processos de enrolar e desenrolar dificultaria ainda mais o processo.

Para evitar toda esta situação, foi pensado num sistema que desenrolasse as fibras do carretel, causasse tensão nas mesmas e permitisse o enrolamento sob tensão no mandril. Um dispositivo foi idealizado de maneira que as fibras fornecidas em carretel pelo fabricante fossem tracionadas pelo mandril no torno e ao passar pelo dispositivo este causasse tensão nas mesmas.

O dispositivo é composto por um eixo onde as fibras devem ser enroladas em duas ou mais voltas antes de serem enroladas no mandril. Este enrolamento no eixo faz com que o mesmo sofra movimento de rotação pelo arraste das fibras sendo enroladas no mandril. Guias de entrada e saída das fibras no dispositivo garantem que as fibras não se acumulem em um mesmo ponto do eixo.

Este eixo apresenta uma resistência ao movimento de rotação causando tensão nas fibras. Esta resistência é causada por um sistema de freio ajustável. O eixo está suspenso por mancais de rolamento nas extremidades. Por meio de uma mola caracol, um tambor é conectado ao eixo, neste tambor há um disco fixado por meio de parafusos, este disco sofre a ação de atrito com pinos de celeron que resistem ao movimento de rotação do eixo, este atrito é ajustado por meio de parafusos e molas helicoidais.

O eixo sendo tracionado pelas fibras causa uma torção na mola caracol presa ao tambor que por meio do disco de freio sofre o atrito dos pinos ajustáveis de celeron. Esta resistência ao movimento de rotação resulta numa tensão nas fibras. A figura 115 ilustra o dispositivo de tensão ou tensionador.

Figura 115 - Dispositivo tensionador. 

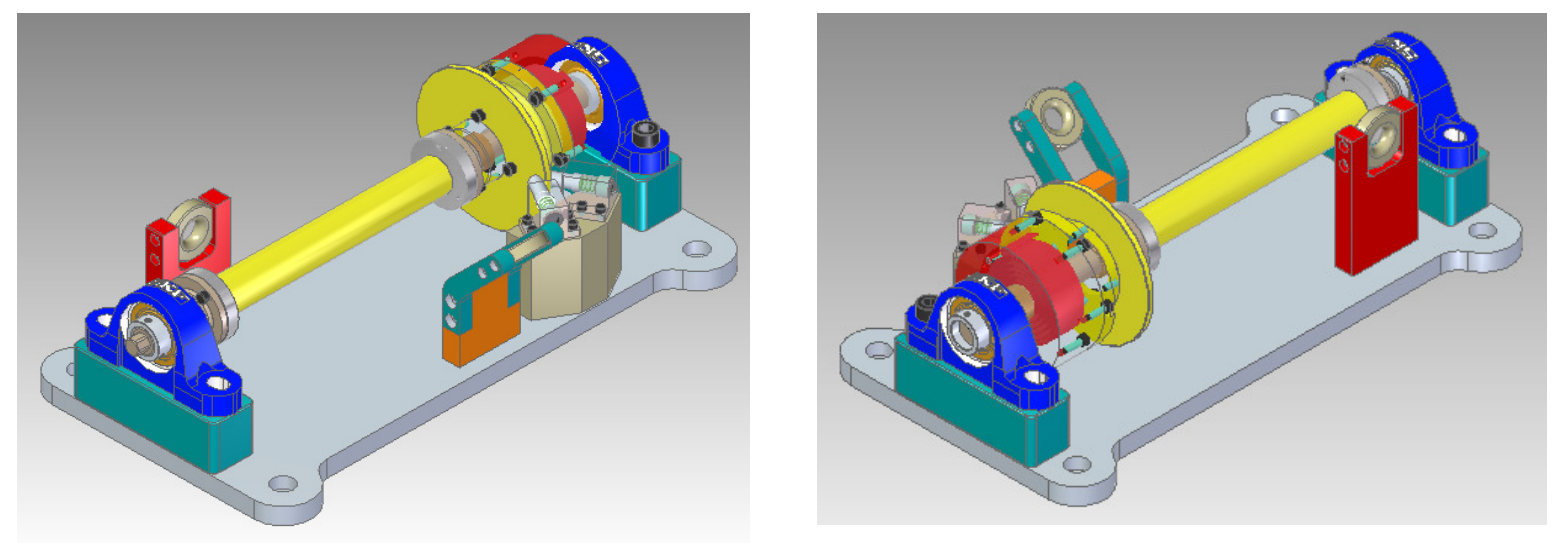

Fonte: Próprio autor (2015).

Antes de testar o dispositivo com as fibras, foi realizado um teste com fita de cetim. Tracionada manualmente, uma força muito alta foi necessária para girar o eixo. Notou-se que devido ao diâmetro do eixo ser pequeno, 25mm, era necessária uma força de tração elevada para girá-lo. O eixo foi substituído por um tubo com diâmetro de $80 \mathrm{~mm}$, isto resultou num esforço menor para girar o tubo e permitiu que a tensão pudesse ser ajustada pelo sistema de freio.

Após o teste com o cetim, iniciou-se o teste com as fibras de vidro. As fibras eram enroladas em duas voltas no tubo e notou-se que havia um deslizamento das fibras no tubo de maneira que o tubo não chegava a girar, sendo impossível causar tensão. Uma solução foi o uso de lixa de baixa granulação, lixa 600. Isto resultou numa ruptura dos filamentos ou desfiamento das fibras. Para solucionar o problema com o deslizamento sem o uso da lixa, foi dar mais de duas voltas no tubo, isto resultou no giro do tubo onde a tensão pôde ser controlada. Ao mesmo tempo em que aumentar o número de voltas em volta do tubo gerou o movimento de rotação, as fibras sofriam 
uma ação de se acumularem em um único ponto sobrepondo umas às outras. A figura 116 ilustra o novo dispositivo de tensão com tubo ao invés de eixo.

Figura 116 - Dispositivo com tubo ao invés de eixo.

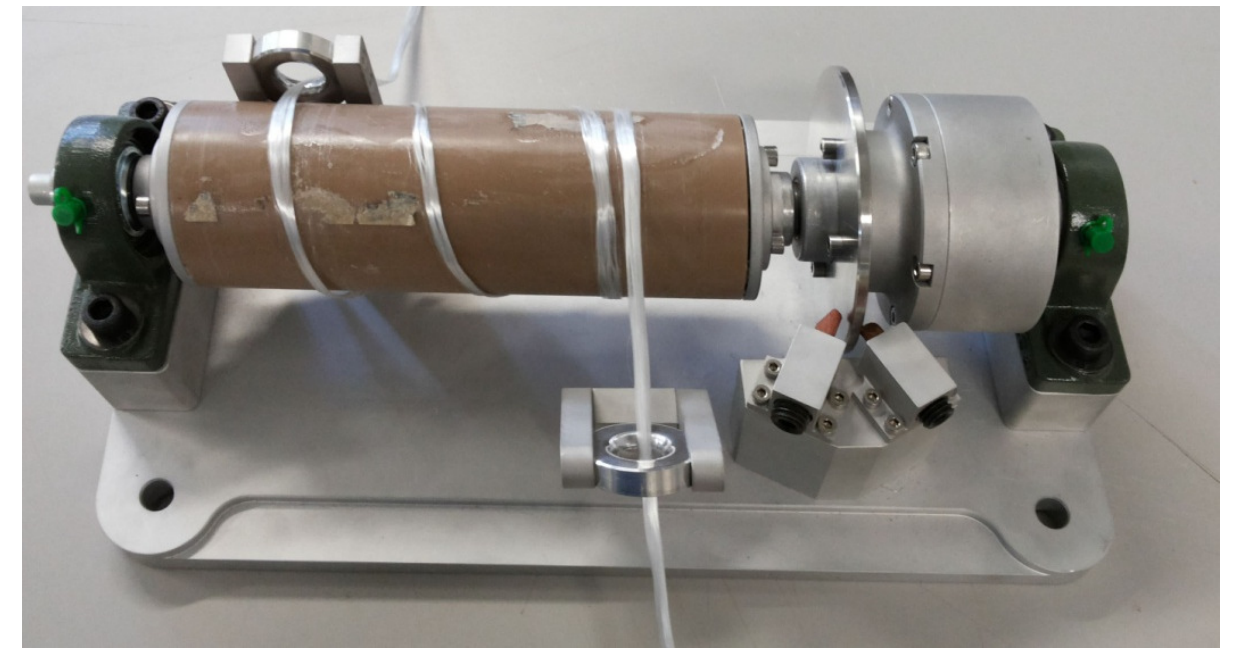

Fonte: Próprio autor (2015).

Embora este problema das fibras de se sobreporem umas às outras, foi possível realizar o processo de filamen winding sem que houvesse um desfiamento considerável das fibras. A figura 117 ilustra a sobreposição das fibras na superfície do tubo do dispositivo.

Figura 117 - Tendência à sobreposição das fibras. 


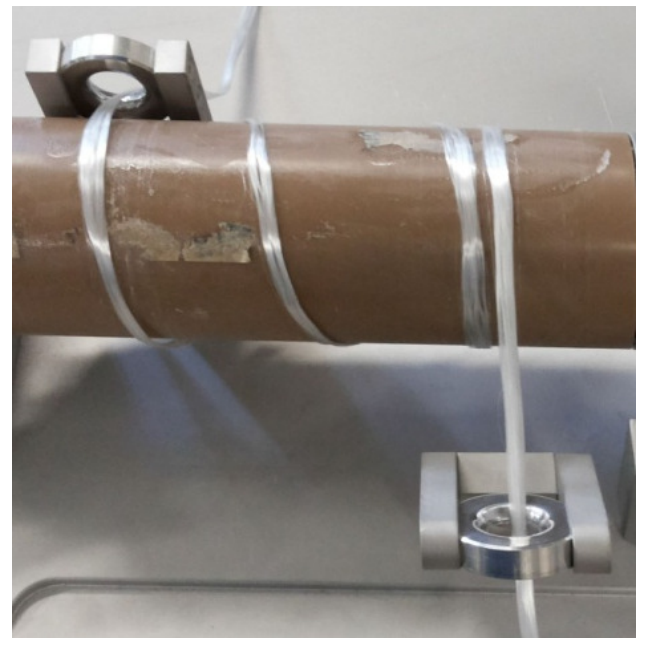

Fonte: Próprio autor (2015).

Após o teste com as fibras ser realizado e o resultado ser satisfatório, era necessário saber se o dispositivo era capaz de remover as fibras do carretel e causar tensão nas fibras. Ambos, dispositivos e carretel foram posicionados próximo ao torno, as fibras foram presas no mandril e uma baixa rotação no eixo árvore foi programada e avaliada a capacidade de enrolamento das fibras no mandril, desenrolamento das fibras do carretel e avaliada a tensão, de maneira visual e teste manual, sem auxílio de calibradores ou aparelhos de medição, se havia tensão nas fibras. Neste momento a avaliação eram as capacidades abordadas acima, o valor da tensão não estava sendo avaliado e o resultado foi satisfatório.

\subsection{REVESTIMENTO}

Após os testes com o dispositivo tensionador e com o programa, iniciou-se o processo de filament winding. Para validar o programa, todos os ângulos necessitavam ser executados. Os parâmetros para execução deste programados foram diâmetro inicial de $50 \mathrm{~mm}$, comprimento de $300 \mathrm{~mm}$, largura da mecha $10 \mathrm{~mm}$, estratégia de enrolamento sequencial, ou seja, início zero grau no primeiro ciclo, no segundo ciclo incremento da largura da mecha em ângulo, no caso deste trabalho o ângulo para cada novo ciclo foi de $22,918^{\circ}$ e os ângulos testados foram $90^{\circ}$ ou revestimento tipo aro, $30^{\circ}, 45^{\circ} \mathrm{e} 60^{\circ}$. A rotação do eixo árvore foi programada para 60 rpm. 
O primeiro ângulo de revestimento foi $90^{\circ}$ ou tipo aro. O torno não lê o ângulo de revestimento, na programação é necessário transmitir o valor do ângulo em passo da hélice, simulando uma usinagem de rosca. O passo para este revestimento é a própria largura da mecha, $10 \mathrm{~mm}$. A figura 118 ilustra o revestimento tipo aro.

Neste enrolamento pode ser observado que a largura da mecha sofria uma variação dimensional em sua largura, embora essa alteração fosse pequena, era notada ao longo do enrolamento. SOEIRA (2014) propôs um dispositivo que regulariza o a largura da mecha, o que poderia minimizar ou até extinguir essa variação de largura da mecha. Essa variação de largura acontece quando os filamentos se sobrepõem durante o processo.

Figura 118 - Revestimento tipo aro.

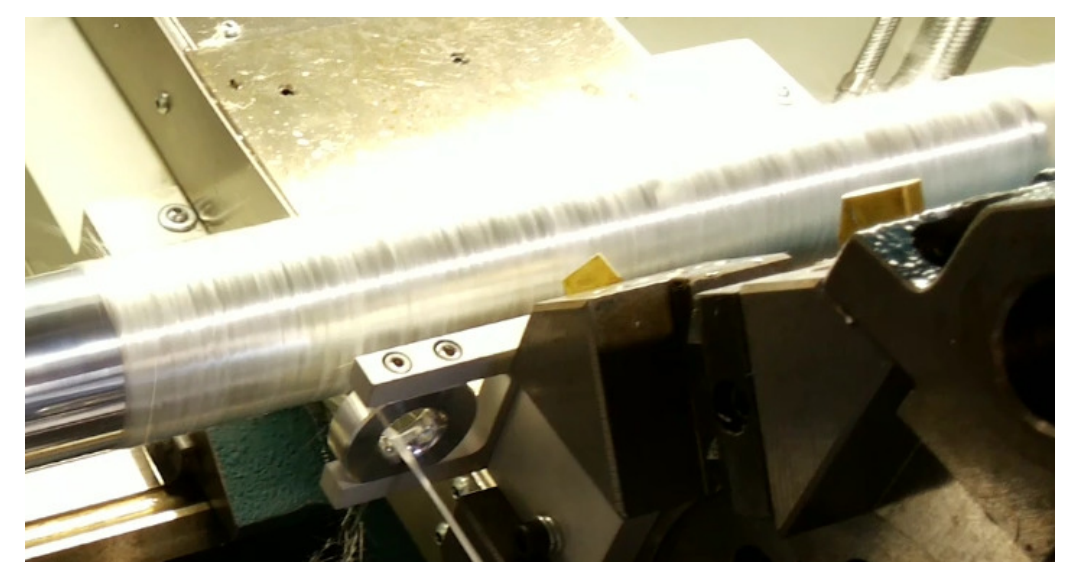

Fonte: Próprio autor (2015).

O revestimento tipo aro foi realizado duas vezes, sendo um ciclo de saída da extremidade do contraponto para a extremidade da placa um ciclo e o retorno para a extremidade do contraponto caracterizado como outro ciclo.

A segunda camada enrolada foi o ângulo de $30^{\circ}$ cujo passo calculado em função da linha de centro do eixo árvore tem o valor de 173,2 mm. Nesta camada 
pode ser destacado o ponto de transição entre os ângulos e o trançado mostrou atingir o objetivo.

Não foi percebido visualmente deslizamento das fibras nesta etapa, o que além de favorável, notou-se um bom comportamento na deposição das fibras ao longo do comprimento eliminando espaços vazios entre as passadas.

Uma limitação encontrada neste ângulo de revestimento foi à velocidade de deslocamento longitudinal do eixo $Z$ e a rotação do eixo árvore que não eram compatíveis, houve a necessidade de redução do número de rotações por minuto do eixo árvore, sendo ajustado para 30 rotações por minuto. A figura 119 ilustra a transição entre o revestimento tipo aro e o revestimento a $30^{\circ}$, a figura 120 ilustra 0 final do revestimento a $30^{\circ}$.

Figura 119 - Transição entre o revestimento tipo aro e o revestimento a $30^{\circ}$.

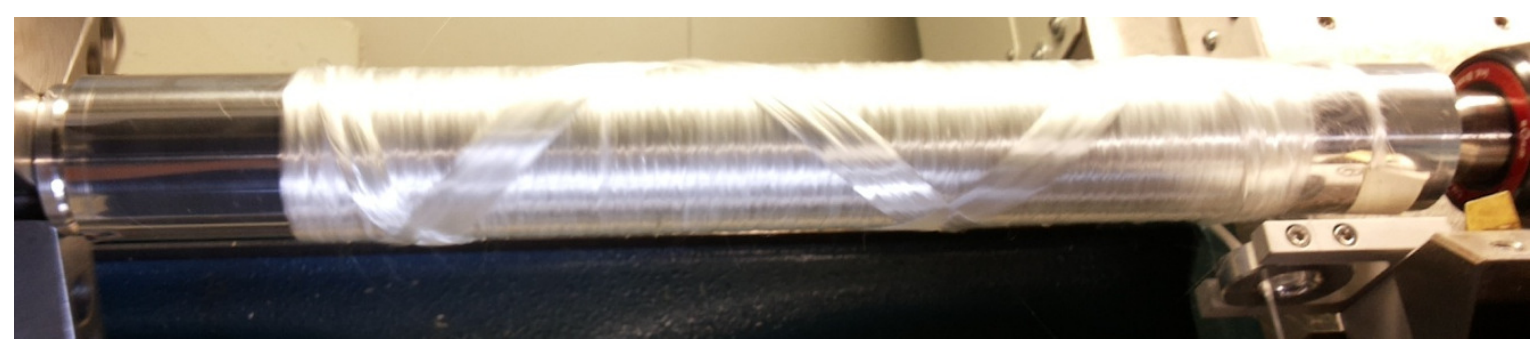

Fonte: Próprio autor (2015).

Figura 120 - Revestimento a $30^{\circ}$. 


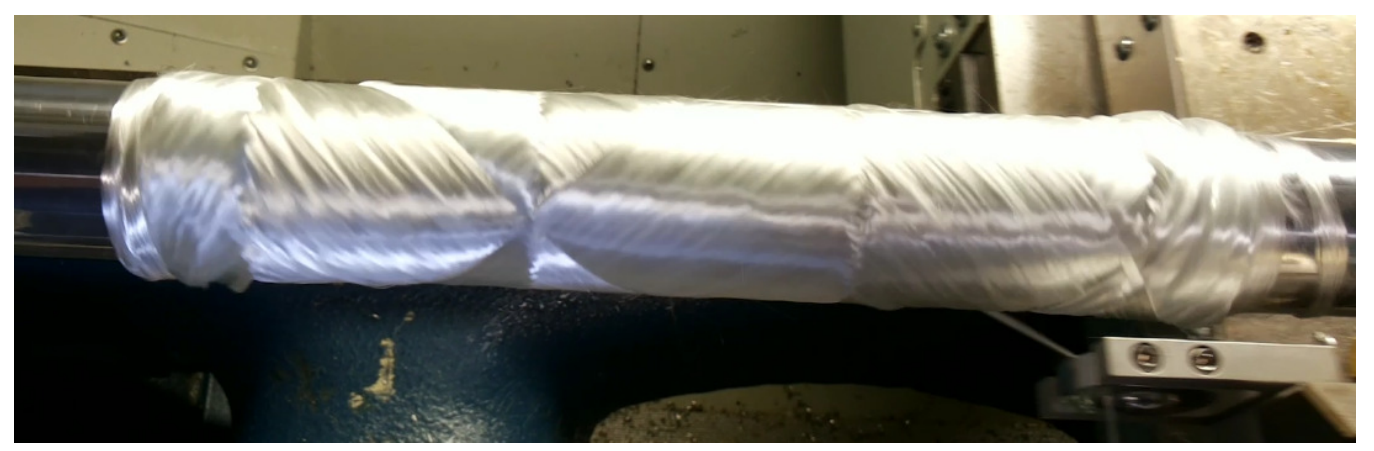

Fonte: Próprio autor (2015).

A terceira camada foi revestida com enrolamento a $45^{\circ}$. Assim como 0 revestimento a $30^{\circ}$, visivelmente não houve problemas com espaços vazios entre as passadas e problema com deslizamento das fibras.

O ângulo de $45^{\circ}$ tem passo calculado com o valor de $100 \mathrm{~mm}$ e a velocidade de deslocamento do eixo $Z$ em função da rotação é menor, sendo assim a rotação do eixo árvore pode ser ajustado novamente em 60 rotações por minuto. Este ângulo de $45^{\circ}$ foi o primeiro a ser enrolado no caráter de teste. Este teste tinha a função de verificar o deslizamento no mandril polido, validar o enrolamento e verificar o comportamento da máquina e do dispositivo tensionador. Como não havia uma dimensão previamente determinada para a mecha, adotou-se mecha com 10mm, cuja dimensão foi considerada grande devido aos espaços vazios deixados entre as passadas.

O teste validou o enrolamento antes do enrolamento final com várias camadas e validou o dispositivo e a máquina. A figura 121 ilustra a transição entre os revestimentos de 30 e e $45^{\circ}$. A figura 122 ilustra o revestimento a $45^{\circ}$.

Figura 121 - Transição entre os revestimentos $30^{\circ}$ e $45^{\circ}$. 


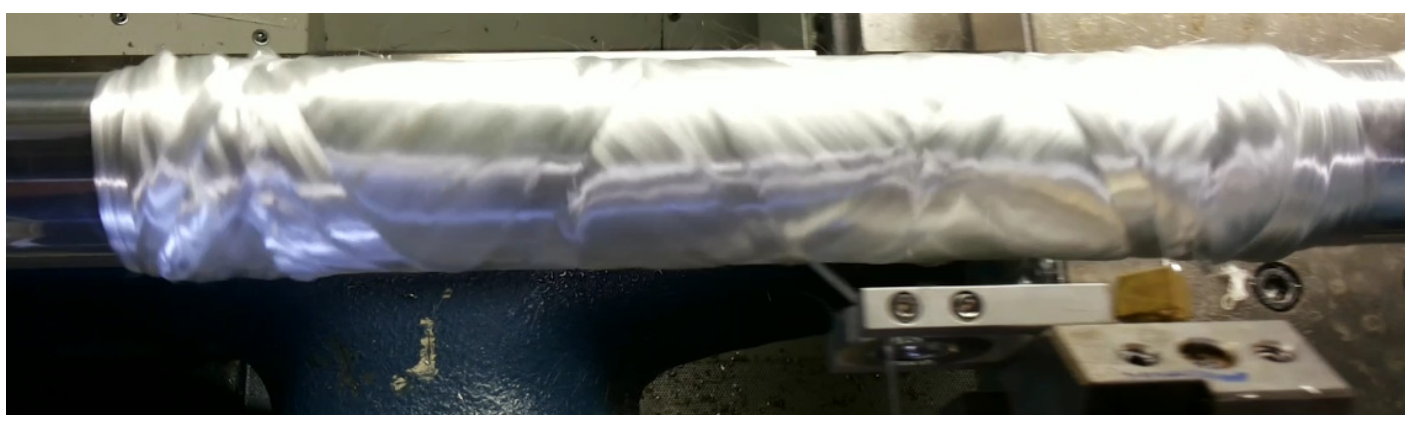

Fonte: Próprio autor (2015).

Figura 122 - Revestimento a $45^{\circ}$.

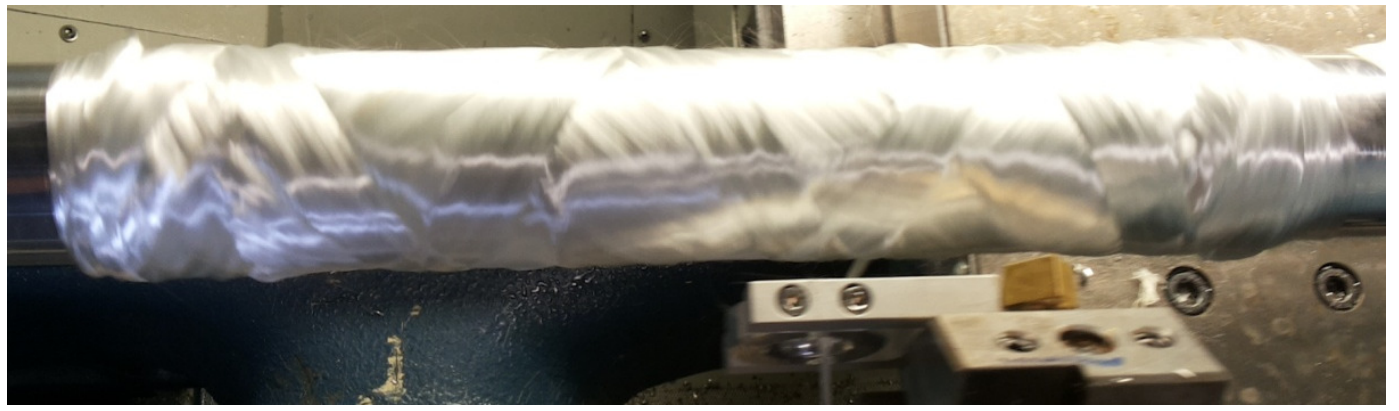

Fonte: Próprio autor (2015).

O enrolamento a $60^{\circ}$ foi a quarta e última camada para verificação e validação do programa, dispositivos e máquina. Como último enrolamento foi notado um volume de fibras na extremidade do mandril, que embora fosse cortado no caso do produto 
embebido com resina e curado, possam ser minimizados diminuindo o tempo Dwell no torno ( $\mathrm{G} 4 \mathrm{X} 1$ ) ou simplesmente diminuindo a rotação do eixo árvore. Estas medidas diminuiriam $o$ volume de fibras deixado nas extremidades do mandril e consequentemente o volume de material. A figura 123 ilustra a transição entre os revestimentos $45^{\circ} \mathrm{e} 60^{\circ} \mathrm{e}$ a figura 124 ilustra o revestimento a $60^{\circ}$.

Figura 123 - Transição entre os revestimentos $45^{\circ}$ e $60^{\circ}$.

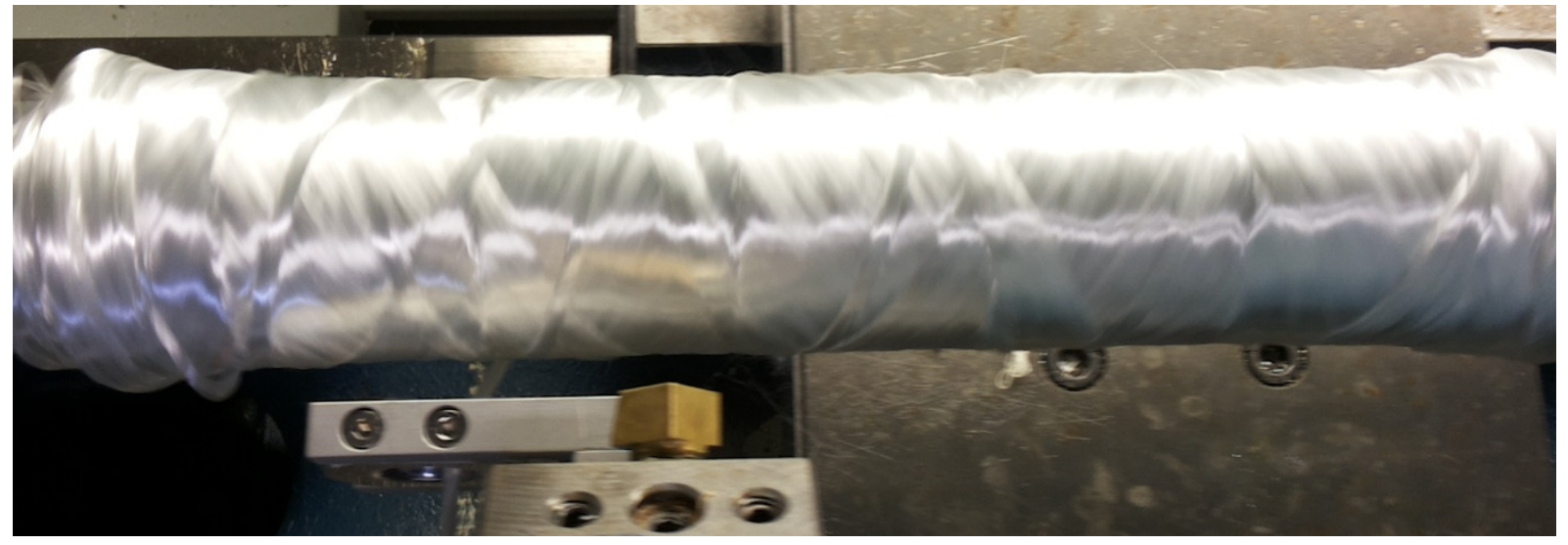

Fonte: Próprio autor (2015).

Figura 124 - Revestimento a $60^{\circ}$.

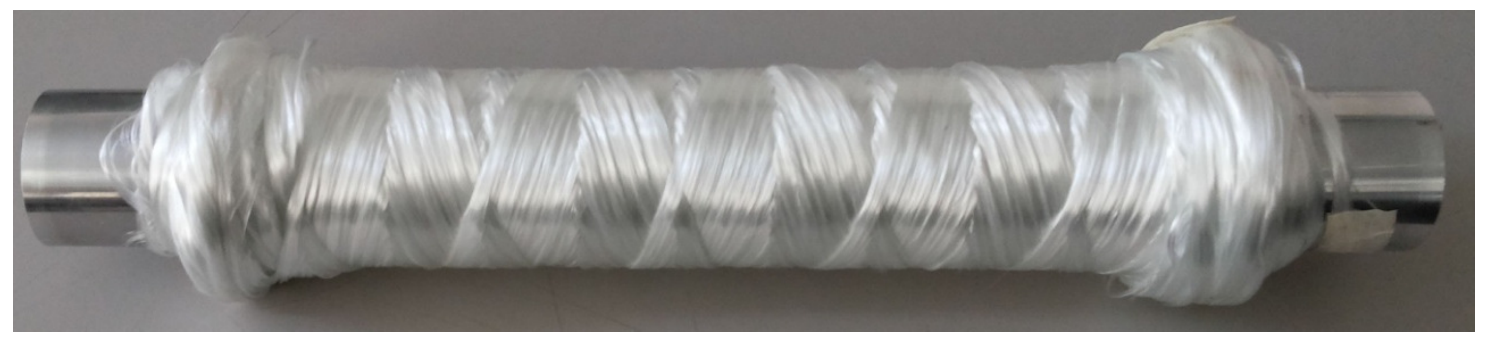

Fonte: Próprio autor (2015). 


\subsection{REVESTIMENTO COM RESINA}

Realizado os testes com o enrolamento a seco, foram adquiridas resinas para validação do filament winding com banho de resina. Não foi projetado um dispositivo para o banho de resina e a resina foi aplicada manualmente por meio de pincel para validar o teste com o programa e com a máquina.

Para este procedimento foi enrolado quatro tubos em dois mandris de mesmas dimensões e geometria. Os mandris foram usinados em alumínio comercial, polidos e com pequena conicidade, sendo esta ao longo do comprimento com $\varnothing 30 \mathrm{~mm}$ em uma extremidade e um comprimento de $250 \mathrm{~mm}$ e $\varnothing 29,5 \mathrm{~mm}$ na outra extremidade.

Entre o mandril e as fibras foi enrolado um papel vegetal para evitar que a resina se impregnasse no mandril e impedisse a remoção do produto manufaturado. $O$ mandril numa extremidade foi preso às castanhas do torno e a outra extremidade foi alocada no contra ponto do torno.

O mesmo dispositivo tensionador foi utilizado para a realização deste procedimento. A mesma fibra de vidro utilizada no procedimento anterior também fi utilizado. Não havia nenhum dispositivo para banhar as fibras com resina. Sendo necessário um banho manual com ajuda de pincel.

O banho de resina com pincel não substitui a eficiência do banho de resina por meio de um dispositivo apropriado para este fim. O banho manual apresenta limitações estas que se reproduzem na superfície da camada que está sendo enrolada, pois depende da habilidade do operador e é interrompida constantemente em função da necessidade de umedecer o pincel novamente.

Barramento e partes móveis sujeitas a respingo de resinas foram protegidos com papelão evitando que a resina danificasse o torno. $O$ enrolamento ocorreu com baixa rotação para evitar que a resina respingasse pelo interior da máquina.

A figura 125 ilustra os tubos enrolados com a aplicação da resina nos ângulos até então implementados no programa. Na figura 125(a) enrolamento com duas camadas a $90^{\circ}$, uma a $30^{\circ} \mathrm{e}$ mais duas a $90^{\circ}$. Na figura 125 (b) enrolamento com duas camadas a $90^{\circ} \mathrm{e}$ uma a $30^{\circ}$. Na figura 125 (c) enrolamento com duas camadas a $90^{\circ}$ e uma a $45^{\circ}$. Na figura 125 (d) enrolamento com duas camadas a $90^{\circ}$ e uma a $60^{\circ}$. 
Figura 125 - Tubos enrolados com aplicação de resina.

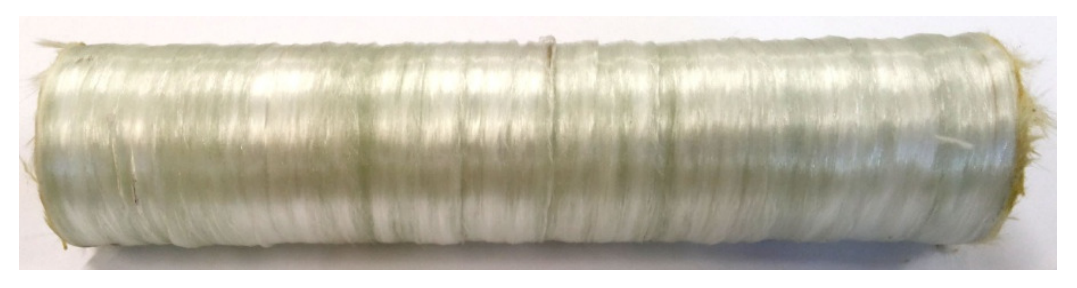

(a)

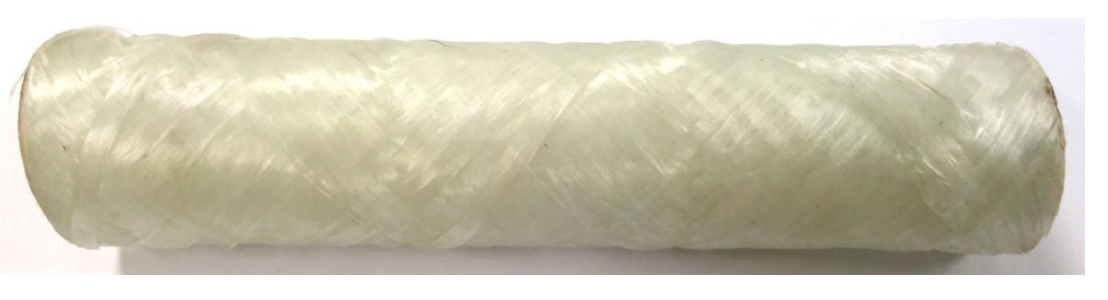

(b)

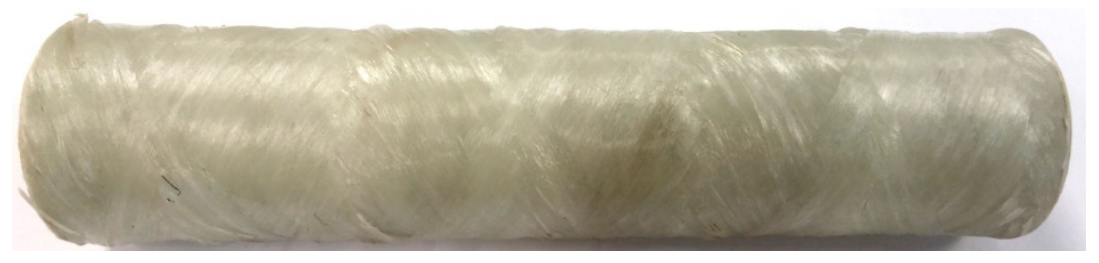

(c)

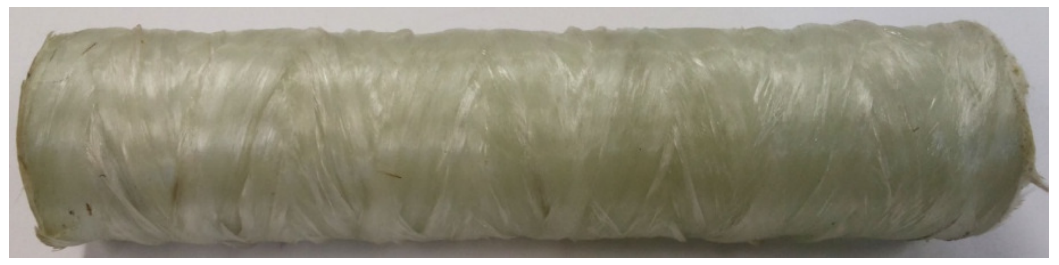

(d)

Fonte: Próprio autor (2015).

Os tubos tiveram suas extremidades cortadas em função do excesso de fibras nas extremidades durante o reposicionamento do novo ciclo de enrolamento. Os tubos foram removidos do mandril com auxílio de um macete de borracha, um pequeno 193 
deslocamento foi o suficiente para a remoção do produto graças a conicidade do mandril.

\section{CAPÍTULO 6}

\section{CONCLUSÕES E SUGESTÕES}

\subsection{PROGRAMA}

O programa desenvolvido em C\# foi capaz, a partir da entrada de dados do usuário, gerar dados para a fabricação, pelo processo de filamen winding, tubos de materiais compósitos reforçados por fibras (neste trabalho fibra de vidro) com comprimentos e diâmetros limitados pelas limitações mecânicas da máquina.

O programa gerou planilhas para o Excel, de modo que estes dados possam ser visualizados no software CAD, Solid Edge utilizado neste trabalho, e curvas que formam uma trajetória de formato em hélice espiral com diâmetro, comprimento e ângulo de hélice determinados pelo usuário.

Algumas curvas não eram possíveis de serem visualizadas no software CAD, embora os dados estivessem corretos, o fato ocorreu pela limitação do software CAD em conectar estes dados, uma vez que estes dados em uma planilha eram divididos em duas ou mais planilhas, era possível visualizar as curvas.

Este programa, para este trabalho, foi idealizado para produção de tubos com diâmetro limitado entre 30 e 100mm, o comprimento limitado entre 150 e $500 \mathrm{~mm}$, a largura da mecha foi limitada a no mínimo $8 x$ o perímetro do diâmetro do mandril. Os ângulos de enrolamento foram limitados a $90^{\circ}, 30^{\circ}, 45^{\circ}$ e $60^{\circ}$. 
O programa também foi capaz de gerar um arquivo texto para que o torno movimentasse os eixos para o processo de filament winding.

Como sugestões para aperfeiçoamento do programa:

- Geração das trajetórias graficamente sem a necessidade da utilização de um sistema CAD para visualização. Isto seria possível incorporando ao código fonte bibliotecas gráficas como o OPEN GL, por exemplo.

- Implementação no programa de dados de entrada da geometria em formatos neutros como, por exemplo, IGES ou STL, o que o tornaria independente do sistema CAD utilizado.

\subsection{DO TORNO}

A máquina foi capaz de produzir um tubo simples dado suas limitações e propósito. Embora não seja esse o propósito da máquina, alguns testes com cilindros cônicos foram realizados e foi possível gerar trajetórias com a programação em comando dos eixos X, Z e C, sem a utilização do ciclo de rosca G33.

Com uma proteção e um banho de resina bem projetada para esta máquina, seria possível realizar o processo com resina e não a seco. Também seria possível construir um sistema de tensionador de vários carretéis para obter uma mecha maior e melhorar o processo de revestimento. O dispositivo para abrir a mecha, elaborado por SOEIRA (2014), poderia ser utilizado fora da máquina, antes que as fibras chegassem ao olhal.

Para o processo de filament winding a máquina trabalhou com a porta frontal de segurança aberta para que as fibras pudessem passar e quando realizado o processo de banho de resina manual a mesma não poderia ser fechada. Embora medidas de segurança forma tomadas com relação ao uso de equipamentos de proteção individual entre eles o óculos de segurança, luvas e máscara, além de baixa rotação do spindle para evitar respingos e tempo de reação do operador caso algum problema acontecesse.

A máquina teve seu barramento e partes móveis protegidas com papelão a fim de evitar o contato da resina com barramento e outras partes. 


\subsection{DO TENSIONADOR}

O dispositivo tensionador atendeu as necessidades do projeto. Contudo alguns problemas ocorreram como o sistema de freio que teve de ser minimizado em sua atuação em virtude da força da mola, pois a tensão nas fibras estava muito alta (manualmente verificadas).

Outra limitação foi quanto à sobreposição das fibras no cilindro do dispositivo tensionador. Para evitar esta sobreposição foram testados dois olhais (que são usados no torno) para afastar as fibras e evitar a sobreposição. O resultado foi positivo. Uma proposta de alteração para eliminar o problema de sobreposição é apresentada na figura 126.

Figura 126 - Proposta para evitar sobreposição das fibras no tensionador.

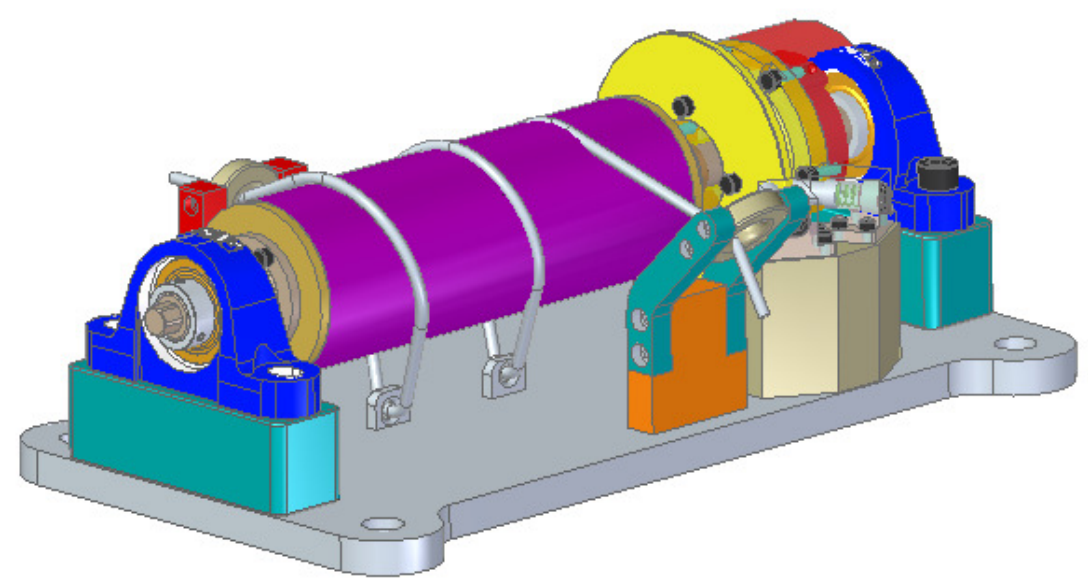

Fonte: Próprio autor (2015).

Outra proposta de alteração é com relação às molas. As molas utilizadas neste dispositivo são molas do tipo caracol comercial utilizada nos braços de máquinas ferramentas furadeiras e fresadoras. Estas molas são dimensionadas para 12 voltas e sustentar a alavanca de manuseio.

Como a força desta mola é elevada, para atender a necessidade do projeto, a mola foi adaptada em aberto e não concentrada. Isto resultou num único tambor, maior 
que o anterior, adaptado para a mola trabalhar relaxada sofrendo torção somente quanto exigida pelas fibras.

Diferente das molas helicoidais de tração e compressão, esta mola não tem uma variedade dimensional como as molas comerciais de tração e compressão. Com a dificuldade de encontrar essas molas no mercado uma solução seria utilizar duas molas de trena convencional, removendo estas molas da trena e adaptando no dispositivo.

\subsection{DO PROCESSO}

O processo de filament winding foi realizado a seco e com banho de resina manual por meio de pincel. Por ambos os processos notou-se a necessidade de um dispositivo que permita a abertura da mecha, tirando as fibras do formato de "corda" para fita, onde os filamentos fiquem mais bem distribuídos na largura da mecha e pouco na altura o que causa um aumento considerável do diâmetro do tubo exigindo mais ciclos para a cobertura de uma camada. Ao passo que uma mecha de largura maior e menor altura resultariam num tubo de diâmetro menor e com maior aproveitamento da largura da mecha e redução de ciclos por camada.

A redução da rotação do eixo árvore (spindle) da máquina favorece a redução do acúmulo de fibras nas extremidades do mandril, porém aumenta o tempo de processo. Um aumento na rotação do eixo árvore e reprogramação do código G4 X1, 2 ou $\mathrm{n}$, onde é programado um tempo de permanência do magazine com a placa girando, reduziria este acúmulo também, porém o limite de velocidade de deslocamento do eixo $Z$ deve ser levado em consideração em relação a passos muito longos tais como o ângulo $30^{\circ}$, onde a rotação teve de ser reduzida para $30 \mathrm{rpm}$ no enrolamento a seco, pois em função da rotação programada anteriormente em 60 rpm o eixo Z não conseguia o deslocamento necessário à realização do movimento.

No enrolamento com o banho manual de resina por meio de pincel, pode ser notada a necessidade de um dispositivo para banhar as fibras, o resultado foi um banho manual deficiente onde alguns filamentos ficaram soltos. A figura 127 ilustra estes filamentos soltos em função da má impregnação da resina nas fibras. 
Outro aspecto que pode ser notado em função da impregnação manual deficiente de resina com o auxílio do pincel foi a remoção do papel que separava o mandril da primeira camada dos tubos manufaturados. Onde houve uma boa impregnação de resina, o papel foi removido sem dificuldade, onde houve baixa impregnação o papel após a remoção mostrava a primeira camada desfiando. Em alguns casos o papel ficou preso à primeira camada sendo impossível sua remoção sem danificar a primeira camada. A figura 128 ilustra estas situações ocorridas.

Figura 127 - Filamentos com má impregnação de resina.

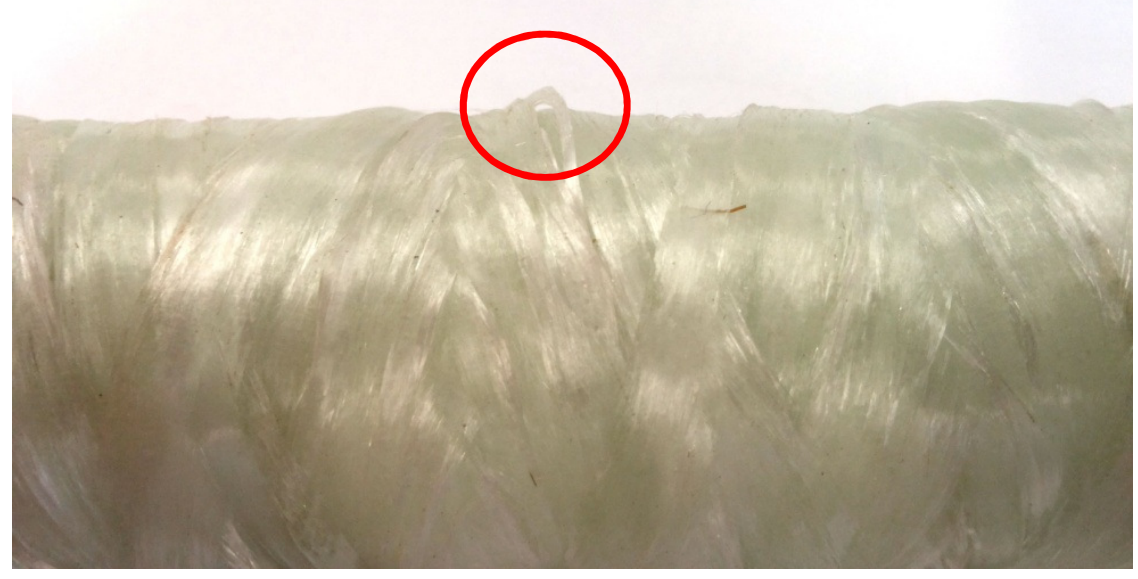

Próprio autor (2015).

Figura 128 - Remoção do papel do tubo manufaturado. 


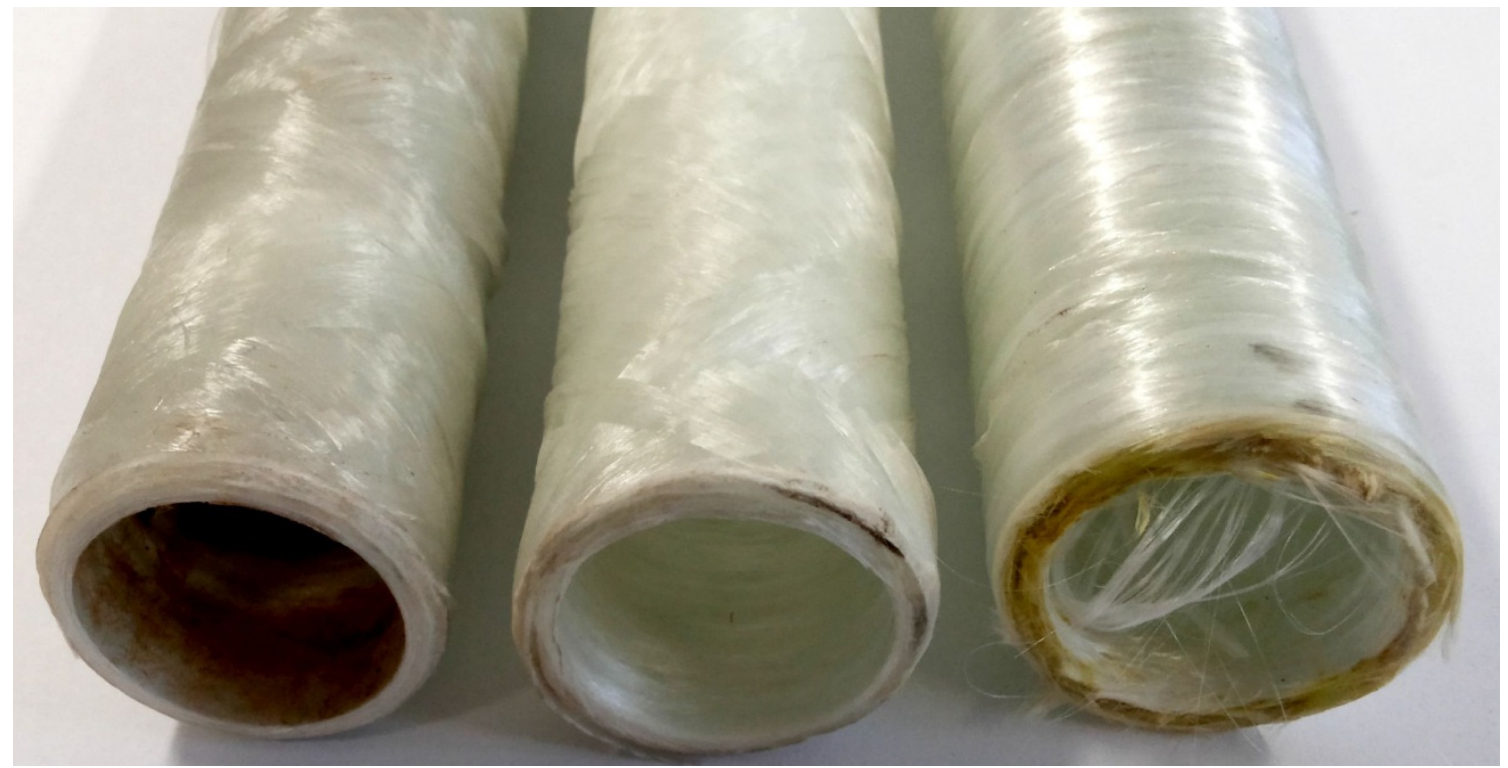

Fonte: Próprio autor (2015). 


\subsection{CONCLUSÃO DOS RESULTADOS}

O programa e o torno se mostraram capazes de executar o processo de filament winding. O passo e o perfil esperado dos tubos manufaturados estavam dentro do esperado.

As limitações para enrolar tubos, com relação à máquina, estão em seu dimensional, no diâmetro e comprimento. Com relação ao passo da hélice, quanto maior o mesmo, menor deve ser a velocidade de rotação do eixo árvore devido à velocidade de avanço do eixo longitudinal $Z$. A máquina deve ser bem protegida contra impregnação de resina em suas partes para evitar danos, principalmente ao barramento.

Durante o processo pode ser observado à necessidade de um dispositivo para abrir a mecha, pois a mesma apresentava variações de dimensão em sua largura durante o enrolamento, embora fosse visual, era perceptível quando era depositada no mandril. Esta necessidade também se tornou perceptível para banhar as fibras com resina. Além do problema da impregnação não é segura para o operador.

As fibras deslizaram relativamente bem pelos olhais de alumínio, porém os mesmos são fixos, sem nenhum grau de liberdade. Se os mesmos pudessem ser móveis de maneira a favorecer a deposição das fibras, o processo se tornaria mais estável para acomodação das fibras.

A tabela 15 mostra os dimensionais programados dos tubos.

Tabela 15 - Tubos programados.

\begin{tabular}{|c|c|c|c|c|}
\hline TUBO & $\begin{array}{c}\text { DIÂMETRO } \\
\text { PROGRAMADO }\end{array}$ & $\begin{array}{c}\text { COMPRIMENTO } \\
\text { PROGRAMADO }\end{array}$ & $\begin{array}{c}\text { ÂNGULO DE } \\
\text { ENROLAMENTO } \\
\text { (PASSO em mm) }\end{array}$ & $\begin{array}{c}\text { LARGURA } \\
\text { DE MECHA }\end{array}$ \\
\hline 1 & $30 \mathrm{~mm}$ & $230 \mathrm{~mm}$ & $\begin{array}{c}90 / 90 / 30 / 90 / 90 \\
(4 / 103,92 / 4)\end{array}$ & $4 \mathrm{~mm}$ \\
\hline 2 & $30 \mathrm{~mm}$ & $230 \mathrm{~mm}$ & $\begin{array}{c}90 / 90 / 30(4 / \\
103,92)\end{array}$ & $4 \mathrm{~mm}$ \\
\hline 3 & $30 \mathrm{~mm}$ & $230 \mathrm{~mm}$ & $90 / 90 / 45(4 / 60)$ & $4 \mathrm{~mm}$ \\
\hline 4 & $30 \mathrm{~mm}$ & $230 \mathrm{~mm}$ & $90 / 90 / 60(4 / 34,64)$ & $4 \mathrm{~mm}$ \\
\hline
\end{tabular}

Fonte: Próprio autor (2015). 
Após o enrolamento os valores obtidos são mostrados na tabela 16.

Tabela 16 - Dimensionais obtidos.

\begin{tabular}{|c|c|c|c|c|}
\hline TUBO & DIÂMETRO & MECHA & ÂNGULO & PASSO \\
\hline 1 & $41,4 / 40,6 / 40,5$ & $4,5 / 4,8 / 5$ & $\begin{array}{c}90 / 90 / 30 / 90 / \\
90\end{array}$ & $4,5 / 4,8 / 5$ \\
\hline 2 & $37,8 / 37,4 / 37,9$ & $4 / 4 / 4$ & $90 / 90 / 30$ & 103,4 \\
\hline 3 & $38,6 / 38,3 / 38,8$ & $4,4 / 4 / 5$ & $90 / 90 / 45$ & 60 \\
\hline 4 & $40,6 / 40,4 / 40,2$ & $\begin{array}{c}6,7 / 4,8 / \\
7,7\end{array}$ & $90 / 90 / 60$ & 34,6 \\
\hline
\end{tabular}

Fonte: Próprio autor (2015).

As medições foram realizadas com paquímetro com precisão de 0,05mm. As medições de diâmetro e largura de mecha não apresentou dificuldade, mas o mesmo não pode ser dito para medir o passo. A figura 129 ilustra as regiões onde ocorreram as medições no tubo. As extremidades dos tubos foram cortadas para remover o acúmulo de fibras nas extremidades.

Figura 129 - Regiões de medição dos tubos.

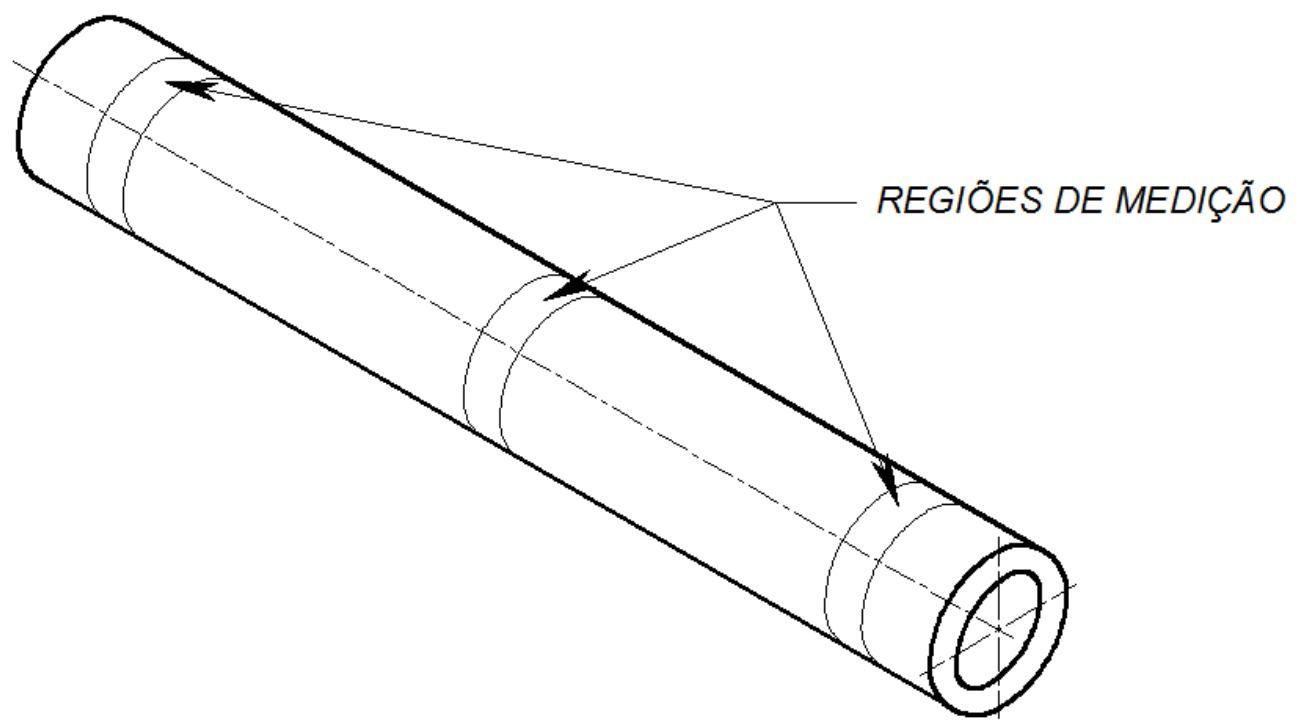


Fonte: Próprio autor (2015).

A figura 130 ilustra o mandril, castanhas da placa do torno, contra ponto e 0 tubo manufaturado a partir de fibras e resina.

O tubo número 1 , teve duas camadas com enrolamento a $90^{\circ}$, uma a $30^{\circ} \mathrm{e}$ duas a $90^{\circ}$. O diâmetro teve pouca variação, sendo essa variação em função da conicidade do mandril. A largura da mecha mostrou acompanhar a tendência da conicidade do mandril, mostrou irregularidades em sua largura ao longo da superfície das camadas.

Figura 130 - Mandril, tubo e contra ponto.

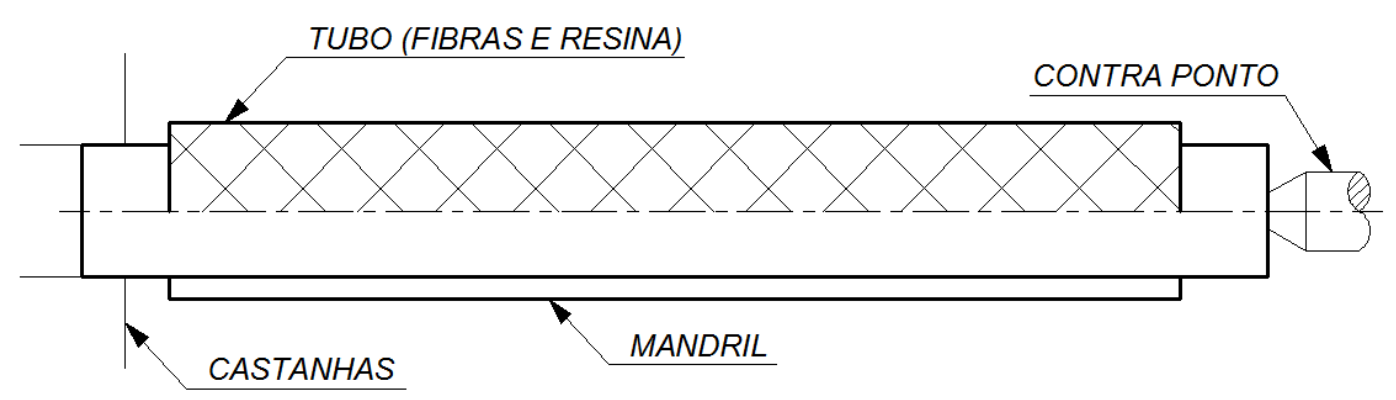

Fonte: Próprio autor (2015). 
O tubo, porém mostrou o comportamento no diâmetro normal ao mandril, dado a conicidade do mesmo.

O tubo número dois, enrolamento $90^{\circ}, 90^{\circ}$ e $30^{\circ}$ foi o tubo que mostrou melhor comportamento da mecha, aspecto de acabamento, linearidade e passo em relação aos demais, porém o diâmetro apresentou uma particularidade de um estreitamento de diâmetro ao centro do tubo.

O tubo número três, enrolamento $90^{\circ}, 90^{\circ}$ e $45^{\circ}$ mostrou um comportamento próximo ao do tubo número dois, mas com linearidade mais comprometida em virtude da variação da largura da mecha.

O tubo número quatro, enrolamento $90^{\circ}, 90^{\circ}$ e $60^{\circ}$ mostrou um comportamento próximo ao do tubo número três, com linearidade mais comprometida e largura de mecha com muita variação, porém o diâmetro acompanhando a conicidade do mandril.

O dispositivo tensionador conseguiu cumprir seu objetivo com limitações, os demais acessórios como olhais, cumpriram o esperado, podendo ser usado novamente sem a necessidade de retrabalho.

\subsection{SUGESTÕES}

\subsubsection{DO TORNO}

Como melhoria para o processo, para a utilização do torno, a possibilidade de trabalhar sem as proteções frontais poderia resultar em mandris de comprimento maiores limitados ao comprimento útil do barramento e não mais do vão livre da proteção.

Proteções móveis para o barramento de maneira a evitar que o mesmo seja atingido pelos respingos da resina. 


\subsubsection{DO PROGRAMA}

Programar e implementar linhas de programa para enrolamentos para peças cônicas, domos, interação com bibliotecas gráficas a fim de não haver necessidade de software CAD para visualizar trajetórias e leitura de modelo CAD para cálculo das trajetórias.

\subsubsection{DOS DISPOSITIVOS E ACESSÓRIOS}

O projeto e construção de dispositivos para melhorar o desempenho do processo. Um dispositivo para abrir a mecha e permitir que a mesma trabalhe numa largura distribuída. Isso resultaria em menor quantidade de ciclos para cobrir a superfície e um diâmetro menor por camada, além de facilitar o banho de resina nas fibras.

Um dispositivo para banhar as fibras de maneira que eliminasse a necessidade de mão de obra para isso e além de garantir um banho mais eficiente.

Um olhal que tivesse mais grau de liberdade para melhorar o processo.

\subsubsection{MÁQUINA DEDICADA}

O processo de Filament Winding é um processo que exige cuidados especiais. Uma limitação clara no torno CNC foi o uso de resina para embebedar as fibras, a resina poderia impregnar no barramento prejudicando o uso do torno para usinagem.

Outra limitação da máquina é o espaço para o mandril e a abertura da porta do torno. Para uma finalidade acadêmica, uma máquina dedicada seria mais conveniente, onde limitações como o uso de resina, poderiam ser previstos.

Neste trabalho apresenta uma proposta de uma máquina dedicada para Filament Winding. A máquina possuiria estrutura em perfil de alumínio. Um cabeçote para acomodar o eixo árvore, um contra ponto, mesas de movimento longitudinal e transversal, dispositivo para abrir a mecha, dispositivo para banhar as resinas e olhal com liberdade de movimento. A figura 131 ilustra a proposta da máquina dedicada para filament winding.

Figura 131 - Proposta de uma máquina dedicada para Filament Winding. 


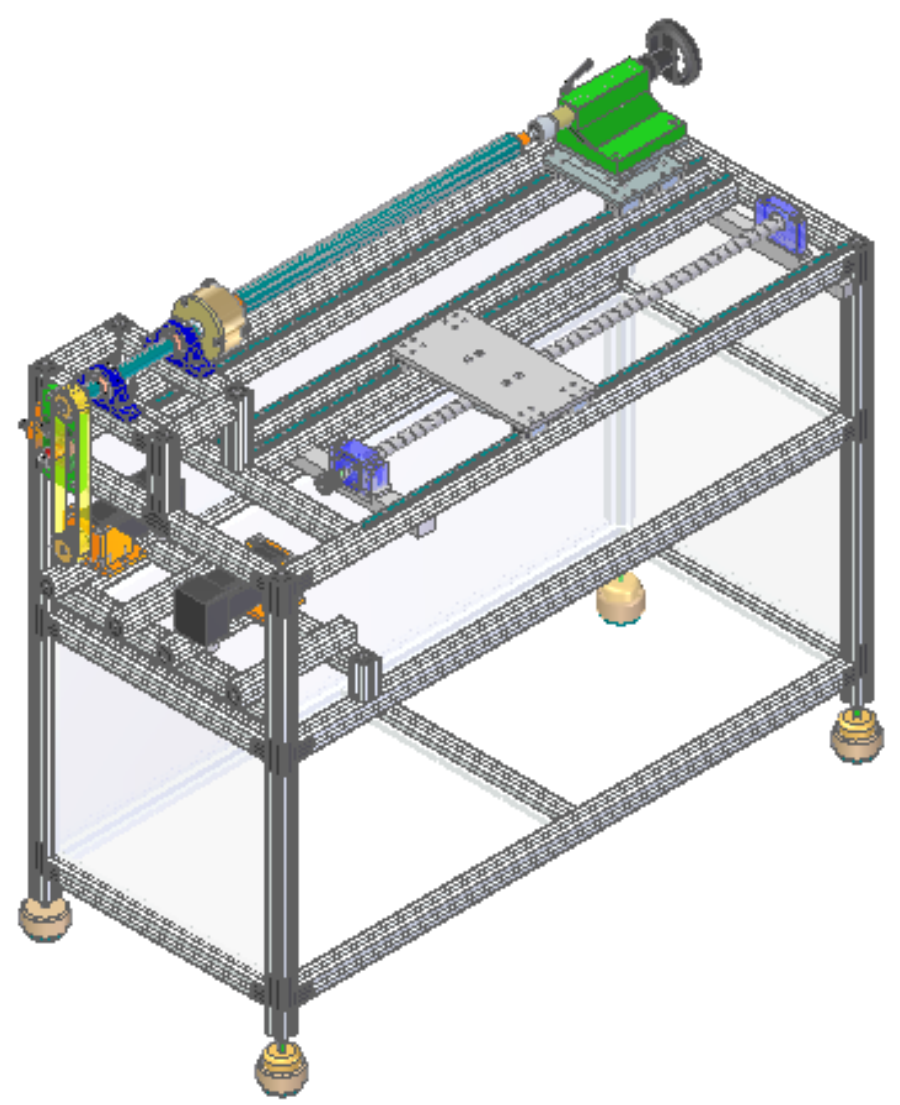

Fonte: Próprio autor (2015).

A estrutura desta máquina foi projetada em perfil de alumínio extrudado, fácil de montar e modificar. A estrutura convencional de metalon não foi utilizada em virtude do peso e facilidade para montar, desmontar e realoca-la em outro local. A facilidade para a montagem e desmontagem também a torna mais versátil para qualquer modificação.

As proteções em volta da estrutura são de acrílico, podendo ser de policarbonato. A fixação do mandril é semelhante à fixação do torno convencional ou $\mathrm{CNC}$, fixa por uma placa universal do lado do servo motor e um contra ponto mecânico de um torno convencional.

As mesas de deslocamento em Z e X seriam controladas por servos-motores, assim como o servo que controla o eixo árvore. O deslocamento das mesas é executado em cima de guias lineares e fusos de esferas. 
Nesta máquina seria adaptado um molhador para embebedar as fibras com resina e receber o dispositivo de abertura de mecha de SOEIRA (2014). Estes dispositivos seriam alocados nas mesas da máquina.

A máquina estaria apoiada em vibra stop. Embora as vibrações da máquina não sejam prejudiciais à máquina e não haja motivo para preocupações com estas vibrações, o contato com o chão diretamente poderia afetar o desempenho, os vibra stop evitam este problema.

Nesta máquina o programa desenvolvido neste trabalho teria interação com a mecatrônica da máquina, gerando as posições do olho, das mesas e do eixo árvore Além de gerar as trajetórias para o programa CAD como já faz.

Há ainda uma opção para esta máquina que ao invés de mesas e olho para realizar o processo, o olho seria guiado por um robô. Isto daria à máquina uma habilidade maior de manufaturar peças de maiores complexidades e desempenhar trajetórias arbitrárias de acordo com a necessidade do projeto.

Uma máquina com robô teria mais liberdade de movimento que um robô adaptado em uma máquina CNC convencional, onde as proteções da máquina imporiam uma grande limitação de movimento. 
Além desta máquina, um dispositivo tensionador para as fibras teria de ser construído antes que as fibras entrassem na máquina. Outra proposta para esta máquina seria ao invés de se utilizar mesas seria um robô próximo à mesa para executar o papel da mesa, a vantagem do robô seria a liberdade para se fazer peças mais complexas que tubos. A figura 132 ilustra a proposta de uma máquina dedicada com auxílio de um robô.

Figura 132 - Proposta de uma máquina dedicada para Filament Winding.

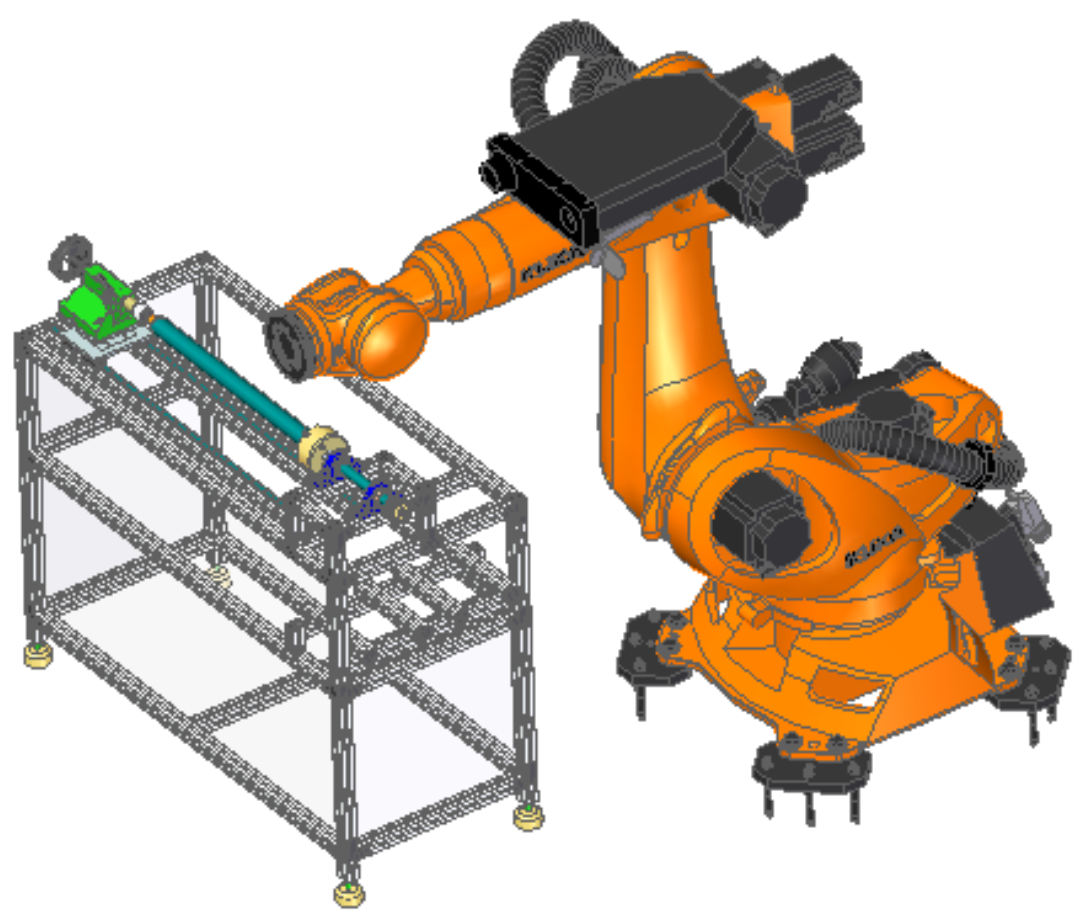

Fonte: Próprio autor (2015). 


\section{REFERÊNCIAS BIBLIOGRÁFICAS}

ABDALLA, F.H. et al. (2005) Design and fabrication of low cost filament winding machine. Materials and Design Science Direct, p. 234-239, ago.

AEROSPACE COMPOSITES A design \& manufacturing guide. First edition 2008.

AKATO, K. M. (2012) Thesis Pretreatment and Pyrolysis of Rayon-Based Precursor for Carbon Fibers.

AKKUS, N. et al. CONTROL OF THE PRETENSION IN FILAMENT WINDING PROCESS (2008). Acta Mechanica et Automatica. V.2, n.3, p.5-10. Disponível em: $<$ http://www_actawm_pb_edu_plvol2no3akkusgencgirgin.pdf>. Acesso em: 8 jan. 2013.

AMRC (The University of Sheffield Advanced Manufacturing Research Centre) and Boeing. (Robotic Filament Winding Capability) Disponível em: < http://www.amrc.co.uk/wp-content/uploads/Robotic-Filament-Winding-CapabilityPDF2.pdf>. Acesso em 25 nov. 2014.

Associação Brasileira de Materiais Compósitos - ABMACO Compósitos 2. Tecnologia de Processos (2009). Associação Latino-Americana de Materiais Compósitos ALMACO.

Associação Latino-Americana de Materiais Compósitos - ALMACO (2012). Compósitos. Disponível em: < http://www.almaco.org.br/compositos.cfm>. Acesso em: 05 jan.2012.

BEAUMONT, P. W. R. (1989) The failure of fibre composites: an overview. Journal of Strain Analysis. v24. n.4, p.189-205.

CADWIND - Filament Winding Software. Disponível em: http://www.material.be/cadwind/download/index.html. Acesso em 10 nov. 2012. 
CALLISTER, W. D. J. (1993) Materials Science and Engineering an Introduction. Third Edition.

CÂNDIDO, G.M.; ALMEIDA, S.F.M.; Instituto Tecnológico de Aeronáutica, Divisão de Engenharia Mecânica Aeronáutica. REZENDE,M.C. Instituto de Aeronáutica e Espaço, Divisão de Materiais. Processamento de Laminados de Compósitos Poliméricos Avançados com Bordas Moldadas. POLÍMEROS: CIÊNCIA E TECNOLOGIA, vol. 10, $\mathrm{n}^{\circ}$ 1,p31-41 (2000).

CARRINO, L. et al. (2003) Method to Evaluate Winding Trajectories in Robotized Filament Winding. Departimento di Ingegneria Industriale - Università degli Studi di Cassino via G. di Biasio 43, Cassino, Italy. Journal of Composite Materials, v. 38, n.1, p. 38 a 41 , mai. 2003.

CARVALHO, J. (1996) Computer Integrated Design Optimization and Manufacturing of Filament Wound Parts. Tese Doutorado - Faculty of Applied Sciences, Division PMA, K.U. Leuven.

CHAN, M. M. S. e FAHIM, A. Accuracy-speed Relationships of a Robotic Filament Winding Cell. Robotics \& Computer Integrated Manufacturing, v. 12, n.1, p. 1 a 13, 1996.

CPIC FIBERGLASS Fibras de vidro. Capivari, SP. Disponível em: $<$ http://br.cpicfiber.com/processos.asp?codigo=9\&cat=Processos/ \#>. Acesso em 20 nov. 2012.

COPMACO - Cooperativismo em Materiais Compósitos - Brasil. Disponível em: $<$ http://coopmaco.com.br/wp-content/uploads/2014/02/Filament-Winding.pdf>. Acesso em Nov. 2012.

CRESCENT CONSULTANTS LIMITED - Cadfil - Filament Winding Software and Technology. Disponível em: http://www.cadfil.com/. Acesso em: Nov. 2012.

Dreamstime.com. Disponível em: <http://thumbs.dreamstime.com/z/inspection-camshaft-machining-process-operator-camshaft-profile-testing-machine-44435843.jpg>. Acesso em 25 nov. 2012. 
EHA Engineering High-tech Assets, Steffenberg - Alemanha. Disponível em: < http://www.ehacomma.com/html/home.php>. Acesso em 21 nov. 2012.

ENTEC Composites Machines Inc. Toray Group. Disponível em: < http://entec.com/>. Acesso em 21 nov. 2012.

FBMIX Compósitos Termofixos para moldagem a quente - BMC e SMC. Rio Claro, SP. Disponível em: <http://www.fbmix.com.br/index.php?pagina=produtos>. Acesso em 21 nov. 2012.

FILHO, G.D.S. (2001) Comportamento Mecânico do Poliuretano Derivado do Óleo de Mamona TReforçado por Fibra de Carbono: Contribuição para o Projeto de Hastes de Implante de Quadril.

FRAUNHOFER ICT Polymer Engineering. Disponível em: <http://www.ict.fraunhofer.de/en/comp/pe/hfv/thermoset_RTM_process.html>. Acesso em 21 nov. 2012.

GALE, N.E.H.S. (2012) Clean Filament Winding. Tese - The University of Birmingham, Birmingham, England, 2012.

GUTOWSKI, T.G. (1997) Advanced Composites Manufacturing. Massachusetts Institute of Technology - Cambridge, MA.

HEITKOETTER, R. F. et al. Simulação Computacional da Bobinagem Filamentar NãoGeodésica de Vaso de Pressão de Motor Foguete. Journal of Aerospace Technology and Management, v.1, n.2, dez. 2009.

HYER, M.W. Stress Analysis of Fiber-Reinforced Composite Materials (1998).

KOPPERT, J.J.M., BOER, H., WEUSTINK, A.B., BERSEE, H.E.N. Virtual Testing of Dry Filament Wound Thick Walled Pressure Vessels - ICCM International Conferences on Composite Materials, 2007, Proceedings of the 16th International Conference on Composite Materials, ICCM-16 - "A Giant Step Towards Environmental Awareness: From Green Composites to Aerospace"

IMAMURA, T. et al. Design and Control Tension of Filament Winding System. Toyohashi University of Technology, Aichi, Japan. Proceedings of the IEEE 
International Conference on Systems, Man and Cybernetics, v. 2, p. II-660 - II-665, 1999.

JOHANSEN, B. S. et al. CADPATH: a complete program for the CAD, CAE and CAM - winding of advanced fiber composites. Journal of Materials Processing Technology. v.77, p. 194-200, 1 mai. 1998.

LI, H. et al. CAM SYSTEM FOR FILAMENT WINDING ON ELBOWS. Journal of Materials Processing Technology, v 161, n.3, p. 491-496, abr. 2005.

$\mathrm{Li}, \mathrm{H}$. et al. SPLINES IN THE PARAMETER DOMAIN OF SURFACES AND THEIR APPLICATION IN FILAMENT WINDING. Computer Aided Design v. 39, n.1, p. 268275, abr. 2007.

Macro-moldes. Disponível em: $\quad$ http://www.macromoldes.pt/galeria/12052312335357.jpg>. Acesso em 25 nov. 2012.

MARKOV, L.; CHENG, R. M. H. (1996) CONCEPTUAL DESIGN OF ROBOTIC FILAMENT WINDING COMPLEXES. Mechatronics v. 6, n. 8, p. $881-896$. Copyright Elsevier Science Ltd. (1996).

MATHEWS, F. L.; RWALINGS, R.D. (1994) Composite Materials: engineering and science. London, Chapman \& Hall.

McCLEAN ANDERSON® Advanced Filament Winding Systems. Schofield, Wisconsin - USA. Disponível em: < http://www.mccleananderson.com/index.cfm>. Acesso em 25 nov. 2012.

Mega Turn Woodturning Lathe. Disponível em: < http://i.ytimg.com/vi/Xz56Q2Q5j5c/maxresdefault.jpg >. Acesso em 25 nov. 2012.

MILTON, G. W. (2002) The Theory of Composites. Cambridge Monographs on Applied and Computational Mathematics. Cambridge University Press.

NETO, E.S. (2006) Tese: ESTUDO DA APLICAÇÃO DE PERFIS PULTRUDADOS EM PROJETOS: ANÁLISE, DIMENSIONAMENTO E FABRICAÇÃO. Universidade de São Paulo. 
NUPLEX

CORPORATE.

Disponível

em:

<http://www.nuplex.com/composites/processes/spray-up>. Acesso em 21 nov. 2012.

PADILHA, A. F. (1997) Materiais de Engenharia - Microestrutura e Propriedades.

PETERS, S. T. Composite Filament Winding - ASM International. The materials information society. Ohio 2011.

PRESSMAN, R.S. and WILLIAMS, J.E. Numerical Control \& Computer Aided Manufacturing 1997.

REN, S. et al. Fiber Winding Precision tension fuzzy control system. Harbin University of Science and Technology, Harbin, China. Material and Manufacturing Technology. V. 129-131, p. $370-375,2010$.

ROMEO ROMEORIM Inc. Disponível em: <http:// www.romeorim.com/about.html/>. Acesso em 21 nov. 2012.

ROMI Ltda. Disponível em: < http://www.romi.com.br/index.php?id=maquina ferramenta>. Acesso em fev. 2013.

ROUSSEAU, J. et al. The influence of winding patterns on the damage behavior of filament-wound pipes. Composites Science and Tecnology. France, nov. (1998).

ROZENFELD, H. (2006) et al. Desenvolvimento de Produto: Uma Referência para Melhoria de Processo. São Paulo. Editora Saraiva.

SANTANA, FRANSÉRGIO DE ALCÂNTARA Estudo do Processamento de Compósitos Termoplásticos a partir de Pré-impregnados Peek/ Fibra de Carbono por Moldagem por Compressão a Quente Universidade de Taubaté, 2010.

SCHOLLIERS, J. (1992) Filament Winding: A Manufacturing Technique for Composites.

SILVA, M.M. (2005) Dissertação - Protótipo de uma Plataforma para Software de Cálculos para Otimização das Trajetórias das Fibras em Revestimento de Materiais Compósitos. EESC USP São Carlos.

SKINNER, Creative Inc., (2006) Trends, advances and innovations in filament winding. Reinforced Plastics, USA, v50, n2, p28-33, fev. 2006. 
SOEIRA, L.E. (2009) Dissertação - Projeto e elaboração de um dispositivo para remodelagem de fibras como subsistema do processo de enrolamento filamentar. EESC USP São Carlos.

TECPLAS Indústria de polímeros injetados. Disponível em: <http://www.tecplasplasticos.com.br/servicos.html>. Acesso em 20 nov. 2012.

WANG, S. e NING, S. Research on Tension Control for Six-Axis Filament Winding Machine. Shandong University of Weihai, China. International Conference on Apperceiving Computing and Intelligence Analysis, ICACIA 2009, p 447-450, 2009.

$\mathrm{XU}$, J. et al. Motion Synchronization System of Filament Winding Machine. College of Automation, Harbin University of Science and Technology. First International Conference on Innovative Computing, Information and Control 2006. p. 105-108, 2006. 